\title{
Rapid Manufacturing of Tailored Thermoplastic Composites by Automated Lay-up and Stamp Forming
}

A Study on the Consolidation Mechanisms

Tjitse K. Slange 



\section{RAPID MANUFACTURING OF \\ TAILORED THERMOPLASTIC COMPOSITES BY AUTOMATED LAY-UP AND STAMP FORMING \\ A Study on the Consolidation Mechanisms}

Tjitse K. Slange 



\title{
RAPID CONSOLIDATION OF TAILORED THERMOPLASTIC COMPOSITES BY AUTOMATED LAY-UP AND STAMP FORMING
}

A study on the Consolidation Mechanisms

\section{PROEFSCHRIFT}

\author{
ter verkrijging van \\ de graad van doctor aan de Universiteit Twente, \\ op gezag van de rector magnificus, \\ prof.dr. T.T.M. Palstra, \\ volgens besluit van het College voor Promoties \\ in het openbaar te verdedigen \\ op vrijdag, 8 maart 2019 om 14:45 uur
}

door

Tjitse Kay Slange

geboren op 10 juli 1990

te Deventer, Nederland 
Dit proefschrift is goedgekeurd door de promotor:

prof.dr.ir. R. Akkerman

en door de co-promotor:

dr.ir. W.J.B. Grouve

De promotiecommissie is als volgt samengesteld:

Voorzitter en secretaris:

prof.dr. G.P.M.R. Dewulf

Universiteit Twente

Promotor:

prof.dr.ir. R. Akkerman

Universiteit Twente

Co-promotor:

dr.ir. W.J.B. Grouve Universiteit Twente

Leden (in alfabetische volgorde):

prof.dr.ir. A. de Boer

Universiteit Twente

prof. C.A. Dransfeld

Technische Universiteit Delft

prof. A. Maffezzoli

Universita del Salento

prof.dr. A.R. Thornton

Universiteit Twente

This research project was financially supported by the ThermoPlastic composite Research Center (TPRC) and the Netherlands Organisation for Scientific Research $(\mathrm{NWO})$.

Rapid Consolidation of Tailored Thermoplastic Composites by Automated Lay-up and Stamp Forming - A Study on the Consolidation Mechanisms

Slange, Tjitse Kay

PhD Thesis, University of Twente, Enschede, the Netherlands

March 2019

ISBN 978-90-365-4728-4

DOI 10.3990/1.9789036547284

(C) 2019 by T.K. Slange, Enschede, the Netherlands

Printed by Gildeprint, Enschede, the Netherlands

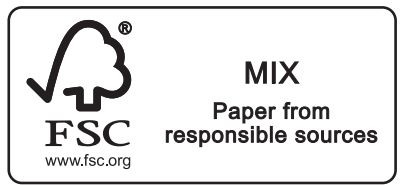

Cover: A photograph of the tailored spar that was manufactured within this research (Chapter (6) in order to demonstrate the capabilities of the developed process route on a realistic component. 


\section{Summary}

Lightweight aircraft design is key to reducing the cost and environmental impact of flying. The high specific stiffness and strength make fiber reinforced polymer composites an attractive material for aircraft design. With the growing demand for aircraft and the increasing use of composite materials, there is a need for cost-effective composite manufacturing processes. Thermoplastic composites are potentially ideal for automated high-rate low-cost manufacturing as they can be repeatedly melted, shaped and solidified in short cycle times, which allows for forming, fusion bonding and recycling. However, despite the potential, existing thermoplastic composite manufacturing still relies mostly on slow processes like press or autoclave consolidation. Moreover, the tailorability of the mechanical performance by optimizing the location and orientation of the fibers is often not fully exploited, leading to a sub-optimal performance over weight ratio. Hence, further development is required for the high-rate manufacturing of load carrying thermoplastic composite structural components.

This thesis proposes rapid automated lay-up followed by stamp forming as a novel processing route. Automated lay-up, for example automated fiber placement (AFP) or automated tape laying (ATL), provides the ability to manufacture flat blanks with tailored and near net-shape lay-ups, which improve the performance over weight ratio of the part and reduce production scrap. Shaping of the blank takes place during a short stamp forming step. The main challenge is to achieve a high consolidation quality at the end of this process cycle, which is required for good mechanical performance. The lay-up of flat blanks is performed at high rates in order to achieve short cycle times, which results in a low degree of consolidation compared to insitu lay-up at lower rates. This means that most consolidation has to take place during stamp forming, where the available time for consolidation is also short. Void content is considered as one of the most important measures for consolidation quality in this thesis. The main objective is to develop an understanding of the physical mechanisms that govern the evolution of void content during stamp forming and of the interrelation between material properties, processing parameters and final consolidation quality. This knowledge is then used to develop material, processing and design guidelines for consolidation using the proposed processing route.

Three key phenomena were found to govern the evolution of void content during 
stamp forming, namely $i$. deconsolidation, ii. the elimination of blank thickness variations and iii. the filling of voids at ply-drops.

Firstly, a study showed that deconsolidation, which is the undesired growth of voids and delaminations in a blank during heating, is governed by two mechanisms. The contribution of each mechanism depends on the blank manufacturing method. Expansion of dissolved moisture dominates deconsolidation in press-consolidated blanks, while the release of interal stresses, present in the prepreg tape, drive deconsolidation of fiber placed blanks. The influence of several heat treatments on moisture content and degree of deconsolidation is investigated and guidelines for minimizing deconsolidation are proposed.

In a further study it is shown that blank thickness variations rather than the initial interlaminar void content, dominate the removal of interlaminar voids during stamp forming. Flow transverse to the fiber direction of the composite plies is responsible for the redistribution of material and development of interlaminar bonding. A model based on transverse squeeze flow of the plies is proposed to study the influence of the prepreg thickness distribution and processing parameters on interlaminar void content. This model is exploited further for developing prepreg design guidelines and lay-up strategies aimed at optimizing the consolidation process.

Finally, transverse flow is also identified as the main mechanism for the consolidation of ply-drops, which are inherent to tailored blanks. The large voids in the pockets next to a ply-drop are filled by transverse flow of the dropped ply and surrounding plies. It is shown that the ability to fill the ply-drop is sensitive to lay-up accuracy during AFP and to blank-tooling alignment during stamp forming. With this knowledge, guidelines are proposed to optimize consolidation.

The work presented in this thesis shows that the final consolidation quality is a complex function of the entire processing chain, where each step has a critical function in the consolidation process. Material, design and processing guidelines are provided to support process development. Finally, the processing route is demonstrated on a tailored spar, which confirms that good consolidation can also be achieved in realistic parts. However, the need for an improved understanding of the forming and consolidation of more complex tailored parts was highlighted. Altogether, this thesis provides a fundamental basis for the further development of the rapid manufacturing route for lightweight tailored composite components. 


\section{Samenvatting}

Lichtgewicht vliegtuigontwerpen zijn essentieel voor het verminderen van de kosten en de milieu-impact van vliegen. Door de hoge specifieke stijfheid en sterkte van vezelversterkte kunststoffen zijn deze composietmaterialen aantrekkelijk voor vliegtuigconstructies. Vanwege de groeiende vraag naar nieuwe vliegtuigen en de toenemende toepassing van composietmaterialen is er behoefte aan snelle verwerkingsprocessen met een hoge mate van automatisering. Thermoplastische composieten hebben een enorme potentie voor de fabricage van hoge productaantallen tegen lage kosten, omdat ze zeer snel herhaaldelijk gesmolten, vervormd en uitgehard kunnen worden. Dit maakt onder andere snelle vervormingsprocessen, assemblage door samensmelten en recyclen mogelijk. Ondanks de grote potentie maken bestaande verwerkingsmethoden voor thermoplastische composieten nog altijd gebruik van langzame processen, zoals consolidatie in een pers of autoclaaf. Bovendien wordt doorgaans de mogelijkheid om de locatie en orientatie van de vezels toe te snijden op de beoogde mechanische belasting niet volledig benut. Hierdoor is er een behoefte aan de verdere ontwikkeling van productiemethoden voor de serieproductie van lastdragende onderdelen van thermoplastisch composietmateriaal.

Dit proefschrift introduceert een nieuwe procesroute voor het verwerken van thermoplastische composieten waarbij snelle geautomatiseerde blenkproductie opgevolgd wordt door persvormen. Geautomatiseerde blenkproductieprocessen, zoals AFP of ATL, maken de fabricage van beter toegesneden en netto-contour blenks mogelijk, wat lichtere onderdelen oplevert en productieafval vermindert. De uiteindelijke geometrie van het onderdeel komt tot stand tijdens een snelle persvormcyclus. Ondanks deze voordelen is het een grote uitdaging om aan het eind van de processtappen een, voor goede mechanische eigenschappen benodigde, hoge consolidatiekwaliteit te bereiken. Door op hoge snelheid vlakke blenks te produceren wordt de blenkfabricagetijd kort gehouden, maar blijft de mate van consolidatie ook laag. Dit betekent dat het overgrote deel van de consolidatie plaats moet vinden tijdens het persvormen, waar de beschikbare tijd voor consolidatie ook kort is. Porositeit wordt gezien als één van de belangrijkste parameters voor consolidatiekwaliteit in dit proefschrift. De hoofddoelen zijn dan ook het begrijpen van de fysische mechanismen die betrekking hebben op het porositeitsbeloop gedurende het persvormen en het beter begrijpen van het verband tussen materiaaleigenschappen, procesparameters en consolidatiekwaliteit. Deze kennis wordt vervolgens toegepast om richtlijnen op 
het gebied van materiaal, verwerking en ontwerp op te stellen die consolidatie via de voorgestelde procesroute mogelijk maakt.

Drie belangrijke fenomenen blijken het beloop van porositeit tijdens persvormen te bepalen, namenlijk $i$. deconsolidatie, $i$. het elimineren van diktevariaties in blenks en iii. het vullen van porositeit bij ply-drops.

Allereerst heeft deze studie aangetoond dat deconsolidatie, het ongewenst groeien van porositeit en delaminaties in een blenk tijdens opwarmen, veroorzaakt wordt door twee mechanismen. De bijdrage van ieder mechanisme is afhankelijk van het blenkfabricageproces. De expansie van opgelost vocht is verantwoordelijk voor deconsolidatie in persgeconsolideerde blenks. Het vrijkomen van interne spanningen, die hun oorsprong hebben in het prepreg materiaal, is dominant in blenks vervaardigd met AFP. De invloed van warmtebehandelingen op het vochtgehalte en de mate van deconsolidatie is onderzocht. Met deze kennis zijn richtlijnen voor het verminderen van deconsolidatie opgesteld.

In een verdere studie is aangetoond dat diktevariaties in blenks, en niet zo zeer de initiële interlaminaire porositeit, een dominante rol spelen in het comprimeren van interlaminaire porositeit tijdens persvormen. Vervorming van de lagen composietmateriaal door stroming dwars op de vezelrichting is verantwoordelijk voor de herverdeling van materiaal en het ontwikkelen van contact tussen de lagen. Er is een model opgesteld gebaseerd op deze dwarsstroming om de invloed van de dikteverdeling van de prepreg en de procesparameters op de interlaminaire porositeit te onderzoeken. Het model is verder benut om richtlijnen voor materiaaleigenschappen en oplegstrategieën op te stellen die het consolidatieproces optimaliseren.

Tot slot is aangetoond dat dwarsstroming van de composietlagen tevens het mechanisme voor de consolidatie van ply-drops is. Deze komen inherent voor in blenks met lokale verschillen in het aantal composietlagen. De grote luchtinsluitingen die naast de ply-drops ontstaan tijdens het oplegprocess worden gevuld door dwarsvloei van de beëindigde laag en omringende lagen. Er wordt aangetoond dat het vullen van ply-drops gevoelig is voor de oplegnauwkeurigheid tijdens het AFP proces en de uitlijning tussen de mal en de blenk tijdens het persvormen. Met deze kennis zijn richtlijnen opgesteld die de consolidatie van ply-drops ondersteunen.

Het werk dat in dit proefschrift gepresenteerd is toont aan dat de uiteindelijke consolidatiekwaliteit een complexe functie is van de hele procesketen, waarbij elke individuele stap een kritische functie heeft. Richtlijnen voor materiaal, ontwerp en verwerking worden gegeven om verdere ontwikkeling te ondersteunen. Tot slot wordt de procesroute gedemonstreerd op een kleine ligger van een vliegtuigvleugel, wat bevestigt dat een goede consolidatiekwaliteit ook bereikt kan worden in een realistisch onderdeel. Desondanks wordt de behoefte aan een beter begrip van het persvormen van complexe onderdelen aangekaart. Tezamen biedt dit proefschrift een fundamentele basis voor het verder ontwikkelen van de voorgestelde productieroute voor lichtgewicht composieten onderdelen. 


\section{Contents}

Summary i

Samenvatting iii

Nomenclature ix

1 Introduction $\quad 1$

1.1 Background and Motivation $\ldots \ldots \ldots \ldots$. . . . . . . . . 1

1.2 Process route . . . . . . . . . . . . . . . . . . . . . . 2

1.3 Consolidation quality $\ldots \ldots \ldots \ldots \ldots$. . . . . . . . . . 4

1.4 Objective and scope $\ldots \ldots \ldots \ldots \ldots \ldots$

1.5 Outline . . . . . . . . . . . . . . . . . . . . . . 6

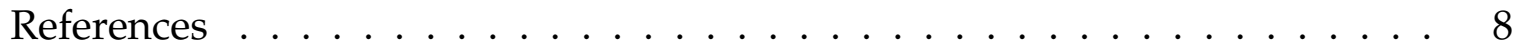

2 Deconsolidation of C/PEEK Blanks $\quad 11$

2.1 Introduction . . . . . . . . . . . . . . . . . . . . . . 12

2.2 Experimental work . . . . . . . . . . . . . . . . . 15

2.2.1 Materials and blank manufacturing . . . . . . . . . . . . . 15

2.2 .2 Oven deconsolidation experiments . . . . . . . . . . . . . . 15

2.2 .3 TMA and RGA experiments . . . . . . . . . . . . . . . . . . . . . . . . . . . . . . . . . . . . . . .

2.3 Results . . . . . . . . . . . . . . . . . . . . . . 18

2.3 .1 Oven deconsolidation experiments . . . . . . . . . . . . . . 18

2.3 .2 TMA and RGA experiments . . . . . . . . . . . . . . 22

2.4 Discussion . . . . . . . . . . . . . . . . . . . 25

2.4 .1 Influence of moisture . . . . . . . . . . . . . 26

2.4 .2 Influence of blank consolidation quality . . . . . . . . . . . . 28

2.4 .3 Influence of prepreg and blank consolidation process . . . . . . . 28

2.5 Conclusions and Recommendations . . . . . . . . . . . . . . 31

References ............................. 32 
3 Consolidation of Blanks Manufactured by Rapid Automated Lay-up 35

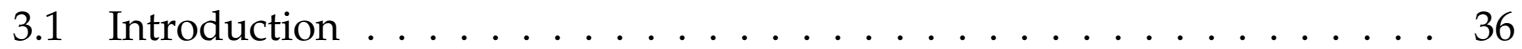

3.2 Experimental work $\ldots \ldots \ldots \ldots \ldots$

3.2 .1 Materials . . . . . . . . . . . . . . . . . . . . . . . . . 38

3.2 .2 Blank manufacturing . . . . . . . . . . . . . . . . . . 40

3.2 .3 Stamp forming . . . . . . . . . . . . . . . . . 41

3.2 .4 Consolidation quality $\ldots \ldots \ldots \ldots \ldots$. . . . . . . . . 42

3.2 .5 Mechanical performance . . . . . . . . . . . . . . . 43

3.3 Results . . . . . . . . . . . . . . . . . . . . 43

3.3 .1 Consolidation quality $\ldots \ldots \ldots \ldots \ldots$

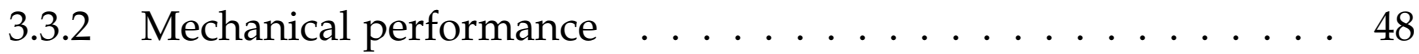

3.4 Discussion . . . . . . . . . . . . . . . . . . . . . . . . . 50

$3.4 .1 \quad$ Prepreg thickness variations $\ldots \ldots \ldots \ldots$

3.4 .2 Other prepreg characteristics . . . . . . . . . . . . . . 52

3.4 .3 Influence of blank preconsolidation state . . . . . . . . . . 53

3.4 .4 Influence of stamp forming parameters . . . . . . . . . . . 54

3.4 .5 Blank manufacturing by rapid automated lay-up . . . . . . . . 54

3.5 Conclusions and Recommendations . . . . . . . . . . . . . . 55

References . . . . . . . . . . . . . . . . . . 57

3.A Appendix: Blank heating behavior . . . . . . . . . . . . . . . 58

4 Consolidation of Blanks with Thickness Variations during Stamp Forming 61

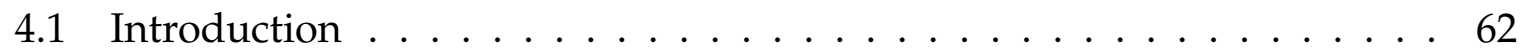

4.2 Model description . . . . . . . . . . . . . . . . . . . . 64

4.3 Parameter study . . . . . . . . . . . . . . . . . . . . . . . . . . . . . . . . . 69

$4.3 .1 \quad$ Material properties . . . . . . . . . . . . . . . . . . . . . . . . 69

$4.3 .2 \quad$ Prepreg profile . . . . . . . . . . . . . . . . . . . . . . . . 69

$4.3 .3 \quad$ Material and processing conditions . . . . . . . . . . . 73

$4.4 \quad$ Application and Discussion $\ldots \ldots \ldots \ldots \ldots \ldots$

$4.4 .1 \quad$ Processing window $\ldots \ldots \ldots \ldots \ldots$

4.4 .2 Material characterization . . . . . . . . . . . . . . 78

$4.4 .3 \quad$ Experimental validation $\ldots \ldots \ldots \ldots \ldots \ldots$

4.4 .4 Optimization of USSW blank lay-up . . . . . . . . . . . . . . . . 81

4.4 .5 Optimization of AFP blank lay-up . . . . . . . . . . . . . . 84

4.5 Conclusions and Recommendations . . . . . . . . . . . . . . . 86

References . . . . . . . . . . . . . . . . . . . . . . . . . 87 
5 Consolidation of Ply-drops in Tailored AFP Blanks by Stamp Forming 89

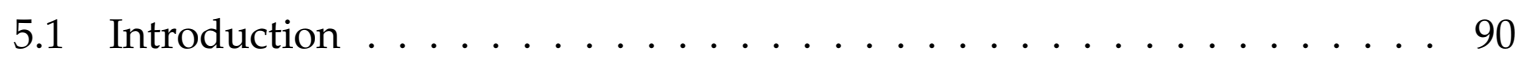

5.2 Experimental work $\ldots \ldots \ldots \ldots \ldots$. . . . . . . . . . . . 94

5.2 .1 Materials . . . . . . . . . . . . . . . . . . . . . 94

5.2 .2 Blank and tooling design . . . . . . . . . . . . . . . . . . . . . . . . . . . 94

5.2 .3 AFP and stamp forming . . . . . . . . . . . . . . . . . . . . . . . . . . . . . . . . 96

$5.2 .4 \quad$ Consolidation quality $\ldots \ldots \ldots$. . . . . . . . . . 97

5.3 Results . . . . . . . . . . . . . . . . . . . . 97

5.3 .1 C-scan . . . . . . . . . . . . . . . . . 97

5.3 .2 Microscopy . . . . . . . . . . . . . . . . 97

5.4 Discussion . . . . . . . . . . . . . . . . . . . . . . . . . 99

5.5 Conclusions and Recommendations . . . . . . . . . . . . . . . . 103

References . . . . . . . . . . . . . . . . . . . . . . 104

5.A Appendix: AFP accuracy . . . . . . . . . . . . . . . . 105

$\begin{array}{llr}6 & \text { Discussion } & 109\end{array}$

6.1 Void evolution mechanisms . . . . . . . . . . . . . . . . . . . . . 109

6.2 Process overview . . . . . . . . . . . . . . . . . . . . . . 110

6.3 Optimum processing strategy . . . . . . . . . . . . . . . . . . . 112

6.3 .1 Prepreg . . . . . . . . . . . . . . . . . . 112

6.3 .2 Blank and tooling design . . . . . . . . . . . . . . . . . . . . . . . . . . . . . . . . . . . . .

6.3 .3 Lay-up strategy . . . . . . . . . . . . . . . . . . . . . . . . . . . . . . . . . . . . . . . . . . . . . . . .

6.3 .4 Stamp forming process . . . . . . . . . . . . . . . . 114

6.4 Forming of tailored blanks . . . . . . . . . . . . . . . . . . . . . 114

6.4 .1 Forming of complex shapes . . . . . . . . . . . . . . . . . . . . . . 115

6.4 .2 Forming induced thickness changes . . . . . . . . . . . . . . 116

6.4 .3 Influence of blank consolidation quality . . . . . . . . . . . . . . 116

6.4 .4 Influence of tailoring . . . . . . . . . . . . . . . . . . 118

6.5 Industrial application . . . . . . . . . . . . . . . . . . . 120

$6.5 .1 \quad$ Typical design and application . . . . . . . . . . . . . . . . 120

6.5 .2 Alternative processing routes . . . . . . . . . . . . . . . . . . . . . . . . . . . . . . . . 121

6.5 .3 Demonstrator: Manufacturing a tailored spar . . . . . . . . . . 122

6.6 Concluding remarks . . . . . . . . . . . . . . . . . . . 130

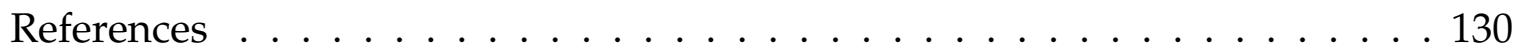

7 Conclusions and Recommendations 131

7.1 Conclusions . . . . . . . . . . . . . . . . . . . . 131

7.2 Recommendations . . . . . . . . . . . . . . . . . 133 
\begin{tabular}{ll}
\hline Dankwoord & 135
\end{tabular}

\begin{tabular}{lr}
\hline Publications & 139
\end{tabular} 


\section{Nomenclature}

The symbols used in this thesis are classified into Roman or Greek symbol group. Although some symbols can represent multiple quantities, its intended meaning follows from the textual context.

\section{Roman symbols}

A Amplitude of the prepreg thickness profile

$[\mathrm{m}]$

$B \quad$ Arrhenius constant for transverse viscosity

$\left[\mathrm{K}^{-1}\right]$

$b \quad$ Specimen width

$[\mathrm{m}]$

C Fitting constant

$[-]$

$C_{b}$

Bulk modulus

$[\mathrm{Pa}]$

d Rate of deformation tensor

$\left[\mathrm{s}^{-1}\right]$

F Vector with normal forces acting on the boundaries of a control volume

$F_{\max } \quad$ Maximum force

$h_{0}, h_{1}$

$h$

Laminate thickness before and after deconsolidation

Specimen thickness or height of control volume

$[\mathrm{m}]$

$h, h_{0}$

Thickness and average thickness of the prepreg thickness

$[\mathrm{m}]$ profile

$h_{\text {rel }} \quad$ Relative increase of laminate after deconsolidation

$\mathbf{K}_{\mathrm{el}}$

Stiffness matrix for the incremental elastic forces

$K_{\mathrm{p}}$ Permeability coefficient

$\mathbf{K}_{\text {visc }}$

Stiffness matrix for the viscous forces

L

Support span

[m]

l

Width of control volume

$P_{\text {app }}$

Applied pressure

[Pa]

$P_{\text {cons }}$

Consolidation pressure

$p \quad$ Hydrostatic pressure

$Q \quad$ Average volumetric flow rate

$t \quad$ Time

$T_{\text {blank }}$

Blank temperature

$t_{\text {cons }}$

Consolidation time 


$\begin{array}{llr}T_{\mathrm{c}} & \text { Crystallization temperature } & {\left[{ }^{\circ} \mathrm{C}\right]} \\ T & \text { Fiber tension } & {[\mathrm{Pa}]} \\ T_{\mathrm{g}} & \text { Glass transition temperature } & {\left[{ }^{\circ} \mathrm{C}\right]} \\ t_{\text {heat }} & \text { Heating time } & {[\mathrm{s}]} \\ t_{\mathrm{ic}} & \text { Time to full intimate contact } & {[\mathrm{s}]} \\ T_{\mathrm{m}} & \text { Melt temperature } & {\left[{ }^{\circ} \mathrm{C}\right]} \\ T_{\text {panel }} & \text { IR panel temperature } & {\left[{ }^{\circ} \mathrm{C}\right]} \\ \mathbf{t} & \text { Boundary traction } & {[\mathrm{Pa}]} \\ T_{\text {tool }} & \text { Tool temperature } & {\left[{ }^{\circ} \mathrm{C}\right]} \\ T & \text { Temperature (Arrhenius law) } & {[\mathrm{K}]} \\ \mathbf{u} & \text { Vector with the normal displacements of the boundaries of } & {[\mathrm{m}]} \\ & \text { a control volume } & \\ \mathbf{v} & \text { Vector with the normal velocities of the boundaries of a } & {\left[\mathrm{m} \cdot \mathrm{s}^{-1}\right]} \\ & \text { control volume } & {\left[\mathrm{m}^{3}\right]} \\ V & \text { Volume } & {\left[\mathrm{m}^{3}\right]} \\ \Delta V & \text { Volume of control volume } & {[-]} \\ V_{\mathrm{f}} & \text { Fibre volume fraction } & {[-]} \\ V_{\mathrm{v}} & \text { Void content } & {[\mathrm{m}]} \\ w & \text { Depth of control volume } & {[\mathrm{m}]} \\ w_{0}, w_{1} & \text { Laminate weight before and after deconsolidation } & {[-]} \\ w_{\text {rel }} & \text { Relative weight loss of laminate after deconsolidation } & \end{array}$

\section{Greek symbols}

$\begin{array}{ll}\varepsilon & \text { Strain } \\ \varepsilon_{v} & \text { Volumetric strain } \\ \eta_{0} & \text { Arrhenius constant for transverse viscosity } \\ \eta_{\mathrm{M}} & \text { Matrix viscosity } \\ \eta_{\mathrm{T}} & \text { Transverse viscosity of the composite } \\ \gamma & \text { Shear angle } \\ \lambda & \text { Wavelength of the prepreg thickness profile } \\ \rho & \text { Composite density } \\ \sigma & \text { Cauchy stress tensor } \\ \sigma_{\max } & \text { Apparent flexural strength }\end{array}$

\section{Abbreviations}
AFP
Automated Fiber Placement
AS
Ambient storage
ATL
Automated Tape Laying 
DSC Differential Scanning Calorimetry

C/PEEK PEEK with carbon fiber reinforcement

CY Cytec APC-2

D Deconsolidation treatment

HCS Humidity chamber storage

HT Heat treatment

IFRM Ideal Fiber Reinforced Material

IR Infrared

PEEK Polyether ether ketone

RGA Residual Gas Analysis

TC TenCate Cetex ${ }^{\circledR}$ TC1200

TMA Thermomechanical Analysis

UD Unidirectional

USSW Ultrasonic spot welding

VOS Vacuum oven storage 



\section{Chapter 1}

\section{Introduction}

\subsection{Background and Motivation}

The aerospace industry is continuously striving to reduce the costs and the environmental impact of aircraft during their service life, which are both directly linked to their fuel consumption. Besides more efficient engines and alternative fuels, weight reduction is a key enabler for the reduction in fuel consumption and $\mathrm{CO}_{2}$ emissions. This has led to a significant increase in the application of composite materials in the aerospace industry over the latest generations of aircraft. Composite materials account form $50 \%$ of the total aircraft weight in the Boeing 787 Dreamliner and the Airbus 350 XWB. The new Boeing 777X will have the largest composite wings ever produced [1-3]. The main reasons for this are the high specific stiffness and strength of composites compared to metals and the ability to tailor the mechanical properties, which allow for lightweight optimized design.

Composites, or more specifically fiber reinforced polymers, can be divided into two categories based on the type of polymer matrix used. The vast majority of composite materials currently applied in the aerospace industry are fiber reinforced thermoset composites [4]. However, fiber reinforced composites with a thermoplastic matrix offer benefits over thermoset-based composites in terms of potential for automated high-rate manufacturing thanks to their lack of a lengthy curing cycle. Instead, thermoplastic composites can be repeatedly melted, shaped and solidified in short cycles. This has lead to the development of rapid forming technologies, such as stamp forming. Moreover, the ability to melt and solidify the thermoplastic matrix enables fastener-free joining methods that rely on fusion bonding, such as ultrasonic, 
induction or resistance welding. Additional benefits are the high fracture toughness, good chemical resistance, infinite shelf life and recyclability.

The global demand for aircraft will continue to increase in the coming decades, especially thanks to the growing aviation market in Asia. Boeing has forecast over 42.000 aircraft deliveries between 2018 and 2037 [5]. This demand, together with the growing use of composite materials, requires rapid composite manufacturing processes with a high degree of automation in order to achieve high production rates and reduce production costs. Thermoplastic composites offer a great potential here. However, existing thermoplastic composite components still rely mostly on slow processes, for example press or autoclave consolidation, as these are well developed and reliable processes. Moreover, the tailorability of the mechanical performance, i.e. by using a lay-up which is optimized for the final application in terms of local thickness and fiber orientations, is often not fully benefited. Further development of manufacturing methods is required to extend the applicability of thermoplastic composites towards the high-rate manufacturing of load carrying structural components.

\subsection{Process route}

In general, most manufacturing processes for thermoplastic composites consist of at least two steps: the lay-up of individual composite plies and the consolidation of the plies to a solid laminate by applying heat and pressure. The composite lay-up process lends itself for a high degree of automation, which has been realized over the past decades with the development of automated lay-up technologies, such as Automated Tape Laying (ATL) and Advanced Fiber Placement (AFP). These technologies use unidirectional prepreg material in the form of tapes to lay up a stack of plies tapeby-tape and ply-by-ply using a robotic system, which offers a high degree of layup freedom. This enables the use of tailored lay-ups, allowing for more efficient material use and weight reduction compared to traditional laminates of uniform thickness. Additionally, near net-shape manufacturing is possible, which reduces scrap generated by trimming operations.

Extensive research and development effort has been put into combining lay-up and consolidation into a one-step process, so-called in-situ consolidation, e.g. [6-13]. Potentially, this is a very attractive manufacturing route, in particular for large aerostructures, such as fuselage or wing skin sections. However, in-situ consolidation still proves to be very challenging, especially at high production rates. Industrial applications therefore still rely on two-step processing where lay-up is followed by a post-consolidation step by press, autoclave or vacuum-bag-only consolidation, which are time and energy consuming processes.

As an alternative, automated lay-up could be followed by a rapid post-consolidation 
step. Here, the combination with stamp forming offers potential, in particular for smaller components. Currently, stamp forming is applied to rapidly shape flat laminates, so-called blanks, into three dimensional components in short cycle times. The process is for example being applied for the manufacturing of the thousands of thermoplastic composite clips that connect the airframe and fuselage skin of the Airbus A350XWB [14]. The short cycle times can be achieved by melting the blank in an IR oven and forming it by applying pressure with a relatively cold tooling. However, there is room for advancing this technology to the next level. Currently, the used blanks are usually cut from larger preconsolidated laminates, which can result in significant trimming scrap when nesting complex blank geometries. The blanks have a uniform thickness and a uniform lay-up, which leaves room for more efficient material use by locally optimizing the lay-up. Although the current standard is to use preconsolidated blanks, the high temperature and pressure potentially also allow for consolidation during stamp forming. This would mean that the expensive and time consuming preconsolidation step can be omitted. For these reasons, it is proposed to combine automated lay-up with stamp forming, as shown in Fig. 1.1. in order to bring the benefits of the two processes together in a rapid manufacturing route; while automated lay-up provides high-rate lay-up of unconsolidated or partially consolidated blanks and the ability to use tailored and near net shape the lay-ups, the final geometry and consolidation are achieved by stamp forming. However, it is yet to be proven that high quality components can be produced by following this rapid processing route.

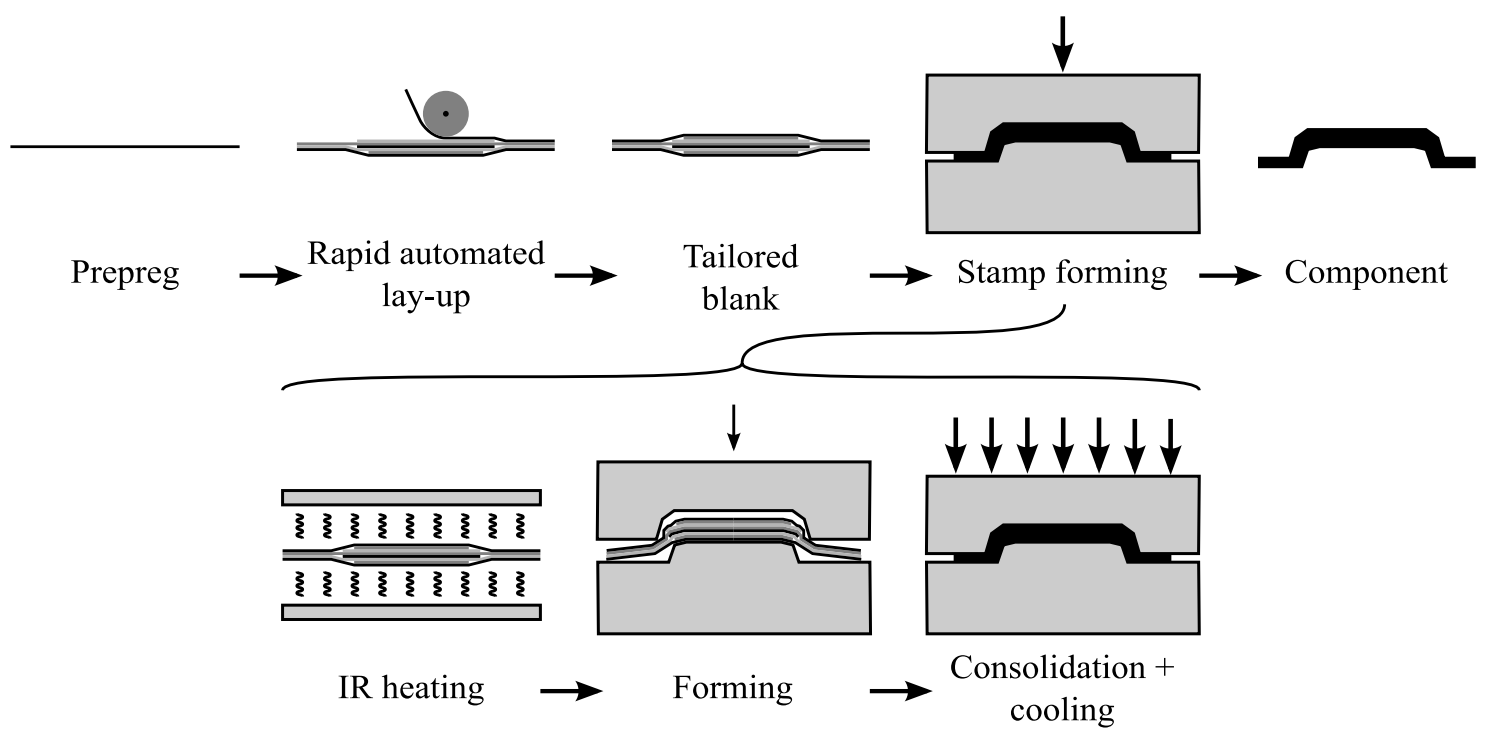

Figure 1.1 The proposed process route, combining automated lay-up and stamp forming for the rapid manufacturing of tailored components. 


\subsection{Consolidation quality}

The mechanical performance of thermoplastic composite structures is, besides the material constituents and lay-up, determined by the consolidation quality. This quality is defined by a number of measures, such as void content, interlaminar bond strength and crystallinity. The aerospace industry demands a high consolidation quality, for example a void content of less than $1 \%$. This requires robust manufacturing processes. However, achieving a high consolidation quality is not straightforward, as the consolidation quality is a function of the input material, the temperature history and the applied pressure throughout the entire process chain. This is illustrated by the countless publications in literature on consolidation processes over the past decades. Processes like press and autoclave consolidation are well established, mainly due to their high quality achieved in long isothermal consolidation cycles. Processes aimed at rapid consolidation, like for example insitu AFP, make use of short highly non-isothermal consolidation cycles. These nonisothermal cycles make robust consolidation challenging due to the small processing window. Stamp forming is also such a non-isothermal consolidation process due to the high cooling rates experienced by the material once pressure is applied by the relatively cold tooling. Robust non-isothermal consolidation requires a thorough understanding of the consolidation mechanisms and the available process window.

In the proposed process route, the final consolidation quality will be a function of the input material, the lay-up process and the stamp forming process. Void content is one of the most important measures for consolation quality. Voids are pockets of entrapped gas in the composite material. They can exist within a ply, i.e. intralaminar voids, or between plies, i.e. interlaminar voids, and their presence degrades the mechanical performance of the structure [15]. This thesis therefore focuses on void content as main measure for consolidation quality.

The evolution of void content during the process route is illustrated in Fig. 1.2. The process route starts with the input material, which may already have an initial intralaminar void content due to incomplete impregnation during the prepreg manufacturing process. The prepreg plies are bonded ply-by-ply to form the blank. This is done by the repeated application of heat and pressure during the lay-up process. The degree of bonding achieved in the blank depends on the used lay-up process; for example, while AFP may provide more global bonding by a continuous weld, an ATL process based on spot welding will provide only local bonding. The consolidation quality of the blank will be low, since the lay-up process is aimed at high-rate lay-up, rather than in-situ consolidation. Hence, interlaminar voids are expected to remain in the blank and the intralaminar voids from the initial prepreg are not eliminated. Furthermore, gaps can be present, as well as large interlaminar voids at locations where locally reinforcing plies are terminated, socalled ply-drops. The blank is then heated in the IR oven to soften the matrix for 


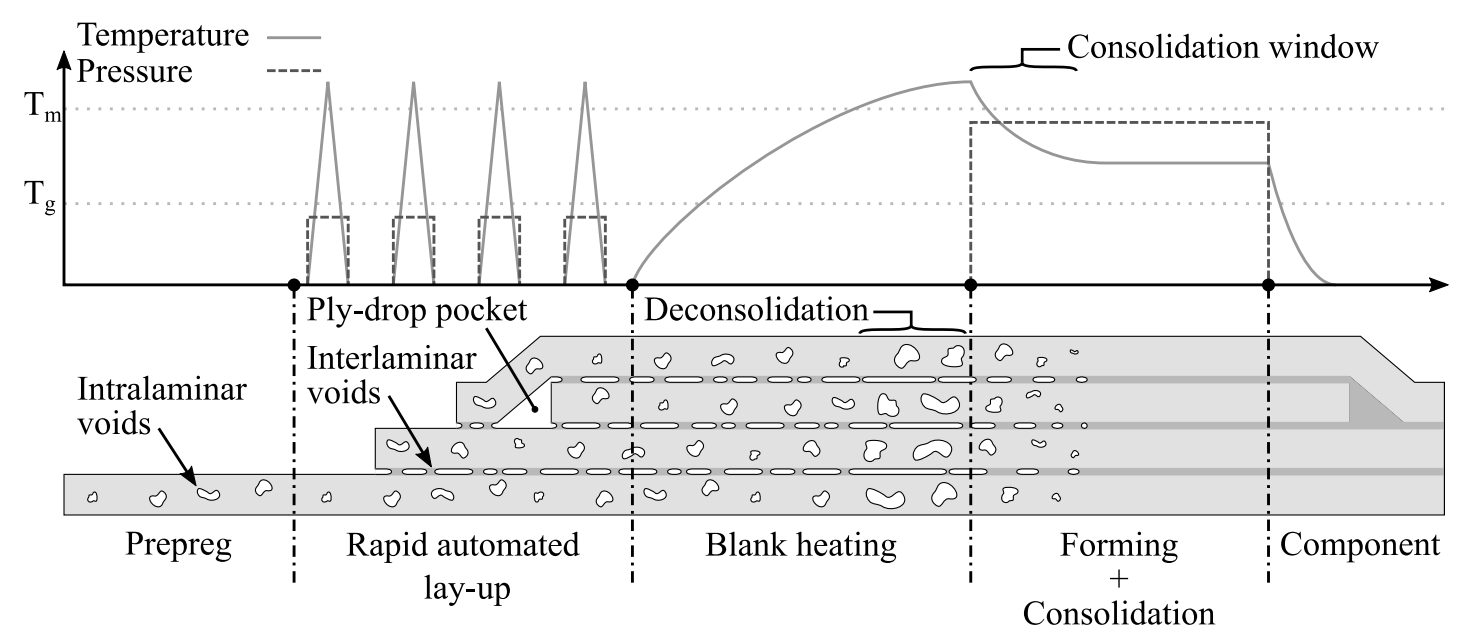

Figure 1.2 Void evolution during rapid automated lay-up and stamp forming. Note: time axis not to scale.

forming and consolidation. However, this can also induce the formation and growth of intralaminar and interlaminar voids, so-called deconsolidation. This is usually caused by a combination of the expansion of dissolved volatiles [16-19] or release of internal stresses [17, 18, 20, 21], in combination with the lack of external pressure during heating. This phenomenon is undesired, as it reduces the consolidation quality of the blank. Next, the tooling is closed and the pressure is applied to shape and consolidate the blank. At this point, the material is essentially quench cooled by the relatively cold tooling. During this phase, material flow is required to eliminate the voids. This flow collapses intralaminar voids and fills interlaminar voids by establishing contact between the plies [22, 23]. Once the plies are in contact, interlaminar bonding can be established by the interdiffusion of polymer chains across the interface, also known as healing or autohesion [22, 23]. However, this is not expected to be a rate limiting process due to the short reptation time at high temperature, typically less then $1 \mathrm{~s}$ [9, 22, 24]. These processes are driven by temperature and pressure, mainly due to the temperature dependence of the viscosity of the matrix. This viscosity increases drastically as the material cools down. In case of a semi-crystalline polymer, the matrix crystallizes at $T_{\mathrm{c}}$, a temperature between $T_{\mathrm{g}}$ and $T_{\mathrm{m}}$, and the polymer can be considered solidified due to the formation of crystalline fraction. This leaves a very small window for flow and consolidation. Finally, the consolidated component is released.

\subsection{Objective and scope}

The objective of this thesis is to develop a processing strategy for the rapid consolidation of tailored components by combining automated lay-up and stamp forming. Ideally, this strategy results in the same consolidation quality as press 
or autoclave consolidation, which are the current industry standards, but in much shorter cycle times. In order to achieve this objective, the main mechanisms contributing to the evolution of interlaminar and intralaminar void content should be identified. Based on these mechanisms, a thorough understanding needs to be developed of the interrelation between the material properties, processing parameters and final consolidation quality. This will be obtained through a combination of experimental work and physical modeling.

Several areas require special attention. Firstly, deconsolidation during the IR heating phase of the stamp forming process poses a potential threat to the success of the process route, as the additionally formed voids must also be eliminated during stamp forming. Identifying the key mechanisms for deconsolidation of blanks will help to understand the phenomenon and to establish methods for reducing deconsolidation. Secondly, practically all knowledge on the stamp forming process is based on preconsolidated blanks. However, for blanks with a low degree of preconsolidation, the final consolidation quality after stamping will most likely be very sensitive to the initial state of the blank. The processing of blanks with a low degree of preconsolidation is new and requires additional knowledge on the highly non-isothermal consolidation during stamp forming. Thirdly, there currently is no knowledge available on the consolidation of ply-drops. Thorough understanding of the consolidation behavior of ply-drops is essential for the application of the process route on components with tailored lay-ups.

The work in this thesis mainly focuses on the consolidation of flat laminates with or without local reinforcements. This way, the influence of forming on consolidation is eliminated. However, the developed knowledge is also applicable to components with more complex geometries, which is demonstrated on an industrial component in the last chapter. The applied lay-up methods are AFP, using a 1/4 inch single tow Coriolis Composites laser assisted AFP machine, and spot welding based ATL, which is simulated by manual spot welding.

The material used in this thesis is unidirectional carbon fiber reinforced poly-etherether-ketone (PEEK) prepreg tape with a fiber volume fraction of approximately $60 \%$. This is a common high performance thermoplastic composite applied in the aerospace industry thanks to its good mechanical properties and high temperature and chemical resistance. Prepreg tapes from various manufacturers are considered.

\subsection{Outline}

Figure 1.3 shows the schematic outline of the main chapters of this thesis. The chapters are reproduced from research papers. This format makes that each chapter can be read independently, while the work is put in a wider perspective in this thesis. 


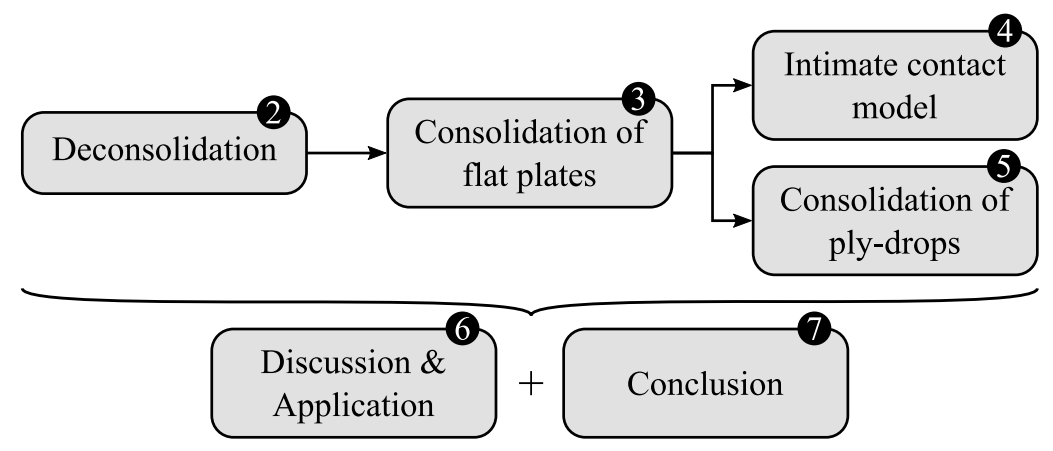

Figure 1.3 Schematic outline of the thesis.

As a consequence, some of the essential details are repeated throughout the chapters, for which the author apologizes on beforehand.

The deconsolidation behavior of blanks is investigated in Chapter 2. Deconsolidation leads to additional voids which have to be removed during stamp forming. This may be impossible in the limited consolidation window, so deconsolidation should be minimized. In order to achieve this, the dominant deconsolidation mechanisms are identified for various type of blanks. Effort is spent on correlating deconsolidation with the expansion of moisture that is dissolved in the polymer by quantifying moisture release. The influence of heat treatments on moisture content and deconsolidation is investigated. Additionally, the role of internal stresses in the prepreg used to manufacture blanks is discussed.

Chapter 3 discusses the interrelation between prepreg, blank state and final consolidation quality as a function of the used blank manufacturing process and stamp forming process parameters. Two prepreg tape materials and three blank manufacturing processes are compared in an experimental study where the consolidation quality and mechanical performance after stamp forming of flat laminates are characterized. The chapter identifies the dominant consolidation mechanisms and highlights relevant characteristics of the prepreg and blank.

Chapter 4 elaborates on intimate contact development during stamp forming, which is identified as one of the dominant consolidation mechanisms in Chapter 3 . A consolidation model based on transverse squeeze flow is developed in order to investigate the influence of prepreg thickness variations on intimate contact development in detail. This model is validated using experimental results from Chapter 3. Subsequently, it is applied to develop prepreg design guidelines and lay-up strategies aimed at optimizing intimate contact development.

Up to Chapter 4 , only uniform thickness blanks are considered. Chapter 5 specifically discusses the consolidation of non-uniform thickness tailored blanks. Such blanks have ply-drops with large air pockets. In this chapter the filling behavior of these pockets is identified based on stamp forming experiments on tailored blanks. The influence of lay-up, placement inaccuracy and blank misalignments is investigated 
and ply-drop design guidelines are provided based on the observations.

In Chapter 6, the results of Chapters 2 to 5 are combined and discussed in a broader perspective. A comprehensive overview of the process route and the consolidation mechanisms is provided. An optimal processing strategy is proposed in terms of prepreg design, blank and tooling design, lay-up strategy and stamp forming process parameters. The relation between forming and consolidation is briefly addressed and pointers for additional research in this area are provided. Furthermore, the industrial application of the developed process route is discussed and demonstrated with the manufacturing of a realistic tailored component. Finally, Chapter 7 presents the important conclusions of this thesis and provides recommendations for future work.

\section{References}

[1] Boeing 787 by design [Webpage]. Retrieved from: https://www . boeing.com/commercial/787/by-design/.

[2] Airbus A350XWB Family [Webpage]. Retrieved from: https://www .airbus.com/aircraft/passenger-aircraft/a350xwb-family.html

[3] C. Red. 777X: Bigger-than-expected carbon fiber impact [Blog post], 2016. Retrieved from: https://www. compositesworld.com/blog/post/ 777x-bigger-than-expected-carbon-fiber-impact

[4] D. Brosius. Thermosets vs. thermoplastics: Is the battle over?, 2015. Retrieved from: https://www. compositesworld.com/articles/ thermosets-vs-thermoplastics-is-the-battle-over

[5] The Boeing Company. Commercial Market Outlook 2018-2037. Technical report, The Boeing Company, 2018.

[6] S. Ranganathan, S. G. Advani, and M. A. Lamontia. A Non-Isothermal Process Model for Consolidation and Void Reduction during In-Situ Tow Placement of Thermoplastic Composites. Journal of Composite Materials, 29(8):1040-1062, 1995.

[7] R. Pitchumani, S. Ranganathan, R. C. Don, J. W. Gillespie, and M. A. Lamontia. Analysis of Transport Phenomena Governing Interfacial Bonding and Void Dynamics During Thermoplastic Tow-placement. International Journal of Heat and Mass Transfer, 39(9):1883-1897, 1996.

[8] F. O. Sonmez and H. T. Hahn. Analysis of the on-line consolidation process in thermoplastic composite tape placement. Journal of Thermoplastic Composite Materials, 10(6):543-572, 1997.

[9] J. Tierney and J. W. Gillespie. Modeling of In Situ Strength Development for the Thermoplastic Composite Tow Placement Process. Journal of Composite Materials, 40(16):1487-1506, 2006.

[10] W. J. B. Grouve. Weld Strength of Laser-Assisted Tape-Placed Thermoplastic Composites. Ph.D. thesis, University of Twente, 2012. 
[11] T. Kok. On the consolidation quality in laser assisted fiber placement: the role of the heating phase. Ph.D. thesis, University of Twente, Enschede, The Netherlands, 2018.

[12] G. Gardiner. Consolidating thermoplastic composite aerostructures in place - Part 1, 2018. Retrieved from: https://www. compositesworld.com/articles/ consolidating-thermoplastic-composite-aerostructures-in-place-part-1.

[13] G. Gardiner. Consolidating thermoplastic composite aerostructures in place - Part 2, 2018. Retrieved from: https://www. compositesworld.com/articles/ consolidating-thermoplastic-composite-aerostructures-in-place-part-2.

[14] S. Black. Thermoplastic composites "clip" time, labor on small but crucial parts, 2015. Retrieved from: https://www.compositesworld.com/articles/ thermoplastic-composites-clip-time-labor-on-small-but-crucial-parts

[15] X. Liu and F. Chen. A review of void formation and its effects on the mechanical performance of carbon fiber reinforced plastic. Engineering Transactions, 64(1):33-51, 2016.

[16] Y. Leterrier and C. G'Sell. Formation and Elimination of Voids During the Processing of Thermoplastic Matrix Composites. Polymer Composites, 15(2):101-105, 1994.

[17] C. Gröschel and D. Drummer. The Influence of Moisture and Laminate Setup on the De-consolidation Behavior or PA6/GF Thermoplastic Matrix Composites. International Polymer Processing, 29(5):660-668, 2014.

[18] H. Shi. Resistance welding of thermoplastic composites - Process and performance. Ph.D. thesis, TU Delft, 2014.

[19] T. Guglhoer and M. G. R. Sause. The Influence of Moisture on the Deconsolidation Behaviour of Carbon Fiber Reinforced PA-6 Laminates. In 17th International Conference on Composite Materials, 2016.

[20] J. Wolfrath, V. Michaud, and J.-A. E. Månson. Deconsolidation in glass mat thermoplastic composites: Analysis of the mechanisms. Composites Part A: Applied Science and Manufacturing, 36(12):1608-1616, 2005.

[21] L. Ye, Z.-R. Chen, M. Lu, and M. Hou. De-consolidation and re-consolidation in CF/PPS thermoplastic matrix composites. Composites Part A: Applied Science and Manufacturing, 36(7):915-922, 2005.

[22] R. Phillips. Consolidation and solidification behavior of thermoplastic composites. Ph.D. thesis, École Polytechnique Fédérale de Lausanne, 1996.

[23] R. S. Dave and A. C. Loos. Processing of Composites, 1999.

[24] P. E. Bourban, N. Bernet, J. E. Zanetto, and J.-A. E. Månson. Material phenomena controlling rapid processing of thermoplastic composites. Composites - Part A: Applied Science and Manufacturing, 32(8):1045-1057, 2001. 


\title{
Chapter 2
}

\section{Deconsolidation of C/PEEK Blanks}

\begin{abstract}
The combination of rapid automated lay-up and stamp forming has great potential for rapid manufacturing of lightweight load carrying components of thermoplastic composites. However, deconsolidation during blank heating is currently limiting the applicability of rapid lay-up blanks. This experimental work investigates the origin of deconsolidation in blanks produced by advanced fiber placement (AFP) versus traditional press consolidation. The influence of moisture on deconsolidation is investigated through deconsolidation experiments in a convection oven, as well as thermo-mechanical and residual gas analyses. The experiments revealed that thermal expansion of dissolved moisture is the main deconsolidation mechanism for pressconsolidated blanks, but not for AFP blanks, which are suggested to deconsolidate mainly due to the release of frozen-in fiber stresses present in the used prepreg.
\end{abstract}




\subsection{Introduction}

Thermoplastic composites are increasingly being used in industry due to their advantages over thermoset composites. The advantages include a higher toughness, recyclability and their potential for automated high volume manufacturing due to their weldability and formability. For these reasons thermoplastic composites are well accepted in aerospace industry and, slowly but surely, also in automotive industry. However, the high demands from industry on performance and costs require both the advancement of existing and the development of new processing technologies, where the focus is on rapid and reliable manufacturing.

Stamp forming is a fine example of a well-established processing technology which uses the formability of thermoplastic composites at elevated temperatures to shape a flat laminate into a three dimensional component. Short cycle times can be achieved as no curing reaction is required, making the process very attractive for large series production. However, the application of stamp forming is currently limited to the production of secondary components with relatively simple geometries and uniform lay-up. Moreover, the blanks used to produce these components are usually cut from larger rectangular laminates, which are manufactured through time and energy consuming press or autoclave consolidation. Additionally, the cutting of blanks and trimming after stamp forming results in significant amounts of scrap material. Further advancement of the stamp forming technology is required to extend its application to structurally loaded primary components, increase weight savings and reduce costs.

The development of rapid automated lay-up technologies over the past decades, such as automated tape lay-up (ATL) and advanced fiber placement (AFP), offers the possibility for highly automated manufacturing of blanks with a high degree of lay-up freedom. This enables the use of tailored lay-ups, which can be optimized for their final application in terms of local thickness and fiber orientations. This allows for more efficient material use and weight reduction compared to traditional lay-ups. Moreover, near-net-shaped blanks can be produced, which reduces production scrap. For these reasons, the combination of rapid automated lay-up and stamp forming, as illustrated in Fig. 2.1. has the potential for a great step forward in the rapid manufacturing of load carrying components.

One of the current limitations of automated lay-up processes is that they do not provide the same level of blank consolidation as traditional press or autoclave consolidation due to the high lay-up rates that are required to achieve a high productivity. The consolidation quality of a blank is relevant, as it forms the basis for the consolidation quality of a component after stamp forming. The consolidation quality comprises several properties, such as void content and degree of interlaminar bonding, which determine the performance of a component [1-6]. These properties depend strongly on the local thermal and pressure history. Due to the high cooling 


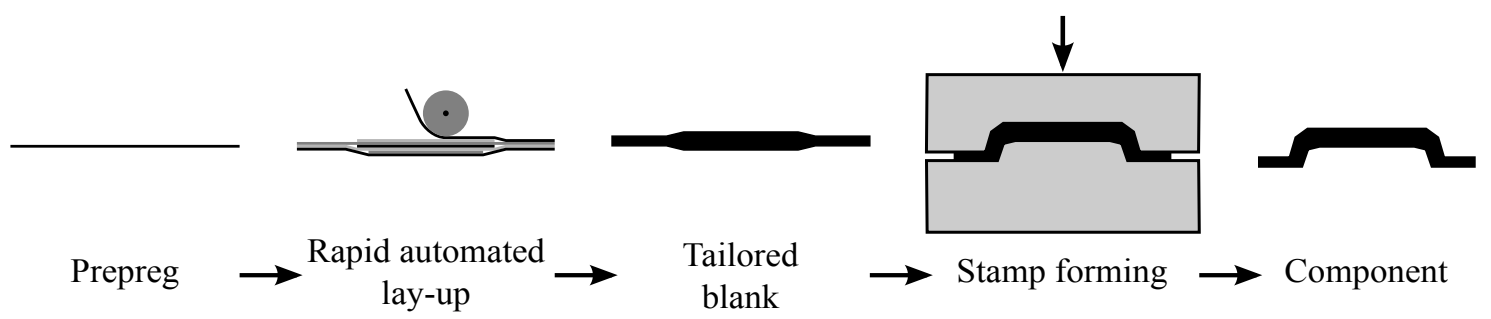

Figure 2.1 Combination of rapid automated lay-up and stamp forming for components with tailored lay-ups.

rates in the stamp forming process, there is limited time available for void elimination and interlaminar bonding. As a result, low blank consolidation quality, e.g. high void content and poor interlaminar bonding, could lead to poor component performance after stamp forming.

The degree of blank consolidation that can be achieved by automated lay-up technologies is depending on the process. Best results can be obtained with AFP, where narrow tapes are bonded together by continuous fusion bonding. However, achieving so-called full in-situ consolidation with AFP remains challenging, especially while maintaining a high productivity [7-11]. The latter is essential for the successful combination of rapid automated lay-up and stamp forming.

The potential of AFP as a blank manufacturing technology was explored by the authors in previous work [12]. The AFP blanks showed an inferior consolidation quality after stamp forming compared to press-consolidated blanks. This was attributed to blank deconsolidation, which was found to be more pronounced for the AFP blanks. Deconsolidation is a common phenomenon during the processing of thermoplastic composites and plays a role in for example stamp forming [3, 12,-14], welding [15] and AFP [16]. It is often described as the lofting or debulking of a composite when being exposed to elevated temperatures (above melting temperature for semi-crystalline thermoplastics), especially when no external pressure is applied. During deconsolidation, voids form and grow within the composite and plies may even delaminate. Deconsolidation is often attributed to two primary causes. Firstly, the release of stresses carried by the fiber bed, which were introduced during manufacturing of the laminate, has been identified as source of deconsolidation by many authors [14, 15, 17,-23]. However, the materials used in these works were mainly woven fabrics. These can store a large amount of elastic energy due to the undulating fiber bundles. The effect is less pronounced for unidirectional pregreg, as this undulation is not present and hence less elastic energy is stored in the fiber bed [24]. Secondly, a well known source of deconsolidation is the thermal expansion of dissolved gas [25] and moisture [15, 21, 26, 27] in the matrix, especially at high heating rates. Deconsolidation can easily be prevented by applying external pressure during heating [15, 20, 28]. However, this requires contact between composite and tooling. For some technologies, including stamp forming, it is 


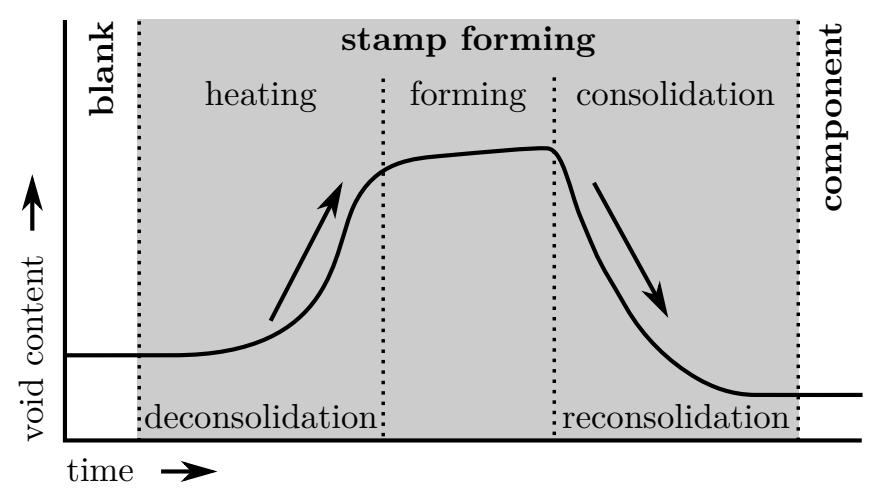

Figure 2.2 Typical void evolution during the three stages of the stamp forming process.

preferred to use contact-less heating methods, such as IR heater panels. In this case, deconsolidation cannot be prevented by applying external pressure. As a result, a blank may deconsolidate during the heating phase of the stamp forming process, as is schematically shown in Fig. 2.2. The voids formed by deconsolidation have to be eliminated again during reconsolidation, making the consolidation process somewhat inefficient. Deconsolidation may even lead to poorly consolidated parts if reconsolidation is insufficient. Additionally, deconsolidation obstructs heat transfer in the blank, increasing the required heating time in the IR oven [12, 13].

The current paper aims to investigate the deconsolidation mechanisms that cause the previously observed [12] differences in deconsolidation behavior between blanks produced by press-consolidation and AFP. Proper characterization of the deconsolidation behavior could lead to methods to reduce or prevent it. Controlling deconsolidation is thought to be essential for improving consolidation quality of stamp formed components, especially for blanks produced by rapid AFP technologies.

In this work the deconsolidation behavior of blanks is characterized experimentally. Blanks produced both by press-consolidation and AFP, aimed at rapid lay-up, are considered, in order to investigate the influence of blank consolidation quality and production method on deconsolidation behavior. As moisture expansion has been identified as the most likely deconsolidation mechanism, this work focuses on the effect of dissolved moisture on deconsolidation. The release of fiber bed stresses is assumed to be less dominant due to the use of unidirectional tapes. Various treatments are applied in order to alter the moisture content of the blanks prior to deconsolidation in a convection oven. Deconsolidation is characterized by thickness measurements and cross-sectional micrographs, while moisture content is measured through weight loss. Additional thermo mechanical (TMA) and residual gas analyses (RGA) are performed in order to identify a relation between thickness increase due to void formation and moisture release. 


\subsection{Experimental work}

\subsubsection{Materials and blank manufacturing}

Cross-ply $[0 / 90]_{4 s}$ laminates were prepared from unidirectional (UD) TenCate Cetex ${ }^{\circledR}$ TC1200 AS4/PEEK prepreg material according to the procedures listed below. This prepreg has a listed consolidated ply thickness and fiber volume fraction after press consolidation of $0.15 \mathrm{~mm}$ and $59 \%$, respectively, and a very low $(<1 \%)$ void content [29]. The glass transition temperature $T_{\mathrm{g}}$ and melting temperature $T_{\mathrm{m}}$ are $143{ }^{\circ} \mathrm{C}$ and $343{ }^{\circ} \mathrm{C}$, respectively. C/PEEK is known for its low moisture uptake (between 0.1 and $0.2 \%$, depending on conditions [30-32]) and the limited effect of moisture on mechanical properties [31, 32].

- Press consolidation. A $600 \times 600 \mathrm{~mm}^{2}$ laminate was laid up by hand from 6 inch wide prepreg. The laminate was placed between $1 \mathrm{~mm}$ stainless steel caul sheets coated with Marbocote 227 CEE release agent and consolidated in a $200 \mathrm{t}$ Pinette P.E.I. press with a 20 minute dwell at $386^{\circ} \mathrm{C}$ and 10 bars and cooled at a rate of $2.5^{\circ} \mathrm{C} / \mathrm{min}$. This procedure results in a void-free laminate.

- AFP. A Coriolis Composites AFP robot with laser heating was used to produce a $330 \times 330 \mathrm{~mm}^{2}$ laminate from $1 / 4$ inch wide prepreg at a rate of $200 \mathrm{~mm} / \mathrm{s}$ and a nip-point temperature of approximately $450{ }^{\circ} \mathrm{C}$ (measured by thermal camera). A compaction force of $100 \mathrm{~N}$ was applied by a deformable silicon roller of $40 \mathrm{SH}$ hardness, resulting in an compaction pressure of approximately $1 \mathrm{bar}$. This procedure results in a laminate which is not void-free and has imperfect interlaminar bonding, as is typical for blanks produced at high lay-up rates.

\subsubsection{Oven deconsolidation experiments}

\section{Pretreatments}

The laminates were given a primary treatment at ambient lab conditions $(\approx 23$ ${ }^{\circ} \mathrm{C} / 50 \% \mathrm{RH}$ ) for 2 months prior to cutting them into smaller $100 \times 100 \mathrm{~mm}^{2}$ specimens. This simulates long term laminate storage between blank manufacturing and stamp forming and results in blanks which are saturated with moisture at ambient conditions. The subsequent secondary treatments are listed in Tbl. 2.1, and include treatments that further alter the moisture content by drying or humidifying. Additionally, various high temperature (above $T_{\mathrm{g}}$ ) heat treatments in a convection oven were included to investigate the effect of treatment temperature and duration. Relaxation of residual stresses and additional crystallization may occur at these temperatures [33], but further analysis of this is not considered within the scope of this work. 
Table 2.1 Secondary treatments prior to deconsolidation.

\begin{tabular}{|c|c|c|c|}
\hline Treatment & Method & Conditions & Duration \\
\hline AS & Ambient storage & $\mathrm{Lab}\left(\approx 23{ }^{\circ} \mathrm{C} / 50 \% \mathrm{RH}\right)$ & 2 months \\
\hline VOS & Vacuum oven storage & $70^{\circ} \mathrm{C} /$ vacuum & 2 months \\
\hline HCS & $\begin{array}{l}\text { Humidity chamber } \\
\text { storage }\end{array}$ & $80^{\circ} \mathrm{C} / 85 \% \mathrm{RH}$ & 2 weeks \\
\hline HT-3H@150C & Heat treatment & $150{ }^{\circ} \mathrm{C}$ & 3 hours \\
\hline HT-15M@250C & Heat treatment & $250{ }^{\circ} \mathrm{C}$ & 15 minutes \\
\hline HT-3H@250C & Heat treatment & $250{ }^{\circ} \mathrm{C}$ & 3 hours \\
\hline $\begin{array}{c}\text { HT-3H@250C + } \\
\text { HCS }\end{array}$ & $\begin{array}{l}\text { Heat treatment }+ \\
\text { Humidity chamber } \\
\text { storage }\end{array}$ & $250^{\circ} \mathrm{C}+80^{\circ} \mathrm{C} / 85 \% \mathrm{RH}$ & 3 hours +5 days \\
\hline
\end{tabular}

A total of three specimens were tested per pretreatment. The press-consolidated specimens were subjected to all pretreatments, while the AFP specimens were only subjected to three treatments based on the results of the press-consolidated specimens; ambient storage (AS), vacuum oven storage (VOS) and one heat treatment (HT-3H@250C). The specimens were weighed regularly on a semi-micro balance in order to monitor the moisture content during the treatments. It was assumed that saturation was reached once no further significant weight change was observed over a period of one week.

\section{Deconsolidation Treatment}

All specimens were deconsolidated within 1 hour after finishing the pretreatment by heating them in a preheated convection oven at $390{ }^{\circ} \mathrm{C}$ for 20 minutes. This is a typical preheating temperature for $\mathrm{C} / \mathrm{PEEK}$ blanks during stamp forming. Temperature measurements have shown that the laminates experience a similar heating curve during heating in the convection oven and heating in an IR oven during stamp forming. This can be seen in Fig. 2.3, which shows the core and surface temperature measured by thermocouples during the deconsolidation cycle and a typical stamp forming cycle. The specimens were held in the oven for 20 minutes to ensure full deconsolidation [20] and cooled to room temperature by natural convection. The effect of gravity on deconsolidation was eliminated by hanging the specimens vertically using alligator clips.

\section{Characterization}

The relative thickness increase after heat treatment of a specimen gives a quantitative measure for the amount of deconsolidation. In case the specimen is initially void-free, 


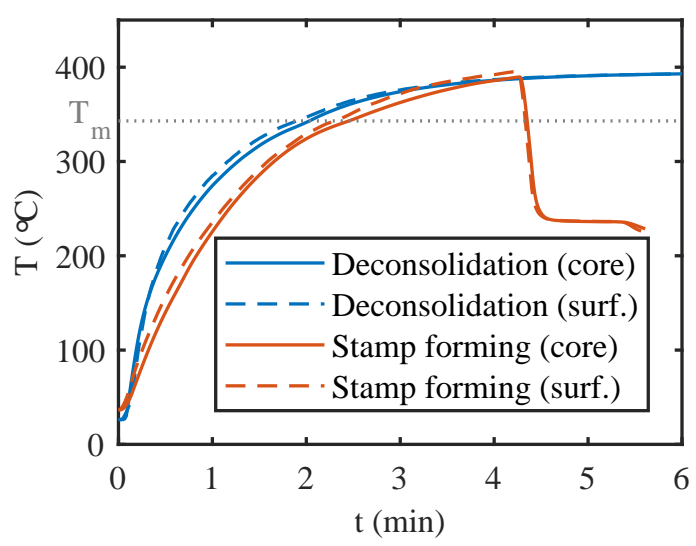

Figure 2.3 Core and surface temperature measured by thermocouples during the deconsolidation cycle (convection oven) and a typical C/PEEK stamp forming cycle (IR oven).

the relative thickness increase also gives an estimate of the void content:

$$
V_{\mathrm{v}} \approx h_{\mathrm{rel}}=\frac{h_{1}-h_{0}}{h_{0}} \times 100 \%
$$

Here, $V_{\mathrm{v}}$ is the void content per unit volume, $h_{\text {rel }}$ the relative thickness increase, $h_{0}$ the thickness before deconsolidation and $h_{1}$ the thickness after deconsolidation. The thickness of each specimen was measured at 5 predefined points just before and after the deconsolidation treatment using a micrometer. Additionally, the void content was characterized qualitatively through cross-sectional micrographs of the specimens.

In case all moisture is removed from the composite during the deconsolidation treatment and no additional weight loss is caused by other phenomena, the moisture content prior to the deconsolidation treatment can be estimated based on the relative weight loss:

$$
w_{\mathrm{m}} \approx w_{\mathrm{rel}}=\frac{w_{0}-w_{1}}{w_{1}} \times 100 \%
$$

Here, $w_{\mathrm{m}}$ is the moisture content per unit weight prior to deconsolidation, $w_{\text {rel }}$ the relative weight loss during deconsolidation, $w_{0}$ the weight before deconsolidation and $w_{1}$ the weight after deconsolidation. Each specimen was weighed using a semi-micro balance (0.01 $\mathrm{mg}$ precision) just before and after the deconsolidation treatment.

\subsubsection{TMA and RGA experiments}

The deconsolidation behavior was further analyzed by performing continuous measurements of thickness increase and moisture release during deconsolidation through zero-force thermo-mechanical analysis (TMA) and residual gas analysis 


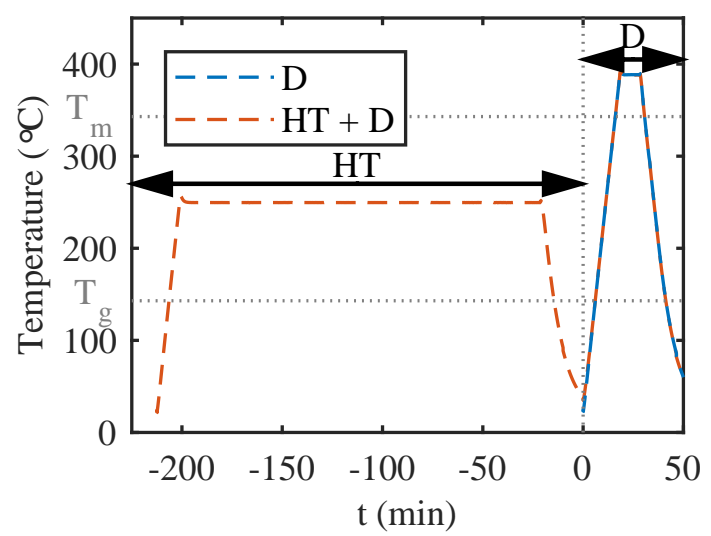

Figure 2.4 Measured temperature during the TMA for a deconsolidation cycle (D) and a cycle with additional heat treatment prior to deconsolidation $(H T+D)$.

(RGA), respectively. The TMA analyses were performed on a Mettler Toledo TMA/SDTA840. The relative thickness increase measured during TMA is a combination of thermal expansion, crystallization effects and deconsolidation. The release of moisture molecules was detected by measuring the ion current for $\mathrm{m} / \mathrm{z}=$ 18 for $\mathrm{H}_{2} \mathrm{O}$ during the RGA in a Netsch STA 449 F3.

Small $8 \times 8 \mathrm{~mm}^{2}$ specimens were cut from the press-consolidated and AFP laminates that were stored at ambient conditions. The specimens were heated inside the test equipment following the thermal profiles shown in Fig. 2.4. The profiles includes either only a deconsolidation cycle (D), or an additional preceding heat treatment cycle (HT) of 3 hours at $250{ }^{\circ} \mathrm{C}$. Heating and cooling rates were set to $20{ }^{\circ} \mathrm{C} / \mathrm{min}$ in order avoid large temperature gradients within the specimens. Both the TMA and RGA were performed under nitrogen atmosphere to prevent degradation of the polymer. A negligible external pressure of $1.5 \mathrm{kPa}$ was applied during the TMA to ensure contact with the specimen.

\subsection{Results}

\subsubsection{Oven deconsolidation experiments}

\section{Press-consolidated specimens}

Figure 2.5 shows the average relative thickness increase versus the relative weight loss during deconsolidation for the press-consolidated specimens. The measurements can be divided into two groups, indicated by the dotted lines in Fig. 2.5. On the one hand, there is a large group of treatments (AS, HCS, HT-3H@150C, HT-15M@250C and HT-3H@250C+HCS) where weight loss differs among the treatments, but thickness 


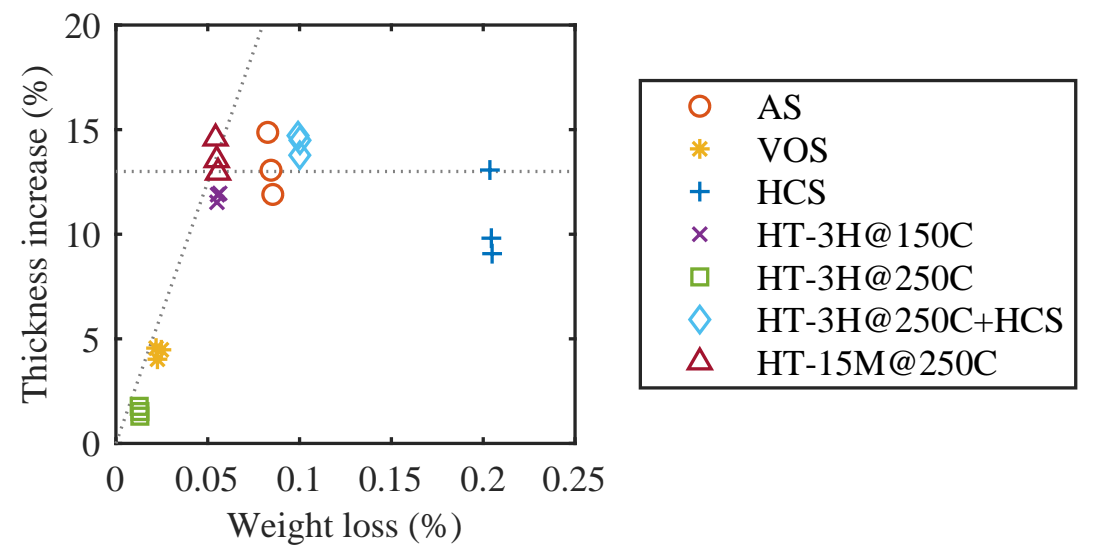

Figure 2.5 Thickness increase vs. weight loss during deconsolidation for press-consolidated specimens. $A S=$ ambient storage, $V O S=$ vacuum oven storage, HCS = humidity chamber storage and $H T=$ heat treatment.

increase does not change significantly and remains at $12-15 \%$, indicating that deconsolidation behavior is not sensitive to moisture content in this group. The group includes all treatments which show a weight loss of $0.06 \%$ and more during deconsolidation. The ambient stored (AS) specimens show a weight loss of $0.08 \%$, which is consistent with the saturation level found literature [30-32]. On the other hand, there is a group of two treatments (VOS and HT-3H@250C) which show a weight loss of less than $0.03 \%$ and a significant reduction in thickness increase to less than $5 \%$. This indicates a more effective reduction in moisture content by these treatments and a much higher sensitivity of deconsolidation to moisture content compared to the other group of treatments.

The heat treatment for 3 hours at $250{ }^{\circ} \mathrm{C}$ (HT-3H@250C) is most effective in reducing both moisture content and deconsolidation to $0.01 \%$ and $1.5 \%$, respectively. The shorter heat treatment (HT-15M@250C) and lower temperature heat treatment (HT3H@150C) have only slightly reduced the moisture content, while not affecting deconsolidation significantly. Rehumidifying a heat treated specimen (HT$3 \mathrm{H} @ 250 \mathrm{C}+\mathrm{HCS})$ restored all deconsolidation. This also indicates that annealing of the matrix or further crystallization during the heat treatments did not influence the deconsolidation behavior. The heat treatments can therefore in this case simply be considered as high temperature drying treatments.

The thickness measurements are further supported by cross-sectional micrographs, which are shown in Fig. 2.6. While a specimen before deconsolidation is void-free, the deconsolidated specimens show more voids for increasing thickness increase. The voids are mainly found at the interfaces between the plies, i.e. interlaminar voids, while the plies have remained mostly intact. Similar deconsolidated states were found for the group of specimens with 12 - 15\% thickness increase. Figure 2.6 (b) shows that interlaminar voids have formed delaminations, which could also 
be observed as blisters on the surface of the specimens. The specimens stored in the vacuum oven (VOS, Fig. 2.6 (c)) show much less interlaminar voids and no delaminations. The voids are mainly located between the plies closest to the midplane. The specimens that were exposed to a heat treatment (HT-3H@250C, Fig. 2.6 (d)) show an almost void-free cross-section. This matches the minimal thickness increase of $1.5 \%$ for these specimens.

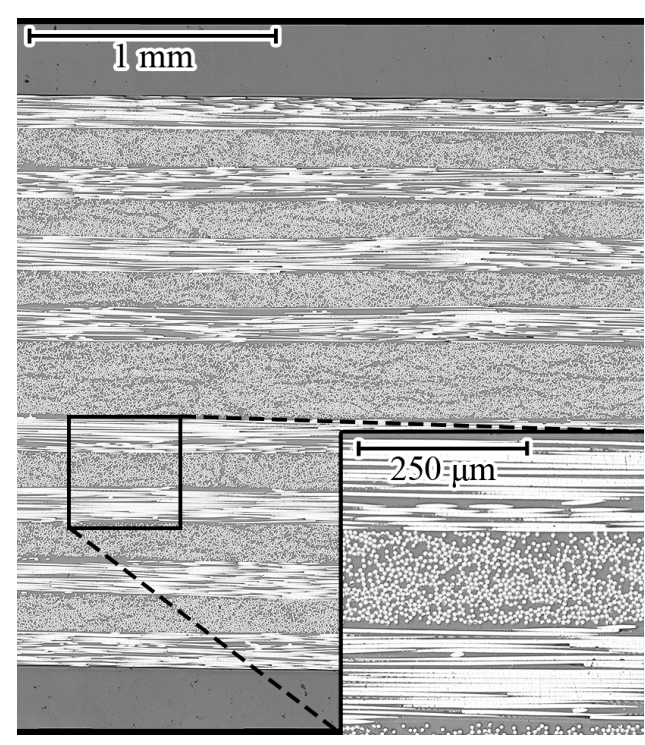

(a) Before deconsolidation

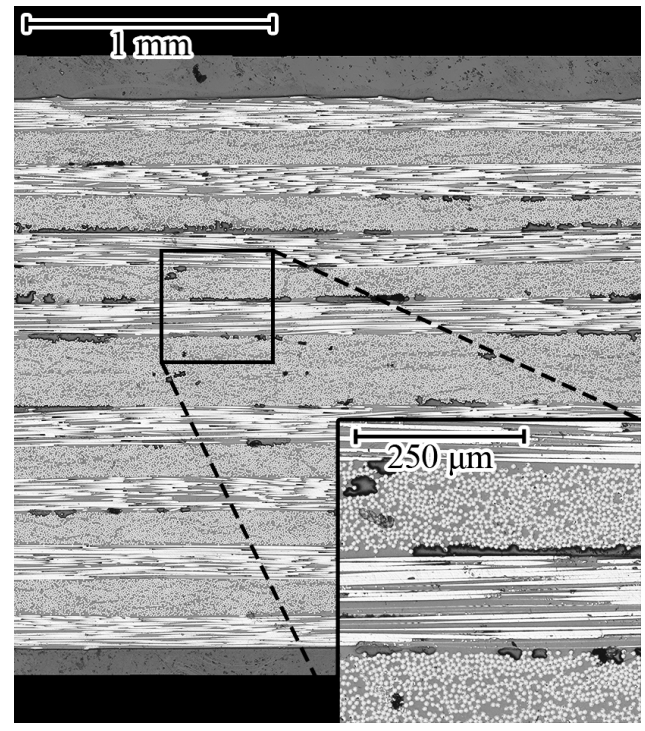

(c) Deconsolidated, VOS $\left(h_{\text {rel }}=4.4 \%\right)$

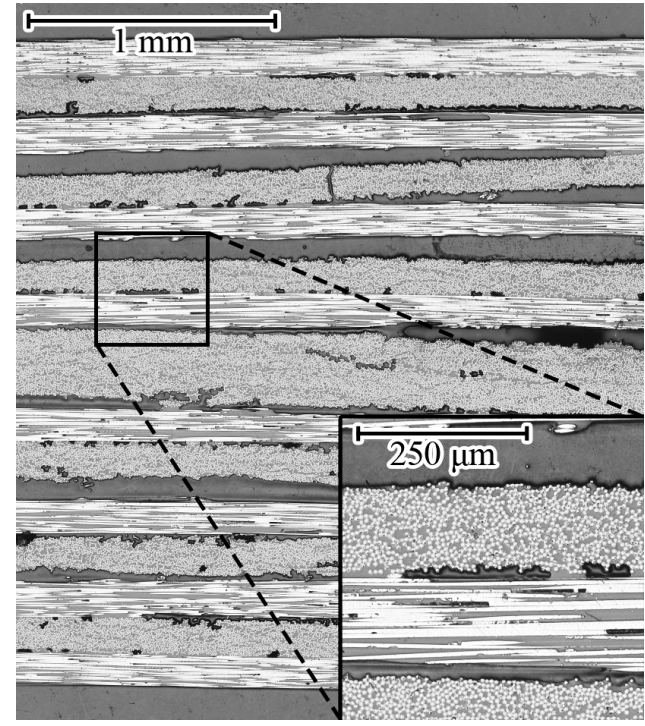

(b) Deconsolitaded, AS ( $\left.h_{\text {rel }}=13.3 \%\right)$

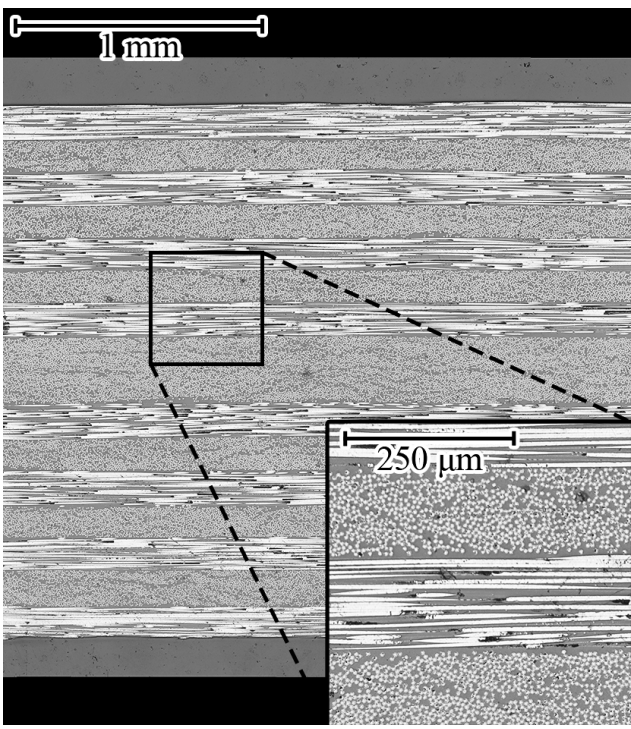

(d) Deconsolidated, HT-3H@250C

$$
\left(h_{\text {rel }}=1.5 \%\right)
$$

Figure 2.6 Micrographs of cross-sections of press-consolidated specimens (a) before deconsolidation, and deconsolidated (b) after ambient storage (AS), (c) after vacuum oven storage (VOS) and (d) after a heat treatment (HT-3H@250C). 


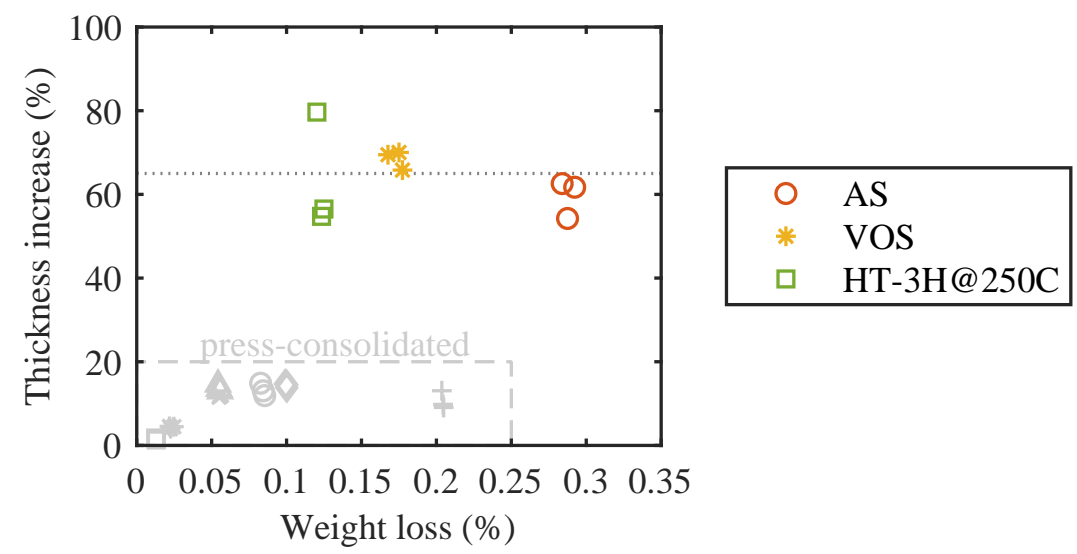

Figure 2.7 Thickness increase vs. weight loss during deconsolidation for AFP specimens. AS = ambient storage, $V O S=$ vacuum oven storage and HT = heat treatment.

\section{AFP specimens}

The average relative thickness increase versus the relative weight loss after deconsolidation is shown in Fig. 2.7 for the AFP specimens. The AFP specimens show a similar plateau as the press-consolidated specimens where thickness increase is not related to weight loss, indicated by the dotted line. However, the observed weight loss and thickness increases are much higher for the AFP specimens compared to the press-consolidated specimens. The AFP specimens stored at ambient conditions (AS) show a weight loss of approximately $0.3 \%$, three times higher than the pressconsolidated specimens and also higher than the saturated moisture content reported in literature [30-32]. Possibly additional moisture was entrapped in voids between the plies. The thickness increase is approximately $60 \%$, about four times higher. Both the vacuum oven treatment (VOS), as well as the heat treatment for 3 hours at $250{ }^{\circ} \mathrm{C}$ (HT-3H@250C), have not significantly affected thickness increase. This is in contrast with the press-consolidated specimens, where these treatments were very effective in reducing deconsolidation. However, a large weight loss was still observed after deconsolidation for both treatments. This could indicate that the treatments did not eliminate all moisture prior to deconsolidation or that additional volatiles are released during deconsolidation.

A cross-sectional micrograph of a deconsolidated AFP specimen is compared to a specimen before deconsolidation in Fig. 2.8. The cross-section of the deconsolidated specimen confirms the larger amount of deconsolidation of the AFP specimens. Plies have almost completely debonded. This is not surprising, given the limited interlaminar bonding of the specimen prior to deconsolidation due to the high lay-up rate during AFP. Besides debonding, the plies themselves also show signs of deconsolidation, as if individual fibers or small bundles of fibers have popped out from the plies, forming rough ply surfaces with loose fibers. This was not observed for the press-consolidated specimens. Moreover, the AFP specimens 


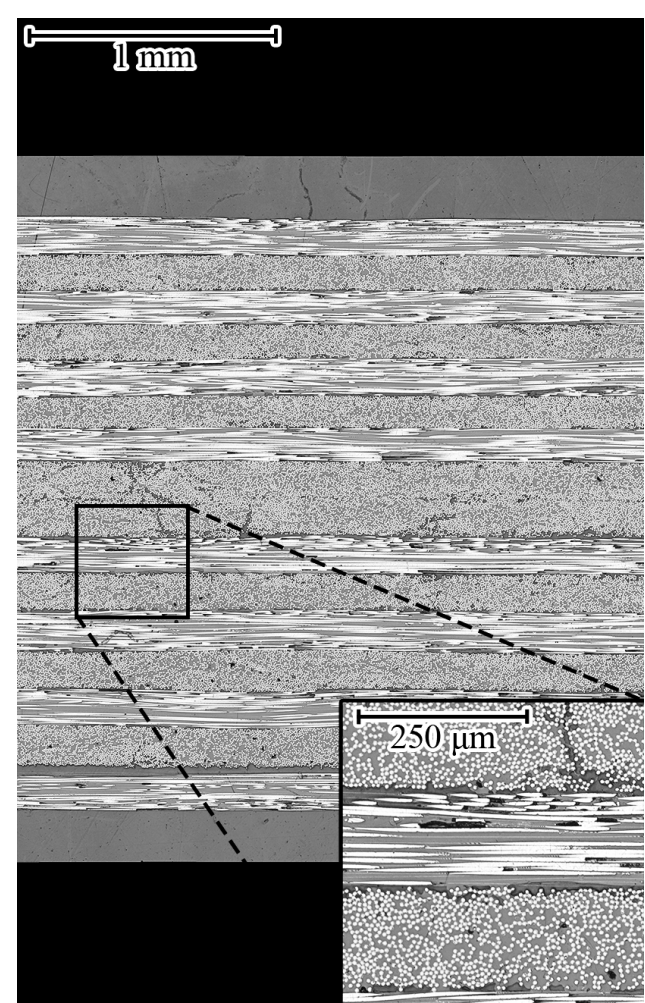

(a) Before deconsolidation

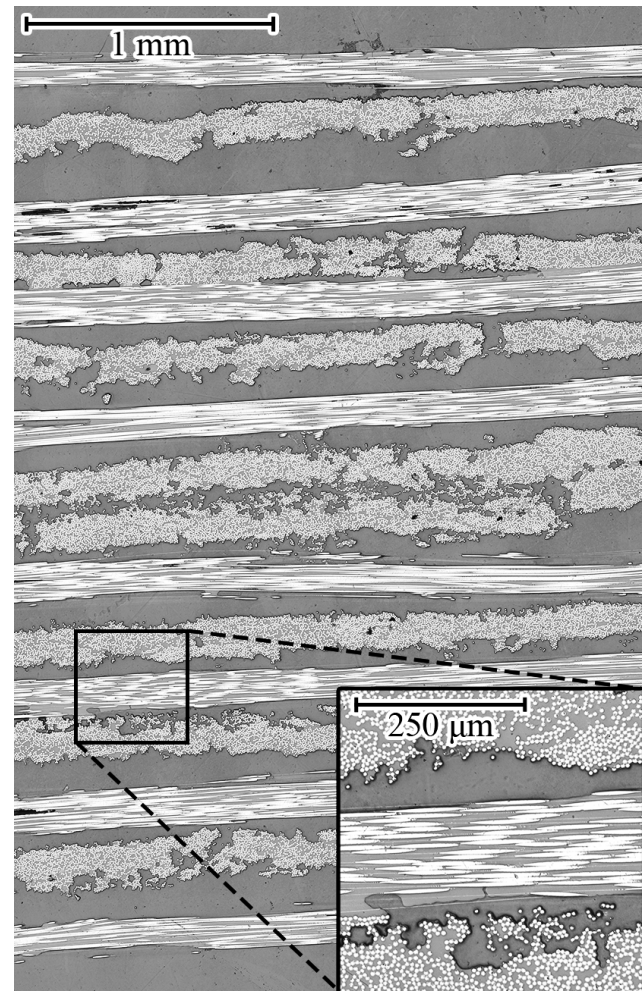

(b) Deconsolidated, AS $\left(h_{\text {rel }}=59.5 \%\right)$

Figure 2.8 Micrographs of cross-sections of AFP specimens (a) before deconsolidation and (b) deconsolidated after ambient storage $(A S)$.

showed significant local out-of-plane ply waviness instead of the large blisters observed for the press-consolidated specimens.

\subsubsection{TMA and RGA experiments}

\section{Heat treatment}

The results of the TMA and RGA during the heat treatment (HT) part of HT + D cycle are shown in Fig. 2.9 (a) and (b), respectively, for the press-consolidated and AFP specimens. The TMA curves show an expansion upon heating to the plateau at $250^{\circ} \mathrm{C}$ of up to $2 \%$ for the press-consolidated specimen. The original thickness is restored for both specimens upon cooling, indicating that only reversible thermal expansion has occurred and no deconsolidation. Moreover, the lack of crystallization shrinkage for both specimens indicate that both specimens had similar high crystallinity. The increase in ion current in the RGA curve above the baseline level of $2 \cdot 10^{-11} \mathrm{~A}$ confirms that moisture is released during the heat treatment. A large peak in the current is observed when crossing $T_{\mathrm{g}}$ at $-204 \mathrm{~min}$. This is followed by a gradually decreasing current during the dwell at $250{ }^{\circ} \mathrm{C}$ until a stable level is reached after 


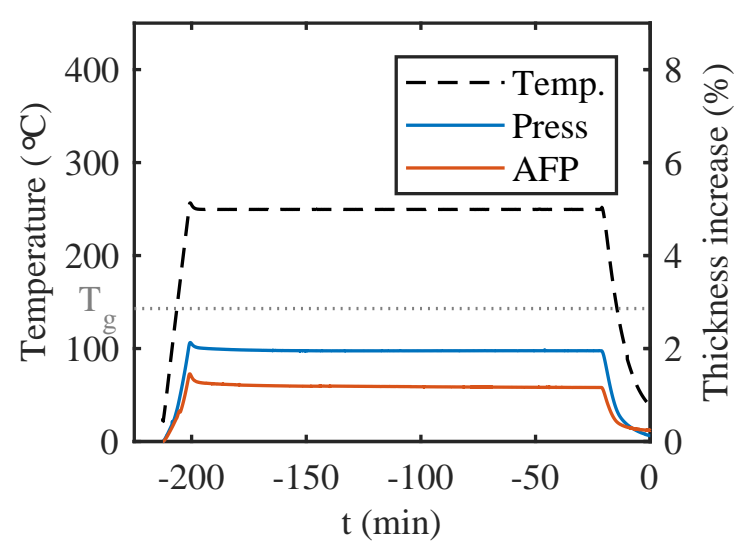

(a) TMA

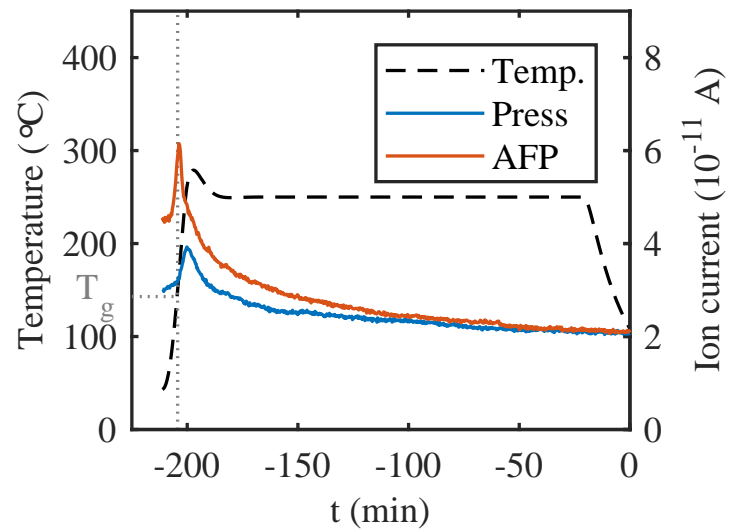

(b) RGA

Figure 2.9 (a) TMA and (b) RGA results of the heat treatment (HT) part of the $H T+D$ thermal cycle for a press-consolidated and AFP specimen.

about 150 minutes. This time is most likely sensitive to the specimen dimensions, as moisture diffusion will occur both in-plane and through thickness. The peak is also larger for the AFP specimen, confirming that the AFP specimen contained more moisture than the press-consolidated specimen.

\section{Deconsolidation - Press-consolidated specimens}

The results of the TMA during the deconsolidation (D) part of both treatments for the press-consolidated specimens are shown in Fig. 2.10 (a) and (b). Initially, both specimens show an identical expansion curve. However, a major difference appears when the melting temperature is approached during heat-up. At this point, the specimen without heat treatment shows a sudden drastic increase in thickness in just a few seconds. This is followed by a gradual decrease in thickness over a period of approximately 1 minute. This confirms that deconsolidation occurs very rapidly and that it completed well within the cycle of 20 minutes. The sudden increase in thickness around $T_{\mathrm{m}}$ is accompanied by a sudden increase in ion current, as is shown in the RGA curve in 2.10 (c). The moisture release had already started to increase above $T_{\mathrm{g}}$. The current drops back to its initial level after the peak.

The heat treated specimen does not show this deconsolidation peak and the ion current remains constant during the deconsolidation cycle. This indicates that almost no moisture is released and confirms that the heat treatment has removed nearly all moisture. No thickness increase is observed for this specimen at the end of the cycle, as also was the case in the oven deconsolidation experiments. This also indicates that only reversible thermal expansion took place for this specimen. 


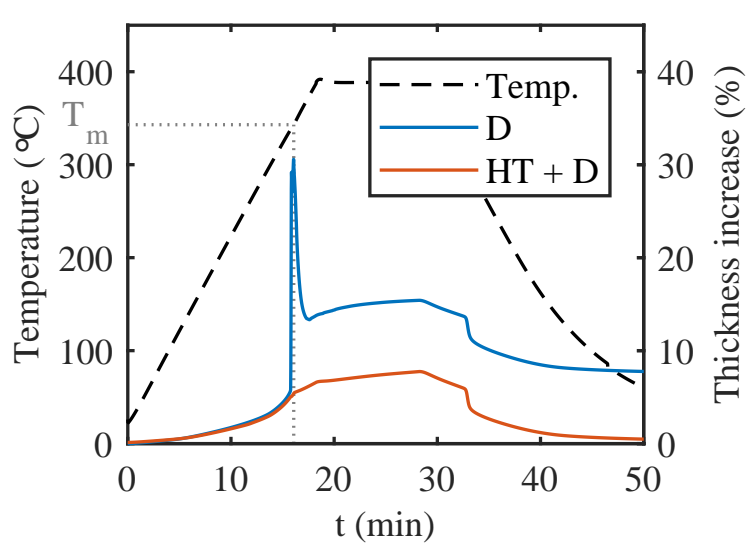

(a) TMA - Press

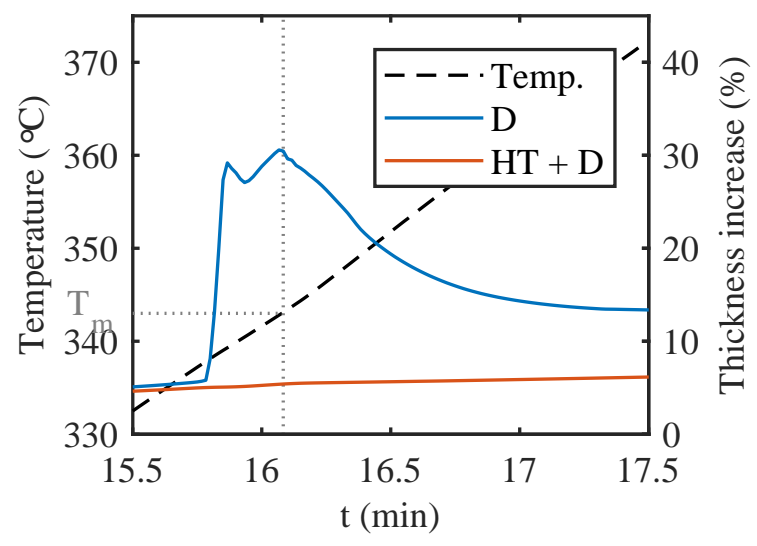

(b) TMA - Press (zoomed in)

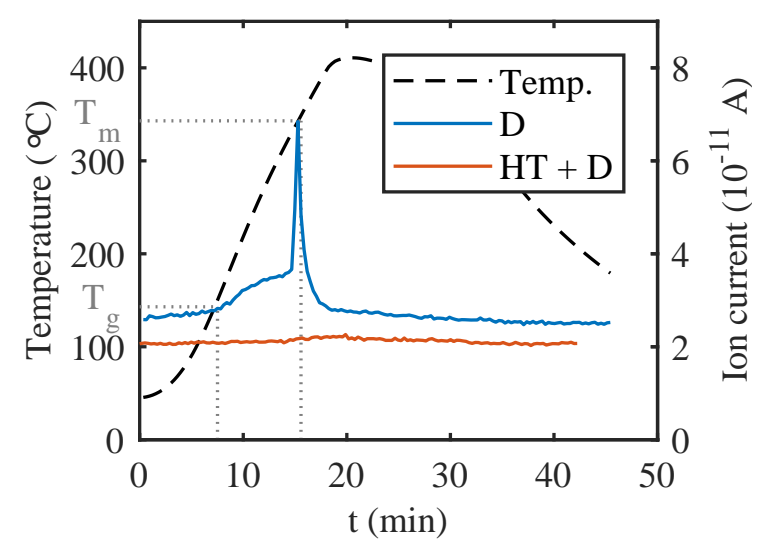

(c) RGA - Press

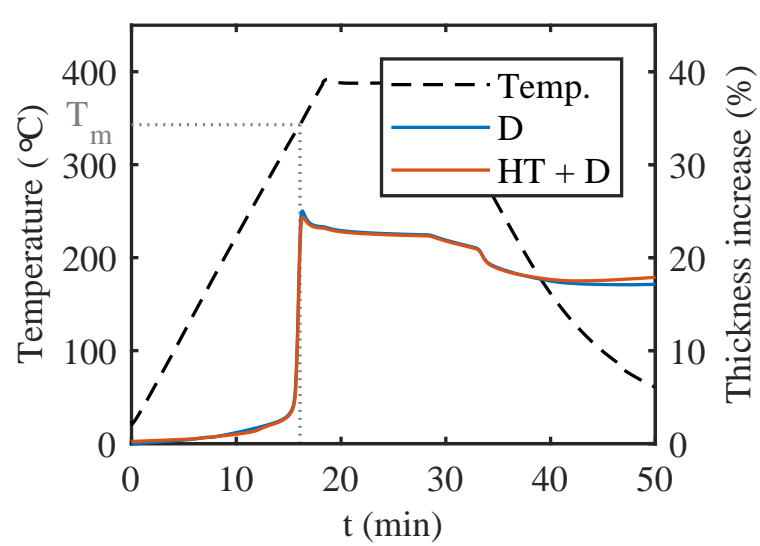

(d) TMA - AFP

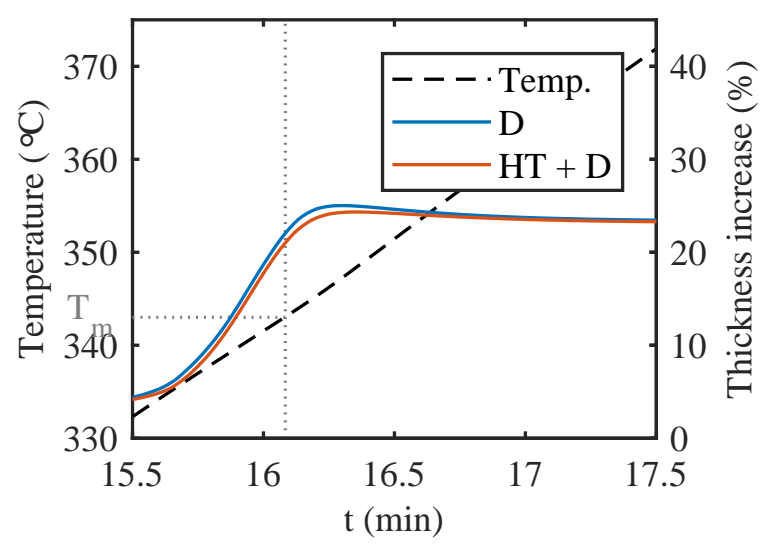

(e) TMA - AFP (zoomed in)

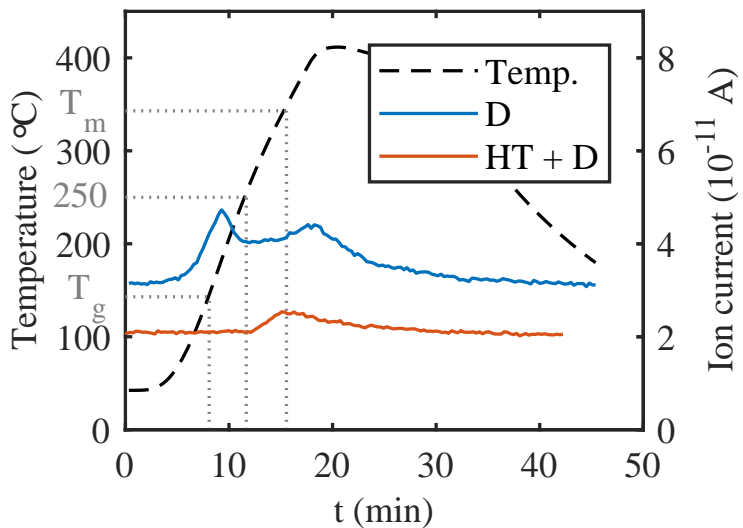

(f) RGA - AFP

Figure 2.10 TMA and RGA results of the deconsolidation cycle for press-consolidated specimens and AFP specimens. 


\section{Deconsolidation - AFP specimens}

The results of the TMA and RGA during the deconsolidation (D) part of both treatments are shown in Fig. 2.10 (d-f) for the AFP specimens. Clearly, both the TMA and RGA curves are very different from the press-consolidated specimens. The AFP specimens do not show the sudden expansion peak that was found in the TMA results for the press-consolidated specimen without heat treatment. Instead, both specimens show a more gradual expansion when approaching the melting temperature, followed by only very limited sagging. The heat treatment did not affect the deconsolidation behavior of the AFP specimen, as both specimens show exactly the same expansion curve. Moreover, the AFP specimens show a larger thickness increase compared to the press-consolidated specimen without heat treatment. This is consistent with the results of the oven deconsolidation experiments.

Although the heat treatment did not affect deconsolidation behavior, the effect is visible in the RGA curves. The specimen without heat treatment shows an early increase in ion current near $T_{\mathrm{g}}$. This peak was not present for the press-consolidated specimen. A second peak appears around the melting temperature, but this peak is much lower and wider, and occurs later than for the press-consolidated specimen. The heat-treated specimen shows a small increase in ion current from the heat treatment temperature of $250{ }^{\circ} \mathrm{C}$ to beyond the melting temperature, indicating that not all moisture was removed from the AFP specimen during the heat treatment.

Besides the release of moisture, the release of other ion fragments $(\mathrm{m} / \mathrm{z}=14,16,20$, $28,29,32,36,38,40$ and 44 ) was also detected during the RGA of AFP specimens. These fragments correspond with the constituents of air, i.e. $\mathrm{N}_{2}, \mathrm{O}_{2}, \mathrm{Ar}$ and $\mathrm{CO}_{2}$, which was most likely entrapped in voids between the plies. No release of air was observed for the press-consolidated specimens. This additional release of air may also explain the larger weight loss that was observed for AFP specimens in the oven deconsolidation experiments.

\subsection{Discussion}

The oven deconsolidation experiments, as well as the TMA and RGA, showed clear differences between the deconsolidation behavior of press-consolidated and AFP specimens and their response to the pretreatments. While the press-consolidated specimens showed mainly interlaminar voids and reduced deconsolidation for two of the treatments, the AFP specimens showed both inter and intralaminar voids and ply roughening and no influence of the treatments. The following sections discuss the origin of these differences. 


\subsubsection{Influence of moisture}

The press-consolidated specimens showed a high sensitivity of thickness increase to weight loss at low weight loss. Additionally, the TMA and RGA experiments showed a correlation between thickness increase and moisture release. This suggests that deconsolidation in press-consolidated laminates is indeed dominated by the formation of voids due to the thermal expansion of moisture that is dissolved in the matrix of the composite material. This is supported by the fact that a heat treatment was able to eliminate all moisture and deconsolidation, and that rehumidifying such heat treated specimens restored deconsolidation.

With this knowledge, a phenomenological explanation of the TMA and RGA curves of the press-consolidated specimen can now be proposed. A schematic representation of the deconsolidation process is shown in Fig. 2.11. (i) The composite contains dissolved moisture. (ii) An increase in temperature causes the water molecules (blue) to diffuse through the composite, as well as to the surroundings. This process is accelerated above $T_{\mathrm{g}}$, due to the increased polymer chain mobility. Voids start to nucleate at the interfaces between the plies. At these locations there is a drastic pressure build-up due to the hot water vapor. (iii) Once the melting temperature is reached, the matrix softens and the composite can no longer withstand the internal pressure of the voids. The voids expand to reduce their internal pressure and cause a sudden increase in thickness. (iv) As the voids grow, they can merge and form void channels at the interfaces between the plies [21, 27]. These channels can eventually reach to the edges of the specimen if sufficient voids are formed. At this point, the internal void pressure is further reduced and the water vapor is released to the surroundings, explaining the moisture release peak in the RGA that accompanies the sudden expansion measured in the TMA. (v) As the internal void pressure is now relieved, the specimen can sag in order to relax stresses induced in the composite by the internal void pressure, explaining the thickness reduction after deconsolidation. This also explains the plateau in Fig. 2.5 at higher moisture contents, as all these specimens have sagged back to a similar thickness.

The press-consolidated specimen subjected to the heat treatment did not show any deconsolidation due to its low moisture content. Instead, all thickness increase during the deconsolidation cycle of the heat-treated specimen can be attributed to reversible thermal expansion and melting and crystallization effects. The net thickness increase due to deconsolidation can now be found by subtracting the thermal expansion from the total thickness increase of the untreated specimen, as is shown in Fig. 2.12. The curve confirms that deconsolidation of the press-consolidated specimen occurs almost instantaneously, i.e. in less than 10 seconds, when crossing the melting temperature. This is followed by some subsequent gradual sagging and a steady thickness is achieved within two to four minutes after reaching $T_{\mathrm{m}}$.

The results demonstrate that dissolved moisture can be a major issue in processing 


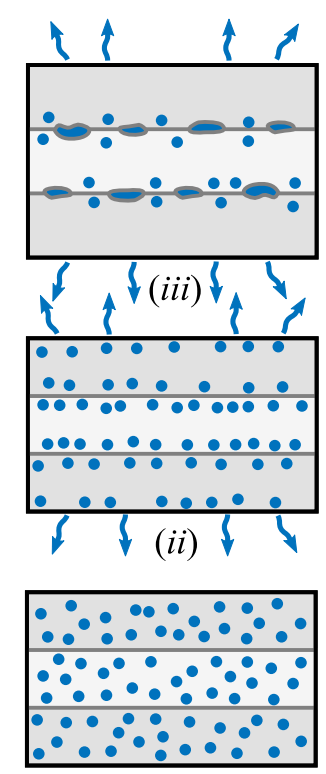

(i)

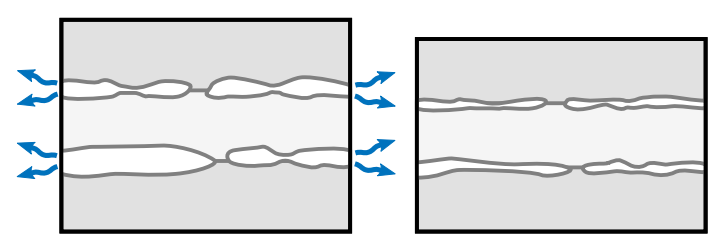

(iv)

$(v)$

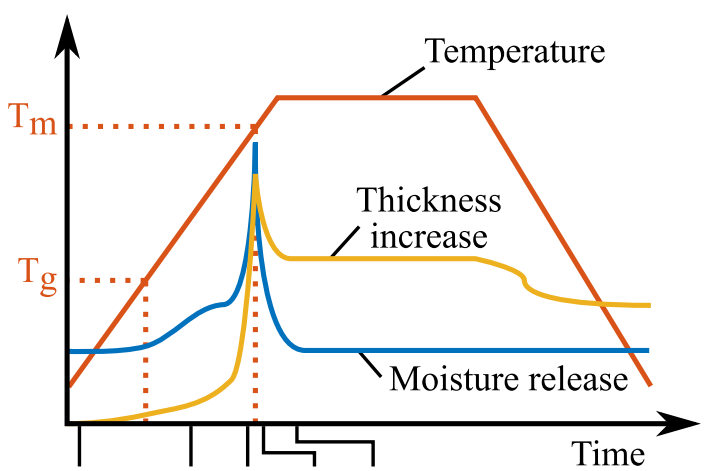

(i) $\quad$ (ii) $($ iii) $($ iv) $(v)$

Figure 2.11 Schematic representation of the deconsolidation process due to moisture (in blue) expansion.

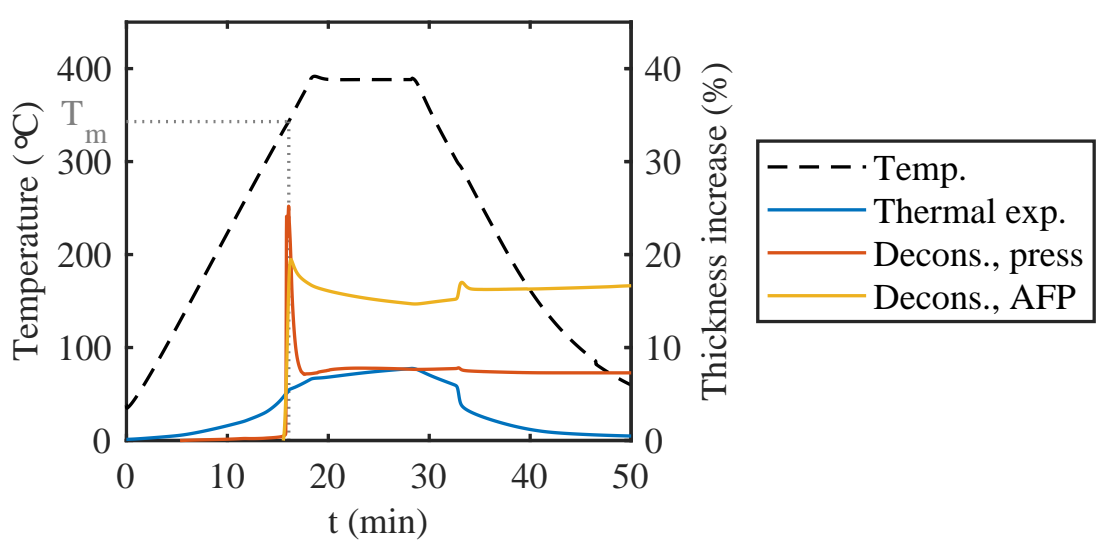

Figure 2.12 Thickness increase due to reversible thermal expansion and melting and crystallization effects, and deconsolidation.

of thermoplastic composites. This is even the case for C/PEEK, although its low moisture uptake and limited knockdown of mechanical properties by moisture are often used as a selling point [31, 32]. Low moisture levels reached under ambient storage conditions can already cause significant deconsolidation. Therefore, removing this moisture is essential in order to avoid deconsolidation during processing. Low temperature vacuum oven storage and a high temperature heat treatment were the most effective treatments tested in this work in reducing both moisture content and deconsolidation. However, vacuum oven storage did not completely eliminate deconsolidation, as some moisture remained. Moreover, drying in a vacuum oven is very time and energy consuming, as it can take months for a 
laminate to dry completely. A short treatment at high temperature in a convection oven is more time and energy efficient and proved even more effective. A temperature well above $T_{\mathrm{g}}$ seems to be essential for rapid drying, as a treatment of 3 hours at $150{ }^{\circ} \mathrm{C}$ did not influence deconsolidation significantly. A treatment of 3 hours at $250{ }^{\circ} \mathrm{C}$ worked particularly well for the C/PEEK material used in this work.

\subsubsection{Influence of blank consolidation quality}

Similar to the press-consolidated specimen, the net deconsolidation of the AFP specimen can be found by subtracting the thermal expansion from the TMA curve, as is shown in Fig. 2.12. This assumes that thermal expansion of the press-consolidated and AFP specimens are identical, although a slight difference can be observed in Fig. 2.9. Besides the initial deconsolidation peak and some subsequent sagging, the curve shows a small second peak due to a difference in shrinkage during cooling between the press-consolidated and AFP specimen. The net thickness increase of the AFP specimen clearly shows a different trend than the press-consolidated specimen, indicating that moisture may not be the main deconsolidation mechanism here.

The different response of the AFP specimens to the drying treatments compared to the press-consolidated specimens can be explained partially by the initial state of the laminates. Interlaminar voids have remained in the laminate due to the rapid lay-up. These voids form a void channel network [34, 35], and allow for the early release of moisture, as can be seen in Fig. 2.10 (f), and prevent pressure build-up. Due to the lack of pressure build-up, the AFP specimen does not show the same sudden expansion in the TMA results as the press-consolidated specimen when crossing the melting temperature. The presence of a void channel network could also explain why additional drying treatments have no significant effect on deconsolidation of the AFP specimens. For the same reason it is also assumed that the additional release of air that was observed during the RGA of the AFP specimens does not contribute significantly to the thickness increase.

The imperfect interlaminar bonding that results from rapid lay-up prevents pressure build-up and void growth by moisture expansion. This means that deconsolidation due to moisture expansion can be influenced by the blank consolidation quality or, more specifically, the degree of interlaminar bonding. This could serve as an advantage of blanks produced by rapid AFP.

\subsubsection{Influence of prepreg and blank consolidation process}

Deconsolidation of the AFP specimens does not seem to be influenced by moisture content and the specimens show a very different deconsolidated state compared to 


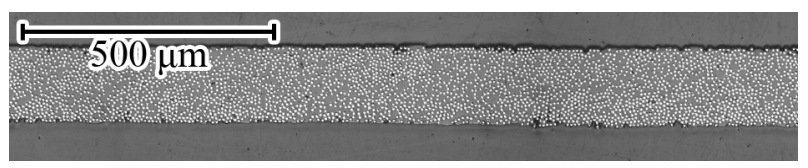

(a) As-received

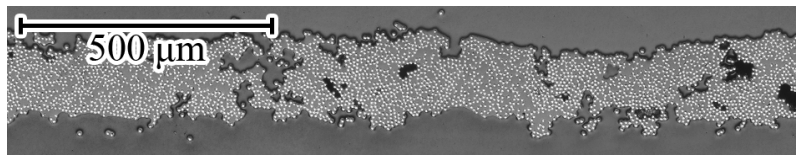

(b) As-received, deconsolidated

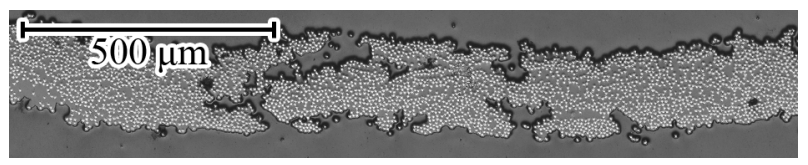

(c) Heat treatment (HT-3H@250C), deconsolidated

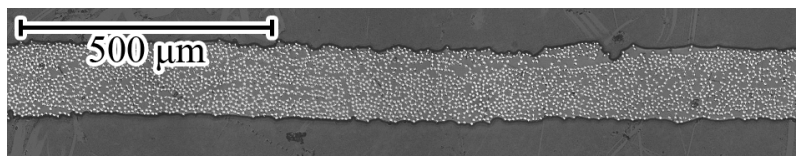

(d) Press-consolidated, deconsolidated

Figure 2.13 Micrographs of cross-sections of prepreg $(a)$ before and $(b-d)$ after deconsolidation.

the press-consolidated specimens. This suggests that deconsolidation of the AFP laminates is governed by a different mechanism.

In order to further investigate the governing mechanism, Fig. 2.13 (a-c) show cross-sectional micrographs of individual prepreg plies before deconsolidation, after deconsolidation, and after deconsolidation with heat treatment of 3 hours at $250{ }^{\circ} \mathrm{C}$. Additionally, Fig. 2.13 (d) shows a deconsolidated prepreg ply which has been press-consolidated prior to deconsolidation. These micrographs show that the heat treatment did not affect deconsolidation behavior of the prepreg, as also was the case for the AFP specimens. Moreover, the deconsolidated prepreg shows a crosssection similar to the AFP specimen in Fig. 2.8(b). Similar out-of-plane ply waviness was also observed. Contrarily, the press-consolidated prepreg does not show this ply deconsolidation, but rather a more intact ply, as was found for the press-consolidated laminates in Fig. 2.6.

Based on the previous observations, the main cause of deconsolidation of the AFP blanks seems to lie in the prepreg and is neither significantly affected by the current AFP process, nor by a heat treatment, while this cause is eliminated by the press consolidation process.

Although not further proven within the scope of this work, it is suggested that the driving force for deconsolidation of the prepreg and AFP blanks is related to frozenin fiber stresses within the plies. These stresses have most likely been introduced during the prepreg production process, for example due to tensioning, compressing 
or bending of individual fibers or small fiber bundles, and are frozen in during solidification of the matrix. Upon remelting, the stresses in these fibers are relieved by allowing deformation of the fibers into a lower stress state. This stress relieve, possibly in combination with the poor interlaminar bonding that was achieved during rapid lay-up, would explain the deconsolidation of the individual plies and out-ofplane waviness after deconsolidation. It would also explain why annealing the matrix does not change the deconsolidation behavior, as fiber mobility is very limited at the annealing temperature. Apparently the fiber stresses are also relieved during press consolidation, while they are not during rapid AFP. This could be explained by the fact that press consolidation gives the fibers the time to settle in a more favorable state by keeping the entire laminate above $T_{\mathrm{m}}$ over a period of 30 minutes. This resettling might not happen during the rapid AFP process, where the time spend above $T_{\mathrm{m}}$ is only 0.1 second and heating is very localized, although this may depend on the process settings used. This is supported by Fig. 2.10 (e), which shows that deconsolidation of the AFP specimen takes about 30 seconds. The fact that press consolidation relieves the fiber stresses is surprising, as press consolidation has often been found to be the origin of deconsolidation by elastic energy stored in the fiber bed [15, 17--23], although it is also known that the effect is less pronounced for unidirectional prepreg [24]. Although some evidence has been provided that points toward the role of frozen-in fiber stresses as source of deconsolidation for the used prepreg and AFP blanks, more research is required to confirm this and investigate the influence of the AFP process by including thermal analysis.

The deconsolidation behavior can be highly prepreg specific, as was observed by the authors in previous work [36]. This demonstrates the large influence that the choice of prepreg (and the way it was manufactured) can have on deconsolidation behavior. Blanks made from a significantly deconsolidating prepreg may lead to poorly consolidated laminates after stamp forming, as the process may not be able to re-establish interlaminar bonding and eliminate all voids, although this is yet to be confirmed. Additionally, a loss of blank integrity due to deconsolidation may lead to undesired forming defects. Press consolidation was found to significantly alter the deconsolidation behavior and take away prepreg related causes for deconsolidation, which is a major benefit of press-consolidated blanks. An additional pressconsolidation step after AFP seems to be required for the prepreg used in this work in order to avoid deconsolidation and ensure good consolidation quality after stamp forming. This additional processing step is undesired, as it takes away the benefit of rapid lay-up. However, the authors have experienced that using a prepreg which shows less deconsolidation also reduces blank deconsolidation, allowing omission of this extra step. 


\subsection{Conclusions and Recommendations}

Deconsolidation plays an important role in the stamp forming process, especially when blanks produced by rapid automated lay-up are used. The time available for reconsolidation is limited during stamp forming and deconsolidation should therefore be kept to a minimum. This requires proper characterization and control of the deconsolidation behavior.

The deconsolidation behavior of UD C/PEEK blanks was characterized experimentally in this work. Blanks produced by press consolidation and AFP, aimed at rapid lay-up, were considered in order to identify the influence of blank manufacturing process and consolidation quality on deconsolidation. The influence of moisture on deconsolidation was investigated during deconsolidation experiments in a convection oven. The moisture content was varied by applying various drying and wetting treatments prior to deconsolidation. Additional thermo-mechanical and residual gas analyses allowed for the coupled measurement of thickness increase due to deconsolidation and moisture release.

The results confirm that thermal expansion of dissolved moisture is the main deconsolidation mechanism for press-consolidated blanks, even for PEEK, which is known for its low moisture uptake. Deconsolidation due to moisture expansion can be eliminated by drying the blanks. A short high temperature heat treatment for 3 hours at $250{ }^{\circ} \mathrm{C}$ proved most effective for the C/PEEK used in this work.

For AFP blanks, deconsolidation was much more pronounced than for the pressconsolidated blanks. However, dissolved moisture is not a major source of deconsolidation here. This is due to imperfect interlaminar bonding generated during rapid lay-up, which results in a void channel network that allows for the release of moisture without void formation. This is a benefit of AFP blanks with imperfect interlaminar bonding and demonstrates the influence of blank consolidation quality on deconsolidation.

It is suggested that deconsolidation in the AFP blanks used in this work is caused by another mechanism, which is related to frozen-in fiber stresses. This hypothesis is supported by the similar deconsolidation behavior of single prepreg plies compared to AFP blanks. Press-consolidation seemed to eliminate the frozenin stresses, demonstrating the influence the blank manufacturing process can have on deconsolidation. However, more in-depth analysis of the prepreg and the AFP process is required to confirm the role of frozen-in fiber stresses.

Blank deconsolidation may cause consolidation problems stamp forming and is therefore best avoided. This paper demonstrates that deconsolidation due to moisture expansion can be eliminated by drying blanks prior to processing, preferably during a high temperature heat treatment. Deconsolidation of AFP blanks due to internal prepreg stresses can be prevented by press consolidating blanks prior to stamp 
forming. However, this additional step is undesired, as it takes away the benefit of rapid lay-up. Therefore, using a prepreg that shows minimal deconsolidation is recommended for blank production with AFP.

\section{References}

[1] L. Ye, K. Friedrich, J. Kästel, and Y.-W. Mai. Consolidation of unidirectional CF/PEEK composites from commingled yarn prepreg. Composites Science and Technology, 54(4):349-358, 1995.

[2] H. Jeong. Effects of Voids on the Mechanical Strength and Ultrasonic Attenuation of Laminated Composites. Journal of Composite Materials, 31(3):276-292, 1997.

[3] M. D. Wakeman, P. Blanchard, and J.-A. E. Månson. Void Evolution During Stamp-Forming of Thermoplastic Composites. In 15th International Conference on Composite Materials (ICCM-15), 2005.

[4] A. Chambers, J. Earl, C. Squires, and M. Suhot. The effect of voids on the flexural fatigue performance of unidirectional carbon fibre composites developed for wind turbine applications. International Journal of Fatigue, 28(10):1389-1398, 2006.

[5] Y. Nikishkov, S. Guillaume, and A. Makeev. Structural analysis of composites with porosity defects based on X-Ray Computed Tomography. Journal of Composite Materials, 48(17):2131-2144, 2013.

[6] X. Liu and F. Chen. A review of void formation and its effects on the mechanical performance of carbon fiber reinforced plastic. Engineering Transactions, 64(1):33-51, 2016.

[7] M. A. Khan and R. Schledjewski. Influencing factors for an online consolidating thermoplastic tape placement process. In 17th International Conference on Composite Materials, 2009.

[8] H. de Vries. AFP Technologies for High Performance Thermoplastics: Characterization of Mechanical Performance and Output Rate. In SETEC 11 - 06th International Technical Conference "Advanced Composites, The integrated System", pages 293-303, 2011.

[9] Z. Qureshi, T. Swait, R. Scaife, and H. M. El-Dessouky. In situ consolidation of thermoplastic prepreg tape using automated tape placement technology: Potential and possibilities. Composites Part B: Engineering, 66:255-267, 2014.

[10] A. J. Comer, D. Ray, W. O. Obande, D. Jones, J. Lyons, I. Rosca, R. M. O' Higgins, and M. A. McCarthy. Mechanical characterisation of carbon fibre-PEEK manufactured by laser-assisted automated-tape-placement and autoclave. Composites Part A: Applied Science and Manufacturing, 69:10-20, 2015.

[11] W. J. B. Grouve. Weld Strength of Laser-Assisted Tape-Placed Thermoplastic Composites. Ph.D. thesis, University of Twente, 2012.

[12] T. K. Slange, L. L. Warnet, W. J. B. Grouve, and R. Akkerman. Influence of preconsolidation on consolidation quality after stamp forming of $\mathrm{C} /$ PEEK composites. In F. Chinesta, E. Cueto, and A.-C. Emmanuelle, editors, ESAFORM 2016: Proceedings of the 19th International ESAFORM Conference on Material Forming, 2016. 
[13] H. Lessard, G. Lebrun, A. Benkaddour, and X.-T. Pham. Influence of process parameters on the thermostamping of a [0/90]12 carbon/polyether ether ketone laminate. Composites Part A: Applied Science and Manufacturing, 70:59-68, 2015.

[14] V. Donadei, M. Wielandt, A. Offringa, and A. Maffezzoli. Effects of Blank Quality on Press Formed PEKK/Carbon Composite Parts. In SAMPE Europe 2017. Stuttgart, 2017.

[15] H. Shi. Resistance welding of thermoplastic composites - Process and performance. Ph.D. thesis, TU Delft, 2014.

[16] T. Kok, W. J. B. Grouve, L. L. Warnet, and R. Akkerman. Quantification of Tape Deconsolidation During Laser Assisted Fiber Placement. In S. V. Hoa, editor, Automated Composites Manufacturing: Third International Symposium. DEStech Publications, Inc, 2017.

[17] T. G. Gutowski. Resin Flow/Fiber Deformation Model for Composites. Sampe Quarterly, 16(4):58-64, 1985.

[18] L. Ye, M. Lu, and Y.-W. Mai. Thermal de-consolidation of thermoplastic matrix composites - I. Growth of voids. Composites Science and Technology, 62(16):2121-2130, 2002.

[19] J. Wolfrath, V. Michaud, and J.-A. E. Månson. Deconsolidation in glass mat thermoplastic composites: Analysis of the mechanisms. Composites Part A: Applied Science and Manufacturing, 36(12):1608-1616, 2005.

[20] L. Ye, Z.-R. Chen, M. Lu, and M. Hou. De-consolidation and re-consolidation in CF/PPS thermoplastic matrix composites. Composites Part A: Applied Science and Manufacturing, 36(7):915-922, 2005.

[21] C. Gröschel and D. Drummer. The Influence of Moisture and Laminate Setup on the De-consolidation Behavior or PA6/GF Thermoplastic Matrix Composites. International Polymer Processing, 29(5):660-668, 2014.

[22] Y. Wan and J. Takahashi. Deconsolidation behavior of carbon fiber reinforced thermoplastics. Journal of Reinforced Plastics and Composites, 33(17):1613-1624, 2014.

[23] M. Brzeski and P. Mitschang. Deconsolidation and its Interdependent Mechanisms of Fibre Reinforced Polypropylene. Polymers and Polymer Composites, 23(8):515-524, 2015.

[24] R. Phillips. Consolidation and solidification behavior of thermoplastic composites. Ph.D. thesis, École Polytechnique Fédérale de Lausanne, 1996.

[25] Y. Leterrier and C. G'Sell. Formation and Elimination of Voids During the Processing of Thermoplastic Matrix Composites. Polymer Composites, 15(2):101-105, 1994.

[26] S. Roychowdhury, J. W. Gillespie, and S. G. Advani. Volatile-Induced Void Formation in Amorphous Thermoplastic Polymeric Materials: I. Modeling and Parametric Studies. Journal of Composite Materials, 35(4):340-366, 2001.

[27] T. Guglhoer and M. G. R. Sause. The Influence of Moisture on the Deconsolidation Behaviour of Carbon Fiber Reinforced PA-6 Laminates. In 17th International Conference on Composite Materials, 2016.

[28] F. Henninger, L. Ye, and K. Friedrich. Deconsolidation Behavior of Glass Fibre-Polyamide 12 Composite Sheet Material During Post-processing. Plastics, Rubber and Composites Processing and Applications, 27(6):287-292, 1998.

[29] Ten Cate Advanced Composites. Product Datasheet Cetex TC1200 PEEK Resin System, 2013.

[30] M. A. Grayson and C. J. Wolf. The Solubility and Diffusion of Water in 
Poly(Aryl-Ether-Ether-Ketone) (PEEK). Journal of Polymer Science: Part B: Polymer Physics, 25:31-41, 1987.

[31] Q. Wang and G. S. Springer. Moisture Absorption and Fracture Toughness of PEEK Polymer and Graphite Fiber Reinforced PEEK. Journal of Composite Materials, 23, 1988.

[32] M. M. Chen-Chi and Y. Shih-Wen. Environmental Effects on the Water Absorption and Mechanical Properties of Carbon Fiber Reinforced PPS and PEEK Composites. Part II. Polymer Engineering \& Science, 31(1):34-39, 1991.

[33] W. J. Unger and J. S. Hansen. The Effect of Cooling Rate and Annealing on Residual Stress Development in Graphite Fibre Reinforced PEEK laminates. Journal of Compo, 27(2):108-137, 1993.

[34] S. Hernández, F. Sket, C. González, and J. LLorca. Optimization of curing cycle in carbon fiber-reinforced laminates: Void distribution and mechanical properties. Composites Science and Technology, 85:73-82, 2013.

[35] P. M. Schaefer, T. Guglhoer, M. G. R. Sause, and K. Drechsler. Development of intimate contact during processing of carbon fiber reinforced Polyamide- 6 tapes. Journal of Reinforced Plastics and Composites, 36(8):593-607, 2017.

[36] T. K. Slange, L. L. Warnet, W. J. B. Grouve, and R. Akkerman. Influence of prepreg characteristics on stamp consolidation. In ESAFORM 2017: Proceedings of the 20th International ESAFORM Conference on Material Forming, 2017. 


\title{
Chapter 3
}

\section{Consolidation of Blanks Manufactured by Rapid Automated Lay-up}

\begin{abstract}
A process route is proposed where automated lay-up is followed by stamp forming for the manufacturing of load carrying components of thermoplastic composite. The focus is on rapid lay-up, rather than insitu consolidation, while the final consolidation quality and shape are achieved by stamp forming. An experimental study offers improved understanding of the relation between blank preconsolidation quality and final quality and the role of the prepreg. Two C/PEEK prepregs are processed into blanks by ATL and AFP and subsequently stamp formed. The consolidation quality of the stamped blanks was characterized by C-scans, micrographs and density measurements, while the mechanical performance was evaluated based on flexural tests. The results demonstrate the key role of the prepreg, especially thickness variations, in the consolidation process, but also that high quality laminates can be obtained.
\end{abstract}




\subsection{Introduction}

Thermoplastic composites are increasingly being used in industry due to their advantages over thermoset composites. These advantages include a higher toughness, recyclability and potential for automated high volume manufacturing due to their weldability and formability. The development of new lay-up technologies, such as automated tape laying (ATL) and automated fiber placement (AFP), over the past decades has provided new opportunities for the rapid manufacturing of large and complex components.

One of the benefits of automated lay-up is the possibility for highly automated manufacturing of blanks with a high degree of lay-up freedom. This enables the use of tailored lay-ups, which can be optimized for their final application in terms of local thickness and fiber orientations, allowing for more efficient material use and weight reduction compared to traditional lay-ups of uniform thickness. Moreover, near net-shaped lay-ups can be produced, which reduces scrap generated by trimming operations.

The current research and development efforts for automated lay-up mainly focus on material and process optimization to allow in-situ consolidation [1-7], where no expensive post-consolidation step is required after lay-up. Potentially, this is a very attractive manufacturing route; especially for larger, relatively simple, aerostructures, such as fuselage or wing skin sections. However, achieving in-situ consolidation still is a major challenge, especially at economically attractive lay-up rates. This is mainly due to the high heating and cooling rates and low pressure during the process, which provide very little time for consolidation phenomena like void elimination and development of interlaminar bonding. Most industrial applications therefore still rely on a post-consolidation step, such as press, autoclave or vacuum-bag-only consolidation, which are time and energy consuming processes.

As an alternative, automated lay-up could also be attractive for smaller and geometrically more complex parts. Here, however, the authors propose to focus on a two-step approach. Rather than aiming for in-situ consolidation, lay-up is performed at high rate, providing limited degree of consolidation. A subsequent, preferably quick and inexpensive, consolidation step has to be applied to achieve the final consolidation quality. Stamp forming may serve as an interesting alternative to conventional post-consolidation processes. Stamp forming uses the formability of thermoplastic composites at elevated temperatures to shape a flat laminate, a socalled blank, into a complex thin-walled three dimensional component. The blank is subjected to high heating rates in an IR oven in order to melt it, then quickly transported to a press, where the blank is quench-cooled by the isothermal tooling during the forming process. Short cycle times can be achieved, especially compared to press consolidation, where the tool is heated to the processing temperature and cooled down again during each cycle. The short cycle times make the stamp forming 


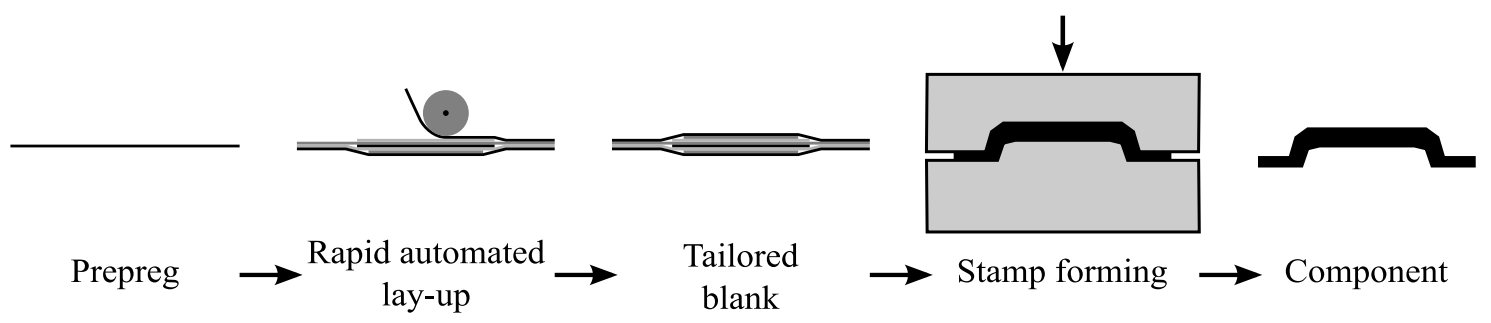

Figure 3.1 The proposed process route, combining rapid automated lay-up and stamp forming for the manufacturing of components with tailored lay-ups.

process very attractive for series production and competitive to metal solutions. Despite the relatively short cycle times, stamp forming provides much more time, in the order of 5-20 seconds, for consolidation phenomena to occur compared to an automated lay-up process, where the available time is typically less than 1 second. This potentially allows for the use of blanks which are not fully preconsolidated prior to stamping, hence enabling higher lay-up rates compared to lay-up with insitu consolidation.

The proposed process route, combining rapid automated lay-up and stamp forming as illustrated in Fig. 3.1, benefits from the high rate lay-up of flat blanks with a tailored lay-up and near net shape contour, while still achieving high consolidation quality and a complex geometry after stamping. For these reasons, the proposed process route may have the potential for a step forward in the rapid manufacturing of load carrying components.

Despite the potential of this process route, the two processes allow little time for consolidation and the feasibility of the route is yet to be proven. Previous work has shown promising results on both consolidation quality and mechanical performance after stamp forming blanks produced by AFP and ultrasonic welding [8-11], as well as unconsolidated commingled yarn preforms [12, 13]. However, the achieved consolidation quality and performance were below that of conventionally consolidated laminates and further optimization is required. Improved understanding of the interrelation between the input prepreg material, the blank manufacturing process, the resulting blank quality, the stamp forming process and the final consolidation quality of the part is required for optimization of the process route in terms of the final consolidation quality and mechanical performance.

In case of partially preconsolidated blanks, void collapse and interlaminar bonding are two of the main consolidation mechanisms that have to occur during stamp forming in order to obtain high quality parts. Therefore, it is expected that there is a strong influence of the degree of blank preconsolidation, i.e. initial void content and degree of interlaminar bonding, on the final consolidation quality due to the limited time for consolidation during stamp forming. Due to the low degree of preconsolidation achieved during rapid lay-up, the quality of the prepreg is likely to play a crucial role in the consolidation process. As with in- 
situ AFP, important parameters are expected to be initial void content, fiber/matrix distribution and roughness [3, 14, 15]. This work focuses on the question whether the final consolidation quality is indeed strongly influenced by the degree of blank preconsolidation and whether the consolidation is indeed governed by void collapse and interlaminar bonding. In order to answer this question, an experimental study is performed where the influence of prepreg, blank manufacturing process and stamp forming parameters on the final consolidation quality and mechanical performance are investigated. The results help to understand the interrelation between the prepreg material, process steps and final consolidation quality and work towards a successful combination of rapid automated lay-up and stamp forming for the manufacturing of high performance tailored structures.

\subsection{Experimental work}

The experimental procedure for this work is illustrated in Fig. 3.2. Two types of $\mathrm{C} /$ PEEK prepregs with similar specifications, but very different cross-sections, are compared in order to investigate the influence of the initial state of the prepreg and highlight important prepreg characteristics. Blanks were manufactured from these prepregs through two automated lay-up processes, resulting in a very different degree of blank preconsolidation. An ATL process with only local bonding provides blanks with a minimal degree of blank preconsolidation. An AFP process provides an intermediate degree of blank preconsolidation with continuous bonding. Additionally, press-consolidated blanks were produced as a reference of a conventional blank that is fully consolidated. The comparison between the three blank types will highlight the influence of blank preconsolidation level on final consolidation quality. A drying treatment was applied before forming to reduce deconsolidation effects by moisture (Chapter 2). The blanks were stamped into flat plates using various process settings in order to investigate the influence of the stamp forming process conditions on the final consolidation quality. The formed laminates were subjected to characterization of consolidation quality, with a focus on void content, and mechanical testing. The procedure is described in more detail in the following sections.

\subsubsection{Materials}

Two unidirectional C/PEEK prepreg tapes are compared in this work. Both are based on AS4 fibers and have a fiber volume fraction of approximately $59 \%$. The prepregs, TenCate Cetex ${ }^{\circledR}$ TC1200 [16] and Cytec APC-2 [17], are from this point referred to as TC and CY, respectively. Both prepregs have a melting temperature $T_{\mathrm{m}}$ of approximately $343{ }^{\circ} \mathrm{C}$ and a recommended processing temperature range 


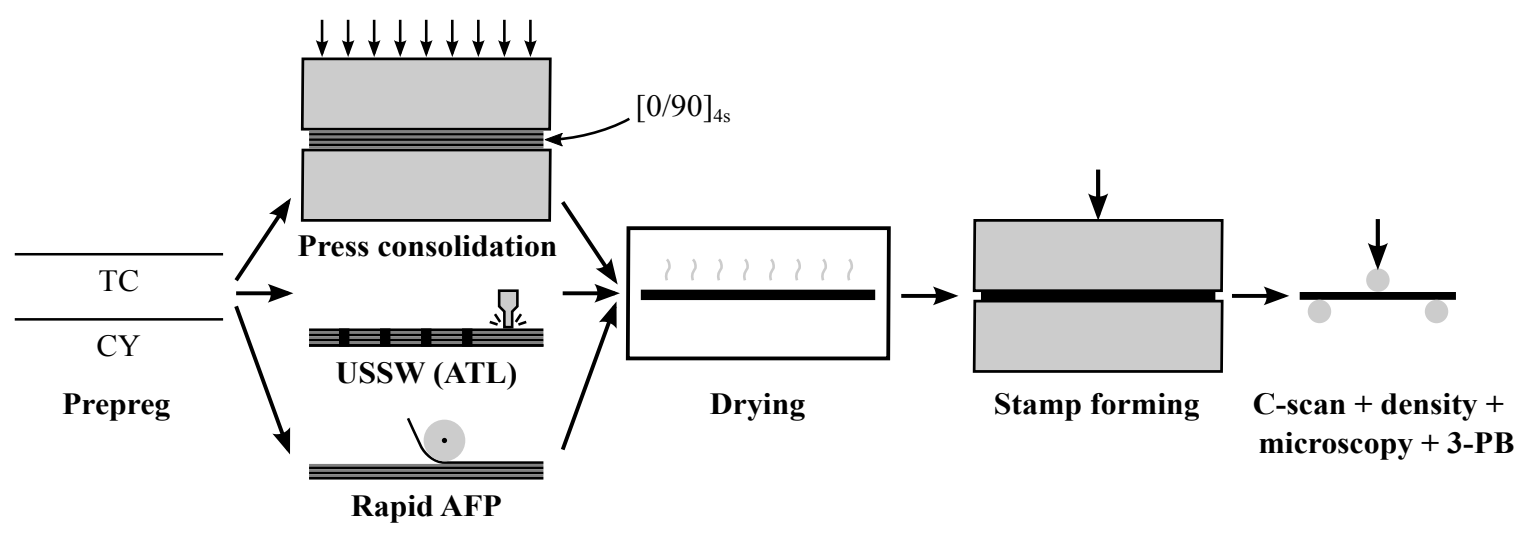

Figure 3.2 The steps in the experimental procedure.

(a)
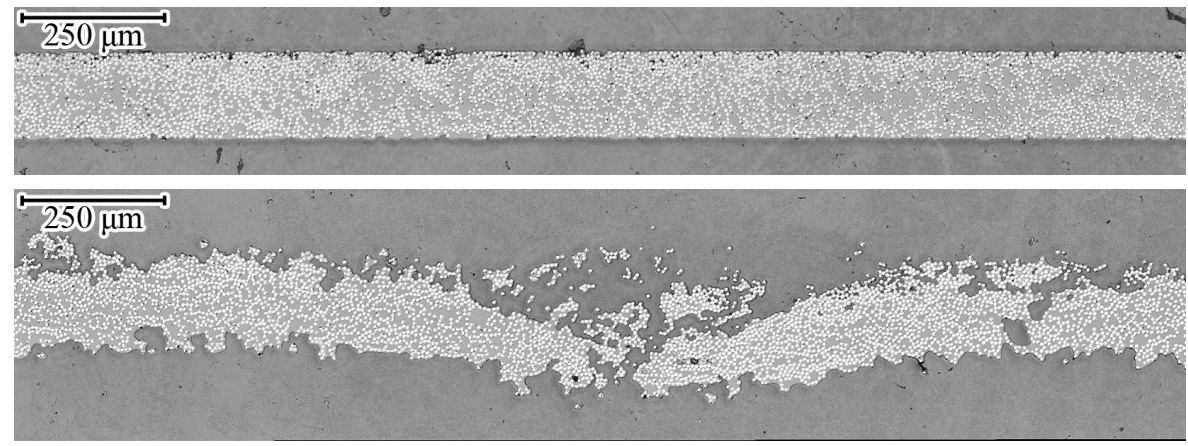

(b)

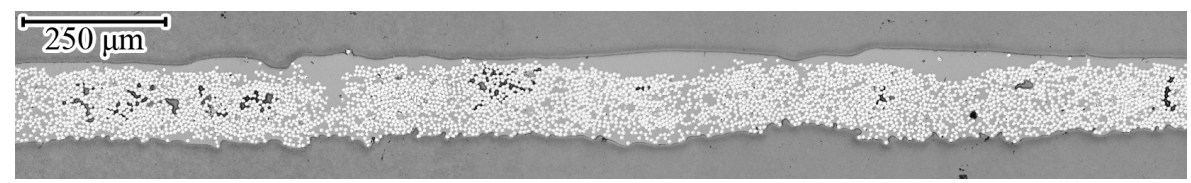

(d)

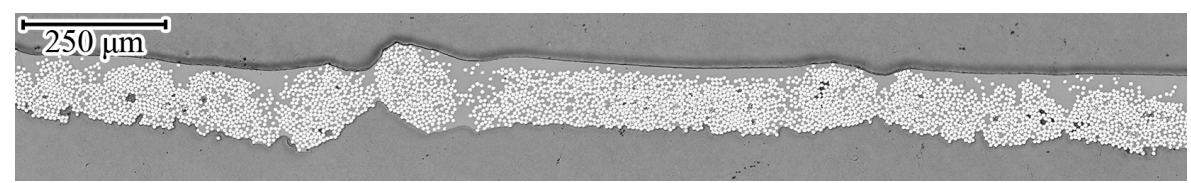

Figure 3.3 Cross-sectional micrographs of the (a) as-received and (b) deconsolidated TC prepreg and the (c) as-received and (d) deconsolidated $\mathrm{CY}$ prepreg. 
of $370-400{ }^{\circ} \mathrm{C}$ and were available in 6 and $1 / 4$ inch width. Although their specifications are very similar, their cross-sections look very different, as shown in Fig. 3.3 (a) and (c). The CY prepreg has been around for a long time and is known for its non-uniform thickness and fiber/matrix distribution and a matrix-rich surface. It has intralaminar micro-voids, roughly $5-10 \%$, especially in areas with a high local fiber volume fraction. The TC prepreg is a more recent tape, which follows the trend of many modern prepregs by having a void-free cross-section, a smooth surface and a very uniform fiber/matrix distribution. There is no matrix-rich surface, which is surprising given that a matrix-rich surface is known to ease interlaminar bonding during rapid processing, like AFP [3, 14, 15]. The different cross-sections suggest that processing behavior during lay-up and stamping is likely to be different as well. A difference in processing behavior can also be seen in Fig. 3.3 (b) and (d), which shows a cross-section of the as-received prepreg after heating it to $390{ }^{\circ} \mathrm{C}$ in a convection oven for 20 minutes with no external pressure applied. Void growth and decompaction of the fiber bed, so-called deconsolidation, is known to occur under these conditions due to the thermal expansion of dissolved moisture or the release of internal stresses (Chapter 2). As a result of the different processing behavior, the final consolidation quality and performance obtained after stamping may also be different.

\subsubsection{Blank manufacturing}

Blanks with a $[0 / 90]_{4 s}$ cross-ply lay-up of approximately $2.2 \mathrm{~mm}$ thick were manufactured from both prepregs using three different processes. The procedures for blank manufacturing are described below.

- USSW. $330 \times 150 \mathrm{~mm}^{2}$ blanks were prepared from 6 inch wide prepreg by ultrasonic spot welding (USSW). Each ply was locally bonded by spot welds with a diameter of approximately $10 \mathrm{~mm}$ on a $70 \times 70 \mathrm{~mm}^{2}$ grid, as is shown in Fig. 3.4. The spot welds provide sufficient blank integrity for handling, while also improving through-thickness heat transfer. USSW provides an extreme case where there is a complete lack of consolidation during lay-up and all consolidation has to take place during stamp forming. Although the spot welding was performed manually, it simulates the case of a blank produced by an ATL process, such as for example applied in the Fiberforge RELAY2000 ${ }^{\circledR}$.

- AFP. A Coriolis Composites AFP robot with laser heating was used to produce $350 \times 350 \mathrm{~mm}^{2}$ laminates from a single $1 / 4$ inch tow at a rate of $200 \mathrm{~mm} / \mathrm{s}$ and a nip-point temperature of approximately $450{ }^{\circ} \mathrm{C}$ (measured by thermal camera). A compaction pressure of approximately 4 bar was applied by a silicone roller of $60 \mathrm{SH}$ hardness. $330 \times 150 \mathrm{~mm}^{2}$ blanks were cut from the laminates. These blanks have improved interlaminar bonding over the USSW blanks due to the continuous welding of the AFP process, but still have limited 


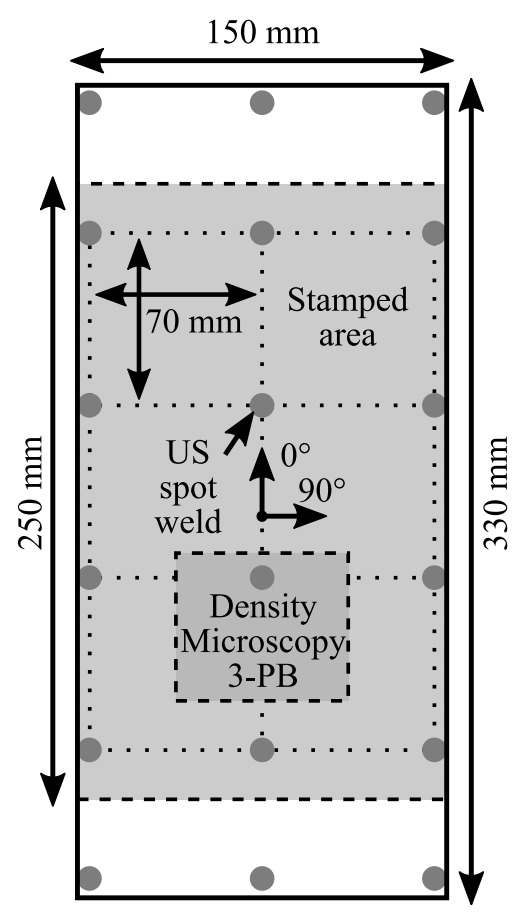

Figure 3.4 Lay-out of blanks with US spot weld locations and specimen location for analysis after stamping.

bonding and contain intralaminar voids, as the focus is on rapid lay-up, rather than in-situ consolidation.

- Press consolidation. $600 \times 600 \mathrm{~mm}^{2}$ laminate stacks were laid up manually from 6 inch prepreg. Each stack was placed between $1 \mathrm{~mm}$ stainless steel caul sheets coated with Marbocote 227 CEE release agent and consolidated in a $200 \mathrm{t}$ Pinette P.E.I. press. A 20 minute dwell at $386^{\circ} \mathrm{C}$ and 10 bar, and a cooling rate of $2.5^{\circ} \mathrm{C} / \mathrm{min}$ were applied, resulting in a 2 hour consolidation cycle. $330 \times 150 \mathrm{~mm}^{2}$ blanks were cut from the laminates. This conventional blank manufacturing process serves as a reference for current practice in industry.

\subsubsection{Stamp forming}

All blanks were dried in a convection oven for 3 hours at $250{ }^{\circ} \mathrm{C}$ prior to stamp forming. In Chapter 2 it was shown that this reduces deconsolidation caused by expansion of dissolved moisture, which is undesired, as it introduces additional voids and delaminations that have to be eliminated again during stamping.

The blanks were then stamp formed using flat $250 \times 250 \mathrm{~mm}^{2}$ aluminum tooling in a 200 t Pinette P.E.I. press equipped with an infrared oven and automated transfer frame. In order to investigate the influence of the stamping process, both the 
Table 3.1 Stamp forming parameters. A tool temperature of $250^{\circ} \mathrm{C}$ and a consolidation time of $60 \mathrm{~s}$ were applied during all experiments.

\begin{tabular}{l|cc}
\hline Blank type & $\begin{array}{c}\mathbf{T}_{\text {blank }}\left(\mathbf{T}_{\text {panel }}, \mathbf{t}_{\text {heat }}\right) \\
{ }^{\circ} \mathrm{C}\left({ }^{\circ} \mathrm{C}, \mathrm{s}\right)\end{array}$ & $\begin{array}{c}\mathbf{P}_{\text {cons }} \\
\text { bar }\end{array}$ \\
\hline Press & $390(450,250)$ & 20 \\
Press & $420(485,250)$ & 100 \\
USSW & $390(450,300)$ & 20 \\
USSW & $420(485,300)$ & 100 \\
AFP & $390(450,250)$ & 20 \\
AFP & $420(485,250)$ & 20 \\
AFP & $390(450,250)$ & 100 \\
AFP & $420(485,250)$ & 100 \\
\hline
\end{tabular}

blank temperature $T_{\text {blank }}$ and the consolidation pressure $P_{\text {cons }}$ were varied, as these parameters are known to have a significant effect on consolidation quality after stamping [18-20]. A $T_{\text {blank }}$ of $390{ }^{\circ} \mathrm{C}$ and a $P_{\text {cons }}$ of 20 bar were applied as baseline, which is usually sufficient for press-consolidated blanks [16]. The consolidation pressure was applied for 60 seconds while the laminate cooled down to the tooling temperature of $250{ }^{\circ} \mathrm{C}$. The tooling temperature and consolidation time were kept constant during all experiments. The USSW and AFP blanks, which were, as mentioned earlier, not fully consolidated, might require a $T_{\text {blank }}$ and higher $P_{\text {cons }}$ in order to achieve sufficient consolidation during stamping. Therefore, an increased $T_{\text {blank }}$ of $420{ }^{\circ} \mathrm{C}$ and an increased $P_{\text {cons }}$ of 100 bar were also applied. The heating times $t_{\text {heat }}$ and IR-heater panel temperatures $T_{\text {panel }}$ that were required to reach the desired blank temperatures were determined during heating trials, as described in 3.A. The process settings are summarized in Tbl. 3.1. Cycle times of 5-6 minutes are achieved thanks to the use of IR blank heating and a isothermal tooling, which is much faster than the 2 hour press consolidation cycle used to preconsolidate blanks.

\subsubsection{Consolidation quality}

The stamp formed blanks were trimmed to their stamped area of $250 \times 150 \mathrm{~mm}^{2}$ and their consolidation quality was evaluated, where the focus was on void content and interlaminar bonding.

Ultrasonic C-scans were performed using a Sonatest RapidScan2 at a frequency of $5 \mathrm{Mhz}$. The scans give a qualitative picture of the global consolidation quality, as areas with porosity or poor interlaminar bonding will cause damping of the signal, which is visible as dark areas in the scans. For further inspection, specimens were cut from the blanks for cross-sectional micrographs and density measurements. The location of the specimens is specified in Fig. 3.4. Three $60 \times 15 \mathrm{~mm}^{2}$ specimens were used for density measurements in ethanol according to ASTM D792. The measured 
density $\rho$ can be used to estimate the void content $V_{\mathrm{v}}$ when compared to a reference density $\rho_{0}$ of a void-free laminate according to:

$$
V_{\mathrm{v}}=1-\frac{\rho}{\rho_{0}} \times 100 \%
$$

In this work, the density of the press-consolidated laminates was used as reference.

\subsubsection{Mechanical performance}

In order to evaluate the mechanical performance of the stamped laminates, flexural performance was determined based on 3-point bending tests according to ASTM D 7264 on an Instron 5900 UTM. Flexural performance is known to be sensitive to voids [21]. The test introduces the highest stresses near the top and bottom surface of the specimen. These areas are also likely to contain most voids, as the cooling rates during stamping are highest near the surface, which limits the time available for consolidation here. The specimens that were used for the density measurements were also used for flexural testing. The $0^{\circ}$ fiber direction was along the length of the specimens. A support span of $44 \mathrm{~mm}$ was applied, resulting in a span-to-thickness ratio of approximately 1:20. The load was applied by a loading nose with a radius of $6.4 \mathrm{~mm}$ at a rate of $1 \mathrm{~mm} / \mathrm{min}$ and measured by a $10 \mathrm{kN}$ force cell. The deflection of the specimen was measured at the center using a deflectometer. The apparent flexural strength $\sigma_{\max }$, which is based on a homogenized elastic beam, is calculated according to:

$$
\sigma_{\max }=\frac{3 F_{\max } L}{2 b h^{3}}
$$

Here, $F_{\max }$ is the maximum force, $L$ the support span and $b$ and $h$ are the width and thickness of the specimen, respectively.

\subsection{Results}

\subsubsection{Consolidation quality}

\section{C-scans}

Figure 3.5 shows amplitude plots of the back-wall echo for both the TC and CY blanks after stamp forming. The press-consolidated blanks show C-scans identical to their unstamped reference blanks with uniform consolidation and no influence of the stamping parameters $T_{\text {blank }}$ and $P_{\text {cons. }}$. The USSW blanks show very poor consolidation quality in a distinct, highly symmetric pattern at a $T_{\text {blank }}$ of $390{ }^{\circ} \mathrm{C}$ 


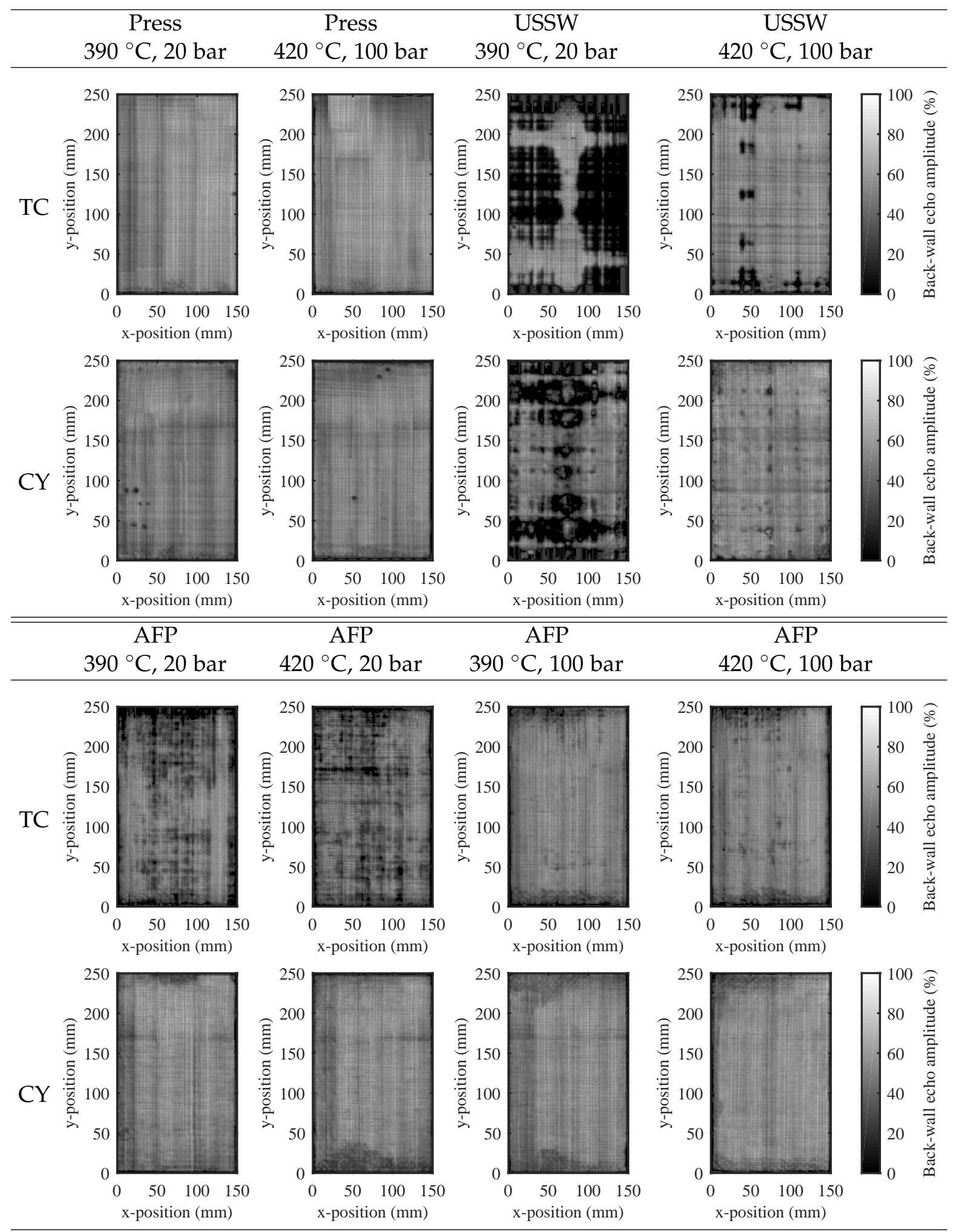

Figure 3.5 C-scans of the blanks after stamping. Shown parameters are $T_{\text {blank }}$ and $P_{\text {cons. }}$. 
and $P_{\text {cons }}$ of 20 bar. Large areas with no signal feedback indicate poor interlaminar bonding and porosity between the plies, possibly due to a lack of pressure. The TC blank showed rough areas on the surface of the blank corresponding to the dark areas in the C-scan, while large blisters from entrapped air pockets were observed on the surface of the CY blank. The consolidation quality of the USSW blanks improves significantly for the increased $T_{\text {blank }}$ and $P_{\text {cons, }}$ although some small defect areas remain. The C-scans of the TC AFP blanks indicate that some porosity is present after stamping at 20 bar, but that consolidation quality improves when increasing $P_{\text {cons }}$ to 100 bar. Increasing $T_{\text {blank }}$ did not affect consolidation quality much. The same trend is not visible for the CY AFP blanks, where the C-scans look similar for all process settings and good consolidation already is achieved at $390{ }^{\circ} \mathrm{C} / 20$ bar.

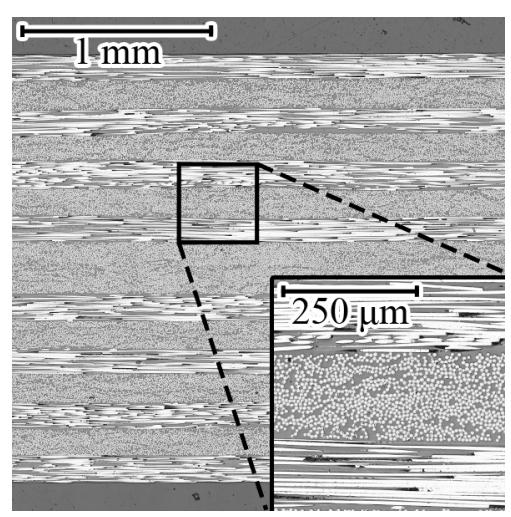

(a) TC Press, unstamped

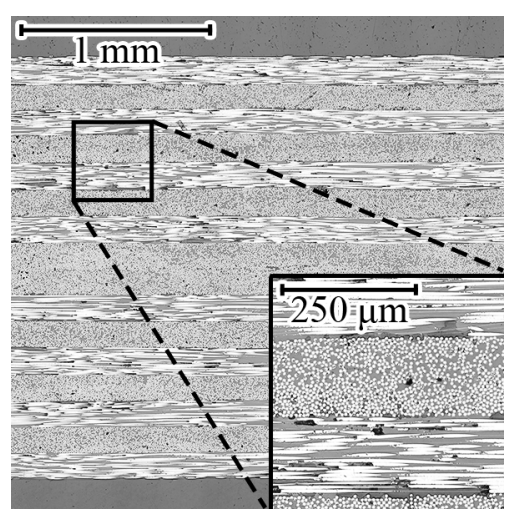

(d) TC AFP, unstamped

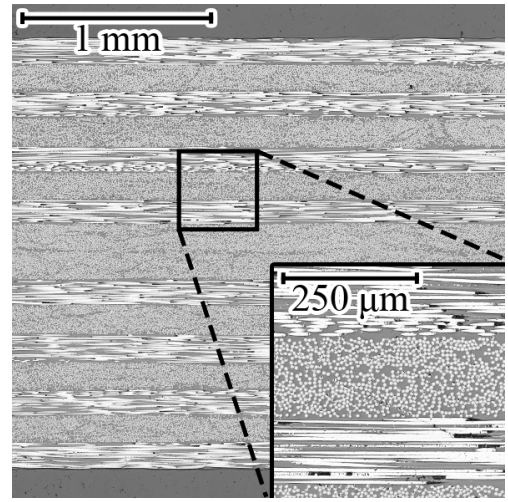

(b) TC Press, $390{ }^{\circ} \mathrm{C} / 20$ bar

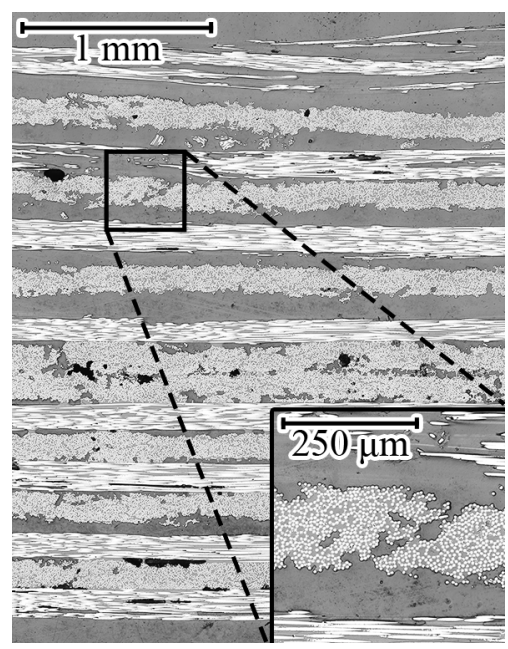

(e) TC AFP, deconsolidated

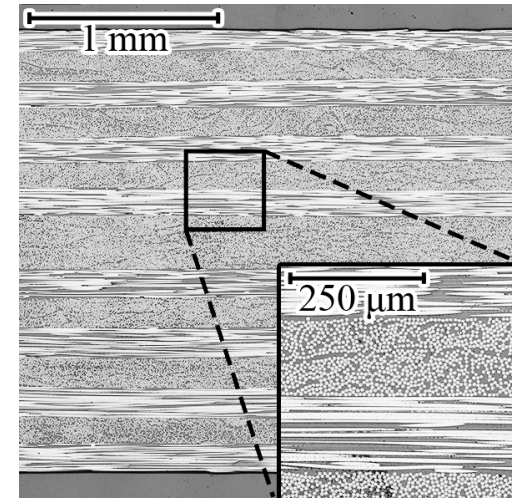

(c) TC USSW, $420{ }^{\circ} \mathrm{C} / 100$ bar

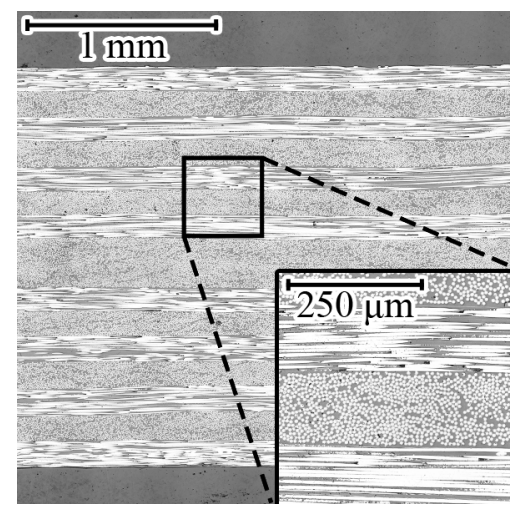

(f) TC AFP, $420{ }^{\circ} \mathrm{C} / 100 \mathrm{bar}$

Figure 3.6 Cross-sectional micrographs of the TC blanks before and after stamping. Shown parameters are $T_{\text {blank }}$ and $P_{\text {cons. Note: cross-section }}(c)$ may not be representative for entire blank. 


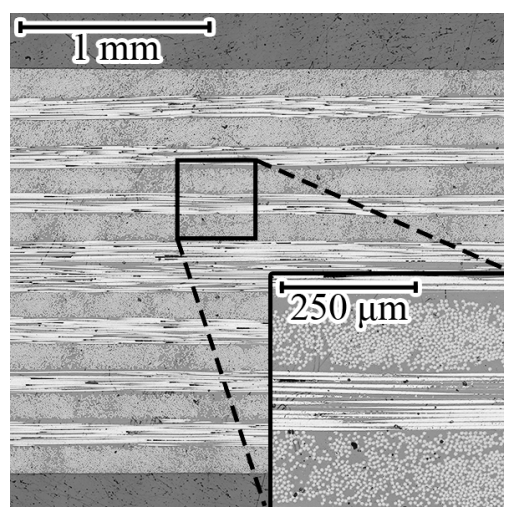

(a) CY Press, unstamped

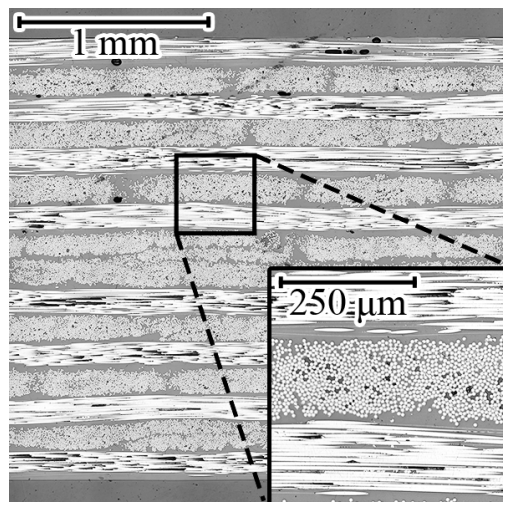

(d) CY AFP, unstamped

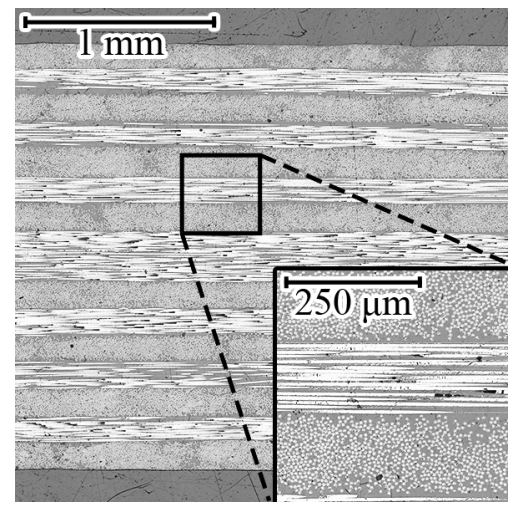

(b) CY Press, $390{ }^{\circ} \mathrm{C} / 20$ bar

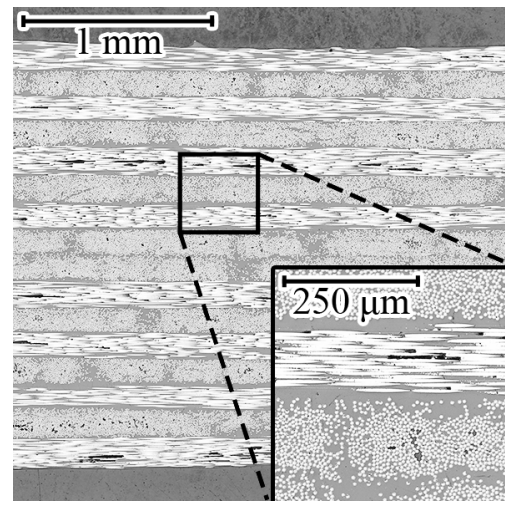

(e) CY AFP, deconsolidated

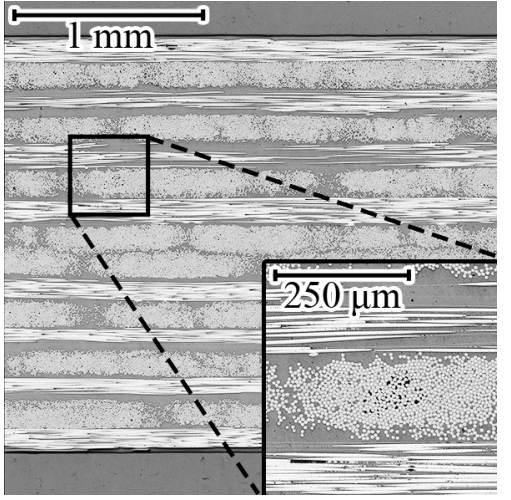

(c) CY USSW, $420^{\circ} \mathrm{C} / 100$ bar

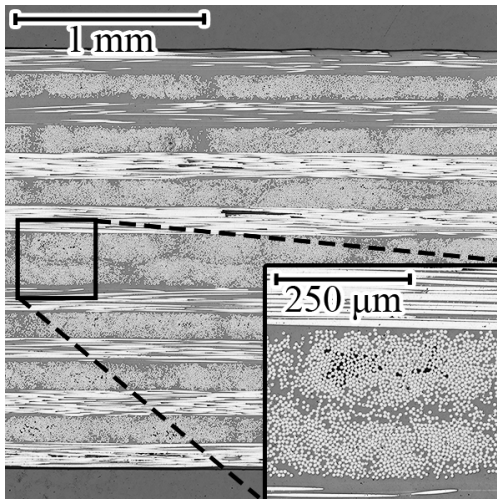

(f) CY AFP, $390^{\circ} \mathrm{C} / 20$ bar

Figure 3.7 Cross-sectional micrographs of the CY blanks before and after stamping. Shown parameters are $T_{\text {blank }}$ and $P_{\text {cons. Note: cross-section }}(c)$ may not be representative for entire blank.

\section{Microscopy}

Figures 3.6 and 3.7 show a selection of cross-sectional micrographs of the three blank types for the TC and CY prepreg, respectively. The press-consolidated blanks are void-free for both prepregs both before (Fig. 3.6 (a) and 3.7 (a)) and after stamping (Fig. 3.6 (b) and 3.7 (b)). The cross-section of the TC USSW blank stamped at a $T_{\text {blank }}$ of $420^{\circ} \mathrm{C}$ and $P_{\text {cons }}$ of $100 \mathrm{bar}$ (Fig. 3.6 (c)) also showed no voids. However, note that this specimen was taken from a region that also showed good consolidation in the C-scan and therefore may not be representative for the entire blank. The TC USSW blank stamped at $390{ }^{\circ} \mathrm{C} / 20$ bar showed poor interlaminar bonding, while an additional cross-section taken from a region of the blank that showed low damping in the C-scan was void-free. Similar results were obtained for the CY USSW blanks, although some intralaminar micro-voids could still be observed in areas with high local fiber density (Fig. 3.7 (c)). The TC AFP blank (Fig. 3.6 (d)) shows incomplete interlaminar bonding and intralaminar voids prior to stamping due to the focus on high lay-up rates, rather than in-situ consolidation. Prior to stamping, the TC AFP blanks showed significant deconsolidation during heating in the IR oven (Fig. 3.6 
(e)). Plies delaminate and intralaminar voids form, even after the drying treatment, which was also observed in previous work by the authors [8, 22]. Some of these voids have remained after stamping at $390{ }^{\circ} \mathrm{C} / 20$ bar, primarily at the outermost plies. Increasing $P_{\text {cons }}$ to 100 bar resulted in a void-free cross-section (Fig. 3.6 (f)). These observations are consistent with the C-scans of the TC AFP blanks. The CY AFP blanks (Fig. 3.7 (d)) show better interlaminar bonding before stamping. This is most likely due to the matrix-rich surface of the prepreg, which facilitates bonding during AFP, even at high lay-up rates. However, the intralaminar voids that were present in the CY prepreg were not eliminated during AFP. In contrast with the TC AFP blanks, the CY AFP blanks did not show any sign of deconsolidation (Fig. 3.7 (e)). In fact, void content appears to decrease during blank heating, even though no external pressure is applied. Improved interlaminar bonding was also observed for a CY USSW blank that was heated to its processing temperature without any external pressure applied. Like with the CY USSW blanks, some intralaminar micro-voids remain in the CY AFP blanks after stamping, even at $420{ }^{\circ} \mathrm{C} / 100$ bar (Fig. 3.7 (f)). Increasing $T_{\text {blank }}$ or $P_{\text {cons }}$ did not seem to influence the void content observed in the micrographs of the CY AFP blanks.

\section{Void content}

The void contents based on the density of the blanks after stamp forming are shown in Figs. 3.8 (a) and (b) for the TC and CY blanks, respectively. The void-free crosssections of the unstamped press-consolidated blanks found in Section 3.3.1 confirm that their densities can be used as a void-free reference density for estimation of the void content. A void-free reference density of $1580 \mathrm{~kg} / \mathrm{m}^{3}$ was found for both prepregs after press-consolidation. Based on the rule of mixtures, a fiber density of $1790 \mathrm{~kg} / \mathrm{m}^{3}$ [23], matrix density of $1304 \mathrm{~kg} / \mathrm{m}^{3}$ at $35 \%$ crystallinity [24], this corresponds with a fiber volume fraction of approximately $57 \%$. The USSW blanks stamped at $390{ }^{\circ} \mathrm{C} / 20$ bar were not included in the density measurement due to their highly non-uniform consolidation found in the C-scans. The density measurements of the TC blanks are in line with their C-scans and micrographs. Void-free laminates are obtained for press-consolidated blanks. A void content of $1 \%$ is achieved for the USSW blank. However, note that the specimens were taken from a region that also showed good consolidation in the C-scan and therefore may not be representative for the entire blank. The void content is slightly lower for the AFP blanks after stamping at $390{ }^{\circ} \mathrm{C} / 20$ bar, while increasing $P_{\text {cons }}$ to 100 bar reduces void content to almost zero. Similar results are found for the CY blanks, although no clear trend is visible for the AFP blanks and the void content seems to be higher for the USSW and AFP blanks compared to the TC blanks. This is not surprising, since the micrographs clearly showed that intralaminar voids were still present in these blanks after stamping. However, the density measurements seem to overestimate the void content of the CY blanks compared to the cross-sectional micrographs, possibly 


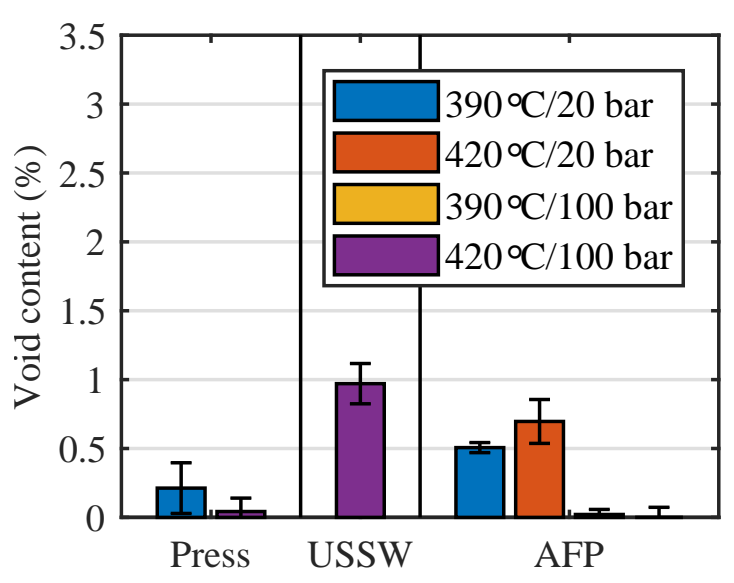

(a) TC

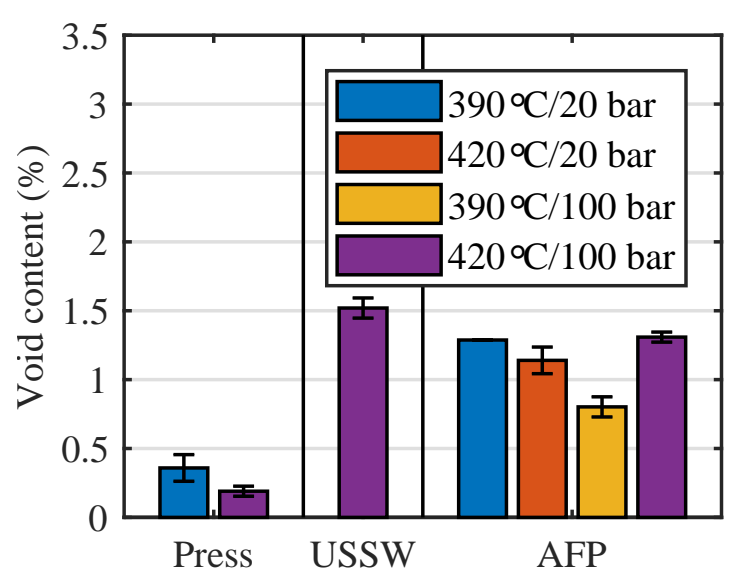

(b) $\mathrm{CY}$

Figure 3.8 Estimated void content of the (a) TC and (b) CY blanks after stamping based on density measurements. Void-free reference density $T C \rho_{0}=1580 \mathrm{~kg} / \mathrm{m}^{3}$ and $\mathrm{CY} \rho_{0}=$ $1580 \mathrm{~kg} / \mathrm{m}^{3}$. Legend shows $T_{\text {blank }}$ and $P_{\text {cons. }}$. Note: the density measurement for the USSW blanks may not be representative for the entire blank.

due to a small difference in fiber volume fraction compared to the reference blank. The void content of the unstamped AFP blanks was above $5 \%$ for both TC and CY, although this value is underestimated due to an overestimation of the density by filling of some of the voids with ethanol.

\subsubsection{Mechanical performance}

Figure 3.9 shows typical force-displacement curves obtained during flexural testing. All tested specimens showed a linearly increasing curve with a flexural modulus of approximately $70 \mathrm{GPa}$. Most specimens showed a minor load drop at approximately $80-90 \%$ of the ultimate flexural stress. Failure occurred by buckling and compressive failure of the top plies close to the loading nose.

The apparent flexural strength of the specimens is shown in Figs. 3.10 (a) and (b) for the TC and CY blanks, respectively. Again, due to the highly non-uniform consolidation found in the C-scans, the USSW blanks stamped at $390{ }^{\circ} \mathrm{C} / 20$ bar were not included in flexural testing. All stamped specimens show an apparent flexural strength of approximately $1100 \mathrm{MPa}$. For the TC blanks there seems to be a slightly increasing trend for higher $T_{\text {blank }}$ and $P_{\text {cons, }}$ corresponding with the improved consolidation quality observed in Section 3.3.1. The CY blanks show similar performance, but no obvious trend for the AFP blanks, which was also observed for the consolidation quality. The intralaminar micro-voids that were observed in the CY USSW and AFP blanks do not seem to affect the flexural performance. The similar strength of the stamped USSW blanks is impressive, given that the plies were completely unbonded prior to stamping. However, note that the 
flexural specimens were taken from a region that also showed good consolidation in the C-scans and therefore may not be representative for the entire blank. A drop in strength of about $10 \%$ is found for all stamped blanks compared to the pressconsolidated reference laminates. Additional DSC analyses showed no difference in bulk crystallinity for all stamped blanks and the press-consolidated reference that could explain this strength drop. Further explanation of the strength drop was considered outside the scope of this work, but may require careful investigation of the obtained microstructure, rather than bulk properties.

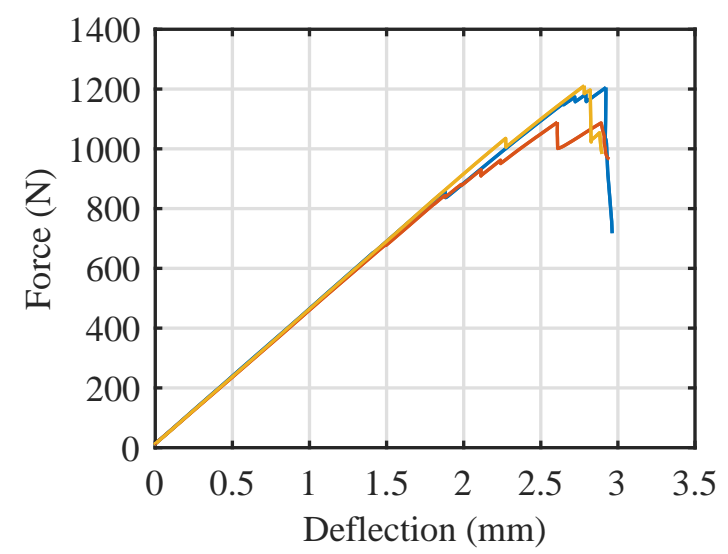

Figure 3.9 Force-deflection curves for the three specimens from the TC AFP blank stamped at a blank temperature of $420^{\circ} \mathrm{C}$ and a pressure of 100 bar.

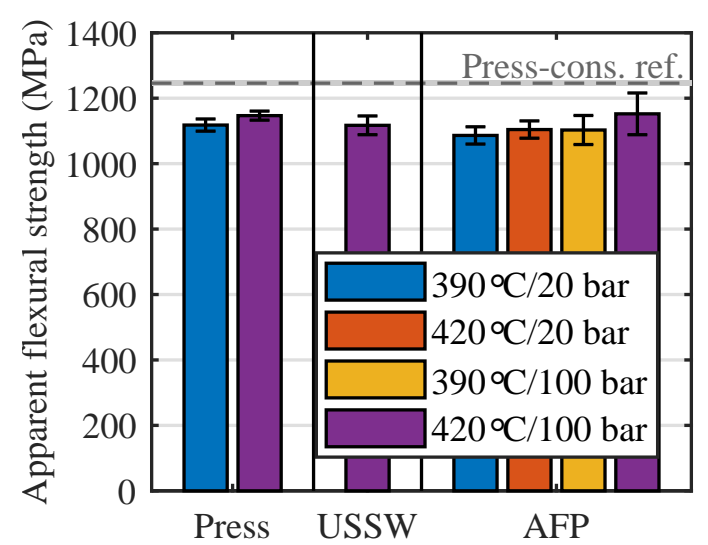

(a) TC

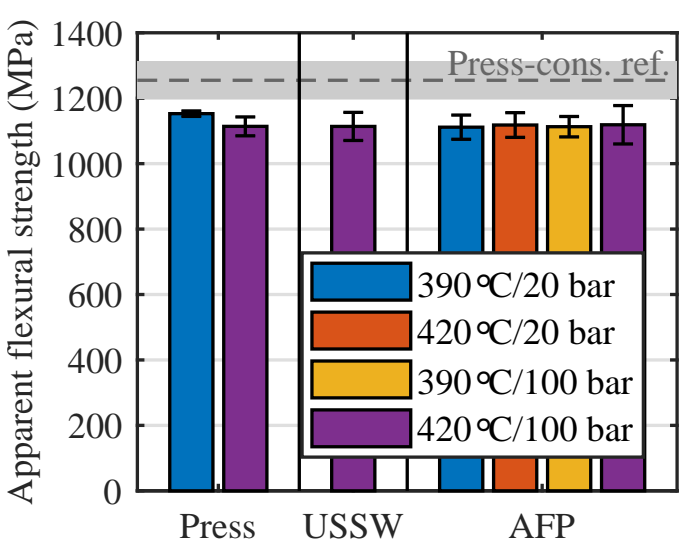

(b) $\mathrm{CY}$

Figure 3.10 Apparent flexural strength of the (a) TC and (b) CY blanks after stamping compared to a press-consolidated TC reference laminate. The legend shows the blank temperature and stamping pressure. Note: the apparent flexural strength for the USSW blanks may not be representative for the entire blank. 


\subsection{Discussion}

The results showed that promising consolidation quality and mechanical performance could be obtained by combining rapid lay-up blanks and stamp forming. The current section further discusses the results and identifies the interrelation between input prepreg material, preconsolidation process, blank quality, stamp forming process and final consolidation quality.

\subsubsection{Prepreg thickness variations}

Non-uniform consolidation quality, in particular poor interlaminar bonding with interlaminar voids, in combination with a rough blank surface, was observed after stamping the USSW blanks for both prepregs. While interlaminar bonding is usually considered as the local deformation of micro-scale surface asperities, also known as intimate contact development, followed by polymer interdiffusion, it is hypothesized that the development of contact between the plies on a more global scale is dominant here. This potentially can be attributed to a mismatch in blank thickness and tooling gap in combination with a lack of material flow. While thickness variations are usually eliminated during blank manufacturing by a long press consolidation cycle, they may remain present during rapid automated lay-up.

In order to further investigate this hypothesis, thickness measurements were performed on the used prepreg. The thickness profile across the width of the prepreg was measured by a micrometer with $3 \mathrm{~mm}$ radius tip. Figure 3.11 shows the average thickness profile of five equidistant measurements over a distance of $10 \mathrm{~m}$ along the length of the prepreg (fiber direction). The results show profiles which deviate sometimes more than $5 \%$ from the average of $150 \mu \mathrm{m}$, but are relatively constant along the length. The CY prepreg shows a larger standard deviation due to the strong local variation of matrix content on the surface of the prepreg.

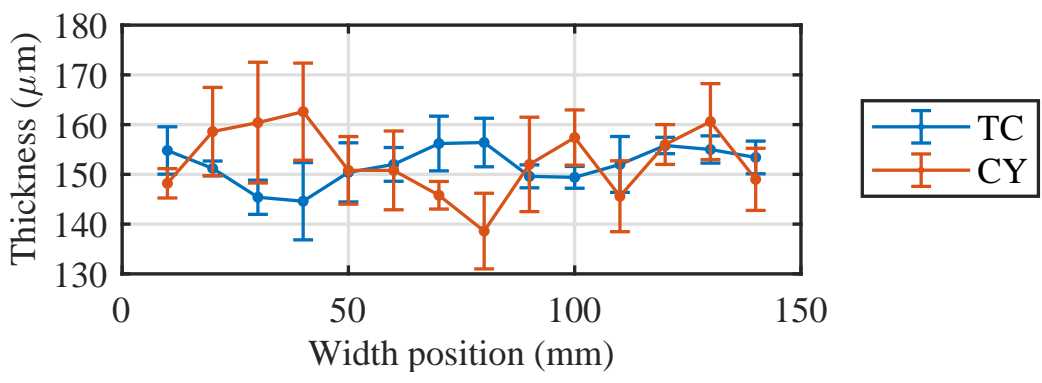

Figure 3.11 Prepreg thickness profile across the width (perpendicular to fiber direction). Measured by micrometer with $3 \mathrm{~mm}$ radius tip. Average and standard deviation of five equidistant measurements over a distance of $10 \mathrm{~m}$ along the length of the prepreg (fiber direction). 


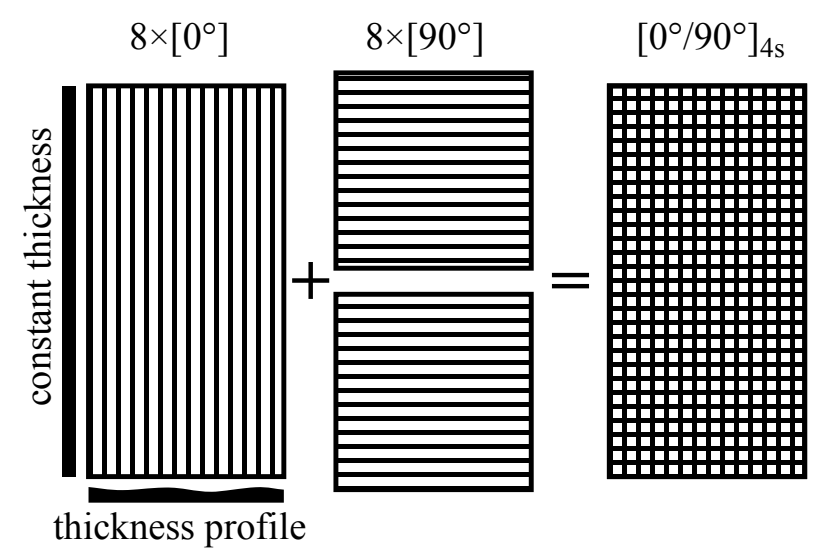

Figure 3.12 Blank thickness estimation based on prepreg thickness profile and stacking pattern.

The thickness of the USSW blanks prior to stamping was estimated based on the prepreg thickness profiles, assuming that the thickness profile is constant along the length of the prepreg, and the stacking pattern, as is shown in Fig. 3.12. The resulting thickness distributions are shown and compared to the C-scans of the stamped blanks in Fig. 3.13. The thickness distributions show highly symmetric patterns similar to the C-scans due to the mirroring of the plies at the mid-plane, as well as the somewhat symmetric thickness profile of the prepreg. The well and poorly consolidated regions in the C-scans seem to correspond with the thickest and thinnest regions, respectively.

The previous observation supports the hypothesis that intimate contact development takes place on a more global scale by the elimination of blank thickness variations which originate from prepreg thickness variations, rather than local intimate contact development. In case of a USSW blank, the small thickness variations in the prepreg are added up when stacking multiple plies on top of each other, especially when the stacking pattern is very regular. At a low pressure of 20 bar there is not enough time for material redistribution by flow and achieving uniform consolidation. Instead, most pressure is carried by the thickest regions and the thin regions experience insufficient pressure for interlaminar bonding and void elimination. Increasing the pressure increases the generated flow, hence consolidation quality of the USSW blanks improved significantly by increasing the pressure to 100 bar. Similar thickness variations may be expected in AFP blanks. Since AFP tows are generally slit from wide prepreg rolls, the thickness profile of the prepreg persists as the tow-to-tow thickness variation. However, the AFP blanks in this work were prepared using a single $1 / 4$ inch tow, hence thickness variations due to tow-to-tow differences were not present within a blank, assuming that the thickness variation along the length of the prepreg is negligible. Additionally, thickness variations may arise from gaps and overlaps that appear due to tow width variation, lay-up tolerances or tape widening. 


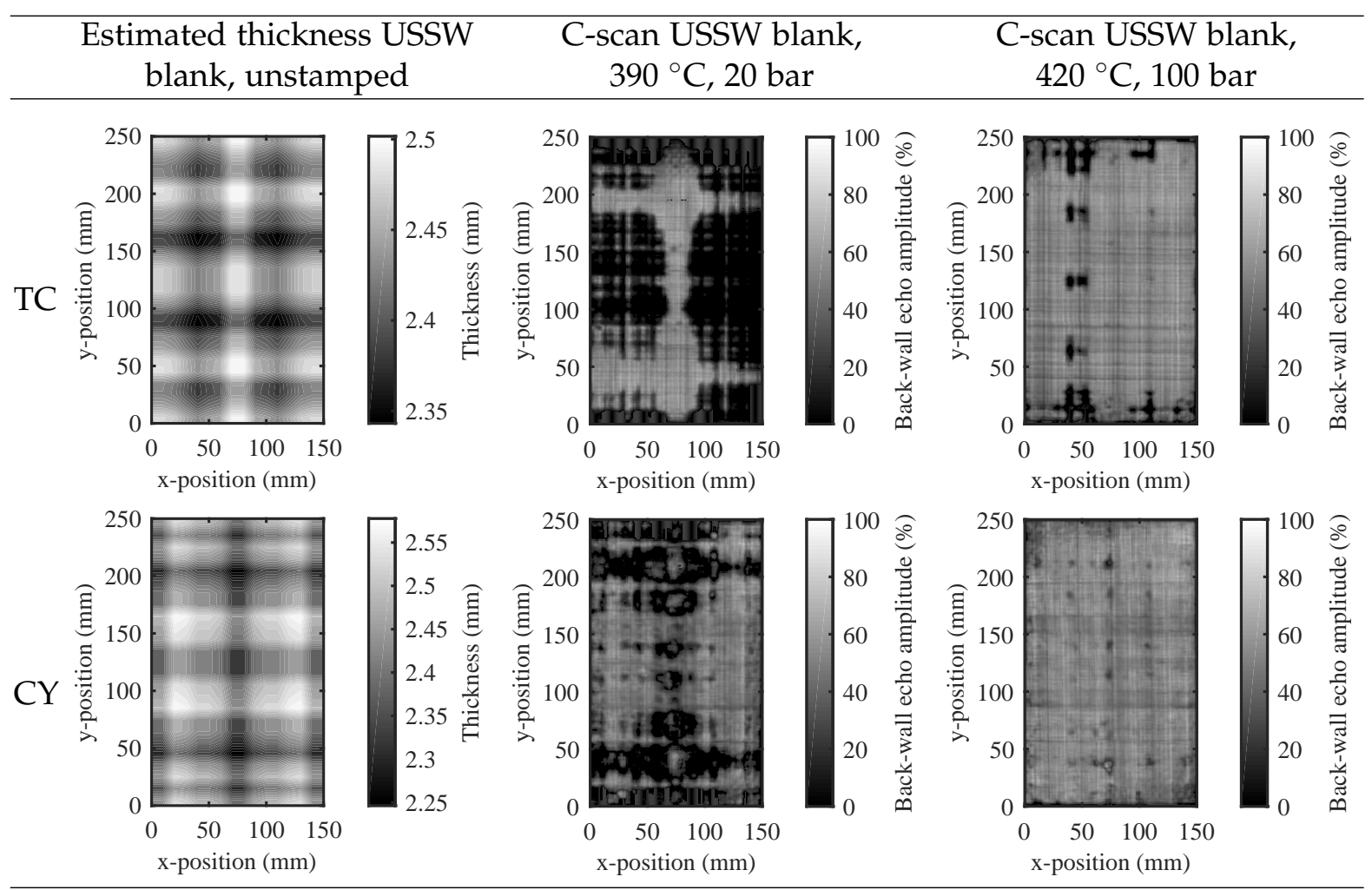

Figure 3.13 Estimated blank thickness distribution of the USSW blanks before stamping and C-scans after stamping. Shown parameters are blank temperature and stamping pressure.

\subsubsection{Other prepreg characteristics}

Besides the previously discussed thickness variations, other characteristics of the prepreg play an important role in the consolidation behavior of the blanks. Firstly, the fiber/matrix distribution plays an important role in interlaminar bonding. This is well known and is confirmed by the results. The non-uniform fiber/matrix distribution and matrix-rich surface of the CY prepreg seem to facilitate interlaminar bonding both during AFP and stamp forming. This is supported by the reasonably good interlaminar bonding in the cross-sectional micrograph of the CY AFP blank (Fig. $3.7(\mathrm{~d})$ ) and the full interlaminar bonding that was already achieved after stamping at low pressure and blank temperature (Figs. 3.7 (f) and 3.5). In fact, interlaminar bonding already improved while heating the CY USSW and AFP blanks to its processing temperature without any external pressure applied (Fig. 3.7 (e)). Achieving good interlaminar bonding seemed more challenging for the TC prepreg with a more uniform fiber/matrix distribution and lack of matrix-rich surface, as the C-scans and micrographs indicated incomplete interlaminar bonding at low pressure and blank temperature (Figs. 3.6 (f) and 3.5). Since it is well known that interlaminar bonding benefits from a matrix-rich surface, it is surprising that many modern prepregs tend to have a lack of matrix on the surface. 
Secondly, the non-uniform fiber/matrix distribution of the CY prepreg is accompanied by the presence of micro-voids in the prepreg (Fig. 3.3 (c)). These were not present in the TC prepreg (Fig. 3.3 (a)). The larger initial void content of the CY prepreg also leads to a higher final void content, as these micro-voids are not completely eliminated during both blank manufacturing and stamp forming (Fig. 3.7 (f)). The local dense fiber packing most likely hinders two flow of matrix that is required to collapse the voids. Nevertheless, it is worth mentioning that the void content was low enough to not significantly affect flexural performance, although other mechanical properties may be more sensitive.

Finally, the two prepregs showed a striking difference in deconsolidation behavior of the as-received prepreg (Figs. $3.3(b, d)$ ). This behavior seems to persist in the AFP blanks (Figs. 3.6 (e) and 3.7 (d)). In both cases, the TC prepreg showed more deconsolidation than the $\mathrm{CY}$ prepreg, possibly due to a combination of frozen-in fiber stresses in the prepreg and a lack of interlaminar bonding in the TC AFP blanks, as was discussed in Chapter 2. The CY prepreg and AFP blank showed no significant deconsolidation. Despite the deconsolidation observed for the TC AFP blanks, the results show that the additional voids and delaminations formed by deconsolidation can be eliminated again during stamp forming. However, the combination of deconsolidation and the absence of a matrix-rich prepreg surface could explain why the TC AFP blanks require more pressure for good consolidation than the CY AFP blanks. Moreover, it is expected that a loss of blank integrity due to deconsolidation will affect forming behavior and lead to forming defects during stamping of more complex geometries.

Based on the discussion of the four important prepreg characteristics, a prepreg that enables good consolidation during the processing route has a very uniform thickness, matrix rich surface, is void-free and does not deconsolidate significantly.

\subsubsection{Influence of blank preconsolidation state}

The three blank manufacturing processes investigated in this work resulted in various degrees of preconsolidation ranging from almost none, with only local bonding between the plies, to fully preconsolidated. While a significant influence of the blank preconsolidation state, in particular degree of interlaminar bonding, on the final consolidation quality was expected, the difference between the three blank types was only modest. However, the consolidation window during stamp forming at low blank temperature and consolidation pressure is clearly too short to fully consolidate the USSW blanks. Unlike initially expected, this is not due to the initial lack of interlaminar bonding in the blank, but can mainly be attributed to the thickness variations in the prepreg, as discussed in Section 3.4.1. Hence, the ability to consolidate a blank during stamp forming seems to be mainly determined 
by the thickness variations and the properties that govern the flow that is required to redistribute the material, such as viscosity, temperature and pressure.

\subsubsection{Influence of stamp forming parameters}

The influence of the stamp forming parameters was confirmed by the fact that increasing the blank temperature and stamping pressure significantly improved the consolidation quality of the USSW blanks to a level that is close to the other blank types. Increasing the consolidation pressure for the AFP blanks also resulted in improved consolidation quality, while the influence of an increased the blank temperature was negligible. Considering this, it may be advisable to stick to lower blank temperatures (within the recommended processing range) in order to reduce heating time and limit potential polymer degradation. Additionally, an increased tool temperature will reduce the cooling rate and increase the consolidation window, although this was not tested in this work. Non-isothermal tooling, for example using induction heating and water cooling, could be helpful in this case, as it allows for high heating and cooling rates in order to maintain a short cycle time.

\subsubsection{Blank manufacturing by rapid automated lay-up}

Despite the large variation in the initial blank quality, similar consolidation quality was achieved after stamp forming for all blank types. A void content of less than $1 \%$ was obtained and flexural performance was identical for all blank types. This confirms that high quality laminates can be produced by stamp forming blanks manufactured by rapid automated lay-up.

Of the two tested automated lay-up technologies, AFP seems most promising, as the consolidation quality and mechanical performance are similar to press-consolidated blanks after stamp forming, even at low blank temperature and consolidation quality. However, this study has only looked at stamp forming of flat laminates manufactured from a single tow. The influence of tow-to-tow thickness variations was not investigated, but could lead to similar problems as with the USSW blanks.

A key challenge in the consolidation of automated lay-up blanks is the elimination of the mismatch in blank thickness and tool cavity. This challenge further increases when parts become more complex. The ability to ensure sufficient consolidation pressure on the entire part during forming depends on the compaction and flow behavior of the used prepreg. Further research on this is required to get more insight in the allowable thickness variations and required process parameters. Additionally, using non-rigid tooling would allow the tooling to accommodate for small variations in blank thickness and provide a more uniform pressure distribution. This would mean that less material flow is required and lower consolidation pressures would 
be possible. Further research should cover more complex geometries, which include forming and tailored lay-ups. The deconsolidation of AFP blanks deserves additional attention, as the reduced blank integrity may affect the forming behavior when forming more complex parts, as was discussed in Section 3.4.2. Similar issues may be expected when forming USSW blanks, since the local spot welding provides very little blank integrity. Another drawback of the USSW blanks is their increased heating time (by $20 \%$ in this work) due to the poor through-thickness thermal conductivity. This increases both cycle time and the risk of polymer degradation.

\subsection{Conclusions and Recommendations}

The combination of rapid automated lay-up and stamp forming was investigated as a potential promising process route for the manufacturing of load carrying tailored components. A main common characteristic of the two processes is the limited amount of time for consolidation. This means that thorough understanding of interrelation between input prepreg material, preconsolidation process, blank quality, stamp forming process and final consolidation quality is necessary to bring this process route forward.

An experimental study was performed where two C/PEEK prepregs were processed into blanks by two rapid lay-up processes, AFP and USSW, and conventional press consolidation, providing various degrees of preconsolidation. These blanks were subsequently stamp formed at various process conditions. Characterization of consolidation quality of the stamped blanks was performed by C-scans, micrographs and density measurements. Mechanical performance was evaluated based on flexural tests.

The results confirm that void collapse and interlaminar bonding are the two main mechanisms that govern consolidation during stamp forming. However, interlaminar bonding was found to be dominated by the elimination of global thickness variations in the blank, rather than local intimate contact development between plies on a microscale. As a result, the blank thickness variations have a far more significant influence on the final consolidation quality than the initial degree of interlaminar bonding in a blank. When the redistribution of material by flow is insufficient during the short consolidation window during stamp forming, this results in a non-uniform pressure distribution and poorly consolidated regions. When the thickness variations are within acceptable limits, full interlaminar bonding can be achieved during stamp forming. An increased the consolidation pressure allowed for larger thickness variations, while the influence of an increased blank temperature was negligible. The results also confirm that the quality of the pepreg used to manufacture the blanks is crucial to the consolidation process. Four key prepreg characteristics were identified. 
- Thickness distribution. Small prepreg thickness variations can cause significant blank thickness variations when stacked into a blank. For this reason, a uniform prepreg thickness can be considered as one of the most important prepreg characteristics. The thickness variations of the tested prepregs were of large influence on the consolidation of USSW blanks. Strong thickness variations were not observed in the tested AFP blanks due to the use of only a single tow, but may also occur in multi-tow AFP blanks due to tow-to-tow thickness variations.

- Fiber/matrix distribution. A matrix-rich surface of the prepreg was found to ease interlaminar bonding and material redistribution both during rapid layup and stamp forming, allowing faster consolidation and the use of lower pressures. Having a matrix-rich surface is therefore very beneficial for blanks produced by rapid automated lay-up.

- Intralaminar void content. Completely removing intralaminar voids that were initially present in the prepreg was not possible during both rapid lay-up and stamp forming under the studied conditions. Nevertheless, the final void content was low enough to not reduce the flexural performance, hence a low initial intralaminar void content seems acceptable.

- Deconsolidation behavior. The deconsolidation behavior of a prepreg was found to persist in blanks manufactured by rapid automated lay-up. Deconsolidation can be significant and highly prepreg specific. The combination of blank deconsolidation and the absence of a matrix-rich prepreg surface increases the time and pressure required for consolidation. Despite this, deconsolidation of AFP blanks was not found to have a major impact on final consolidation quality.

The current work has demonstrated that high quality laminates with a void content below $1 \%$ can be obtained after stamp forming, even when using blanks with a very low degree of preconsolidation. The flexural strength obtained after stamping of the rapid lay-up blanks considered was identical to that of stamped press-consolidated blanks. Results were most promising for lay-up by AFP. This gives confidence that the proposed process route has the potential for a step forward in the manufacturing of load carrying components. Further research should focus on the compaction and flow behavior of blanks in order to obtain more insight in the maximum allowable thickness variations and required stamping parameters. Furthermore, smart stacking of prepreg and the use of non-rigid tooling may improve consolidation quality after stamp forming by reducing blank thickness variations and by providing a more uniform pressure distribution, respectively. The current work should be extended to the consolidation of more complex parts, which include lay-up tailoring and single and double curvatures. The influence of a low blank integrity due to limited interlaminar bonding or deconsolidation on forming requires additional attention, as this may lead to unexpected forming behavior and forming defects. 


\section{References}

[1] M. A. Khan and R. Schledjewski. Influencing factors for an online consolidating thermoplastic tape placement process. In 17th International Conference on Composite Materials, 2009.

[2] W. J. B. Grouve. Weld Strength of Laser-Assisted Tape-Placed Thermoplastic Composites. Ph.D. thesis, University of Twente, 2012.

[3] M. Gruber, I. Z. Lockwood, T. L. Dolan, S. B. Funck, J. J. Tierney, P. Simacek, J. W. Gillespie, S. G. Advani, B. J. Jensen, R. J. Cano, and B. W. Grimsley. Thermoplastic In Situ Placement Requires Better Impregnated Tapes and Tows. Proceedings of the 2012 International SAMPE Technical Conference, 2012.

[4] Z. Qureshi, T. Swait, R. Scaife, and H. M. El-Dessouky. In situ consolidation of thermoplastic prepreg tape using automated tape placement technology: Potential and possibilities. Composites Part B: Engineering, 66:255-267, 2014.

[5] C. M. Stokes-Griffin and P. Compston. The effect of processing temperature and placement rate on the short beam strength of carbon fibre-PEEK manufactured using a laser tape placement process. Composites Part A: Applied Science and Manufacturing, 78:274-283, 2015.

[6] A. J. Comer, D. Ray, W. O. Obande, D. Jones, J. Lyons, I. Rosca, R. M. O' Higgins, and M. A. McCarthy. Mechanical characterisation of carbon fibre-PEEK manufactured by laser-assisted automated-tape-placement and autoclave. Composites Part A: Applied Science and Manufacturing, 69:10-20, 2015.

[7] K. Yassin and M. Hojjati. Processing of thermoplastic matrix composites through automated fiber placement and tape laying methods: A review. Journal of Thermoplastic Composite Materials, 2017.

[8] T. K. Slange, L. L. Warnet, W. J. B. Grouve, and R. Akkerman. Influence of preconsolidation on consolidation quality after stamp forming of C/PEEK composites. In F. Chinesta, E. Cueto, and A.-C. Emmanuelle, editors, ESAFORM 2016: Proceedings of the 19th International ESAFORM Conference on Material Forming, 2016.

[9] T. K. Slange, L. L. Warnet, W. J. B. Grouve, and R. Akkerman. Influence of prepreg characteristics on stamp consolidation. In ESAFORM 2017: Proceedings of the 20th International ESAFORM Conference on Material Forming, 2017.

[10] T. Zenker, F. Bruckner, and K. Drechsler. Experimental Analysis of Consolidation Processes for Preforms Manufactured by Thermoplastic Automated Fiber Placement. In SAMPE Europe 2017, 2017.

[11] A. Schug, D. Rinker, R. Hinterhoelzl, and K. Drechsler. Evaluating the potential of forming spot-welded layups out of fibre reinforced thermoplastic tape without previous consolidation. International Journal of Material Forming, 2018.

[12] N. Bernet, V. Michaud, P.-E. Bourban, and J.-A. E. Månson. Commingled yarn composites for rapid processing of complex shapes. Composites Part A: Applied Science and Manufacturing, 32(11):1613-1626, 2001.

[13] D. Trudelboucher, B. Fisa, J. Denault, and P. Gagnon. Experimental investigation of stamp forming of unconsolidated commingled E-glass/polypropylene fabrics. Composites Science and Technology, 66(3-4):555-570, 2006.

[14] M. A. Lamontia, M. B. Gruber, J. Tierney, J. W. Gillespie, B. J. Jensen, and R. J. Cano. In 
Situ Thermoplastic ATP Needs Flat Tapes and Tows with Few Voids. In 30th International SAMPE Europe Conference. Paris, 2009.

[15] R. Schledjewski and A. K. Schlarb. In-Situ Consolidation of Thermoplastic Tape Material Effects of Tape Quality on Resulting Part Properties. In International SAMPE Symposium and Exhibition. Baltimore, 2007.

[16] Ten Cate Advanced Composites. Product Datasheet Cetex TC1200 PEEK Resin System, 2013.

[17] Cytec. Technical Data Sheet APC-2-PEEK Thermoplastic Polymer, 2016.

[18] M. D. Wakeman, P. Blanchard, and J.-A. E. Månson. Void Evolution During Stamp-Forming of Thermoplastic Composites. In 15th International Conference on Composite Materials (ICCM-15), 2005.

[19] R. McCool, A. Murphy, R. Wilson, Z. Jiang, M. Price, J. Butterfield, and P. Hornsby. Thermoforming carbon fibre-reinforced thermoplastic composites. Proceedings of the Institution of Mechanical Engineers, Part L: Journal of Materials: Design and Applications, 226:91-102, 2012.

[20] H. Lessard, G. Lebrun, A. Benkaddour, and X.-T. Pham. Influence of process parameters on the thermostamping of a [0/90]12 carbon/polyether ether ketone laminate. Composites Part A: Applied Science and Manufacturing, 70:59-68, 2015.

[21] X. Liu and F. Chen. A review of void formation and its effects on the mechanical performance of carbon fiber reinforced plastic. Engineering Transactions, 64(1):33-51, 2016.

[22] T. K. Slange, L. L. Warnet, W. J. B. Grouve, and R. Akkerman. Deconsolidation of C/PEEK blanks: on the role of prepreg, blank manufacturing method and conditioning. Composites Part A: Applied Science and Manufacturing, 113(April):189-199, 2018.

[23] Hexcel. HexTow (R) AS4 Carbon Fiber Product Data Sheet, 2018.

[24] P. Cebe and S.-D. Hong. Crystallization behaviour of poly(ether-ether-ketone). Polymer, 27(8):1183-1192, 1986.

\section{A Appendix: Blank heating behavior}

The heating times $t_{\text {heat }}$ in the IR oven that are required to achieve the desired blank temperatures $T_{\text {blank }}$ were determined during heating trials with laminates having thermocouples embedded at the mid-plane and underneath the surface plies. Figure 3.14 shows results of the heating trials for the three blank types at a panel temperature $T_{\text {panel }}$ of $450{ }^{\circ} \mathrm{C}$ and a desired $T_{\text {blank }}$ of $390{ }^{\circ} \mathrm{C}$. The time required for the entire blank (i.e. both surface and mid-plane) to reach the desired temperature is dependent on the blank type. The AFP and press-consolidated blanks show very similar heating curves with very minimal temperature lag between surface and mid-plane, indicating good through-thickness thermal conductivity. The temperature lag is much larger for the USSW blanks due to the poor through-thickness thermal conductivity. This is because of the local bonding, which results in a lack of ply contact and insulating air layers between the plies. All blanks show a divergence of the mid-plane and 


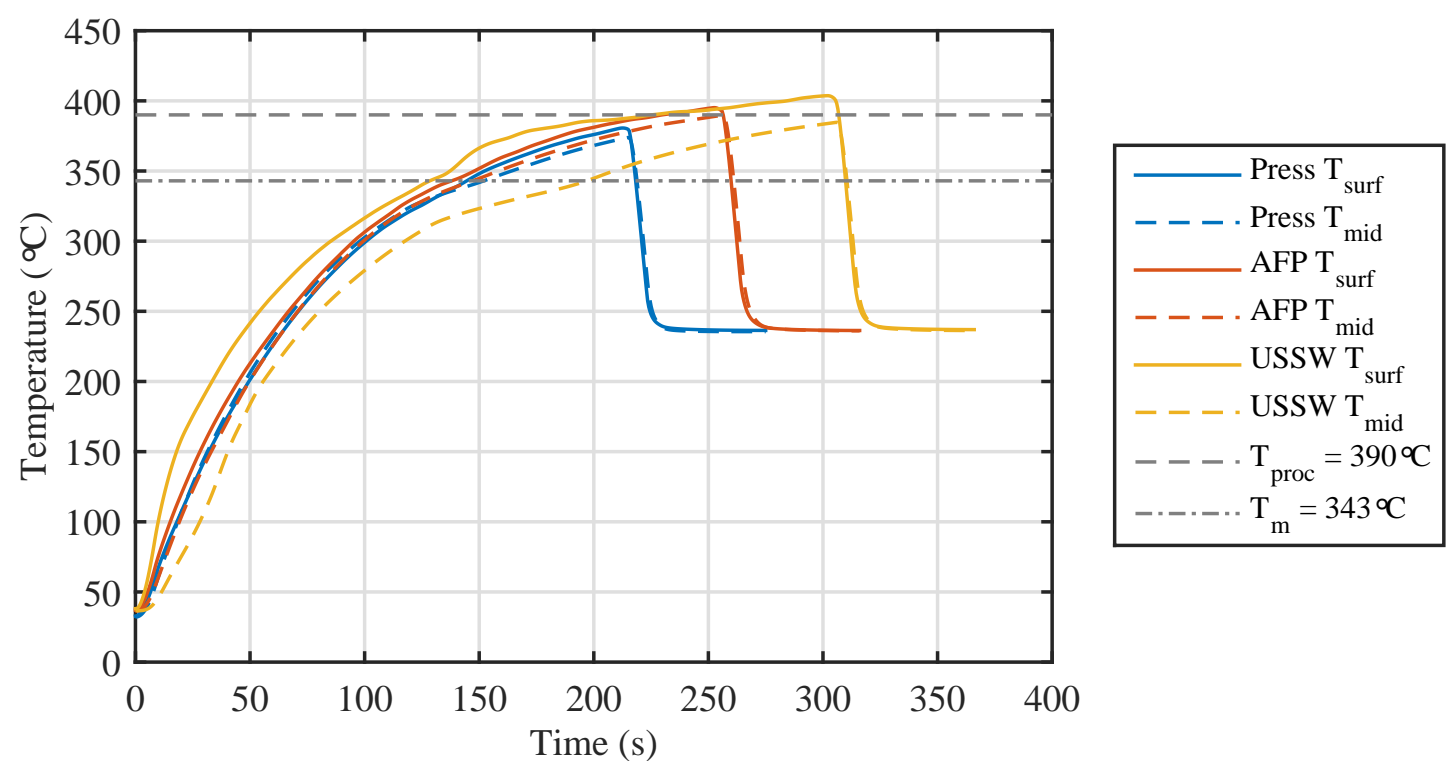

Figure 3.14 Blank mid-plane and surface temperature measured by embedded thermocouples during heating trials at a $T_{\text {panel }}$ of $450^{\circ} \mathrm{C}$. Note: tool temperature was $240{ }^{\circ} \mathrm{C}$ during heating trials.

Table 3.2 IR heating parameters.

\begin{tabular}{l|ccc}
\hline Blank type & $\begin{array}{c}\mathrm{T}_{\text {blank }} \\
{ }^{\circ} \mathrm{C}\end{array}$ & $\begin{array}{c}\mathrm{T}_{\text {panel }} \\
{ }^{\circ} \mathrm{C}\end{array}$ & $\begin{array}{c}\mathrm{t}_{\text {heat }} \\
\mathrm{s}\end{array}$ \\
\hline Press, AFP & 390 & 450 & 250 \\
USSW & 390 & 450 & 300 \\
Press, AFP & 420 & 485 & 250 \\
USSW & 420 & 485 & 300 \\
\hline
\end{tabular}

surface temperature when crossing the melt temperature due to deconsolidation, which reduces the through-thickness thermal conductivity by the formation of voids and delaminations.

The required heating parameters determined from the heating trials are shown in Tbl. 3.2. A $t_{\text {heat }}$ of 250 seconds at a $T_{\text {panel }}$ of $450{ }^{\circ} \mathrm{C}$ were sufficient to reach a $T_{\text {blank }}$ of $390{ }^{\circ} \mathrm{C}$ for press-consolidated and AFP blanks, while the USSW blanks require 300 seconds. Note that, at this time, the surface ply of the USSW blanks already has been above the processing temperature for 75 seconds, which could potentially lead to polymer degradation. Increasing $T_{\text {panel }}$ to $485{ }^{\circ} \mathrm{C}$ was sufficient to reach a $T_{\text {blank }}$ of $420{ }^{\circ} \mathrm{C}$ in the same $t_{\text {heat }}$.

In Fig. 3.14 all blanks show the same cooling curve with almost no through-thickness thermal gradient once they are stamped between the isothermal tooling. The blanks reach the tooling temperature of, in case of the heating trials, $240{ }^{\circ} \mathrm{C}$ in approximately 20 seconds. 


\section{Chapter 4}

\section{Consolidation of Blanks with Thickness Variations during Stamp Forming}

\section{Abstract}

The elimination of thickness variations in a stack is an important part of the consolidation process. However, the high cooling rates during stamping provide only a very small window for transverse flow, which is the main mechanism for material redistribution during consolidation. A model for the elimination of thickness variations by transverse flow of the plies is proposed. This model is applied for a parameter study, which highlights the influence of the wavelength and amplitude of the prepreg thickness profile, as well as the process parameters. The model is used to propose material and processing guidelines and lay-up strategies aimed at enhancing consolidation during stamp forming of blanks manufactured by automated lay-up. 


\subsection{Introduction}

The introduction of automated lay-up technologies, such as automated tape laying (ATL) and advanced fiber placement (AFP), provides new opportunities for the rapid manufacturing of components and structures of thermoplastic composite material. One of the benefits of automated lay-up is the possibility for highly automated manufacturing with a high degree of lay-up freedom. This enables the use of tailored lay-ups, which can be optimized for their final application in terms of local thickness and fiber orientations, allowing for more efficient material use and weight reduction compared to traditional lay-ups of uniform thickness. Moreover, near net-shaped lay-ups can be produced, which reduces scrap generated by trimming operations.

The majority of research and development efforts for automated lay-up focuses on achieving in-situ consolidation, where no post-consolidation step is required after lay-up. However, an alternative processing route was proposed in Chapter 1. The focus in this route is on rapid lay-up, rather than aiming for high consolidation quality, of flat blanks with tailored lay-ups. This is then followed by a fast postconsolidation step by stamp forming, which also provides the final shape of the component. While in-situ consolidation could be very promising for large and relatively simple aerostructures, such as fuselage sections and wing skins, the proposed processing route would be more interesting for smaller load carrying components.

In order for the processing route to be successful, it is important that it results in high performance components. This performance is largely determined by the consolidation quality, which includes properties such as void content and interlaminar bonding. The achieved consolidation quality is a function of the processing history and therefore relies on all steps involved in the process route, from the input prepreg material, through lay-up to a tailored blank and from the blank through stamp forming to the final component.

In general, a low degree of consolidation is achieved during lay-up of the blank, due to the focus on high lay-up rates. This means that most of the consolidation has to take place during stamp forming. This is challenging, due to the high cooling rates that occur once pressure is applied by the relatively cold (between $T_{g}$ and $T_{m}$ for semicrystalline polymer composites) tooling. The drop in temperature rapidly increases the viscosity of the polymer, which slows down consolidation processes that involve material flow, such as void elimination and interlaminar bonding. The small window, typically 1-10 seconds, that is available for consolidation requires an optimum state of the blank before stamping. This state mainly depends on the input prepreg material and the process used to manufacture the blank. For example, the continuous welding of an AFP process provides more interlaminar bonding than an ATP process where ultra-sonic spot welding (USSW) is applied. The degree of interlaminar bonding that is achieved during AFP depends in turn on, for example, the flow behavior of the 


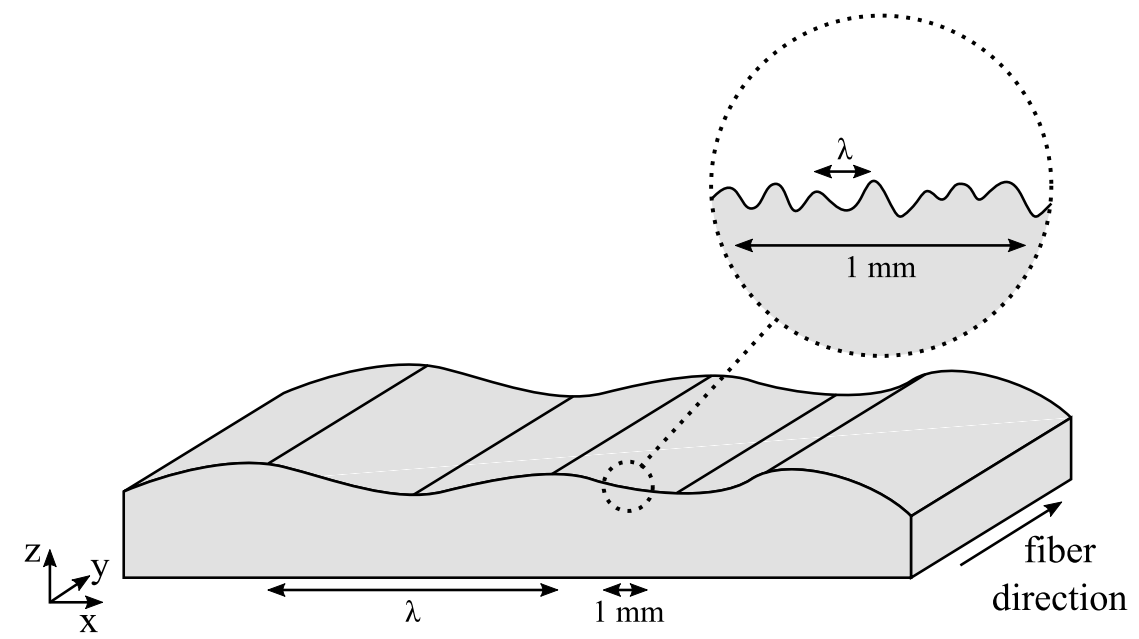

Figure 4.1 Intimate contact development on a micro-scale by elimination of surface roughness $(\lambda<1$ $\mathrm{mm})$ and on a meso-scale by elimination of thickness variation $(\lambda>1 \mathrm{~mm})$.

prepreg or the presence of a matrix rich surface.

Despite the large variation in interlaminar bonding between a blank produced by AFP or USSW, this was not found to be one of the major factors that control the final consolidation quality. This was demonstrated in Chapter 3, where similar consolidation quality and mechanical performance were achieved by stamping blanks manufactured by AFP, USSW and conventional press consolidation. However, it was highlighted that blank thickness variations do play a key role in the consolidation process. These thickness variations arise from small non-uniformities in the thickness of the prepreg. These prepreg thickness variations are usually eliminated during a conventional lengthy press or autoclave consolidation cycle, but this is not the case during rapid lay-up. Blank thickness variations influence the local consolidation pressure during stamping, which, in combination with the high cooling rates, can lead to local poor consolidation due to lack of material flow.

The success of the process route depends on the ability to eliminate thickness variations during stamp forming, such that sufficient pressure can be applied for consolidation to occur in all regions. The elimination of thickness variations requires a redistribution of material by flow. This flow is mostly limited to transverse squeeze flow due to the high fiber volume fraction and high fiber modulus [1, 2]. The redistribution of thickness variations by transverse flow is also known as intimate contact development; the flatter two surfaces in contact are, the larger the contact area, i.e. degree of intimate contact, between the two surfaces. Intimate contact development can occur by material flow on two length scales, as illustrated in Fig. 4.1.

On a micro-scale, intimate contact is established by eliminating surface roughness, which has a very short wavelength, e.g. $\lambda<1 \mathrm{~mm}$. In literature, this is described by the classical models by Lee and Springer [3], Mantell and Springer [4], and Yang 
and Pitchumani [5]. These models consider intimate contact development as the local deformation of the surface asperities in the roughness profile, where the asperities are represented by a series of rectangles and interaction between the rectangles is neglected. These models have been applied to describe intimate contact development during processing, such as press consolidation, fusion bonding and AFP [3, 5-10].

On a meso-scale, intimate contact is established by eliminating thickness variations in the plies. These thickness variations have a much larger wavelength than the surface roughness, e.g. $\lambda>1 \mathrm{~mm}$, and require a much more global flow to be eliminated, i.e. over the entire thickness of the ply and over a longer distance. This meso-scale flow is not captured in the current micro-scale models. The compaction of multiple adjacent tows has been modeled by Dara and Loos using a similar approach [6]. However, no interaction between the adjacent tows was considered.

The current work aims to develop a thorough understanding of the influence of relevant parameters on intimate contact development during stamp forming of rapid lay-up blanks with thickness variations. For this purpose, a novel intimate contact model is proposed on squeeze flow of the entire thickness profile of a ply. The model is used to perform a parameter study in order to identify the influence of the prepreg thickness profile and material and process parameters on intimate contact development. The results are used to develop guidelines which can be used for optimization of the prepreg, lay-up strategy and process parameters.

\subsection{Model description}

Consider a rectangular domain of a single ply of prepreg material with a certain thickness distribution $h$ across the width, as shown in Fig. 4.2. Assuming laminar creeping flow and neglecting body forces, the mechanical power balance of the system with a volume $V$ and boundary surface $S$ is given by

$$
\int_{S} \mathbf{t} \cdot \mathbf{v} d S=\int_{V} \sigma: \mathbf{d} d V
$$

Here, $\mathbf{v}$ is the velocity vector, $\mathbf{t}$ are the boundary tractions, $\sigma$ is the Cauchy stress tensor and $\mathbf{d}$ is the rate of deformation tensor, defined as

$$
d_{i j}=\frac{1}{2}\left(\frac{\partial v_{i}}{\partial x_{j}}+\frac{\partial v_{j}}{\partial x_{i}}\right) .
$$

The left hand side of Equation 4.1 represents the external power at the boundary, which is induced by the external force applied on the material by the tool. The right hand side represents the internal power that is stored or dissipated into heat.

Equation 4.1 can be approximated by discretizing the domain into $N$ control volumes 

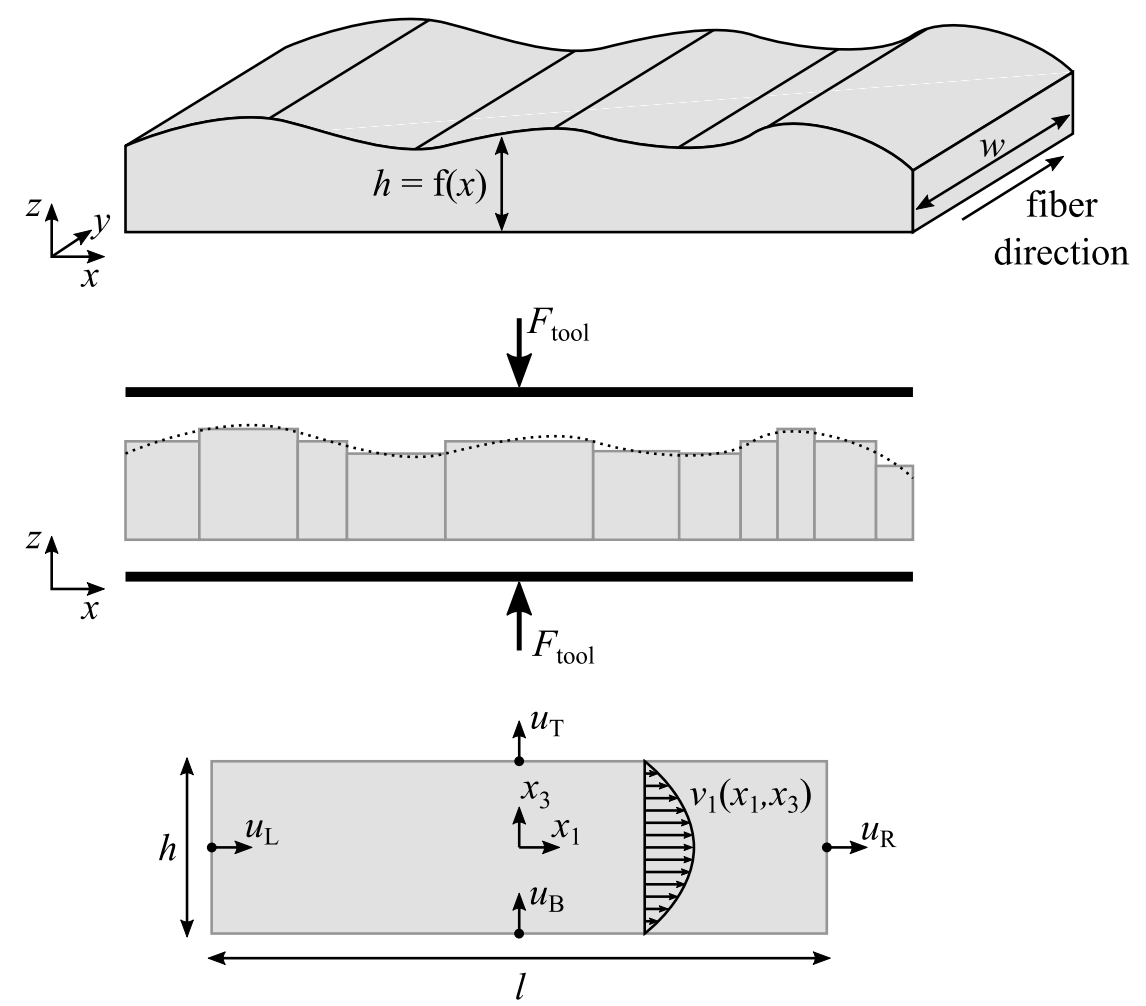

Figure 4.2 Illustration of a rectangular ply with fibers parallel to the $y$-axis and a thickness variation across its width (top), the domain of the ply discretized into control volumes (middle) and a single control volume with fibers in the $x_{2}$ direction and squeeze flow in the $x_{13}$-plane (bottom).

$\Delta V$. These control volumes have dimensions $l, w$ and $h$ in the $x_{1}, x_{2}$ and $x_{3}$-direction, respectively, and have their fibers aligned with the $x_{2}$-axis. For a $0^{\circ}$ ply the $x_{2}$-axis is parallel the the $y$-axis of the global coordinate system. After discretization, Equation (4.1) becomes

$$
\sum_{n=1}^{N} \mathbf{F}_{n} \cdot \mathbf{v}_{n}=\sum_{n=1}^{N} \int_{\Delta V_{n}} \sigma: \mathbf{d} d V .
$$

Here $\mathbf{F}_{n}$ are the normal forces acting on the boundaries of the control volume and $\mathbf{v}_{n}$ are the average normal velocities of the boundaries of the control volume.

The constitutive behavior of the control volumes is assumed to follow the Ideal Fiber Reinforced Material (IFRM) model [2, 11]. This model considers an incompressible Newtonian fluid where the inextensible fibers convect with the deformation. When the direction of the fibers remains constant throughout the flow and no shearing occurs in the fiber direction, it is shown by Rogers [2] that the flow is planar, i.e. 
$v_{2}=0$ in the fiber direction, and that the constitutive behavior is given by

$$
\begin{aligned}
& \sigma_{11}=-p+2 \eta_{T} d_{11} \\
& \sigma_{22}=-p+T \\
& \sigma_{33}=-p+2 \eta_{T} d_{33} \\
& \sigma_{13}=2 \eta_{T} d_{13} \\
& \sigma_{12}=\sigma_{23}=0 .
\end{aligned}
$$

Here, $p$ is the hydrostatic pressure, $T$ is the fiber tension and $\eta_{\mathrm{T}}$ is the transverse viscosity.

Rogers [2] has also shown that the velocity field for squeezing flow between two parallel platens of an initially rectangular block of material with no-slip conditions at the top and bottom surface is a quadratic function of $x_{3}$. Hence, the velocity field in the $x_{1}$-direction of a control volume is chosen here as

$$
v_{1}\left(x_{1}, x_{3}\right)=\frac{3}{2} \bar{v}_{1}\left(1-\frac{1}{4} \frac{x_{3}^{2}}{h^{2}}\right)
$$

with $\bar{v}_{1}$ as the average velocity over the height of the control volume, which is a linear function of $x_{1}$. The velocity $\bar{v}_{1}$ can be expressed as a linear interpolation of the average velocity at the left and right boundary, given by

$$
\bar{v}_{1}\left(x_{1}\right)=v_{\mathrm{L}} \frac{l / 2-x_{1}}{l}+v_{\mathrm{R}} \frac{x_{1}+l / 2}{l} .
$$

With the fibre inextensibility constraint acting in the $x_{2}$ direction, incompressibility implies that

$$
\frac{\partial v_{3}}{\partial x_{3}}=-\frac{\partial v_{1}}{\partial x_{1}}
$$

which after integration leads to

$$
\begin{aligned}
v_{3}\left(x_{1}, x_{3}\right) & =-\frac{\partial \bar{V}_{1}\left(x_{1}\right)}{\partial x_{1}} \cdot\left(\frac{3}{2} x_{3}-2 \frac{x_{3}^{3}}{h^{2}}\right), \\
& =-\frac{v_{\mathrm{R}}-v_{\mathrm{L}}}{l} \cdot\left(\frac{3}{2} x_{3}-2 \frac{x_{3}^{3}}{h^{2}}\right), \\
& =\frac{v_{\mathrm{T}}-v_{\mathrm{B}}}{h} \cdot\left(\frac{3}{2} x_{3}-2 \frac{x_{3}^{3}}{h^{2}}\right) .
\end{aligned}
$$


For convenience, the fluid is described as slightly compressible, with

$$
\begin{aligned}
p(t+\Delta t) & =-C_{\mathrm{b}} \varepsilon_{\mathrm{V}}(t+\Delta t) \\
& \approx p(t)-C_{\mathrm{b}} \Delta \varepsilon_{\mathrm{V}}, \\
& \approx p(t)-C_{\mathrm{b}} \Delta t\left(\frac{v_{\mathrm{R}}-v_{\mathrm{L}}}{l}+\frac{v_{\mathrm{T}}-v_{\mathrm{B}}}{h}\right),
\end{aligned}
$$

where $C_{b}$ is the bulk modulus, which is very large for nearly incompressible materials, and $\varepsilon_{\mathrm{v}}$ is the volumetric strain.

Substituting Equations 4.4, 4.5, 4.8 and 4.9 into the right hand side of Equation 4.3 and integrating over a single control volume yields an equation which is a function of the average velocities and displacements at the boundaries of the control volume. Differentiation of Equation 4.3 with respect to the average velocities, i.e.

$$
\frac{\partial}{\partial v_{i}}(\mathbf{F} \cdot \mathbf{v})=\frac{\partial}{\partial v_{i}}\left(\int_{\Delta V} \sigma: d d V\right)
$$

then results in a system of equations in the form of

$$
\mathbf{F}(t+\Delta t)=\mathbf{F}_{\mathrm{el}}(t)+\left(\Delta t \mathbf{K}_{\mathrm{el}}+\mathbf{K}_{\mathrm{visc}}\right) \mathbf{v},
$$

where

$$
\begin{aligned}
& \mathbf{F}_{\mathrm{el}}(t)=-p(t) w\left[\begin{array}{c}
-h \\
-l \\
h \\
l
\end{array}\right] \\
& \mathbf{K}_{\mathrm{el}}=-C_{\mathrm{b}} w\left[\begin{array}{cccc}
h / l & 1 & -h / l & -1 \\
1 & l / h & -1 & -l / h \\
-h / l & -1 & h / l & 1 \\
-1 & -l / h & 1 & l / h
\end{array}\right] \\
& \mathbf{K}_{\mathrm{visc}}=\frac{\eta_{\mathrm{T}} w}{5}\left[\begin{array}{cccc}
24 h / l+40 l / h & 0 & -24 h / l-40 l / h & 0 \\
0 & 24 l / h & 0 & -24 l / h \\
-24 h / l-40 l / h & 0 & 24 h / l+40 l / h & 0 \\
0 & -24 l / h & -0 & 24 l / h
\end{array}\right] \text {, } \\
& \mathbf{F}=\left\{F_{\mathrm{L}}, F_{\mathrm{B}}, F_{\mathrm{R}}, F_{\mathrm{T}}\right\}^{\mathrm{T}}, \\
& \mathbf{v}=\left\{v_{\mathrm{L}}, v_{\mathrm{B}}, v_{\mathrm{R}}, v_{\mathrm{T}}\right\}^{\mathrm{T}} \text {. }
\end{aligned}
$$

Here, $\mathbf{F}_{\mathrm{el}}(t)$ and $\Delta t \mathbf{K}_{\mathrm{el}} \mathbf{v}$ represent the initial and incremental elastic forces due to compression, respectively, and $\mathbf{K}_{\mathrm{visc}} \mathbf{V}$ represents the viscous forces. Note that 
the index $n$ has been omitted from the equations for convenience. Applying time discretization, i.e. $v=\Delta u / \Delta t$, Equation 4.11 can be rewritten to

$$
\mathbf{F}(t+\Delta t)-\mathbf{F}_{\mathrm{el}}(t)=\Delta \mathbf{F}=\left(\mathbf{K}_{\mathrm{el}}+\frac{1}{\Delta t} \mathbf{K}_{\mathrm{visc}}\right) \Delta \mathbf{u}=\mathbf{K} \Delta \mathbf{u}
$$

The global system of equations can be obtained by summing the contributions of all control volumes, following Equation 4.3. An additional degree of freedom is added for the tool. Contact between the tool and control volumes is evaluated by comparing the height of the control volume with the position of the tool at the beginning of each time step. When there is contact, the vertical displacements are coupled to the displacement of the tool. Further boundary conditions, e.g. prescribed forces or displacements, are applied and the displacements of adjacent control volumes are coupled. This reduces the system and allows the unknown displacements to be solved by inversion, i.e.

$$
\Delta \mathbf{u}_{\text {red }}=\mathbf{K}_{\text {red }}^{-1} \Delta \mathbf{F}_{\text {red }}
$$

With the updated dimensions of the control volumes, tool contact can be re-evaluated. The degree of intimate contact $D_{\text {ic }}$ is then defined as the ratio between the in-plane area of the control volumes that are in contact with the tooling and the total in-plane area of the domain.

The approach can also applied to multi-ply lay-up, which can include both $0^{\circ}$ and $90^{\circ}$ plies. In this case, a grid of control volumes is formed where the vertical nodal displacements are connected, as shown in Fig. 4.3. No-slip conditions are assumed at the ply-ply interfaces. For $90^{\circ}$ plies, the $x_{1}$-axis will be aligned with the $y$-axis instead of the $x$-axis. Any interaction between control volumes in the fiber direction of the ply is neglected and hence the flow in the control volumes remains planar and the fibers are assumed to remain parallel. Note that in reality this assumption could be violated in case of a cross-ply lay-up due to the inextensibility of the fibers.

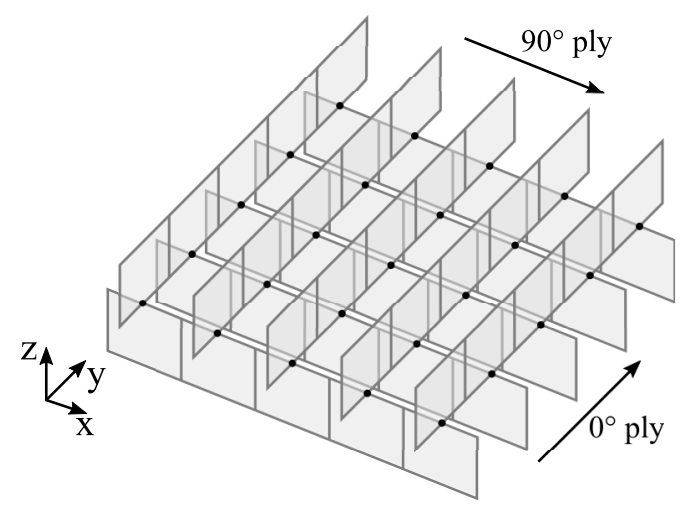

Figure 4.3 A multi-ply grid for a [0/90] lay-up. 
Tool contact for a multi-ply lay-up is evaluated by comparing the cumulative height of a stack of control volumes with the tool position. In this case it is convenient when the in-plane dimensions of the control volumes remain constant. Hence, the control volumes are remapped to their original in-plane dimensions by redistributing the volume at the beginning of each time step.

Finally, the algorithm was implemented in a MATLAB ${ }^{\circledR}$-code with a GUI for convenient evaluation of the results. Adaptive time stepping was applied in order to prevent significant tool penetration during contact development.

\subsection{Parameter study}

The developed model can be used to investigate the influence of the prepreg thickness profile, material properties and processing conditions on the consolidation behavior. A parameter study was performed to identify the influence of the individual parameters.

\subsubsection{Material properties}

The model requires material properties, in particular a transverse fiber-matrix viscosity, as input. This transverse viscosity $\eta_{\mathrm{T}}$ is temperature dependent and its temperature dependency is often described in the form of the semi-empirical Arrhenius equation

$$
\eta_{\mathrm{T}}=\eta_{0} \exp (B / T),
$$

where $\eta_{0}$ and $B$ are empirically determined constants and $T$ is given in $K$. The constants are usually determined from squeeze flow experiments. In this work, Arrhenius constants for C/PEEK are taken from the work of Khan et al. [12], where $\eta_{0}=0.0037 \mathrm{~Pa} \cdot \mathrm{s}$ and $B=11115 \mathrm{~K}^{-1}$.

\subsubsection{Prepreg profile}

Let us consider a single prepreg ply with a wave-like thickness profile. The thickness $h$ of this profile can be described by the average thickness $h_{0}$, the amplitude $A$ and the wavelength $\lambda$ through

$$
h=h_{0}-A \cos \left(\frac{2 \pi}{\lambda} x\right)
$$

where $x$ is the position across the width of the prepreg, transverse to the fiber direction. The profile is assumed to be constant along the length of the fibers. 


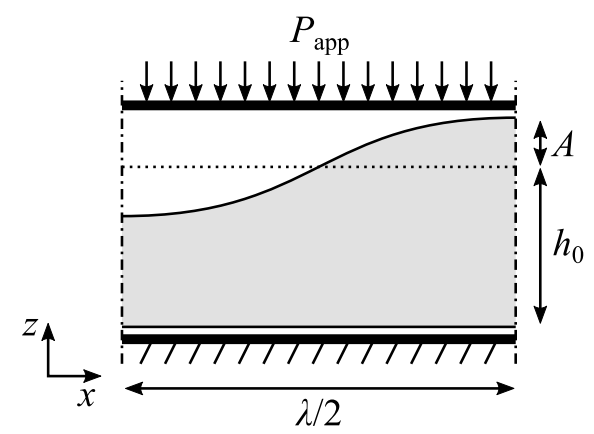

Figure 4.4 Simplified profile geometry.

Table 4.1 Geometrical parameters of the prepreg thickness profile and their range used in the parameter study.

\begin{tabular}{lc|ccc}
\hline Parameter & Unit & Minimum & Baseline & Maximum \\
\hline$h_{0}$ & $\mu \mathrm{m}$ & 100 & 150 & 200 \\
$A$ & $\mu \mathrm{m}$ & 5 & 10 & 25 \\
$\lambda$ & $\mathrm{mm}$ & 5 & 20 & 50 \\
\hline
\end{tabular}

Assuming an infinitely large ply, periodic boundary conditions can be applied and the profile can be reduced to only half a wavelength. The simplified profile geometry is shown in Fig. 4.4

The influence of the geometrical parameters $h_{0}, A$ and $\lambda$ on the intimate contact development can now be investigated. Ten simulations were performed for each parameter while varying the parameter within a realistic range listed in Tbl. 4.1 and keeping the other parameters constant at an arbitrarily chosen baseline value. A constant pressure of 20 bar and constant viscosity of $7.06 \times 10^{4} \mathrm{~Pa} \cdot \mathrm{s}$ are assumed, based on a processing temperature of $390{ }^{\circ} \mathrm{C}$. The profile was discretized by 50 equally sized elements, which was more than sufficient for a converged solution.

Figure 4.5 shows an example of the discretized baseline geometry, the degree of intimate contact as a function of time and the progression of contact development across the width of the profile. Initially, contact develops rapidly due to the high pressure on the small contact area of the peak. As the material flows towards the valley and the contact area increases, the pressure is reduced and so is flow rate. Figure 4.6 shows the results of the variation of the geometrical parameters on the time required to reach full intimate contact $\left(t_{\text {ic }}\right)$. The time to full intimate contact reduces for increasing average ply thickness and is proportional to $1 / h_{0}^{3}$. The time to intimate contact increases linearly with the amplitude. The time to full intimate contact is most sensitive to the wavelength in the used ranges and is proportional to $\lambda^{2}$.

Up to now only the compaction of a single ply was considered. However, composite laminates are made by consolidating a stack of multiple plies with multiple fiber orientations. Stacking these plies results in a complex thickness distribution, which 


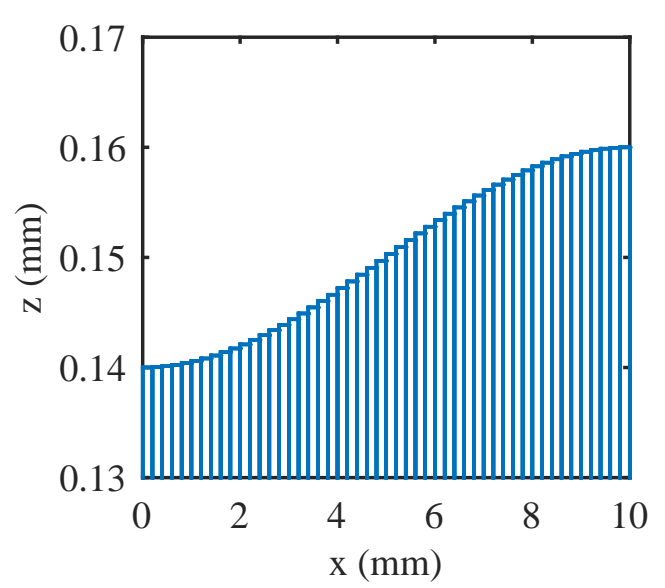

(a)

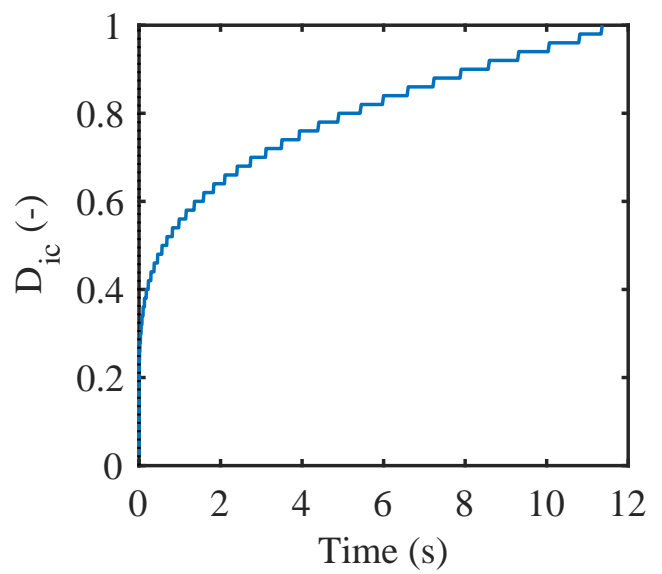

(b)

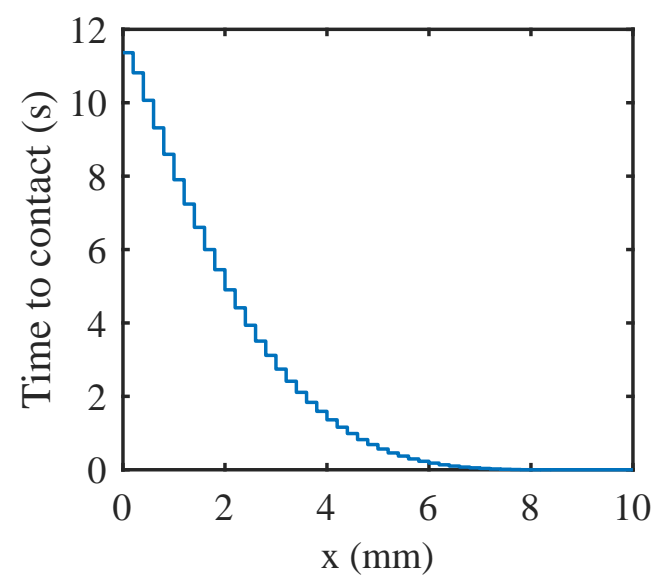

(c)

Figure 4.5 (a) Geometry of half a wavelength (50 elements). (b) Intimate contact development of the baseline surface profile. (c) Time to contact per element.

will affect the pressure distribution and material flow during consolidation. The simplest multi-ply lay-up is a $\left[0^{\circ} / 90^{\circ}\right]$ cross-ply. Let us consider the same wave-like thickness profile across the width of the plies as for the single ply. Then stacking two of these plies with their fiber orientations, and thus thickness profiles, perpendicular to each other results in a wave-like thickness profile of the stack in two directions. This is shown in Fig. 4.7 (a) for the baseline profile listed in Tbl. 4.1. Figure 4.7 (b) compares intimate contact development of this cross-ply with the single ply, while Fig. 4.7 (c) shows the contact development over time in the $x y$-plane. The instantaneous contact area is much smaller for the cross-ply compared to the single ply. Due to this small contact area, the pressure is very high, resulting in a high flow rate and a quick progression of contact. However, due to the rapid increase of contact area, the pressure decreases and flow is reduced to a level where the contact development progresses much slower than for the single ply. Ultimately, the cross-ply 


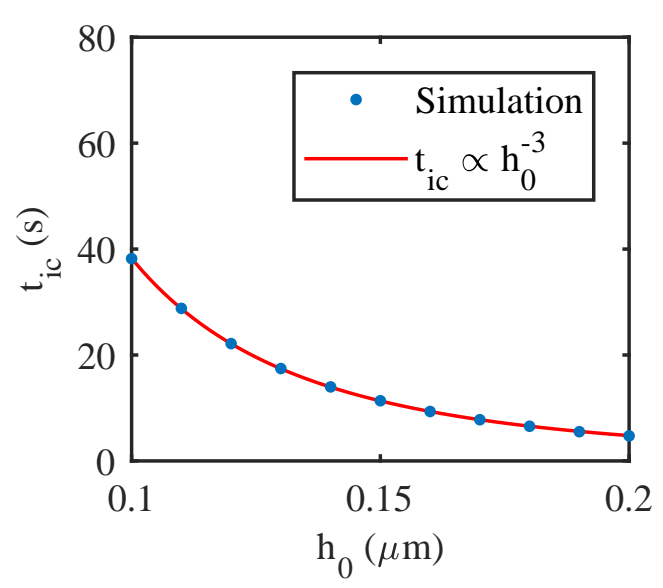

(a)

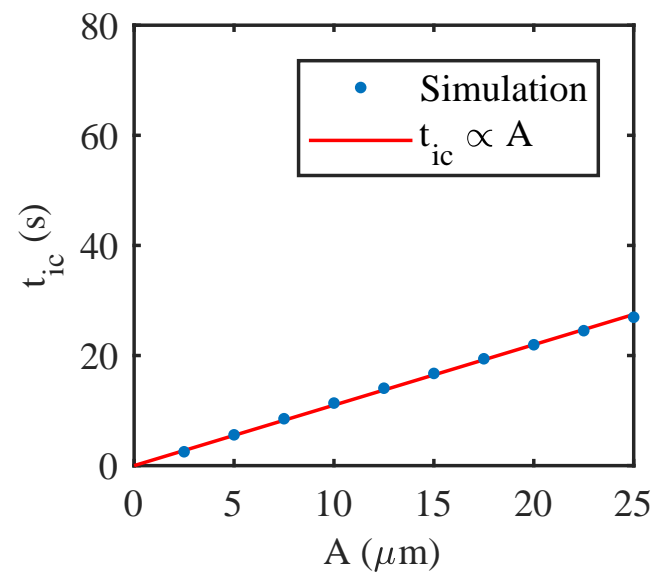

(b)

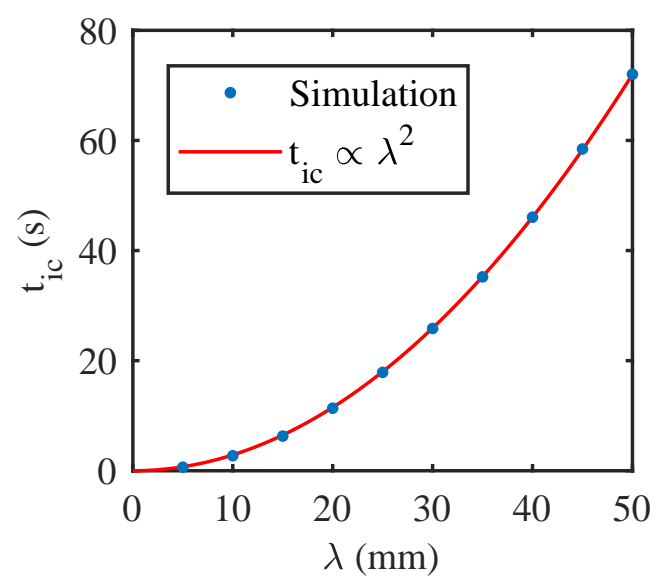

(c)

Figure 4.6 Time to full intimate contact as a function of (a) average ply thickness, $(b)$ amplitude and (c) wavelength.

takes roughly twice as long to reach full intimate contact.

Based on the previous observations, it seems that the time to full intimate contact can be expressed as a linear function of the dimensionless geometrical parameter $h^{-3} A \lambda^{2}$ for single ply compaction. This relation was verified by performing 100 simulations on random profiles generated with parameters listed in Tbl. 4.1. Additionally, the same profiles were used to evaluate the influence of the dimensionless geometrical parameter on intimate contact development for a cross-ply lay-up. The result is shown in Fig. 4.7 (d), which confirms the linear relation of the time to full intimate contact with the dimensionless geometrical parameter for the single ply. The slope of the line is determined by the remaining parameters of the model, such as the material and process parameters. The linear relationship also holds for a cross-ply. However the slope is increased by a factor two by changing from a single ply to a cross-ply. 


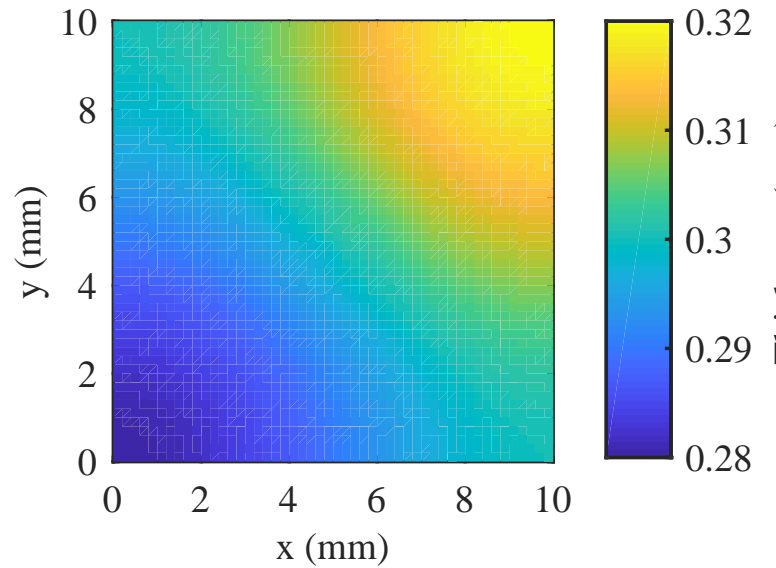

(a)

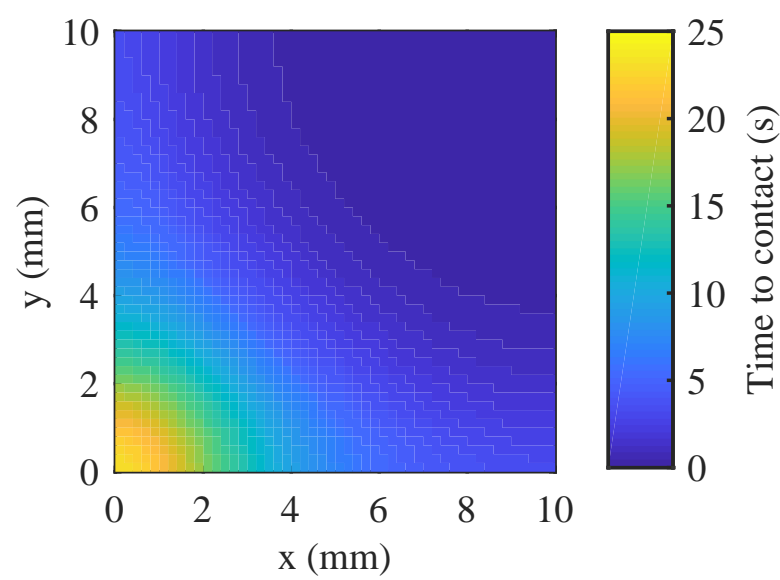

(c)

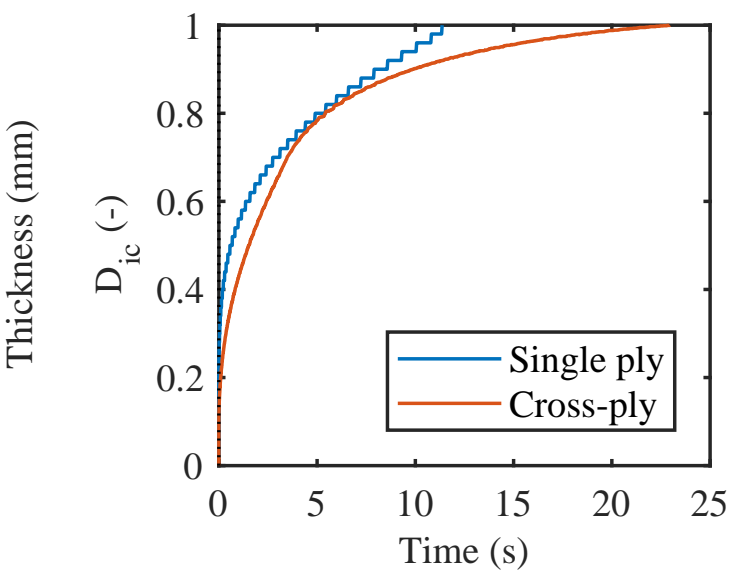

(b)

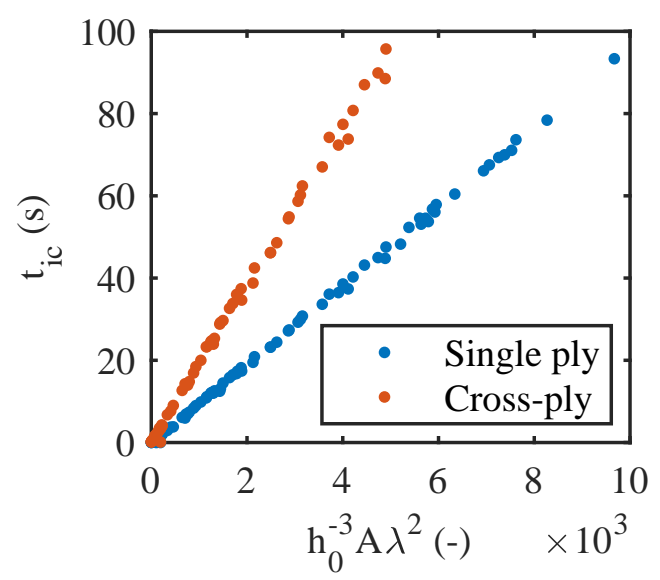

(d)

Figure 4.7 (a) Total stack thickness of a $\left[0^{\circ} / 90^{\circ}\right]$ cross-ply for the baseline surface profile. (b) Intimate contact development of a single ply and a cross-ply for the baseline surface profile. (c) Time to contact per element in $x y$-plane for the cross-ply stack. (c) Time to full intimate contact as a function of the dimensionless geometrical parameter $h_{0}^{-3} A \lambda^{2}$ for 100 random profiles.

\subsubsection{Material and processing conditions}

Similarly to the previous section, the influence of the material and processing parameters can be investigated. The main material parameter present in the model is the transverse viscosity $\eta_{T}$, which in turn depends on the processing temperature. The other process parameter is the average applied pressure $P_{\text {app }}$. Ten simulations were performed for each parameter while varying the parameter between the minimum and maximum values listed in Tbl. 4.2 and keeping the other parameter constant at the baseline value. The profile is kept constant using the baseline parameters listed in Tbl. 4.1 .

Figure 4.8 shows the results of the variation of the viscosity and applied pressure 
Table 4.2 Material and processing parameters and their range used in the parameter study.

\begin{tabular}{lc|ccc}
\hline Parameter & Unit & Minimum & Baseline & Maximum \\
\hline$\eta_{T}$ & $\mathrm{~Pa} \cdot \mathrm{s}$ & $5 \times 10^{4}$ & $7.06 \times 10^{4}$ & $5 \times 10^{5}$ \\
$P_{\text {app }}$ & $\mathrm{Pa}$ & $5 \times 10^{5}$ & $20 \times 10^{5}$ & $100 \times 10^{5}$ \\
\hline
\end{tabular}

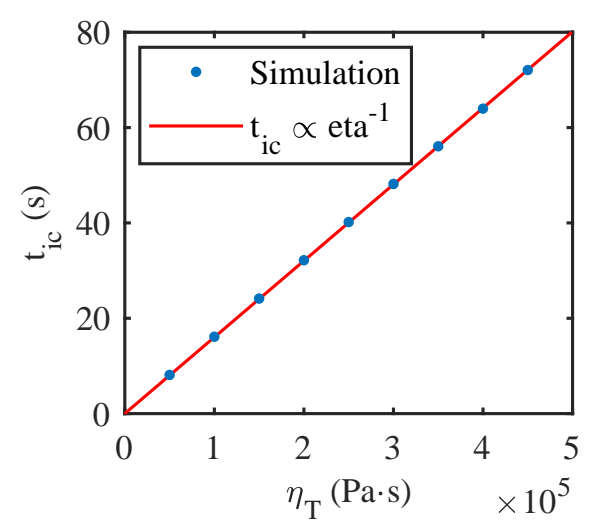

(a)

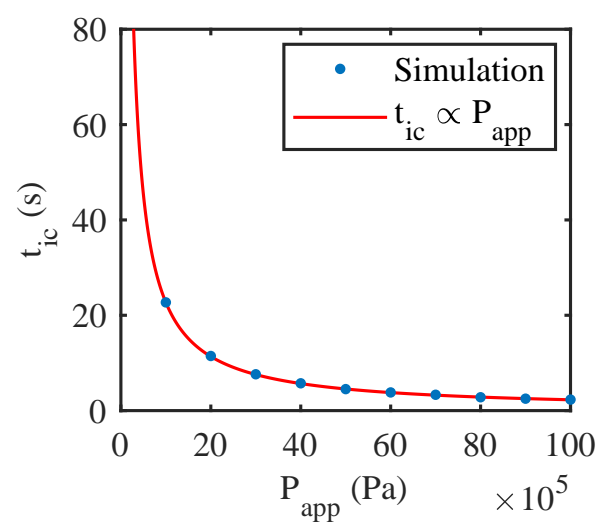

(b)

Figure 4.8 Time to full intimate contact as a function of (a) transverse viscosity, (b) applied pressure.

on the time required to reach full intimate contact. The time to full intimate contact increases linearly with the transverse viscosity, while it decreases inversely proportional to the applied pressure. This follows directly from the underlying Navier-Stokes equation $-\nabla p+\eta \nabla^{2} \mathbf{v}=0$ since $t_{\text {ic }} \propto 1 / v$ and was confirmed by these simulations.

The temperature dependency of the transverse viscosity plays an important role in the development of intimate contact. As the temperature increases, the viscosity reduces and intimate contact can develop more rapidly. This is shown in Fig. 4.9. which shows the time to full intimate contact for the baseline geometry and pressure over a range of processing temperatures which is typical to C/PEEK.

The temperature dependency becomes even more important for processes where intimate contact development has to take place under highly non-isothermal conditions, such as is the case in stamp forming. Figure 4.9 (b) shows an example where intimate contact development under isothermal and non-isothermal conditions are compared. The baseline geometry listed in Tbl. 4.1 and a pressure of 50 bar were used. The nonisothermal temperature curve is an approximation of the blank temperature during a stamp forming process where the blank is quench-cooled from $390{ }^{\circ} \mathrm{C}$ to $250{ }^{\circ} \mathrm{C}$ in approximately 10 seconds by an isothermal tooling. As can be seen in Fig. 4.9 (b), intimate contact development stagnates rapidly for the stamp forming process as the temperature decreases and the viscosity increases. After the temperature has dropped below $320{ }^{\circ} \mathrm{C}$, the viscosity has increased so much that almost no further material flow occurs. Only $68 \%$ contact is achieved for the non-isothermal case, 


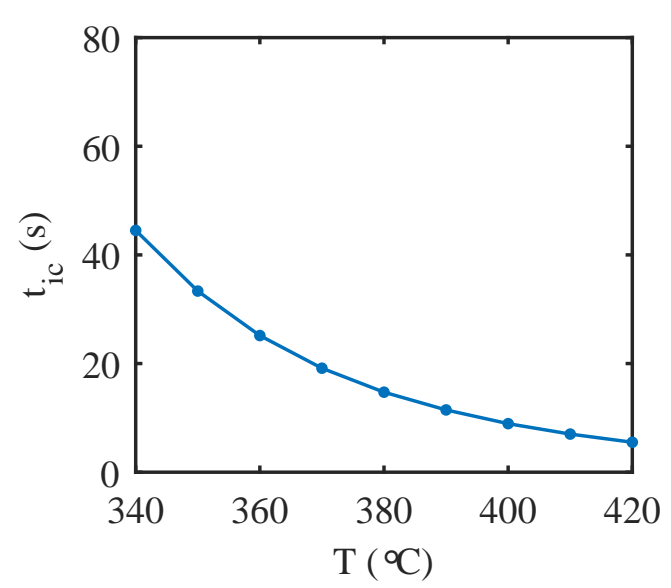

(a)

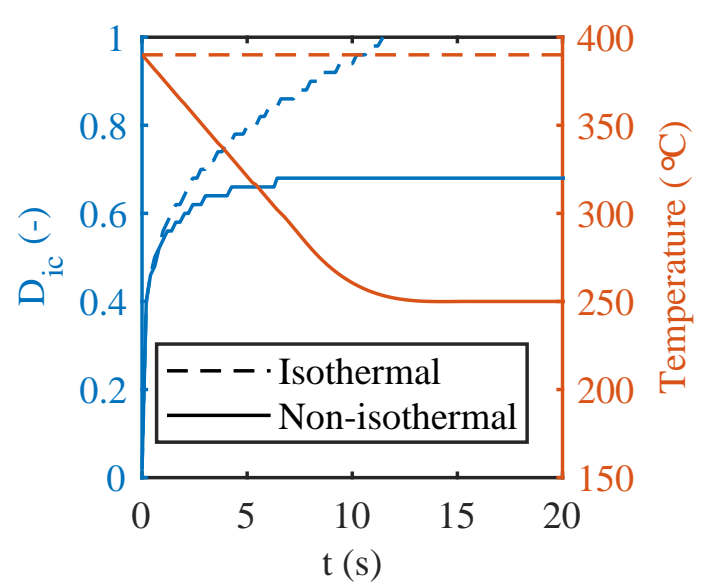

(b)

Figure 4.9 (a) Time to full intimate contact as a function of temperature for isothermal conditions. (b) Intimate contact development of the baseline surface profile for isothermal and non-isothermal conditions.

while full intimate contact is achieved within 12 seconds for the isothermal case.

\subsection{Application and Discussion}

\subsubsection{Processing window}

From Sections 4.3 .2 and 4.3 .3 there seem to be clear correlations between intimate contact development and the geometrical parameters of the prepreg thickness profile and material and process parameters. In fact, the relations found in Sections 4.3.2 and 4.3 .3 can be combined to show that $t_{i c} \propto \eta_{T} P_{\text {app }}^{-1} h_{0}^{-3} A \lambda^{2}$. This relation can be explained by looking at Fig. 4.10 (a). The development of intimate contact requires that the flow of material occurs, such that a volume of the size of the peaks is displaced towards the valleys of the thickness profile. The time required to displace this volume is proportional to the volume itself and the distance of displacement, while it is inversely proportional to the volumetric flow rate, i.e. $t_{i} c \propto V \Delta x Q^{-1}$. In case of Fig. 4.10 (a), the displaced volume $V$ is proportional to $A \lambda$ and the displacement distance $\Delta x$ to $\lambda$. In case of pure shear flow, the velocity profile over the thickness is parabolic and the average flow rate $Q$ is proportional to $P_{\text {app }} \eta_{T}^{-1} h_{0}^{3}$ [2]. Hence, $t_{i c}=C \eta_{T} P_{\text {app }}^{-1} h_{0}^{-3} A \lambda^{2}$, where $C$ is a proportionality constant. For a two-ply cross-ply lay-up the two flow directions in the stack are perpendicular. Therefore the flow in the two plies is coupled and the time to full intimate contact increases. In case of an identical profile in each ply, the time to full intimate contact is twice that of the a single ply. Note that this relies on the assumption that the fibers in each ply remain parallel, which may be violated in a cross-ply lay-up. 
The constant $C$ can be found by fitting the function $t_{i c}=C \eta_{T} P_{\text {app }}^{-1} h_{0}^{-3} A \lambda^{2}$ to the solution of 100 simulations with random geometrical, material and processing parameters from the ranges listed in Tbls. 4.1 and 4.2. Figure 4.10 (b) shows the time to full intimate contact for a single ply as a function of the dimensionless geometrical parameter $h_{0}^{-3} A \lambda^{2}$ and the material and processing parameter $\eta_{T} P_{\text {app. }}^{-1}$. A blue star $\left.{ }^{*}\right)$ marks the case for the baseline parameters of Tbl. 4.1 and 4.2. As can be seen, the window for rapid intimate contact development is very small. Minimization of the time to full intimate contact requires a low $h_{0}^{-3} A \lambda^{2}$ and a low $\eta_{T} P_{\text {app }}^{-1}$. While the ply thickness $h_{0}$ is typically fixed due to the desired mechanical performance, both $A$ and $\lambda$ can be minimized by improving dimensional control during the prepreg manufacturing process. Here, reducing the wavelength of the profile is most efficient due to the quadratic relation. The transverse viscosity is mostly fixed by the used matrix material and fiber volume fraction, again based on the desired performance. However, the viscosity can be reduced by an increased consolidation temperature, although the window for increasing the temperature is usually small. The window for increasing the consolidation pressure is much larger and mainly limited by the equipment.

Figure 4.11 shows an example of a thickness profile of a $150 \mathrm{~mm}$ wide TenCate Cetex $^{\circledR}$ TC1200 C/PEEK prepreg which was measured in Chapter 3 using a micrometer with $3 \mathrm{~mm}$ radius tip. An average of five profile measurements at different locations along the length of the prepreg is shown. Looking at the profile, there appears to be a dominant wave with $h_{0} \approx 150 \mu \mathrm{m}, \lambda \approx 75 \mathrm{~mm}$ and $A \approx 5 \mu \mathrm{m}$ and hence, $h_{0} A \lambda^{2} \approx 8333$. According to Fig. 4.10 and assuming the baseline pressure and transverse viscosity, full intimate contact development will take at least 75 seconds for this profile.

The processing window will be even smaller for the non-isothermal conditions experienced during stamp forming. Figure 4.12 compares the time required for intimate contact development of a single ply as a function of the geometrical parameters for isothermal and non-isothermal conditions at a pressure of 100 bar. The cooling curve from Fig. 4.9 (b) is applied for non-isothermal conditions. For small $h_{0}^{-3} A \lambda^{2}$, the non-isothermal curve remains close to the $390{ }^{\circ} \mathrm{C}$ isothermal curve. The inflection point is at $h_{0}^{-3} A \lambda^{2} \approx 1300$, at which intimate contact development takes roughly 5 seconds. For larger values of $h_{0}^{-3} A \lambda^{2}$, the time to full intimate contact increases rapidly and approaches the $250{ }^{\circ} \mathrm{C}$ isothermal curve. Cooling must be delayed in order to shift the non-isothermal curve to the right for these profiles. For example, keeping the temperature at $390{ }^{\circ} \mathrm{C}$ for 15 seconds before cooling to $250{ }^{\circ} \mathrm{C}$ could be sufficient for achieving full intimate contact using the experimental profile with $h_{0} A \lambda^{2} \approx 8333$. However, this requires tooling that can rapidly heat and cool instead of isothermal tooling in order to maintain short cycle times. This could for example be achieved by using induction heating in combination with water cooling. 


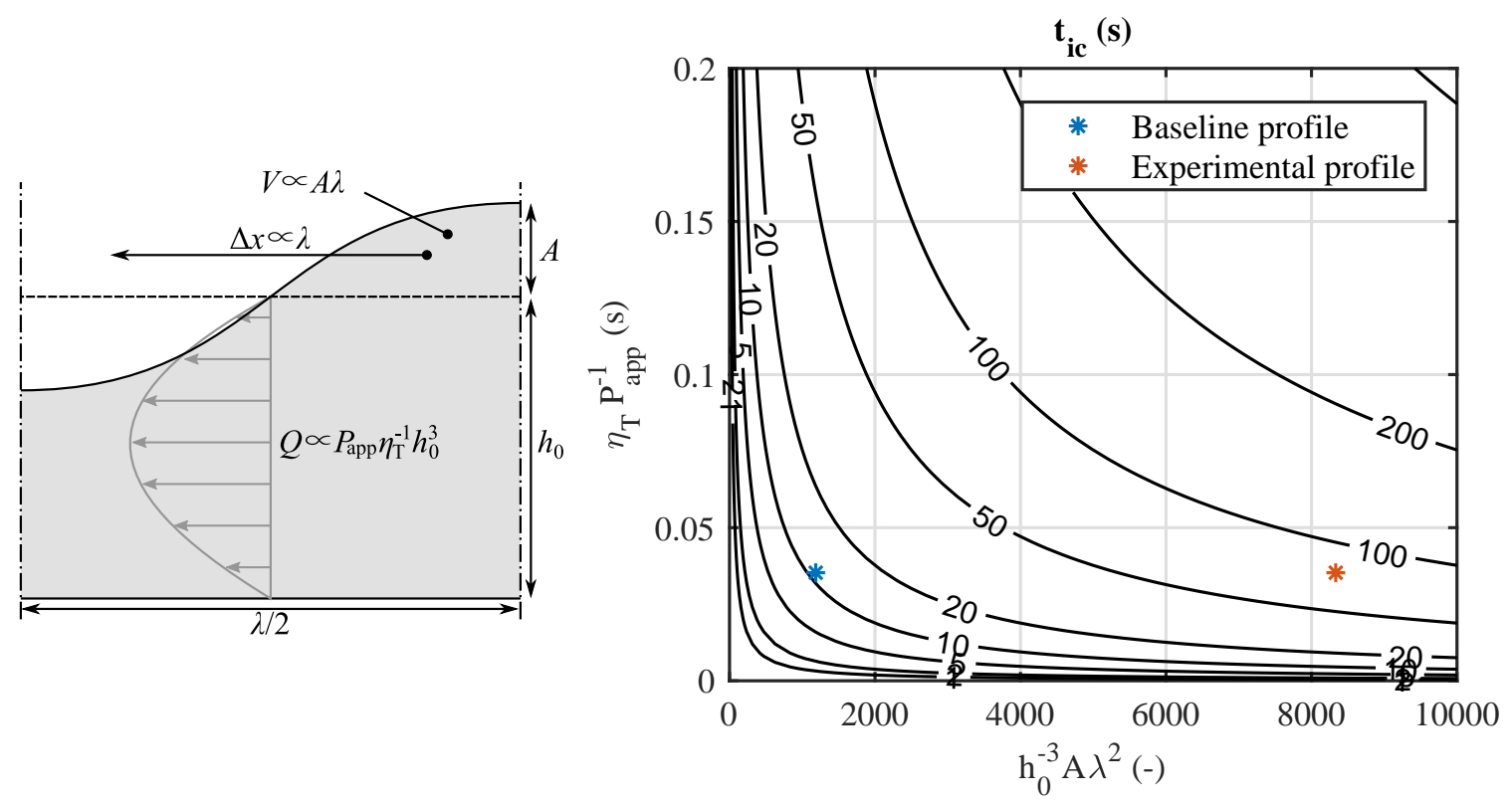

(a)

(b)

Figure 4.10 (a) Representation of the idealized surface profile and relevant parameters (b) Time to full intimate contact for a single ply as a function of geometrical, material and processing parameters. Baseline profile: $h_{0}=150 \mu \mathrm{m}, A=10 \mu \mathrm{m}, \lambda=20 \mathrm{~mm}$, $\eta_{T}=7.06 \times 10^{-4} \mathrm{~Pa} \cdot \mathrm{s}$ and $P_{\mathrm{app}}=20 \times 10^{5} \mathrm{~Pa}$. Experimental profile: $h_{0}=150 \mu \mathrm{m}$, $A=5 \mu m, \lambda=75 \mathrm{~mm}, \eta_{T}=7.06 \times 10^{-4} \mathrm{~Pa} \cdot \mathrm{s}$ and $\mathrm{P}_{\mathrm{app}}=20 \times 10^{5} \mathrm{~Pa}$.

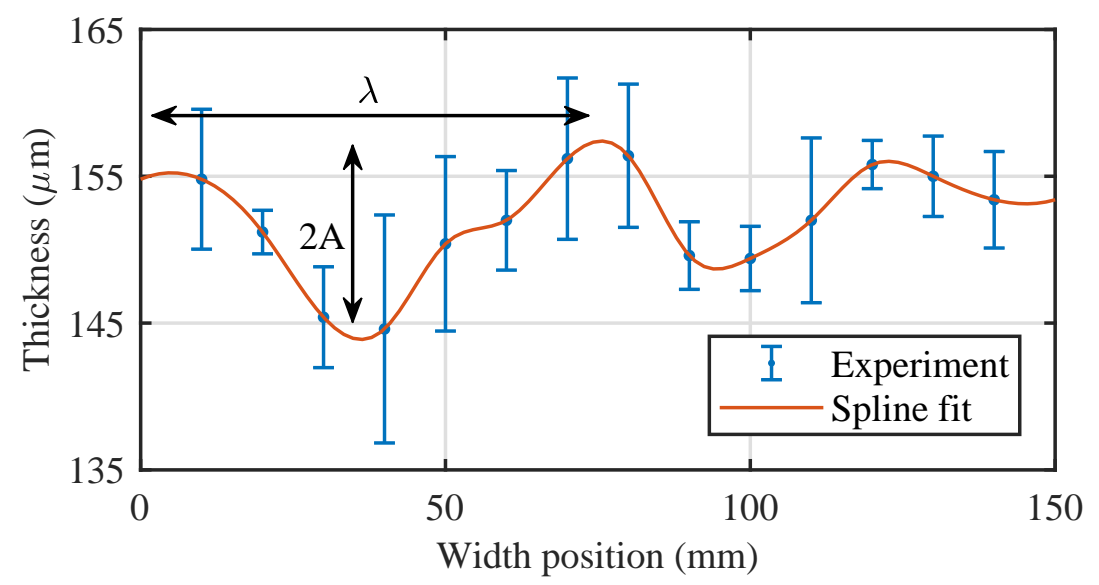

Figure 4.11 Experimental profile geometry for a TenCate Cetex ${ }^{\circledR}$ TC1200 C/PEEK prepreg. Average of five measurements along the length of the prepreg using a micrometer with $3 \mathrm{~mm}$ radius tip. 


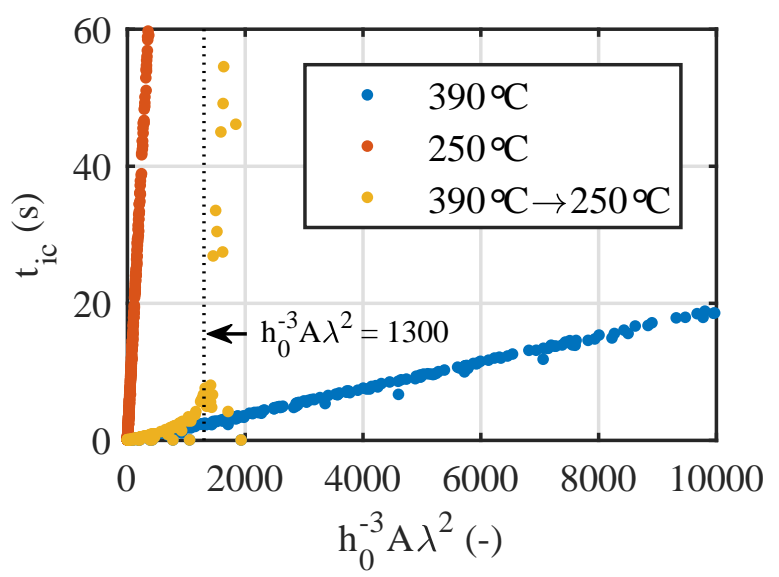

Figure 4.12 Time to full intimate contact development for a single ply as a function of the geometrical parameters at isothermal and non-isothermal conditions and a pressure of $100 \mathrm{bar}$.

\subsubsection{Material characterization}

The development of intimate contact is highly sensitive to the temperature dependency of the transverse viscosity, which is determined by the used Arrhenius constants. Table 4.3 lists Arrhenius constants found in literature for C/PEEK material. The viscosity at relevant processing temperatures based on these constants is shown in Fig. 4.13. As can be seen, the various references do not agree well on the temperature dependency of the transverse viscosity. The outcome of the model will therefore vary drastically depending on the used Arrhenius constants, as the intimate contact development is proportional to the transverse viscosity. Intimate contact development will be even more sensitive for non-isothermal conditions. Despite this, the trends observed in this work will remain the same, regardless of the set of constants used. The Arrhenius constants provided by Khan et al. [12] provide a rough average and will be applied for the remainder of this work. However, proper material characterization is recommended for accurate prediction of intimate contact development.

The current model assumes a homogenized equivalent transverse viscosity of the composite. While this assumption seems valid for prepregs with a uniform fibermatrix distribution, it may not be for a prepreg with a more non-uniform fiber matrix distribution. Additionally, the presence of a matrix rich surface may affect the toolply and ply-ply friction.

\subsubsection{Experimental validation}

The model can be validated by comparing the model with C-scans of stamp formed blanks from experimental work performed in Chapter 3. The results of the experiments performed on blanks produced by ultra-sonic spot welding 
Table 4.3 Arrhenius constants for C/PEEK found in literature.

\begin{tabular}{l|ccc}
\hline Reference & Material & $\left.\eta_{\mathbf{0}} \mathbf{( P a} \cdot \mathbf{s}\right)$ & $\mathbf{B ~ ( 1 / K )}$ \\
\hline Lee \& Springer (1987) [3] & Cytec APC-2 & $1.14 \times 10^{-12}$ & 26300 \\
Mantell \& Springer (1992) [4] & Cytec APC-2 & 132.95 & 2969 \\
Phillips (1996) [13] & Cytec APC-2 & $5.66 \times 10^{-8}$ & 19032 \\
Khan et al. (2010) [8] & Suprem T & 643 & 4367 \\
Khan et al. (2013) [12] & C/PEEK & 0.0037 & 11115 \\
\hline
\end{tabular}

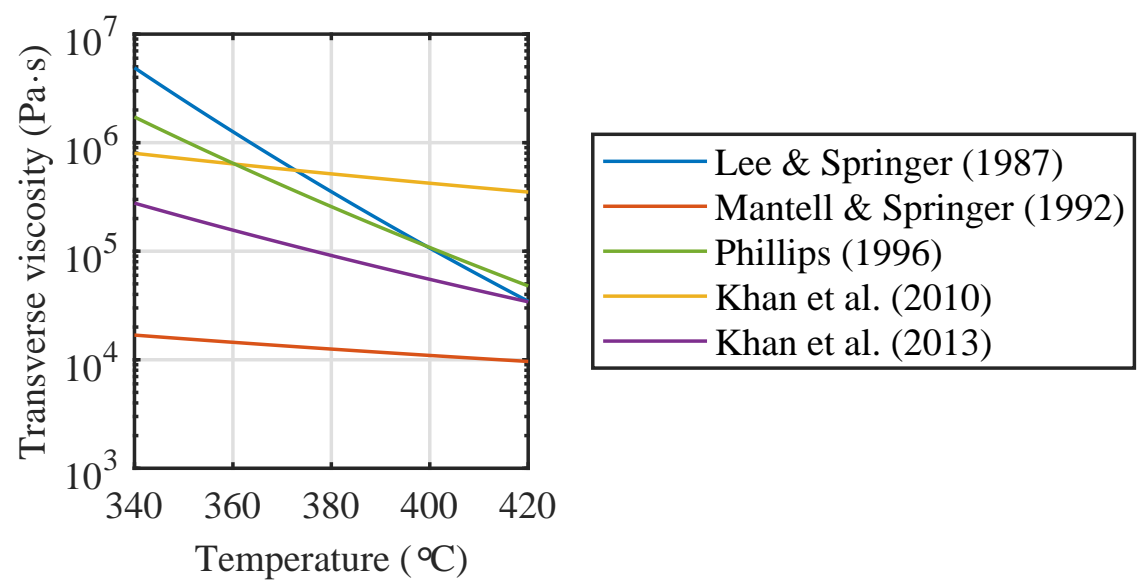

Figure 4.13 Transverse viscosity for C/PEEK as a function of temperature for various Arrhenius constants found in literature.

(USSW) of TenCate Cetex ${ }^{\circledR}$ TC1200 C/PEEK prepreg are used as an example. The thickness profile of the prepreg and stacking pattern of the lay-up and the processing conditions are readily available.

The thickness profile of the prepreg was already shown in Fig. 4.11. The profile was discretized into 25 elements ( $6 \mathrm{~mm}$ per element) across its width. This number of elements was found to be sufficient for a good approximation of intimate contact development, as the solution converges rapidly with the number of elements due to the large wavelength and low amplitude of the thickness profile. Intimate contact development for the $\left[0^{\circ} / 90^{\circ}\right]_{4 s}$ lay-up can be approximated by simulating only a $\left[0^{\circ} / 90^{\circ}\right]_{S}$ stack, since all plies with the same orientation exhibit identical flow behavior. In case of the experimental work, both the $0^{\circ}$ and $90^{\circ}$ plies were rotated by $180^{\circ}$ along the $0^{\circ}$ orientation on the plane of symmetry. The resulting thickness distribution of the stack is shown in Fig. 4.14 (a).

The temperature was found to decrease almost linearly from the blank temperature to the tooling temperature in approximately 10 seconds. Figure 4.14 (b) shows the first 30 seconds of the approximated cooling curves for a blank temperature of 390 and $420{ }^{\circ} \mathrm{C}$, with a cooling rate of -14 and $-17^{\circ} \mathrm{C} / \mathrm{s}$, respectively. The tool temperature was $250^{\circ} \mathrm{C}$. The average applied pressure was constant at either 20 bar or 100 bar during the 60 second cooling and consolidation step. Thermal gradients through the 


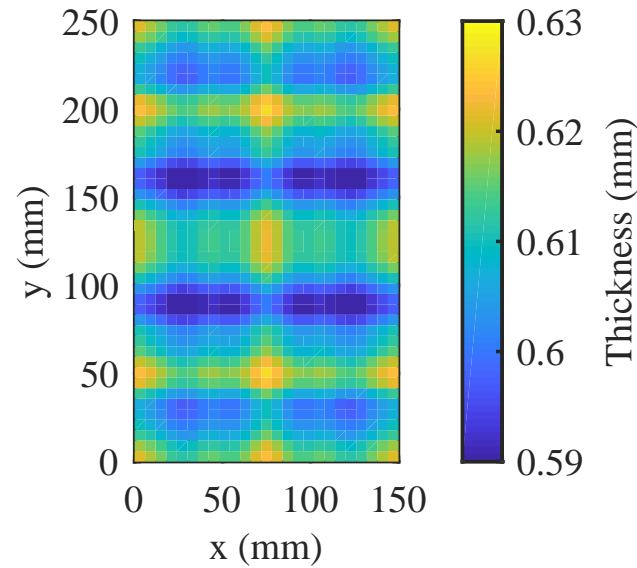

(a)

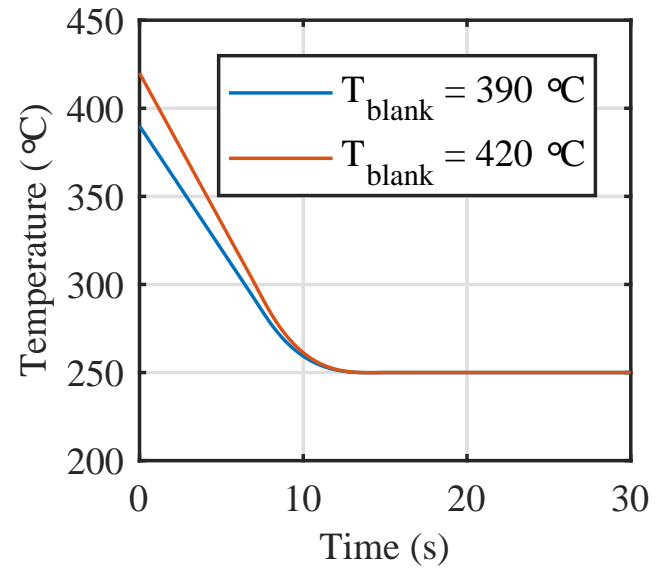

(b)

Figure 4.14 (a) Total stack thickness of a $\left[0^{\circ} / 90^{\circ}\right]_{s}$ lay-up. (b) Approximated cooling curves for different blank temperatures.

thickness of the blank were found to be negligible in the experimental work.

Figure 4.15 (a) shows the resulting intimate contact development predictions for the two blank temperatures and pressures. The model predicts a significant difference for the blank temperature and pressure used in the experimental work. While $390{ }^{\circ} \mathrm{C}$ and 20 bar only results in $52 \%$ intimate contact, $420{ }^{\circ} \mathrm{C}$ and 100 bar yields $91 \%$. Nearly all contact is developed during the first 5 seconds after closing of the tooling, after which the temperature has dropped so much that almost no further material flow occurs due to the increase in viscosity.

Figure 4.15 compares the results of the simulations with the C-scans of the stamp formed blanks. The black areas in the C-scan indicate poor intimate contact between the plies, while the bright areas indicate good contact. At $390{ }^{\circ} \mathrm{C}$ and 20 bar there is insufficient flow to eliminate thickness variations in the blank, resulting in poor intimate contact $4.15(\mathrm{~b}))$. The model is able to capture the pattern found in the Cscan as a result of these thickness variations $4.15(\mathrm{a}))$. Note that this pattern closely resembles the thickness distribution found in Fig. 4.14 (b). At $420{ }^{\circ} \mathrm{C}$ and 100 bar there is much more flow due to the increased blank temperature and pressure and most thickness variations are eliminated. A much higher degree of intimate contact is achieved $4.15(\mathrm{~d}))$, which is also captured by the model $(4.15(\mathrm{c}))$, although the pattern slightly different. The differences between the model and experiments can most likely be explained by the use of the averaged thickness profile in the model, which is assumed constant along the length of the prepreg. In reality, some variation in the profile is present, especially at the position where the differences between the model and experiment occur (e.g. $x=40 \mathrm{~mm}$ ), as can be seen in Fig. 4.11. Despite these small differences, the results give confidence that the model can be used for further evaluation of intimate contact development during stamp forming 
of automated lay-up blanks.

Figure 4.15 (a) also shows additional simulations at a blank temperature and pressure of $390^{\circ} \mathrm{C}$ and $100 \mathrm{bar}$, and $420^{\circ} \mathrm{C}$ and 20 bar, respectively. This demonstrates that the effect on intimate contact development is much larger for an increased pressure than for an increased blank temperature. This was also observed in Chapter 3 for AFP blanks, where no improvement in the C-scans was seen for an increased blank temperature.

\subsubsection{Optimization of USSW blank lay-up}

Stamp forming only allows a very short time for intimate contact development due to the high cooling rate. For blanks produced by rapid automated lay-up, such as USSW, this time may be too short for full intimate contact development, as was experienced in 4.4.3. From Sections 4.3.2 and 4.4.3 it is evident that intimate contact development is very much dependent on the thickness profile of the prepreg and the resulting blank thickness distribution after stacking the prepreg into a blank. In order to minimize the time required for intimate contact development, two strategies can be applied. The first strategy is optimizing the prepreg thickness profile, which was discussed in Section 4.4.1. The second strategy is optimizing the lay-up strategy. This can be done by applying a smart stacking pattern for plies with the same fiber orientation that minimizes the thickness variation of the total stack. In this way, less flow is required to generate intimate contact for the full stack.

A simple way of doing this is by staggering plies with the same orientation, i.e. applying a shift transverse to the fiber direction, as illustrated in Fig. 4.16 (a). The effect of staggering can be demonstrated using the baseline profile and material and process parameters used in Section 4.3 . The profile is stacked into a $\left[0^{\circ} / 0^{\circ}\right]$ lay-up, where the second ply is shifted with respect to the first ply. The staggering shift is varied between 0 and $\lambda / 2$. The simulated domain includes 20 waves in order to reduce boundary effects, as the periodic boundary conditions are no longer valid once a shift is applied. Figure 4.16 (b) shows the total thickness of the stack, zoomed on a single wave for various staggering shifts. As the staggering shift increases towards $1 / 2 \lambda$, the total thickness variation of the stack is reduced, since the peaks and valleys of the profile start canceling each other out. Figure 4.16 (c) shows the influence of the applied staggering shift on the time required to reach full intimate contact for the isothermal simulations. The time to full contact decreases drastically for increasing staggering shift due to a reduction of thickness variation in the total stack.

The same strategy can be applied on the stamp forming of a USSW blank manufactured from prepreg with the thickness profile from Fig. 4.11. The prepreg is stacked into $\left[0^{\circ} / 90^{\circ}\right]_{6}$ cross-ply stacks where, for each ply with the same orientation, the thickness profile of each ply is shifted to the left by a certain staggering shift with respect to the previous ply. Figure 4.17 (a) and (b) show examples of the 

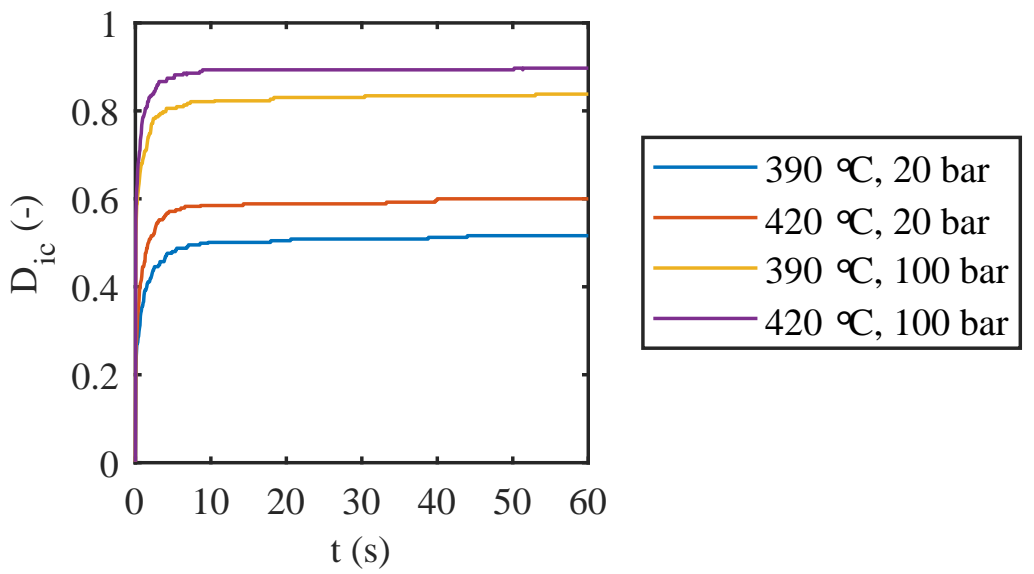

(a)

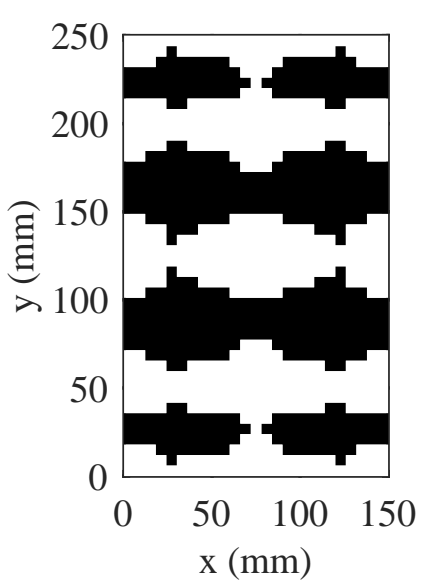

(b) $390{ }^{\circ} \mathrm{C}, 20$ bar

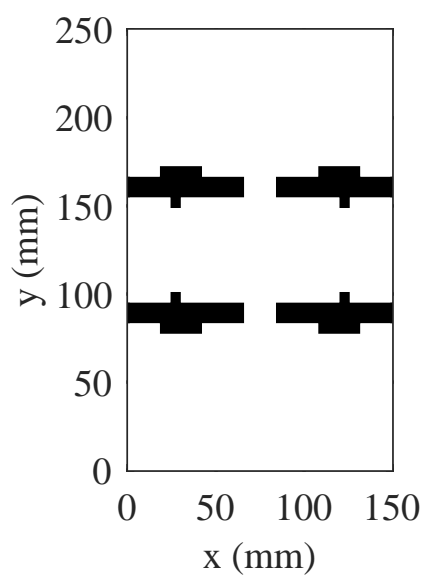

(d) $420{ }^{\circ} \mathrm{C}, 100 \mathrm{bar}$

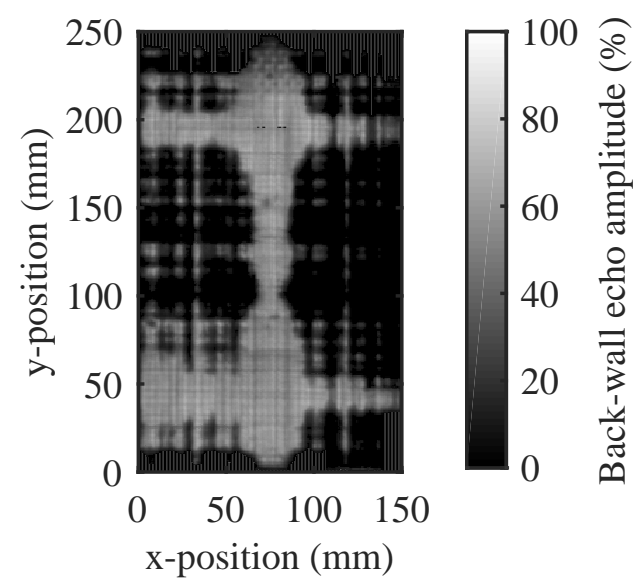

(c) $390{ }^{\circ} \mathrm{C}, 20 \mathrm{bar}$

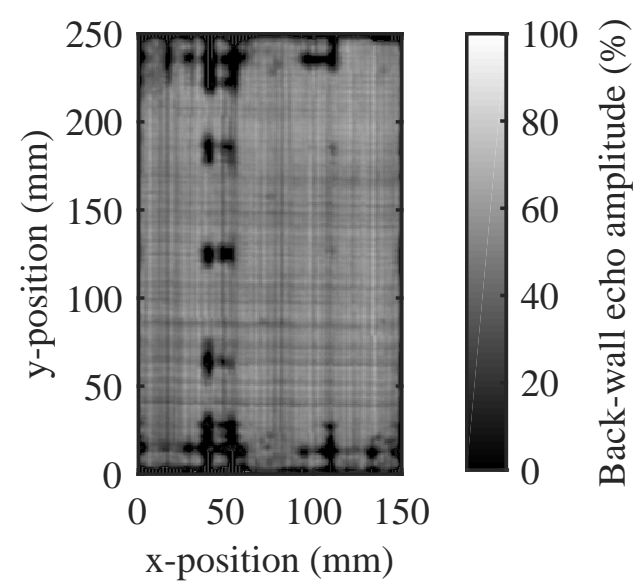

(e) $420{ }^{\circ} \mathrm{C}, 100 \mathrm{bar}$

Figure 4.15 (a) Intimate contact development simulations for the $\left[0^{\circ} / 90^{\circ}\right]_{s}$ stack for various blank temperatures and pressures. $(b, d)$ Simulated intimate contact after 60 seconds (white $=$ contact, black $=$ no contact) and $(c, e)$ experimental $C$-scans (grey $=$ good contact, black $=$ poor contact) of stamp formed USSW blanks at different blank temperature and pressure. 


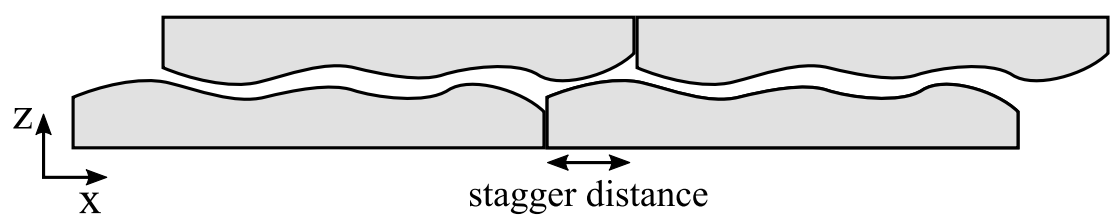

(a)

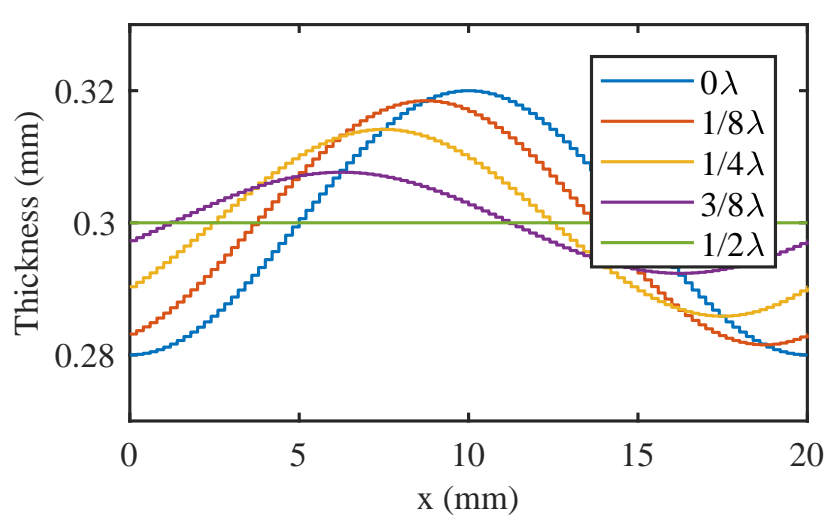

(b)

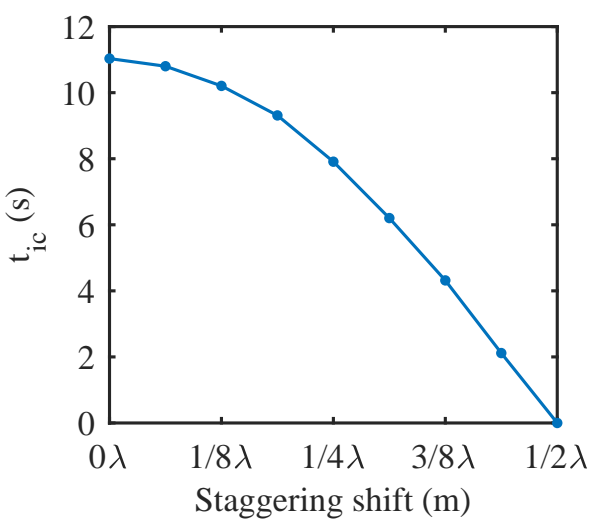

(c)

Figure 4.16 (a) Staggering of plies with the same orientation by a transverse shift in order to reduce thickness variation of the stack. (b) Total thickness of a $\left[0^{\circ} / 0^{\circ}\right]$ stack for various staggering shifts using the baseline profile. (c) Time to full intimate contact as a function of the applied staggering shift.

total stack thickness for a $0 \mathrm{~mm}$ and $25 \mathrm{~mm}$ shift, respectively. Both the amplitude and wavelength of the total thickness profile is reduced by reducing the staggering shift. The non-isothermal cooling curve for a blank temperature of $390{ }^{\circ} \mathrm{C}$ and a pressure of 20 bar were applied to simulate the stamp forming process. Figure 4.17 shows the simulation results for the various staggering shifts on intimate contact development. The effect on intimate contact development is small up to a staggering shift of $50 \mathrm{~mm}$, but the achieved degree of intimate contact increases drastically for a shift of $37.5 \mathrm{~mm}$. This shift cancels out the large amplitude of the most dominant wavelength of the profile $(\lambda \approx 75 \mathrm{~mm}$ ). For an even smaller staggering shift of $25 \mathrm{~mm}$ the thickness variations have become so small that full intimate contact is achieved almost instantaneously. On the one hand, this demonstrates how effective staggering can be for achieving intimate contact in rapid lay-up blanks during stamp forming, especially when the shifts are small compared to the width of the prepreg. On the other hand, the results demonstrate that stacking the plies without a staggering shift should be avoided, as this maximizes the time required for full intimate contact development by placing the peaks on the peaks and valleys on the valleys. However, while staggering is clearly beneficial for enhanced consolidation, it may introduce additional cutting loss. 


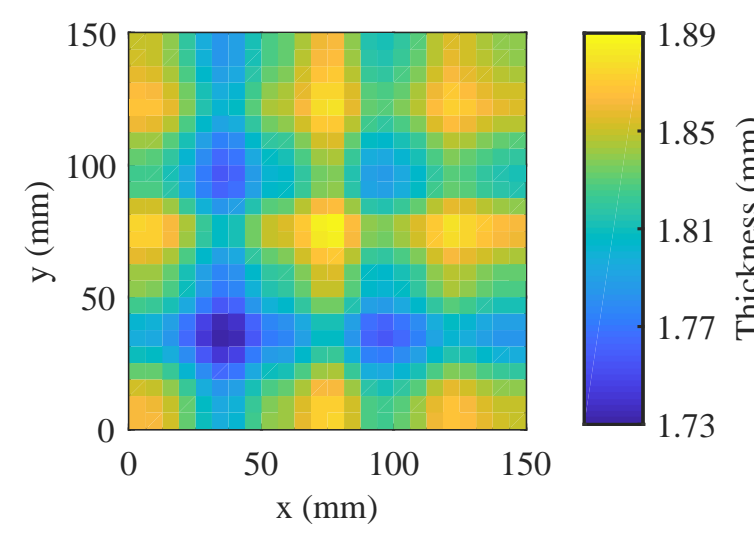

(a)

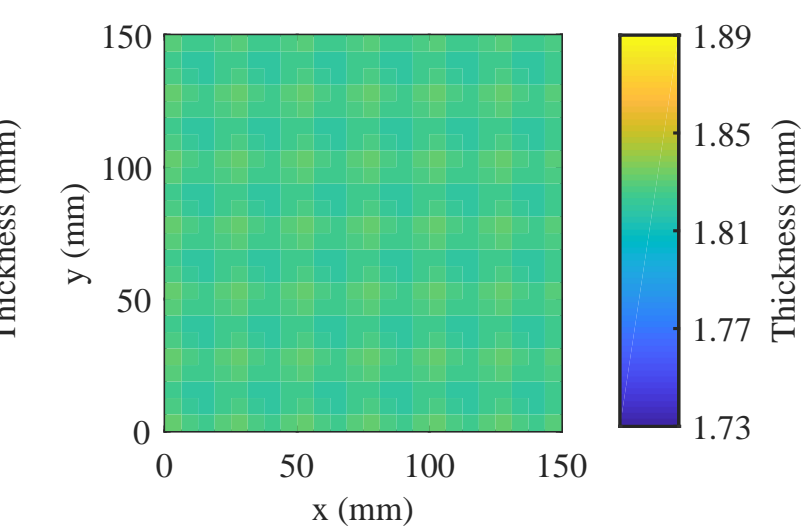

(b)

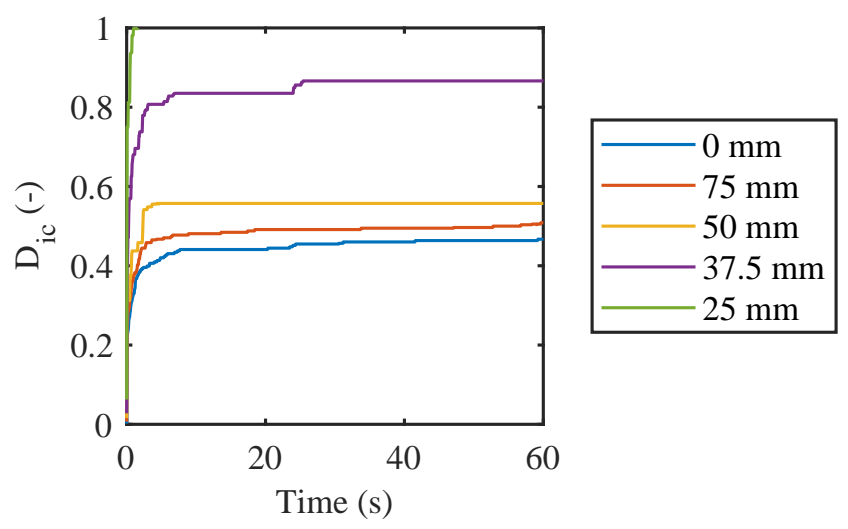

(c)

Figure 4.17 Total stack thickness of the $\left[0^{\circ} / 90^{\circ}\right]_{6}$ lay-up for a staggering shift of $(a) 0 \mathrm{~mm}$ and $(b)$ $25 \mathrm{~mm}$. (c) Intimate contact development under non-isothermal conditions for various staggering distances at a pressure of 20 bar.

\subsubsection{Optimization of AFP blank lay-up}

Blank produced by AFP experience similar thickness variations as blanks produced by USSW. However, in this case the thickness variations in a ply and blank are governed by the thickness of each tow used in the lay-up process. Given that it is common practice in industry to slit these tows from a wider prepreg, the thickness variations observed in the prepreg will continue to exist as tow-to-tow thickness variations after slitting. An advantage of these slit tows is that the thickness profile that existed in the prepreg now can be manipulated by rearranging the tows in such a way that intimate contact development is improved. This is an interesting benefit of the AFP process, although it requires the measurement of the thickness of the slit tows.

Consider the $150 \mathrm{~mm}$ wide prepreg thickness profile from Fig. 4.14 (a), which is slit into 24 tows of $6.25 \mathrm{~mm}$ wide $(\approx 1 / 4$ inch), a common tow width used in industry. 


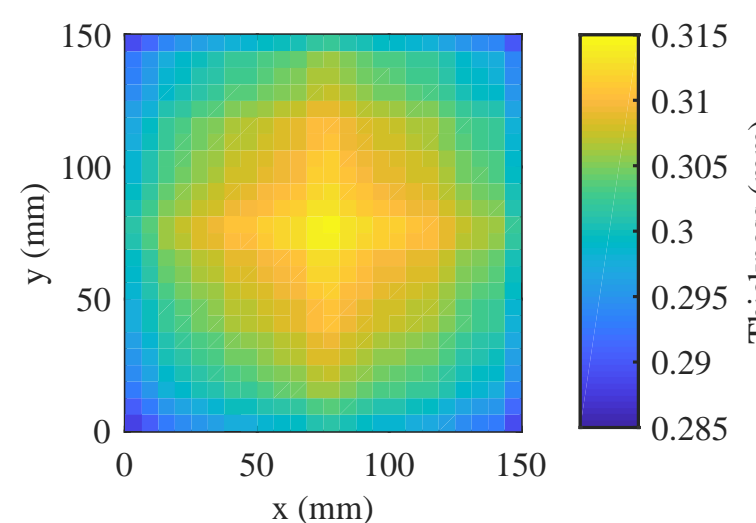

(a)

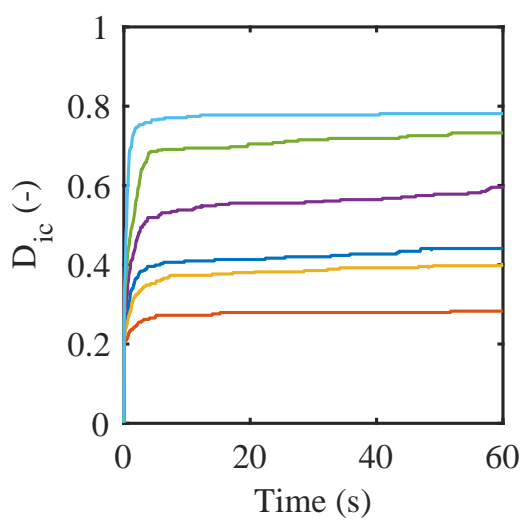

(c)

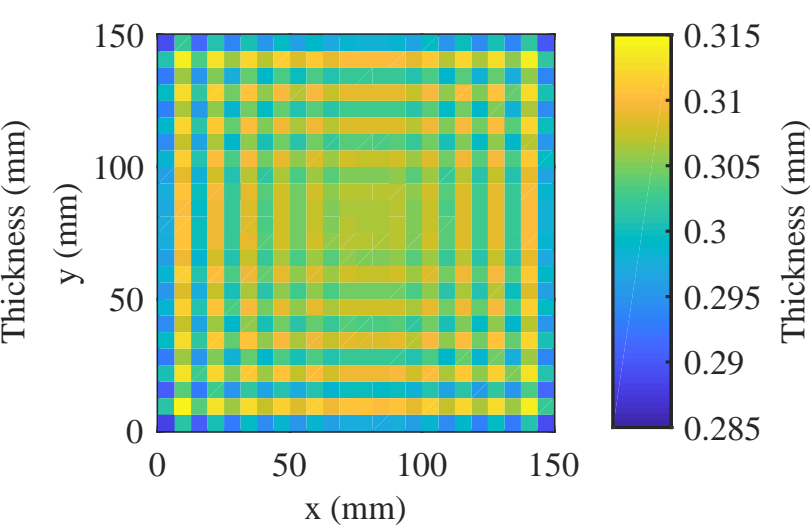

(b)

Figure 4.18 Total stack thickness of the $\left[0^{\circ} / 90^{\circ}\right]$ lay-up for a tow rearrangement with a wavelength of (a) 24 tows and (b) 2 tows. (c) Intimate contact development under non-isothermal conditions for the original and rearranged tow orders at a pressure of 20 bar. (d) Time to full intimate contact development under non-isothermal conditions for a $\left[0^{\circ} / 90^{\circ}\right]$ lay-up with $\lambda=2$ tows as a function of tow-to-tow thickness variation at a pressure of 100 bar.

These tows can now be rearranged such that a wave-like ply profile appears when the tows are placed by a 24-tow AFP machine. The order of the tows can be used to control the wavelength of the profile that is created during lay-up and thus, according to Section 4.3.2, the development of intimate contact. The rearranged profile is stacked into a $\left[0^{\circ} / 90^{\circ}\right]$ cross-ply blank, which is stamp formed using the nonisothermal cooling curve for a blank temperature of $390{ }^{\circ} \mathrm{C}$ and a pressure of 20 bar. Figure 4.18 (a) gives an example of the stack thickness for a rearrangement with a wavelength of 24 tows, which is the largest possible wavelength that can be formed with the 24 tows and provides a worst case scenario. Figure 4.18(b) shows a best-case rearrangement with the smallest possible wavelength of 2 tows. Periodic boundary conditions are applied to all four edges. Figure 4.18 (c) compares simulation results on intimate contact development for the original tow order with the rearranged tows. Reordering the tows indeed does show to have a large influence on intimate contact 
development. Minimizing the wavelength of the rearranged profile by alternating thick and thin tows yields the fastest intimate contact development.

Even with the most optimal tow arrangement, full intimate contact is not achieved at a pressure of 20 bar for this particular prepreg thickness profile. The maximum tow-to-tow thickness variation $\Delta h$ for a pressure of 100 bar can be estimated based on Fig. 4.12, which showed that $h_{0}^{-3} A \lambda^{2}$ must be smaller than 1300 . This will be $h_{0}^{-3} A \lambda^{2}<650$ for a cross-ply lay-up. For an average prepreg thickness of $150 \mu \mathrm{m}$ and a wavelength of $12.5 \mathrm{~mm}(2 \times 6.25 \mathrm{~mm})$, this estimates a maximum tow-to-tow thickness variation of $28 \mu \mathrm{m}(\Delta h=2 \times A)$. This value is confirmed by simulations, as shown in Fig. $4.18(\mathrm{~d})$.

\subsection{Conclusions and Recommendations}

The combination of rapid automated lay-up and stamp forming is a potential interesting processing route for manufacturing load carrying tailored components. However, the short time available for consolidation during stamping demands an optimal state of the blank. Especially thickness variations in a blank were found to limit intimate contact development during stamping. These thickness variations originate from a non-uniform prepreg thickness. The influence of the prepreg thickness profile and material and processing parameters on intimate contact development was studied here, aiming to develop guidelines for prepreg design, stacking strategies during lay-up and stamp forming.

A novel consolidation model was developed that is able to predict intimate contact development in a multi-ply lay-up. The model is based on transverse squeeze flow over the entire height of the prepreg thickness profile, rather than the deformation of surface asperities commonly found in models in literature. The model is used to perform a parameter study on a simplified wave-like thickness profile in order to investigate the influence of the geometrical parameters of the thickness profile and the influence of material and processing parameters.

The parameter study has revealed that the time required to reach intimate contact for a thickness profile with a single wave and under isothermal conditions is dominated by the wavelength of the profile. Intimate contact development stagnates quickly during stamp forming due to the high cooling rate that the material experiences once the tooling is closed. For the highly non-isothermal conditions experienced during stamp forming intimate contact has to be developed within several seconds.

The model was validated by reproducing earlier experimental work on stamp formed USSW blanks. Although the model is sensitive to proper material characterization, it was able to capture the patterns observed in intimate contact after stamping in the experimental work. These patterns can be related to the prepreg thickness variations and the applied stacking pattern. The influence of pressure on intimate contact was 
found to be larger than the influence of blank temperature, which is in line with the experimental work.

With the knowledge from the parameter study, some strategies were proposed for minimizing the time required for full intimate contact development and demonstrated for USSW and AFP blank lay-up. They can be summarized into the following guidelines:

- Staggering plies during lay-up significantly reduces the time required to full intimate contact due to averaging of the total thickness profile of the stack.

- Arranging prepreg tows in an AFP machine such that the wavelength of the resulting thickness profile is minimized, i.e. by alternating thick and thin tows, enhances intimate contact development.

The current work has provided valuable insight in intimate contact development during consolidation processes, in particular during stamp forming of blanks produced by rapid lay-up. It was shown that the thickness profile of the prepreg used to manufacture the blank plays a key role in the consolidation process. By using the gained knowledge, strategies were developed for minimizing the time required for intimate contact development, which is essential for the successful application of rapid lay-up followed by stamp forming.

\section{References}

[1] F. N. Cogswell. Thermoplastic Aromatic Polymer Composites. Butterworth-Heinemann Ltd, Oxford, 1992.

[2] T. G. Rogers. Squeezing flow of fibre-reinforced viscous fluids. Journal of Engineering Mathematics, 23(1):81-89, 1989.

[3] W. I. Lee and G. S. Springer. A Model of the Manufacturing Process of Thermoplastic Matrix Composites. Journal of Composite Materials, 21, 1987.

[4] S. C. Mantell and G. S. Springer. Manufacturing Process Models for Thermoplastic Composites. Journal of Composite Materials, 1992.

[5] F. Yang and R. Pitchumani. Interlaminar contact development during thermoplastic fusion bonding. Polymer Engineering \& Science, 42(2):424-438, 2002.

[6] P. H. Dara and A. C. Loos. Thermoplastic Matrix Composite Processing Model. Ph.D. thesis, Virginia Polytechnic Insitute and State University, 1985.

[7] F. O. Sonmez and H. T. Hahn. Analysis of the on-line consolidation process in thermoplastic composite tape placement. Journal of Thermoplastic Composite Materials, 10(6):543-572, 1997.

[8] M. A. Khan, P. Mitschang, and R. Schledjewski. Identification of Some Optimal Parameters to Achieve Higher Laminate Quality Through Tape Placement Process. Advances in Polymer Technology, 29(2):98-111, 2010. 
[9] W. J. B. Grouve. Weld Strength of Laser-Assisted Tape-Placed Thermoplastic Composites. Ph.D. thesis, University of Twente, 2012.

[10] P. M. Schaefer, T. Guglhoer, M. G. R. Sause, and K. Drechsler. Development of intimate contact during processing of carbon fiber reinforced Polyamide- 6 tapes. Journal of Reinforced Plastics and Composites, 36(8):593-607, 2017.

[11] S. Haanappel. Forming of UD fibre reinforced thermoplastics: a critical evaluation of intra-ply shear. Ph.D. thesis, University of Twente, Enschede, The Netherlands, 2013.

[12] M. A. Khan, P. Mitschang, and R. Schledjewski. Parametric study on processing parameters and resulting part quality through thermoplastic tape placement process. Journal of Composite Materials, 47(4):485-499, 2013.

[13] R. Phillips. Consolidation and solidification behavior of thermoplastic composites. Ph.D. thesis, École Polytechnique Fédérale de Lausanne, 1996. 


\title{
Chapter 5
}

\section{Consolidation of Ply-drops in Tailored AFP Blanks by Stamp Forming}

\begin{abstract}
Rapid blank lay-up by AFP, followed by stamp forming, offers a potential solution for the rapid manufacturing of tailored thermoplastic composite components. However, the high cooling rates during stamping make consolidation of the blank challenging, especially in the ply-drop regions. Improved understanding of the filling behavior of ply-drop pockets in tailored AFP blanks is essential for the successful application of the process route for high performance structural components. An experimental study was performed where AFP blanks with various ply-drop configurations were stamp formed and their consolidation quality was characterized. The influence of lay-up on the consolidation behavior was investigated, as well as the sensitivity to placement inaccuracies or blank misalignments. Transverse flow of the dropped and surrounding plies was identified as the dominant filling mechanism and ply-drop design guidelines were developed. This provides an important step forward in the application of rapid AFP followed by stamp forming for the manufacturing of tailored components for structural applications.
\end{abstract}




\subsection{Introduction}

Fiber reinforced composites offer a unique potential for the lightweight design of structural components thanks to the tailorability of the lay-up. Material use can be minimized, thus saving both weight and cost, by placing the fibers in such a way that their location and fiber orientation provide optimum use of their stiffness and strength when a load is exerted on the component. Additionally, thermoplastic composites offer additional benefits over thermoset composites for automated high volume manufacturing thanks to their weldability, formability and lack of lengthy curing cycle. However, high volume production of thermoplastic composites is still challenging, as the past decades have shown. Current manufacturing methods therefore still often rely on consolidation processes with long cycle times, like press or autoclave consolidation. Moreover, mostly simple non-tailored uniform thickness lay-ups are applied and thus the full potential of the composite material is not yet exploited.

The development of automated lay-up technologies, such as advanced fiber placement (AFP), has provided new opportunities for the manufacturing of tailored thermoplastic composite components. As a key benefit, AFP offers a high lay-up flexibility, which allows for local reinforcements and tailored lay-ups, optimizing the performance/weight ratio of components. AFP with in-situ consolidation offers a promising manufacturing route for large and complex components. For this reason, in-situ consolidation has been and still is a topic of extensive research. However, up to now in-situ AFP at acceptable deposition rates remains challenging and is rarely found in industrial applications. Alternatively, a two step approach for the manufacturing of smaller components has been proposed in Chapter 1. In this approach, the focus is on rapid lay-up with AFP, rather than in-situ consolidation, of a flat tailored blank. The final consolidation quality and shape of the component are obtained by stamp forming this blank. The ability to consolidate the component by means of stamp forming allows for a lower initial blank quality (e.g. containing voids or having limited interlaminar bonding) and therefore higher lay-up rates during blank manufacturing. The short cycle times and ability to apply tailored lay-ups makes the process route a potential solution for the rapid manufacturing of tailored composite components.

A major challenge with this process route is achieving a good consolidation quality after stamp forming by eliminating voids and developing interlaminar bonding. The process window for these consolidation mechanisms is very small due to the high cooling rates experienced by the material during stamp forming once the blank comes in contact with the cold tooling. However, in Chapter 3 the process route has been successfully demonstrated on flat laminates of uniform thickness, without local tailoring. Applying the proposed process route on non-uniform thickness tailored blanks poses additional consolidation challenges, in particular for composites 

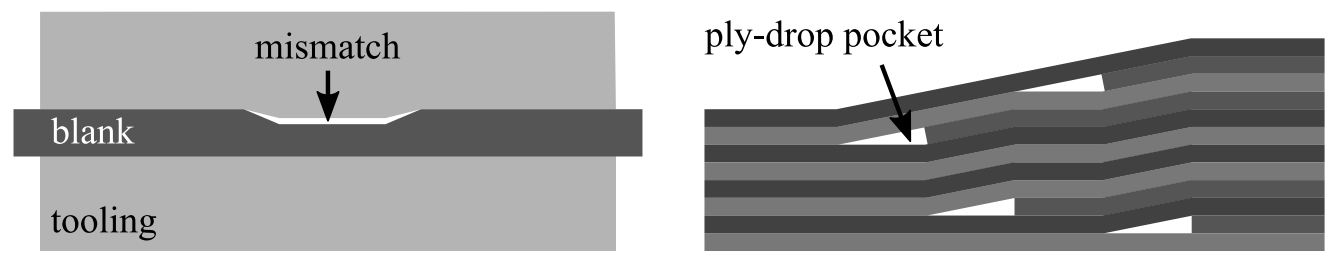

Figure 5.1 Consolidation challenges in tailored blanks. Left: local mismatch between blank thickness and tooling cavity due to a locally too thin blank. Right: a ply-drop pocket remains next to the dropped ply after blank lay-up by rapid AFP and must be consolidated during stamp forming.

intended for high-end structural applications, i.e. with a high fiber volume fraction.

As a first challenge, the consolidation quality after stamping of uniform thickness blanks was found to be very sensitive to thickness variations in the blank. These variations originate from thickness variations in the prepreg and can lead to a local mismatch between material thickness and tooling cavity. Since tailored blanks have regions with different thicknesses, each of these regions should closely match the tooling cavity for uniform pressure and good consolidation. A mismatch in one or more regions could lead to a local reduction in consolidation pressure and poor consolidation, as illustrated in Fig. 5.1. The influence of thickness variations on the consolidation of flat sections was investigated in Chapter 4.

A second challenge lies in the local consolidation of the tapering zones between the regions with various thickness. Here, plies are dropped to taper the transition between the regions. Large void pockets remain present in the tapering zone after placement due to the high lay-up rate during AFP, as illustrated in Fig. 5.1. These voids have to be eliminated during stamp forming, as they may serve as crack initiators and decrease the mechanical performance of the component. The current work focuses on the latter challenge, as improved understanding of the consolidation behavior of ply-drops is key to the successful application of the process route.

Flow of material has to take place in order to fill the voids in the ply-drop pockets. Two possible flow mechanisms can be expected. Firstly, the applied pressure generates flow of the dropped ply transverse to the fiber direction to fill the pocket with both fibers and matrix. Secondly, the applied pressure generates matrix bleedout from the dropped ply to fill the pocket with matrix only. However, matrix bleedout is less likely to occur in composites with a high fiber volume fraction due to the low matrix content and low permeability of the fiber bed. The dominant filling mechanism can be identified by estimating the characteristic filling times for the two mechanisms.

Consider a ply-drop where the height of the ply-drop pocket equals the ply thickness $h_{0}$ and the length is $20 h_{0}$ (i.e. a tapering ratio of 1:20), as shown in Fig. 5.2. The layup is symmetric and the distance between the two ply-drops is $2 L_{0}$. For transverse squeeze flow, the filling time $t_{\text {fill,squeeze }}$ can be estimated based on the equation 

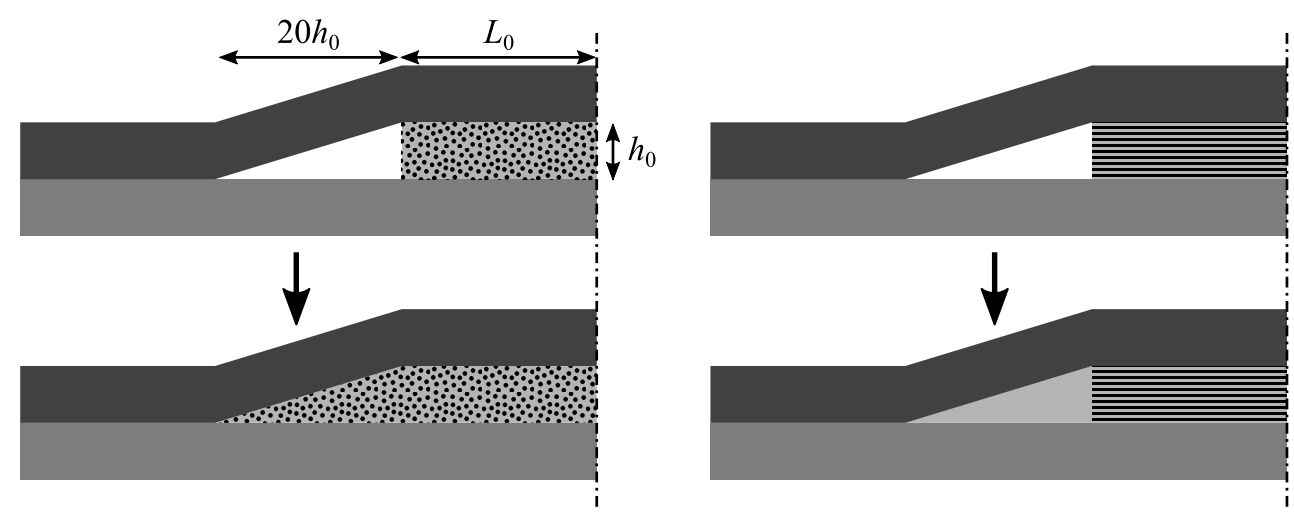

Figure 5.2 Two ply-drop filling mechanisms can be expected. Left: transverse squeeze flow of the dropped ply. Right: matrix bleed-out from the dropped ply.

provided by Rogers [1]

$$
t_{\text {fill,squeeze }}=\left(\frac{1}{h^{2}}-\frac{1}{h_{0}^{2}}\right) \frac{\eta_{\mathrm{T}} L_{0}^{3}}{4 F} .
$$

Here, $\eta_{\mathrm{T}}$ is the transverse viscosity of the composite material and $F$ is the applied force, which equals $2 L_{0} P_{\text {app}}$. The final height $h$ can be approximated, based on the pocket volume and volume conservation, by

$$
h=\frac{h_{0} L_{0}}{10 h_{0}+L_{0}} .
$$

For matrix bleed-out, the filling time $t_{\text {fill,bleed }}$ can be estimated based on Darcy flow and is given by the equation provided by Ye et al. [2]

$$
t_{\text {fill,bleed }}=\frac{\eta_{\mathrm{M}} z^{2}}{2 K_{\mathrm{p}} P_{\mathrm{app}}}
$$

where $\eta_{\mathrm{M}}$ is the matrix viscosity and $K_{\mathrm{p}}$ is the permeability coefficient. The penetration depth $z$ can be approximated, based on the pocket volume and volume conservation, by

$$
z=\frac{10 h_{0}}{1-V_{\mathrm{f}}}
$$

where $V_{\mathrm{f}}$ is the fiber volume fraction.

The characteristic filling times can now be estimated based on the parameters listed in Tbl. 5.1. A C/PEEK prepreg with a fiber volume fraction of $60 \%$, isothermal processing temperature of $420^{\circ} \mathrm{C}$ and applied pressure of $100 \mathrm{bar}$ are assumed. The resulting filling times are 46 and 333 seconds for the transverse flow and matrix bleed-out, respectively. This indicates that the transverse flow is most likely the 
Table 5.1 Parameters for estimation of the filling times.

\begin{tabular}{lccc}
\hline Parameter & Symbol & Value & Ref. \\
\hline Ply thickness & $h_{0}$ & $0.15 \mathrm{~mm}$ & - \\
Distance between ply-drops & $2 L_{0}$ & $100 \mathrm{~mm}$ & - \\
Applied pressure & $P_{\mathrm{app}}$ & $100 \mathrm{bar}$ & - \\
Fiber volume fraction & $V_{\mathrm{f}}$ & $60 \%$ & - \\
Permeability coefficient $\left(\right.$ at $\left.V_{\mathrm{f}}\right)$ & $K_{\mathrm{p}}$ & $2.3 \cdot 10^{-13} \mathrm{~m}^{2}$ \\
Transverse viscosity $\left(\mathrm{C} / \mathrm{PEEK}\right.$, at $V_{\mathrm{f}}$ and $\left.T=420^{\circ} \mathrm{C}\right)$ & $\eta_{\mathrm{T}}$ & $34 \mathrm{kPa} \cdot \mathrm{s}$ & {$[\overline{4}]$} \\
Matrix viscosity $\left(\mathrm{PEEK}\right.$, at $V_{\mathrm{f}}$ and $\left.T=420^{\circ} \mathrm{C}\right)$ & $\eta_{\mathrm{M}}$ & $109 \mathrm{~Pa} \cdot \mathrm{s}$ & {$[2]$} \\
\hline
\end{tabular}

dominant filling mechanism. However, it also indicates that filling the complete pocket may be impossible, as the blank is quenched by the relatively cold tooling in about $5-20$ seconds. This rapid drop in temperature drastically reduces the amount of flow that can take place due to the increase in viscosity. Additionally, transverse flow can only occur perpendicular to the fiber direction, indicating that lay-up may play an important role in the consolidation behavior of the ply-drops.

Another important parameter that determines the filling time is the volume of the ply-drop pocket. This volume is dictated by the ply thickness and the tapering slope. However, this assumes that the dropped ply is positioned exactly at its intended location during AFP and that the blank is aligned exactly in line with the tooling during stamp forming, such that there is a perfect match between the blank and tooling cavity. In reality, a certain tolerance on the position of tapes and on the alignment of blanks with respect to the tooling is inevitable. Both lead to an apparent shift of the dropped plies with respect to the tooling and lead to either an increase or decrease of the effective size of the pocket. This is illustrated in Fig. 5.3. Additionally, the local pressure is affected, which influences the generated flow. As a result, depending on the magnitude of the shift, inaccuracies during lay-up or misalignments during forming may cause poor consolidation of ply-drops.

The current work aims to investigate the consolidation behavior of ply-drop regions in tailored AFP blanks during stamp forming. Improved understanding of the filling behavior of ply-drop pockets is essential for the successful application of the process route for high performance structural components. For this purpose, an experimental study was performed. AFP blanks with various ply-drop configurations were stamp formed and their consolidation quality was characterized in order to investigate the influence of lay-up. Intentional ply shifts were applied to check whether the consolidation behavior of the ply-drops is sensitive to placement inaccuracies or blank misalignments. The results were used to identify the dominant filling mechanism of the ply-drops and to develop ply-drop design guidelines for the application of tailored AFP blanks. 

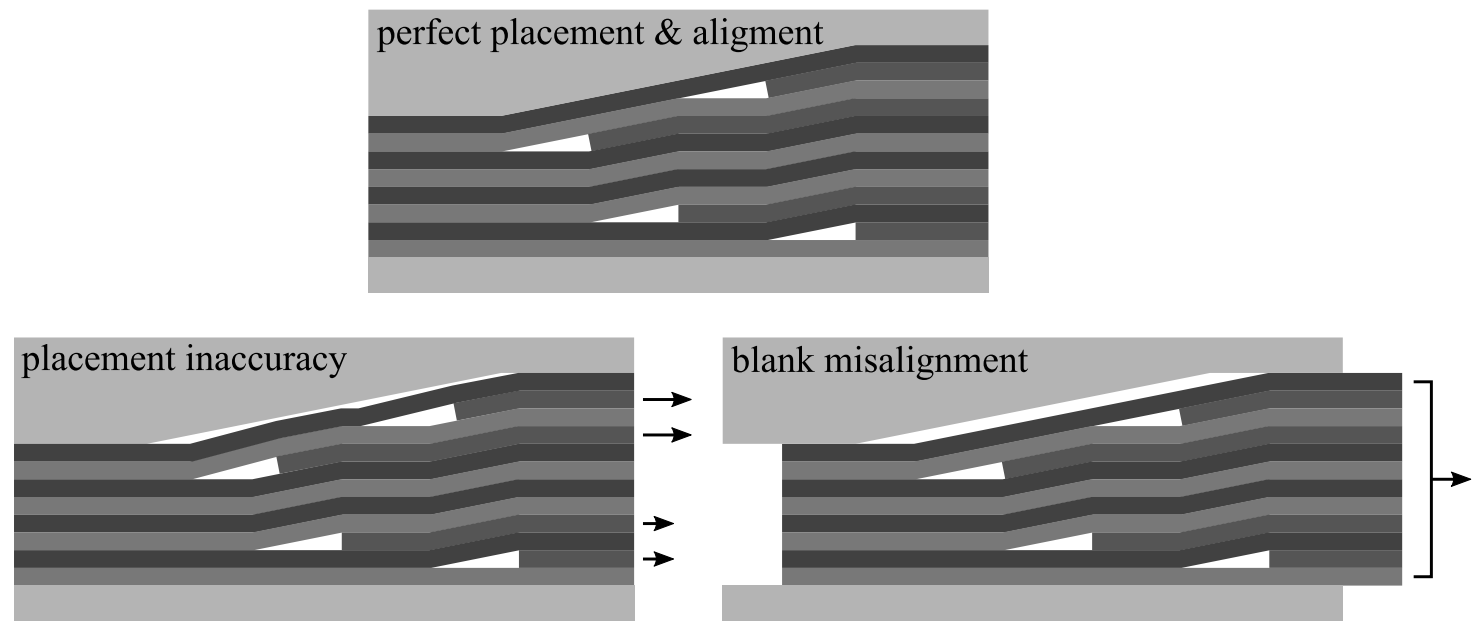

Figure 5.3 Top: Perfect placement during AFP and perfect blank alignment during stamp forming. Bottom left: an apparent shift of the dropped plies as a result of inaccurate placement during AFP. Bottom right: an apparent shift of the dropped plies as a result of a blank misalignment during stamp forming.

\subsection{Experimental work}

\subsubsection{Materials}

Cytec APC-2 [5] unidirectional AS4/PEEK prepreg tape, slit to $1 / 4$ inch width $(6.35 \mathrm{~mm})$, was used. This tape has a fiber volume fraction of approximately $59 \%$, a melting temperature $T_{\mathrm{m}}$ of approximately $343{ }^{\circ} \mathrm{C}$ and a recommended processing temperature range of $370-400^{\circ} \mathrm{C}$. The APC-2 material has shown good consolidation quality after stamping uniform thickness blanks produced by rapid AFP in Chapter 3. This is mainly due to the matrix rich tape surface, which facilitates interlaminar bonding both during AFP and stamp forming and may also aid the consolidation of ply-drops.

\subsubsection{Blank and tooling design}

Flat $250 \times 250 \mathrm{~mm}^{2}$ aluminum tooling with a symmetric tapering on the top side was used for stamp forming, as shown in Fig. 5.4. The thickness step accommodates for a drop of four plies $(0.56 \mathrm{~mm}$, based on an average consolidated ply thickness of $0.14 \mathrm{~mm}$ for uniform thickness AFP blanks after stamping). Minimum tapering slopes suggested in literature vary between $1: 3[6], 1: 8[7], 1: 10[8]$ and $1: 20[9]$. A tapering ratio of $1: 23$ was applied this work, resulting in a tapering region of $12.7 \mathrm{~mm}$ wide. The dropped plies were extended $1.6 \mathrm{~mm}$ into the ply-drop region $(-1.6 \mathrm{~mm}$ shift $)$ in order to guarantee pressure on the ply-drop region. The distance between the two tapering regions was $80 \mathrm{~mm}$. 


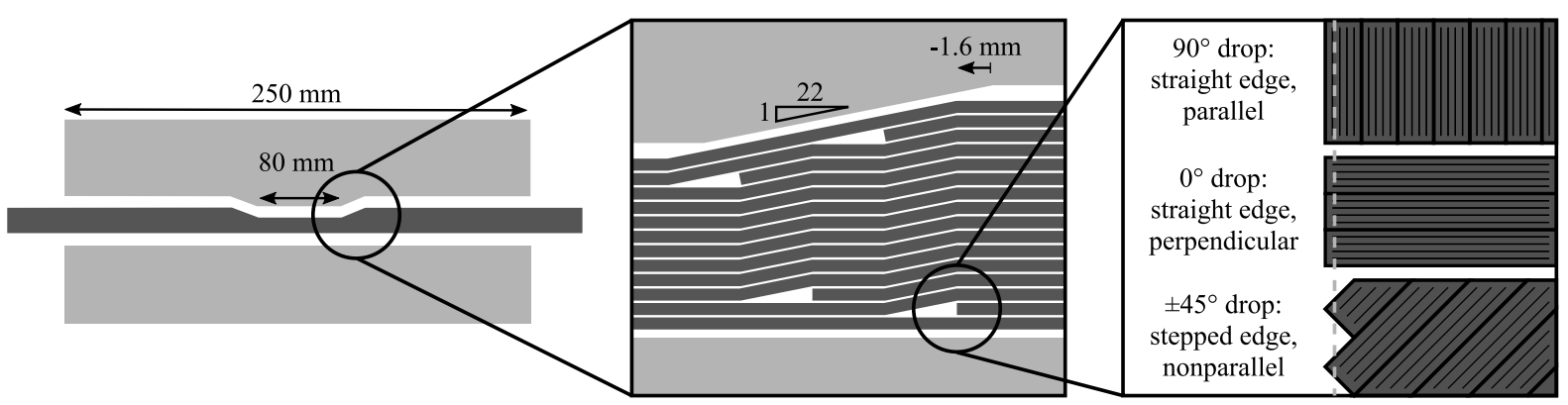

Figure 5.4 Tooling design, tapering region and ply edges.

Table 5.2 The tested lay-ups. The subscript L denotes dropped plies.

\begin{tabular}{lcc}
\hline Configuration & Lay-up thick section & Lay-up thin section \\
\hline $0^{\circ} / 90^{\circ} / 0^{\circ}$ & {$\left[0 / 90_{\mathrm{L}} / 0 / 90_{\mathrm{L}} / 0 / 90 / 0 / 90\right]_{s}$} & {$[0 / 0 / 0 / 90 / 0 / 90]_{s}$} \\
$0^{\circ} / \pm 45^{\circ} / 0^{\circ}$ & {$\left[0 /+45_{\mathrm{L}} / 0 /-45_{\mathrm{L}} / 0 / 90 / 0 / 90\right]_{s}$} & {$[0 / 0 / 0 / 90 / 0 / 90]_{s}$} \\
$+45^{\circ} / 0^{\circ} /-45^{\circ}$ & {$\left[+45 / 0_{\mathrm{L}} /-45 / 0_{\mathrm{L}} /+45 /-45 / 0 / 90\right]_{s}$} & {$[+45 /-45 /+45 /-45 / 0 / 90]_{s}$} \\
\hline
\end{tabular}

The filling behavior is likely to be dependent on the lay-up, in particular the orientation of the dropped ply. Figure 5.4 illustrates various fiber orientations of the dropped ply. Three cases can be distinguished. Firstly, a $90^{\circ}$ dropped ply allows for transverse flow due to the fact that the fibers are parallel to the drop. Secondly, a dropped $0^{\circ}$ ply does not allow for transverse flow due to the perpendicular fibers. Matrix bleed out or transverse flow of neighboring plies is required to fill the pocket. Finally, a stepped edge appears for any orientation between $0^{\circ}$ and $90^{\circ}$, e.g. $45^{\circ}$. This is due to the fact that tapes are cut perpendicularly to the fiber direction during placement with the AFP machine used in this work. This leads to a sawtooth profile along the edge of the dropped ply. The sawtooth profile effectively increases the ply-drop pocket and requires more flow of material to fill the pocket. The increased pocket size, in combination with a fiber orientation that is not parallel to the drop, may make consolidation of this case challenging.

Various lay-ups were investigated in order to investigate the influence of the fiber orientation of the dropped plies on the ply-drop filling behavior. The authors have limited themselves to commonly used fiber orientations of $0^{\circ}, 90^{\circ}$ and $\pm 45^{\circ}$. As plydrop design guidelines recommend dispersed ply-drops [7, 9], all dropped plies are separated by a continuous ply. The plies were dropped one-by-one from the outside to the inside. The cooling rates during stamping are highest close to the surface of the blanks, which makes this the most critical location for ply-drops. In order to test a worst-case scenario, the dropped plies were located closest to the surface. The three tested lay-ups are shown in Tbl. 5.2. Since each blank has two tapering regions, the $0^{\circ} / 90^{\circ} / 0^{\circ}$ and $0^{\circ} / \pm 45^{\circ} / 0^{\circ}$ configurations could be combined into the same blank.

As discussed in Section 5.1, it can be expected that a shift of the dropped plies with respect to the tooling, either caused by inaccurate placement during AFP or a blank- 

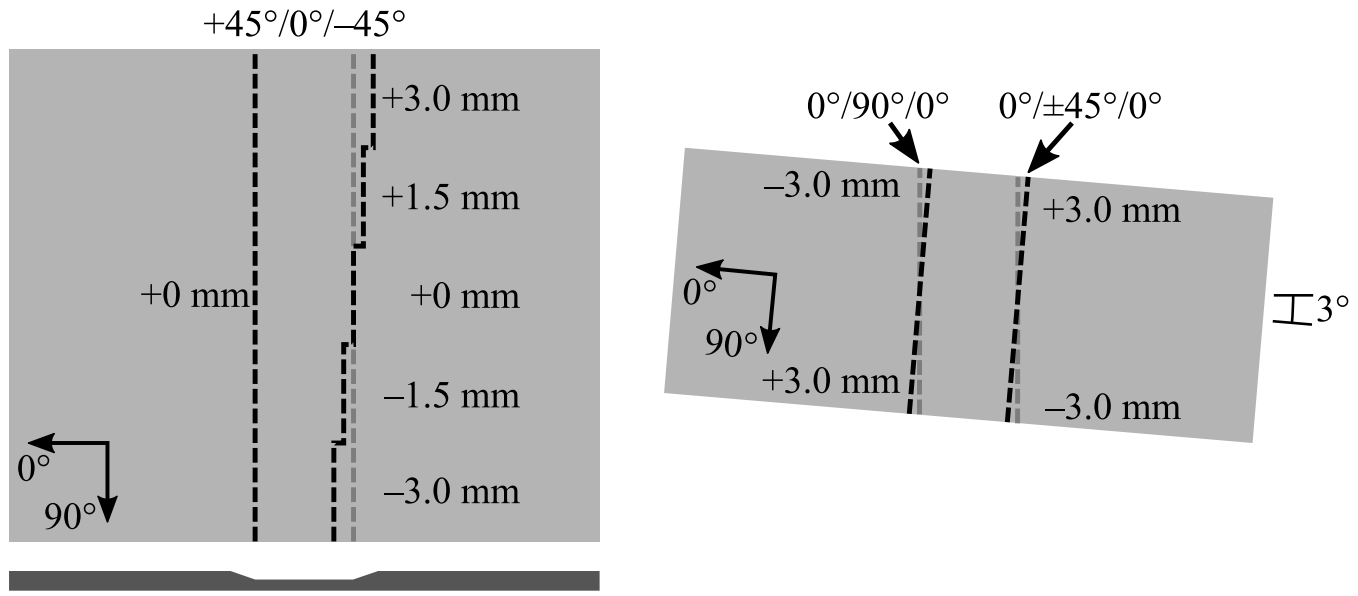

Figure 5.5 Left: Ply shifts in the blank with the $+45^{\circ} / 0^{\circ} /-45^{\circ}$ configuration by shifting the local ply contour during lay-up in steps of $1.5 \mathrm{~mm}$. Right: Ply shifts in the blank with the $0^{\circ} / 90^{\circ} / 0^{\circ}$ and $0^{\circ} / \pm 45^{\circ} / 0^{\circ}$ configurations by a rotation of $3^{\circ}$ of the blank with respect to the tooling during stamp forming.

tooling misalignment during stamping, affects the filling behavior of the ply-drops. The influence of shifted plies was investigated either by intentionally shifting the dropped plies (on top of the already existing $-1.6 \mathrm{~mm}$ shift) by $-3,-1.5,+0,+1.5$ and $+3.0 \mathrm{~mm}$ in zones of $5 \mathrm{~cm}$ wide during lay-up (in case of the $+45^{\circ} / 0^{\circ} /-45^{\circ}$ drops) or by intentionally misaligning the blank during stamping by $3^{\circ}$ (in case of the $0^{\circ} / 90^{\circ} / 0^{\circ}$ and $0^{\circ} / \pm 45^{\circ} / 0^{\circ}$ drops). This is illustrated in Fig. 5.5. In both cases, a positive shift leads to an effective increase of the ply-drop pocket and a reduction in local pressure, while a negative shift leads to an effective decrease of the ply-drop pocket and an increase in local pressure.

\subsubsection{AFP and stamp forming}

A Coriolis Composites AFP robot with laser heating was used to lay up blanks on a flat tool. A single $1 / 4$ inch tow was placed at a rate of $200 \mathrm{~mm} / \mathrm{s}$ and a nip-point temperature of approximately $450{ }^{\circ} \mathrm{C}$ (measured by thermal camera). A compaction pressure of approximately 4 bar was applied by a silicon roller of $60 \mathrm{SH}$ hardness. A gap of $0.2 \mathrm{~mm}$ was applied between adjacent tows to accommodate for transverse flow during placement and prevent overlaps. The ply-drops are not fully consolidated during AFP, as the focus is on rapid lay-up, rather than in-situ consolidation. The placement accuracy was checked as described in Appendix 5.A. The results indicate that both feeding and cutting have a delay. After optimization, the feed accuracy ranged between 2 and $2.5 \mathrm{~mm}$, while the cut accuracy ranged between 1 and $2 \mathrm{~mm}$.

All blanks were dried in a convection oven for 3 hours at $250{ }^{\circ} \mathrm{C}$ prior to stamp forming. It was shown in Chapter 2 that this reduces deconsolidation caused by 
expansion of dissolved moisture, which is undesired, as it introduces additional voids and delaminations that have to be eliminated again during stamping.

The blanks were then stamp formed in a $200 \mathrm{t}$ Pinette P.E.I. press equipped with an infrared oven and automated transfer frame. The blanks were preheated to $420{ }^{\circ} \mathrm{C}$ in 250 seconds. Subsequently, the blank was rapidly transferred to the press, where the tooling was closed. A consolidation pressure of 100 bar was applied for 60 seconds while the laminate cooled down to the tooling temperature of $250{ }^{\circ} \mathrm{C}$. Blank alignment with respect to the tooling was checked before stamping by a line laser and after stamping by the imprint left by an engraved alignment cross in the tooling. The obtained alignment was within $\pm 1 \mathrm{~mm}$ and $\pm 0.5^{\circ}$.

\subsubsection{Consolidation quality}

The stamp formed blanks were trimmed to their stamped area and their consolidation quality was evaluated, where the focus was on void content in the ply-drop regions.

Ultrasonic C-scans were performed using a Sonatest RapidScan2 at a frequency of $5 \mathrm{Mhz}$. The scans give a qualitative picture of the global consolidation quality, as areas with porosity or poor interlaminar bonding will cause damping of the signal, which appears as dark areas in the scans. For further inspection of the ply-drop region, specimens were cut from the blanks for cross-sectional micrographs.

\subsection{Results}

\subsubsection{C-scan}

Figure 5.6 shows the amplitude plots of the C-scans of the blanks after stamping. The two tapering regions appear as slightly darker bands on the scans due to a partial loss of signal from the non-parallel surfaces. However, consolidation appears to be good and uniform throughout all tapering regions, as no (near) black spots are present. Visual inspection of the surface also showed no rough areas, which would indicate lack of pressure and potential poor consolidation.

\subsubsection{Microscopy}

Figure 5.7 shows a selection of cross-sectional micrographs from the tapering regions. The micrographs of the AFP blanks prior to stamping (Fig. 5.7 (a)) showed interlaminar voids, unconsolidated ply-drop pockets and intralaminar micro-voids. The interlaminar voids and unconsolidated ply-drops are due to the high lay-up rate 


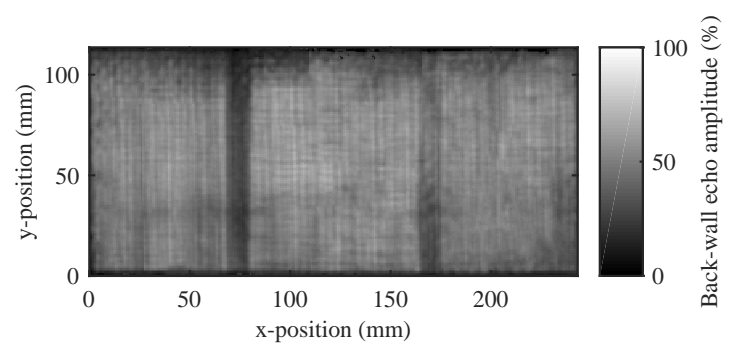

(a) $0^{\circ} / 90^{\circ} / 0^{\circ}$ (left) and $0^{\circ} / \pm 45^{\circ} / 0^{\circ}$ (right)

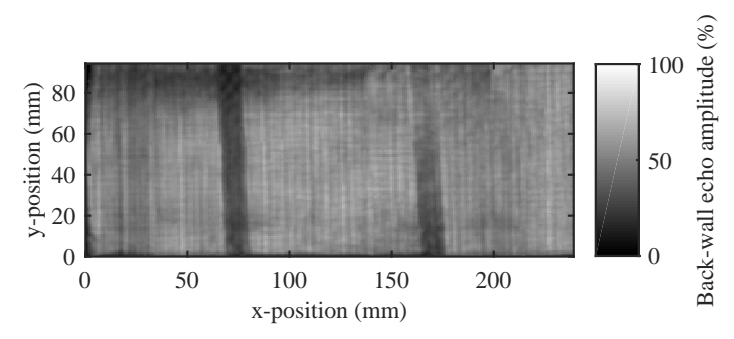

(b) $0^{\circ} / 90^{\circ} / 0^{\circ}$ (left) and $0^{\circ} / \pm 45^{\circ} / 0^{\circ}$, $3^{\circ}$ misaligned (right)

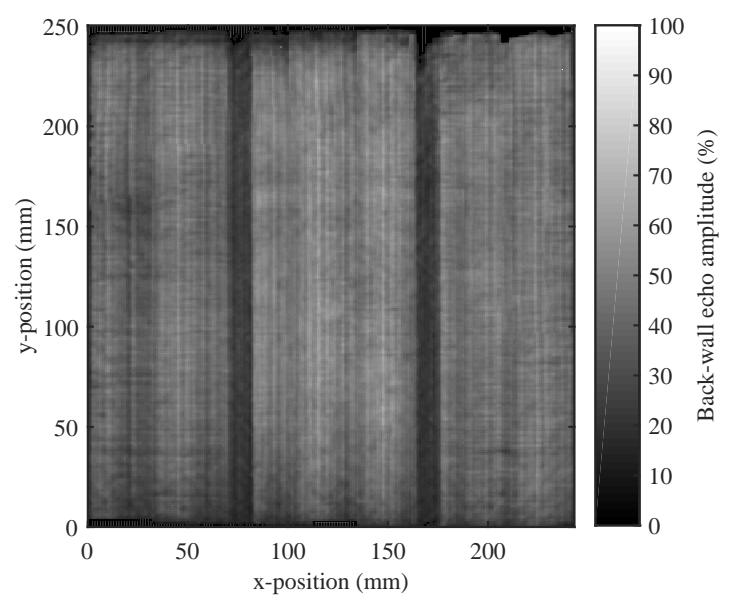

(c) $+45^{\circ} / 0^{\circ} /-45^{\circ}$

Figure 5.6 C-scans of the blanks after stamping.

during AFP, which does not allow for full consolidation. The intralaminar voids were already present in the prepreg and are not eliminated.

Micrographs of a selection of stamped blanks are shown in Fig. 5.7 (b-e). Based on the cross-sections it was confirmed that all ply-drops were positioned within $\pm 1 \mathrm{~mm}$ from their intended location, despite the tolerances during AFP and stamp forming. Stamp forming the blanks has eliminated the voids in the ply-drop pockets in almost all cases. The intralaminar micro-voids that were present in the AFP blank have also largely been removed, but are not completely eliminated. Figure 5.7 (b) shows a cross-section of the $0^{\circ} / 90^{\circ} / 0^{\circ}$ configuration. Both matrix and fibers have migrated far into the pocket, which confirms that transverse squeeze flow has been the main filling mechanism. However, the observed pocket is much smaller than the theoretical pocket ( $1 \mathrm{~mm}$ versus $3.2 \mathrm{~mm}$ long, respectively). This is due to the fact that not only transverse flow of the dropped ply has occurred, but also squeezing of the underlying $90^{\circ}$ plies. Both a shift of +3 and $-3 \mathrm{~mm}$ introduced by the blank misalignment did not seem to affect consolidation of the ply-drops for this configuration.

Similar results were found for the $0^{\circ} / \pm 45^{\circ} / 0^{\circ}$ configuration (Fig. 5.7(c)). However, fibers have moved less far into the pocket due to the $45^{\circ}$ fiber orientation and a more matrix rich pocket is found. The $-3 \mathrm{~mm}$ shift introduced by the blank misalignment did not affect the consolidation of the ply-drop. However, the $+3 \mathrm{~mm}$ shift resulted in voids remaining in the ply-drop pocket and between plies near the ply-drop, as can be seen in Fig. 5.7(d). The intralaminar void content also appears to be higher 
compared to the well-consolidated ply-drop regions.

In case of the $+45^{\circ} / 0^{\circ} /-45^{\circ}$ configuration (Fig. 5.7 (e)), no transverse flow of the dropped ply was possible. Yet, no voids are visible for this particular prepreg. The pockets have been filled with matrix, most likely primarily from redistribution of the matrix on the ply interfaces, and by transverse flow of the surrounding $\pm 45^{\circ}$ plies. The +3 and $-3 \mathrm{~mm}$ ply shift introduced during AFP did not influence consolidation of the ply-drops for this configuration.

\subsection{Discussion}

The results confirm that the dominant mechanism for filling of the ply-drop pockets is transverse flow, as was expected based on the characteristic filling times discussed in Section 5.1. However, the actual filling times appear to be shorter than estimated, as good consolidation was found after stamping in most of the cases, even under the highly non-isothermal conditions during stamp forming. The filling behavior is affected by the orientation of the dropped ply. For a $90^{\circ}$ ply, the fibers are positioned parallel to the drop and the pocket is completely filled by both fibers and matrix. For a $45^{\circ}$ ply, the fibers are no longer parallel, but some transverse flow still occurs. However, the pocket tends to be more matrix rich, as fiber motion is limited. For a $0^{\circ}$ ply, the fibers are oriented perpendicularly to the drop, such that transverse flow of the composite is restricted and the pocket is filled by matrix. This matrix most likely originates from the matrix rich ply interfaces, as resin percolation is too slow to significantly contribute to the filling of the pocket.

Not only the orientation of the dropped ply plays an important role in the filling behavior of the ply-drop pockets, but also the orientation of the plies that surround this ply. The observed length of the ply-drop pockets ranged from 0.2 to $1.5 \mathrm{~mm}$, while the theoretical length was $3.2 \mathrm{~mm}$, as dictated by the tapering slope in the tooling. This indicates that the actual size of the ply-drop pocket is significantly reduced by flow of the surrounding plies. Again, transverse flow is the main flow mechanism here, as illustrated in Fig. 5.8. This can for example be observed in Fig. 5.7 (b), where the thickness of the $90^{\circ}$ ply below the dropped ply has locally changed to accommodate for the ply drop off. Flow of the surrounding plies is even more important when the dropped ply has a $0^{\circ}$ orientation. In this case, shown in Fig. 5.7 (d), the pocket size is greatly reduced by transverse flow of the surrounding plies.

Based on the previous, it can be concluded that transverse flow is key for the consolidation of ply-drops. It is therefore beneficial to have ply orientations that allow for transverse flow, such as $90^{\circ}$ and $\pm 45^{\circ}$, in the dropped ply or the plies surrounding the dropped ply. Alternatively, placing a single $90^{\circ}$ tow, or even a strip of pure polymer, next to the dropped ply might facilitate filling of the pocket. 


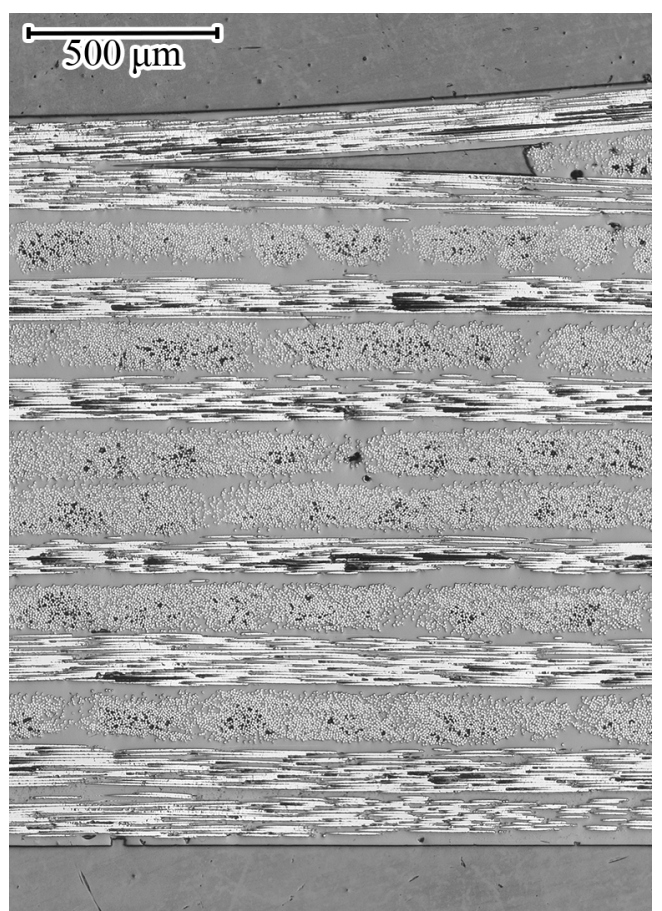

(a) $0^{\circ} / 90^{\circ} / 0^{\circ}$, unstamped

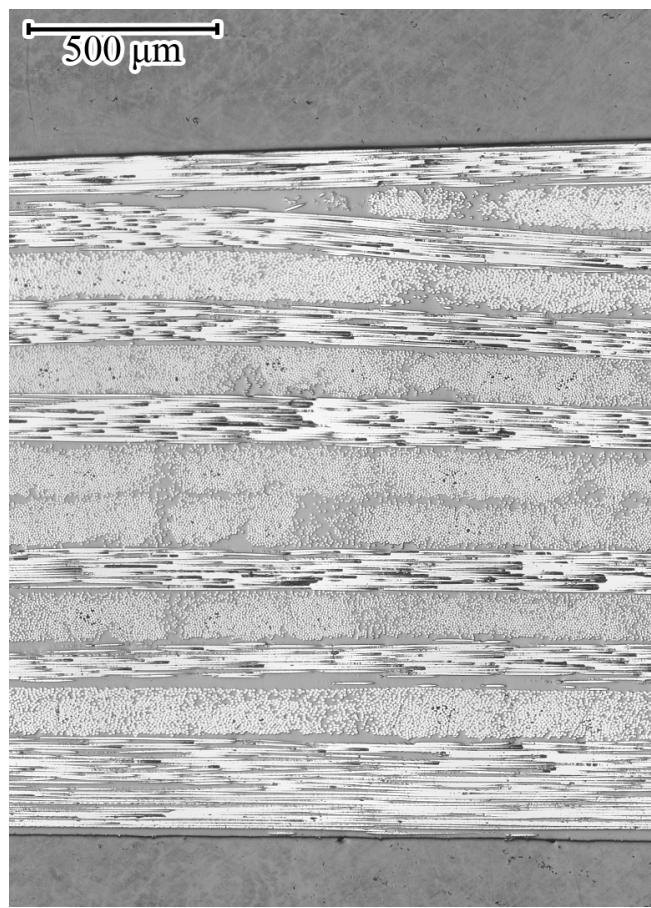

(c) $0^{\circ} / \pm 45^{\circ} / 0^{\circ},+0 \mathrm{~mm}$ shift

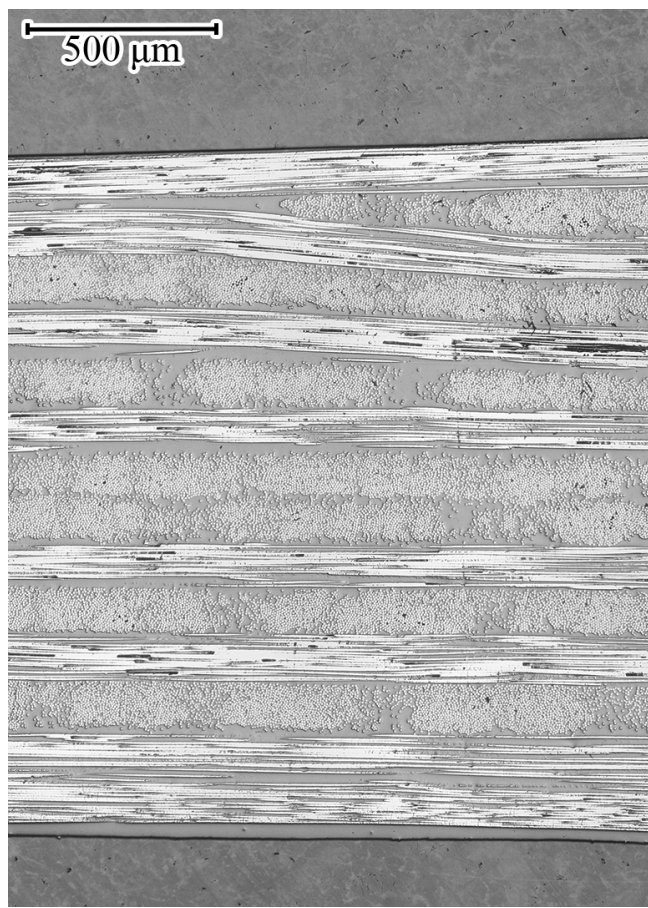

(b) $0^{\circ} / 90^{\circ} / 0^{\circ},+0 \mathrm{~mm}$ shift

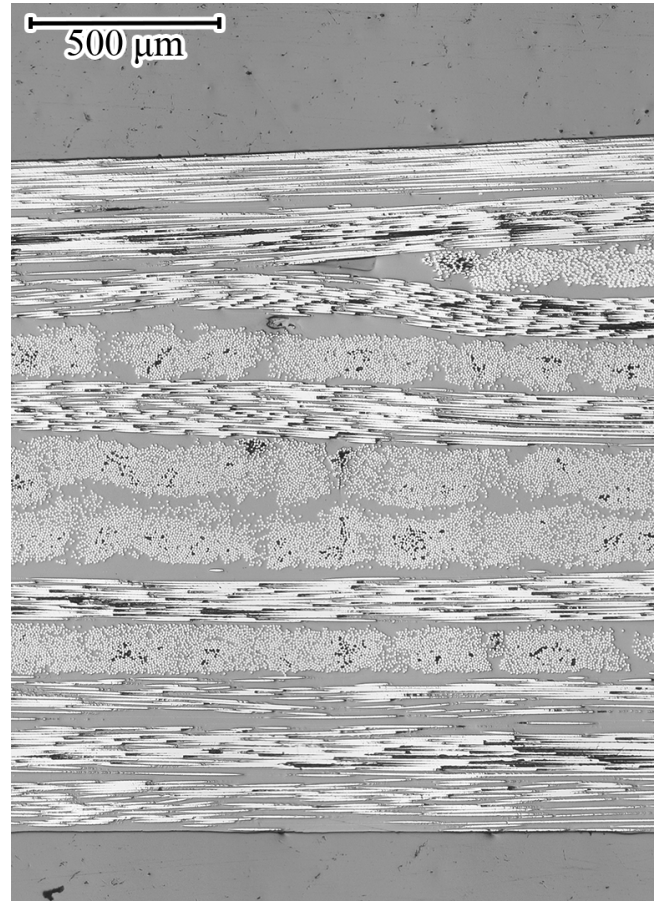

(d) $0^{\circ} / \pm 45^{\circ} / 0^{\circ},+3 \mathrm{~mm}$ shift

Figure 5.7 Cross-sectional micrographs of the tapering regions in the blanks (a) before and (b-e) after stamping. 


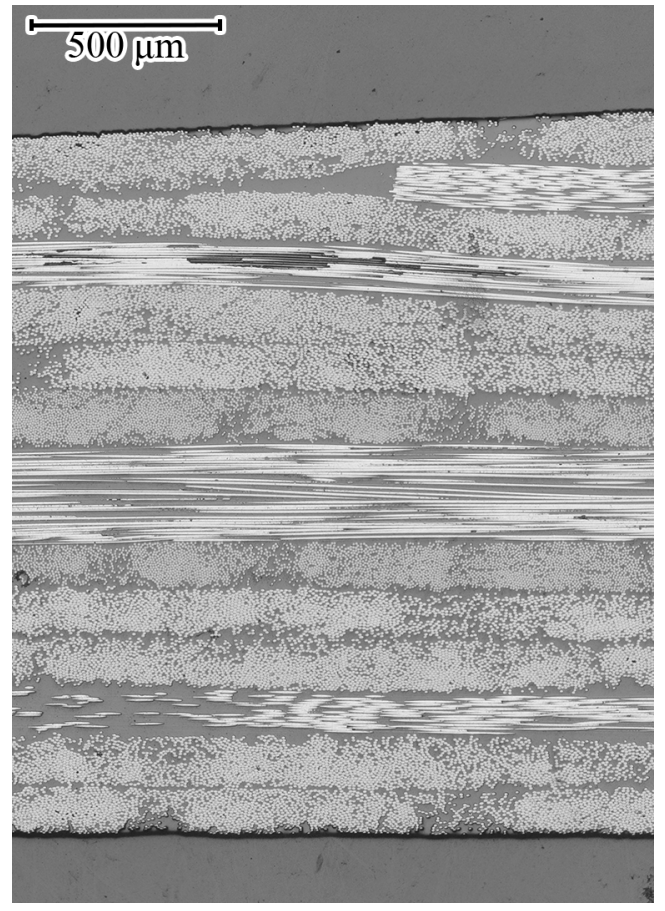

(e) $45^{\circ} / 0^{\circ} /-45^{\circ},+0 \mathrm{~mm}$ shift

Figure 5.7 Cross-sectional micrographs of the tapering regions in the blanks (a) before and (b-e) after stamping. (cont.)

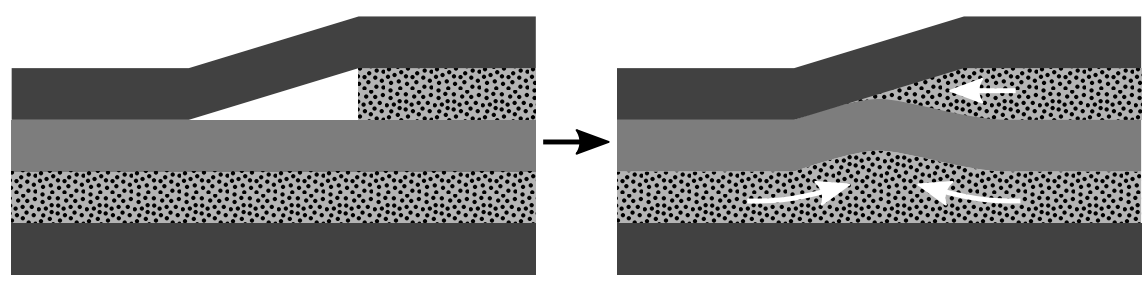

Figure 5.8 Ply-drop consolidation by transverse flow of the dropped ply and surrounding plies. 
As discussed in Section 5.1, both placement accuracy during AFP and blank alignment during stamping may affect consolidation of a tapering region due to the local mismatch between blank thickness and tooling cavity by effectively shifting the dropped ply. However, small ply shifts, up to $\pm 3 \mathrm{~mm}$ tested in this work, did not seem to cause significant issues in consolidating the ply-drops. Negative shifts, i.e. extending the dropped plies into the tapering region, did not lead to poor consolidation. In fact, a negative shift effectively reduces the size of the ply-drop pocket and increases the pressure on the tip of the ply-drop. However, a positive shift, i.e. retracting the dropped plies from the tapering region, did lead to poor consolidation of the ply-drop pockets in one of the tested cases. In this specific case, the $0^{\circ} / \pm 45^{\circ} / 0^{\circ}$ configuration, the ply-drop pocket is already larger compared to the other configurations due to the sawtooth edge. An additional positive shift effectively further increases the size of the pocket, while reducing the local pressure. As a result, the flow is decreased, while the pocket size has increased and incomplete filling of the pocket occurs. Since negative ply shifts did not lead to poor consolidation, it is recommended to intentionally extend the dropped plies into the tapering region during lay-up to prevent consolidation issues due to positive shifts caused by blank misalignments. A shift of $-1.6 \mathrm{~mm}$ was applied by default in the current work. This was sufficient for most configurations, except in case of the sawtooth $\pm 45^{\circ}$ ply drop.

Since the consolidation of ply-drops is governed by transverse flow of the composite and matrix at the ply interfaces, it is most likely affected by the prepreg used to manufacture the blank. This was verified by repeating some of the experimental results with a prepreg from a different manufacturer. This prepreg, TenCate Cetex ${ }^{\circledR}$ TC1200, has the same fiber volume fraction, but has a much more uniform fiber matrix distribution compared to the Cytec APC-2 and lacks a matrix rich surface. Figure 5.9 shows a C-scan and cross-section of a TC1200 blank with with $0^{\circ} / 90^{\circ} / 0^{\circ}$ and $0^{\circ} / \pm 45^{\circ} / 0^{\circ}$ configuration after stamping. The $\mathrm{C}$-scan shows good consolidation for the $0^{\circ} / 90^{\circ} / 0^{\circ}$ configuration. However, poor consolidation is found for the $0^{\circ} / \pm$ $45^{\circ} / 0^{\circ}$ configuration. This is confirmed by the cross-section, which shows voids in the ply-drop pocket and additional voids in other plies. Similar results were found for a $45^{\circ} / 0^{\circ} /-45^{\circ}$ configuration with $+3 \mathrm{~mm}$ shift. Both of these configurations did not show voids for the APC-2 prepreg.

The difference in consolidation quality after stamping between the two prepregs could indicate that flow is more limited for the TC1200, making it more sensitive to the sawtooth edge for $\pm 45^{\circ}$ ply-drops and positive misalignments. Although the flow behavior is likely different due to the more homogeneous fiber/matrix distribution and lack of a matrix rich ply surface, the C-scans also show that there is another possible cause for the poor consolidation quality in the tapering regions of the TC blanks. The C-scan in Fig. 5.9 (a) shows not only poor consolidation in the tapering region of the $0^{\circ} / \pm 45^{\circ} / 0^{\circ}$ configuration, but also in the center section of the blank. As was discussed in Section 5.1, the tooling cavity should closely 


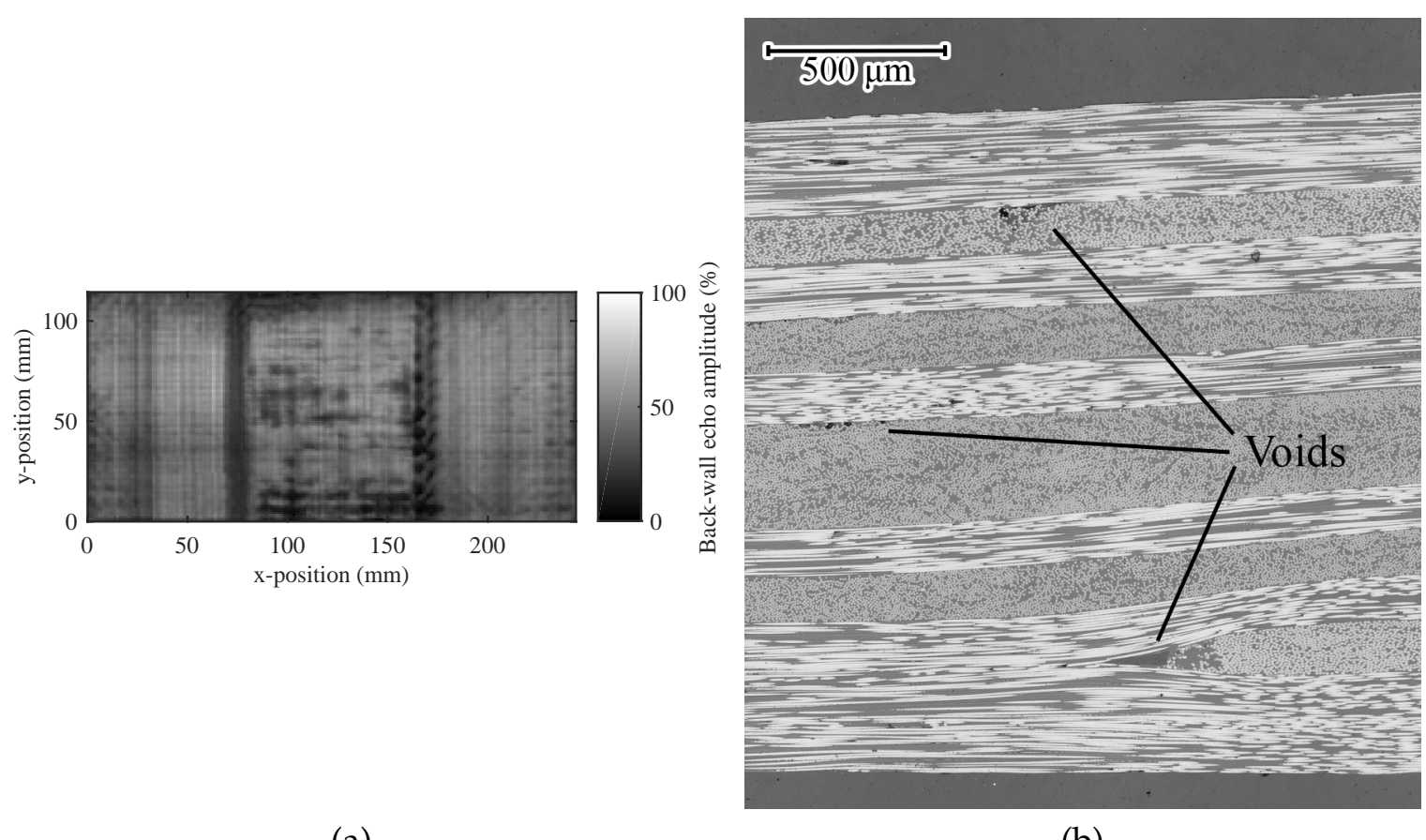

(a)

(b)

Figure 5.9 (a) C-scan of a TC1200 blank with $0^{\circ} / 90^{\circ} / 0^{\circ}$ (left tapering region) and $0^{\circ} / \pm 45^{\circ} / 0^{\circ}$ (right tapering region) configuration after stamping. (b) Cross-section of the $0^{\circ} / \pm 45^{\circ} / 0^{\circ}$ configuration showing a large void in the ply-drop pocket and interlaminar voids.

match each thickness region for uniform pressure and good consolidation. The poor consolidation in the center region indicates that the thickness step in the blank was larger than the thickness step in the tooling cavity, leading to a lack of pressure in the center region, while most pressure was carried by the two outer regions. Thickness measurements on the stamped blanks showed that the average ply thickness was approximately $5 \mu \mathrm{m}$ larger for the TC1200 prepreg and hence a $20 \mu \mathrm{m}$ mismatch existed between the blank thickness and tooling cavity. This increased thickness is the result of a slightly larger thickness of the input prepreg material. The fact that a local thickness mismatch of only $20 \mu \mathrm{m}$ for the four ply tapering region $(0.56 \mathrm{~mm})$ already leads to poor consolidation indicates how important a matching blank thickness and tooling cavity are. It also shows how important it is to use a prepreg with a well defined thickness.

\subsection{Conclusions and Recommendations}

Rapid blank lay-up by AFP, followed by stamp forming, offers a potential solution for the rapid manufacturing of tailored composite components. However, the high cooling rates during stamping make consolidation of the blank challenging. In particular, the consolidation of ply-drops poses a challenge, as the large voids that 
appear next to the ply-drops due to the high lay-up rates during AFP have to be eliminated during stamp forming in order to ensure high mechanical performance. Better understanding of the consolidation behavior of ply-drops is therefore essential for the successful application of this process route for the manufacturing of high performance structural components.

An experimental study was performed in order to identify the main filling mechanism of the ply-drop pockets during stamp forming. Blanks of C/PEEK prepreg with various ply-drop configurations were stamp formed in order to investigate the influence of fiber orientation of the dropped ply on the filling behavior. Intentional ply shifts were introduced to study the influence of placement tolerances during AFP and blank alignment tolerances during stamp forming. The consolidation quality of the blanks was characterized qualitatively by C-scan and cross-sectional micrographs.

The results indicate that consolidation of ply-drops in tailored AFP blanks by stamp forming is feasible, as nearly all tested configurations were void-free after stamping. The ply-drop pockets are mostly filled by a mixture of fibers and matrix. Transverse flow of the dropped ply and surrounding plies is identified as the main filling mechanism. Resin percolation is too slow to significantly contribute to the filling of the ply-drop pockets. Having fiber orientations that allow for transverse flow, such as $90^{\circ}$ and $\pm 45^{\circ}$, in the dropped ply or surrounding plies is therefore beneficial for the consolidation of ply-drops. The large ply-drop pockets that appear due to the sawtooth edge of a $\pm 45^{\circ}$ drop make this configuration more challenging to consolidate and more sensitive to placement and blank alignment tolerances. The consolidation of all other tested configurations did not appear to be affected up to the tested $\pm 3 \mathrm{~mm}$ ply shifts. In fact, intentionally applying negative ply shifts, i.e. extending the dropped ply into the tapering zone, could serve as a method to make ply-drop consolidation more robust against placement inaccuracy and blank misalignments.

The current work has demonstrated that consolidation of ply-drops in tailored AFP blanks by stamp forming is feasible. The main consolidation mechanism was identified and ply-drop design guidelines were established. Therefore, this work provides an important step forward in the application of rapid AFP followed by stamp forming for the manufacturing of tailored components for structural applications. Future research should extend this work to more complex geometries, such that the effect of forming features on the consolidation behavior can be investigated.

\section{References}

[1] T. G. Rogers. Squeezing flow of fibre-reinforced viscous fluids. Journal of Engineering Mathematics, 23(1):81-89, 1989. 
[2] L. Ye, K. Friedrich, J. Kästel, and Y.-W. Mai. Consolidation of unidirectional CF/PEEK composites from commingled yarn prepreg. Composites Science and Technology, 54(4):349-358, 1995.

[3] F. N. Cogswell. The experience of thermoplastic structural composites during processing. Composites Manufacturing, 2(3-4):208-216, 1991.

[4] M. A. Khan, P. Mitschang, and R. Schledjewski. Parametric study on processing parameters and resulting part quality through thermoplastic tape placement process. Journal of Composite Materials, 47(4):485-499, 2013.

[5] Cytec. Technical Data Sheet APC-2-PEEK Thermoplastic Polymer, 2016.

[6] A. Mukherjee and B. Varughese. Design guidelines for ply drop-off in laminated composite structures. Composites Part B: Engineering, 32(2):153-164, 2001.

[7] F.-X. Irisarri, A. Lasseigne, F.-H. Leroy, and R. Le Riche. Optimal design of laminated composite structures with ply drops using stacking sequence tables. Composite Structures, 107:559-569, 2014.

[8] P. Dhurvey and N. D. Mittal. Review on various studies of composite laminates with ply drop-off. ARPN Journal of Engineering and Applied Sciences, 8(8):595-605, 2013.

[9] J. A. Bailie, R. P. Ley, and A. Pasricha. A Summary and Review of Composite Laminate Design Guidelines. Technical report, NASA Langley Research Center, 1997.

\section{A Appendix: AFP accuracy}

Placement accuracy during AFP plays an important role in the manufacturing of tailored blanks. The accuracy in placement direction is determined by the feed and cut accuracy, where feeding controls the start of a tape and cutting the end of a tape, as illustrated in Fig. 5.10. High feed and cut tolerances may lead to poor consolidation during stamp forming, as the contour of the local reinforcement is not at the intended location, which leads to a mismatch between blank thickness and tooling cavity. The lateral placement accuracy is generally high.

The accuracy in placement direction of the AFP machine by Coriolis Composites used in this work is specified as $\pm 2.5 \mathrm{~mm}$. The feed and cut accuracy were checked by performing a series of lay-up experiments. Rectangular plies of $300 \mathrm{~mm}$ in length and $43 \times 1 / 4^{\prime \prime}$ tapes $(275 \mathrm{~mm})$ in width were placed at $0^{\circ}, \pm 45^{\circ}$ or $90^{\circ}$ orientation and at a rate of $200 \mathrm{~mm} / \mathrm{s}$. These plies were scanned with a flatbed scanner at $600 \mathrm{dpi}$ to obtain images of the plies. These scans were thresholded to black and white images and the contour of the ply was traced. The error was obtained by comparing the traced and the nominal ply contour. The error is defined as positive in the direction of placement. A normal distribution was fitted to the error in order to find the average error and the standard deviation.

Figure 5.11 shows an example of the results for the feed contour of a ply placed at $0^{\circ}$ orientation. Fig. 5.11 (c) and (d) show that the error varies between 1.5 and 4.4 $\mathrm{mm}$ with an average at $2.6 \mathrm{~mm}$. The positive error indicates that feeding starts too late. Figure 5.12 shows the average feed and cut error for all tested orientations. 


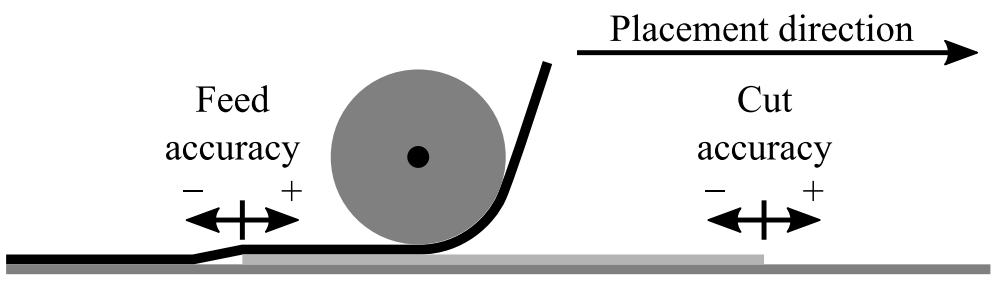

Figure 5.10 Feed and cut accuracy.

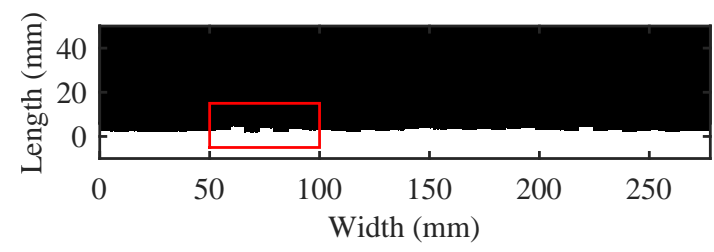

(a)

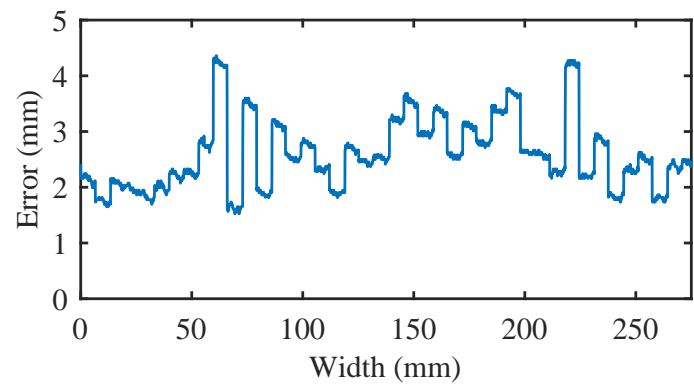

(c)

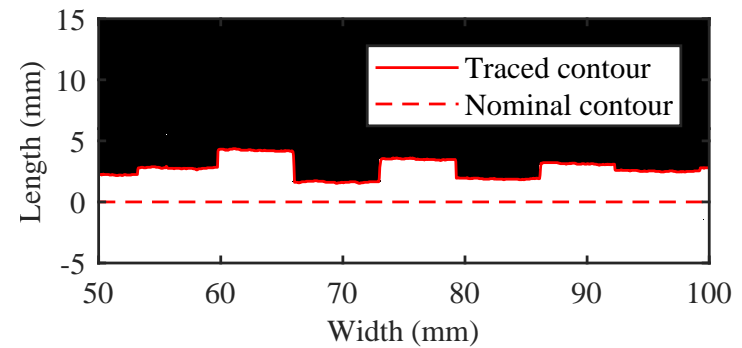

(b)

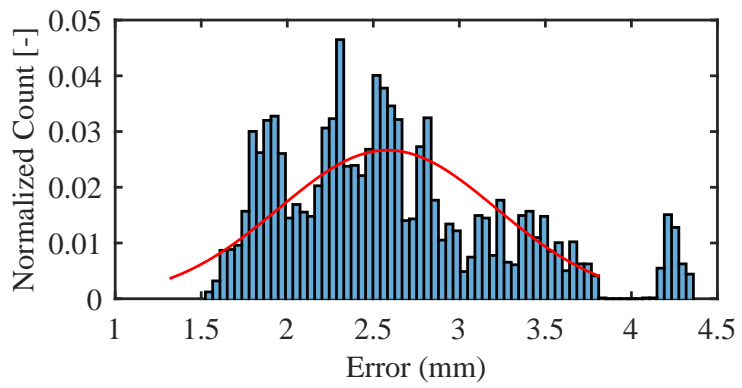

(d)

Figure 5.11 Accuracy analysis results for the ply contour at feed for $0^{\circ}$ orientation. (a) Thresholded image of ply contour. (b) Zoomed thresholded image of ply contour. (c) Error over full ply width. (d) Histogram of the error with normal distribution fit.

All orientations show a positive error. The feed error is much larger than the cut error and depends strongly on the orientation. The feed error exceeds the specified accuracy of the machine for $-45^{\circ}$ and $90^{\circ}$ orientations.

The feed error and its sensitivity to the fiber orientation are believed to be caused by friction in the feeding system of the used AFP machine. This system consists of the spool, a tensioning mechanism, a feeding tube and the feeding actuator. The tape has to be accelerated from stationary to the placement velocity of $200 \mathrm{~mm} / \mathrm{s}$ upon feeding. The feeding actuator appears to lack grip on the tape to overcome the friction in the feeding tube and accelerate the tape fast enough to keep up with the acceleration of the placement head. As a result, the tape is fed too slow and the tape starts too late. Changing the placement direction twists the feeding tube, which is in its neutral position at $0^{\circ}$ orientation, and increases the friction in the tube and thus further increases the feed delay. 


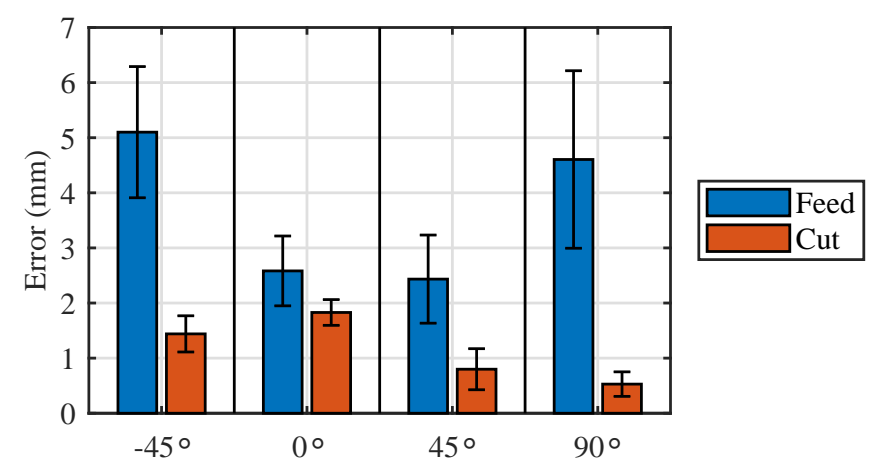

Figure 5.12 Feed and cut accuracy at $200 \mathrm{~mm} / \mathrm{s}$ for various fiber orientations.

The feed and cut errors may be reduced by recalibrating the feeding system such that feeding and cutting is initiated earlier to compensate for the late feed and cut. Improved grip of the feeding actuator or reduced friction in the feeding tube are required to reduce the influence of placement direction on the feed accuracy in the used AFP machine. Installing a new feeding tube reduced the feed error to below $2.5 \mathrm{~mm}$ for all placement directions. 


\section{Chapter 6}

\section{Discussion}

The previous chapters have described the consolidation of tailored components through automated lay-up followed by stamp forming. This chapter elaborates on the interrelation between the chapters by providing an overview of the process and by proposing design and processing guidelines. Issues that can arise during forming of tailored blanks are briefly addressed. Finally, the use of the process route in industrial applications is briefly outlined, including a demonstration on a realistic component.

\subsection{Void evolution mechanisms}

The previous chapters focused on void content as the main measure for the consolidation quality of the stamp formed component. The void content evolution, both interlaminar and intralaminar, is governed by several mechanisms. A generic overview of these mechanisms is provided in Fig. 6.1. An initial quantity of intralaminar voids can be present in the prepreg material due to incomplete impregnation of the fibers during the prepreg manufacturing process. Interlaminar voids are formed by entrapping air when multiple prepreg plies are stacked. Heat and pressure are applied to eliminate the voids and to consolidate the laminate. However, in case insufficient pressure is applied while heating, such as for example during IR heating prior to stamp forming, the blank may deconsolidate, thereby increasing the void content. Thermal expansion of moisture that is dissolved in the composite is responsible for the growth of both intralaminar and interlaminar voids once the matrix softens. Additionally, the release of internal stresses in the stack, for example frozen-in fiber stresses in the prepreg, can lead to decompaction 


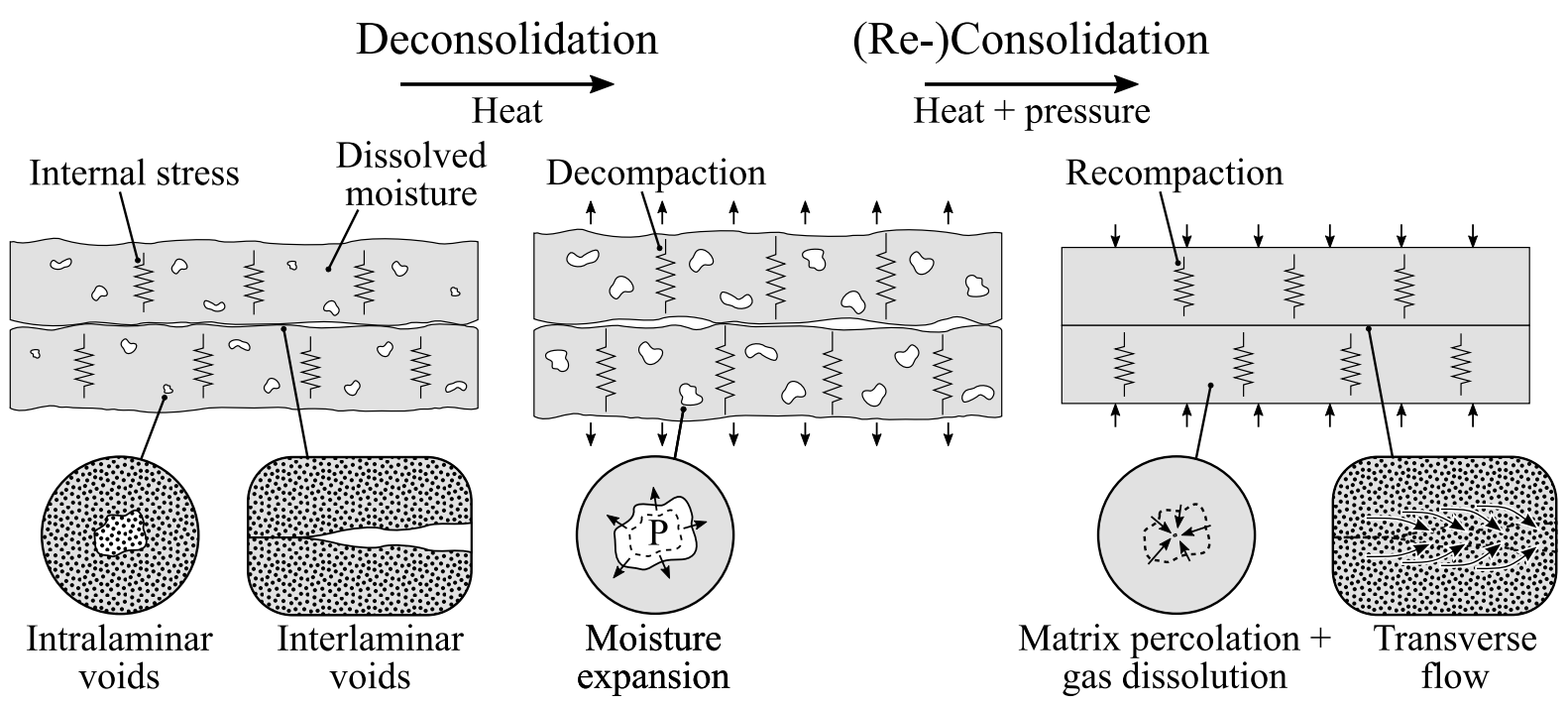

Figure 6.1 Void evolution and the contributing mechanisms during deconsolidation and (re-)consolidation.

of the fiber bed, which contributes to the formation of voids. Sufficient pressure is required to reduce and eliminate the voids. The fiber bed is recompacted and an in-plane pressure gradient generates transverse flow of the composite, which redistributes the material and closes the interlaminar voids. Transverse flow is also the main mechanism for consolidation of ply-drop pockets. The intralaminar voids are eliminated by percolation flow of the matrix through the fiber bed, which is a slow process for composites with high fiber volume fraction due to the low permeability of the fiber bed. The entrapped gas inside the voids is compressed and dissolved into the matrix.

\subsection{Process overview}

As with all processing techniques for thermoplastic composites, the consolidation quality of the final component is a function of the entire process chain. This makes manufacturing of high quality components not straightforward, but complex due to the many parameters involved in the process chain. The previous chapters have shed new light on the interrelation between important input parameters and the final part quality by studying the development in void content in more detail. Several important topics were addressed, ranging from deconsolidation of the blank during IR heating to the consolidation of ply-drops. Figure 6.2 schematically illustrates the process route along with relevant parameters and their relation to the chapters in this thesis. This section summarizes the process route and discusses the effect of the input parameters on the consolidation quality of the final component.

The process route starts with the selection of the input prepreg material. The 


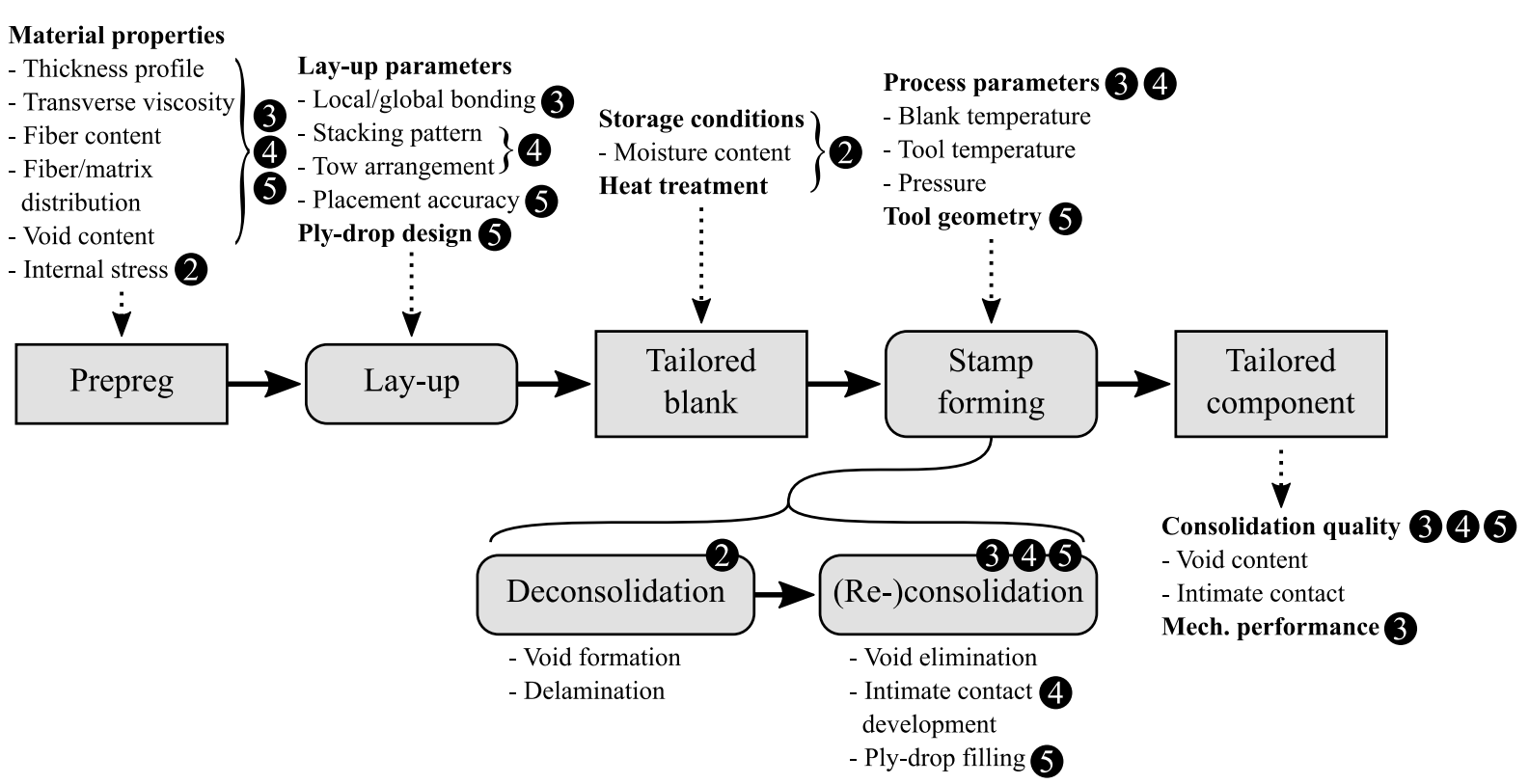

Figure 6.2 A schematic overview of the process route with input and output parameters. The numbers indicate the chapters that provides more detailed information on specific subjects.

material determines not only to a large extent the mechanical performance of the final component, but also the behavior during processing. Chapter 2 addressed the deconsolidation behavior of blanks, where internal stresses in the studied prepreg were found to cause an unwanted increase in void content or even delamination during blank heating. Other relevant prepreg properties are related to the material flow that is required for the two most important consolidation mechanisms, void elimination and intimate contact development. Chapter 3 discussed the influence of material parameters on these consolidation mechanisms from a qualitative point of view. Intimate contact development depends on the transverse viscosity, which, in turn, is closely related to the selected matrix material, fiber volume fraction and fiber/matrix distribution. The presence of a matrix rich prepreg surface aids intimate contact development due the locally low viscosity. The presence of intralaminar voids in a prepreg was found to have a negative influence on the final void content for the studied materials, as these voids are not completely eliminated during both layup and stamping when the required percolation flow is restricted by a dense fiber packing and the rapidly decreasing temperature during stamping. The final degree of intimate contact was found to be closely related to the thickness profile of the prepreg, which requires material redistribution by transverse flow during stamp forming. Chapter 4 elaborated on this by modeling the material flow during consolidation in order to illustrate that waves in the prepreg profile with a large amplitude and wavelength are dominant. Chapter 5 continued to show the importance of the transverse viscosity on the local consolidation of ply-drops, which is mostly governed by transverse flow of the dropped ply or surrounding plies. 
Next is the lay-up process. Chapter 3 compared ATP, where plies are bonded locally, with AFP, where plies are bonded by continuous welding. It was shown that both methods can yield good consolidation quality and mechanical performance after stamp forming. However development of intimate contact was found to be affected by the stacking pattern used during ATP. This was further elaborated in Chapter 4. which showed how applying ply staggering during lay-up can improve intimate contact development by reducing thickness variations in the blank. It was also shown that AFP blanks can benefit from a tow arrangement that minimizes the wavelength of the produced thickness profile. The design of the blank, in particular the ply-drops, as well as the accuracy at which these ply-drops are placed, influence the transverse flow that is required to consolidate ply-drops, which was discussed in Chapter 5.

Once the blank is manufactured, the processing behavior during stamp forming is mostly fixed. However, Chapter 2 showed that the deconsolidation behavior can be affected by moisture that has dissolved into the blank during storage. A subsequent heat treatment, for example drying in a convection oven, is then required to prevent deconsolidation by moisture expansion.

Only few parameters can control the consolidation behavior during stamp forming. Chapters 3 and 4 discuss the influence of the blank temperature and the applied pressure during stamping. Temperature controls the transverse viscosity, which increases rapidly during stamping as the blank cools from the blank temperature to the tool temperature in a matter of seconds. This leaves only a very small window for void elimination and intimate contact development. The pressure applied by the tooling provides the driving force for the required material flow. A well designed tool ensures that cavity and blank thickness match, such that little flow is required and sufficient consolidation pressure is guaranteed throughout the entire component. Chapter 5 discusses the importance of proper tool design, as well as blank alignment, for the consolidation of ply-drops.

\subsection{Optimum processing strategy}

This section provides a strategy for selecting important parameters for manufacturing tailored components by automated lay-up followed by stamp forming based on findings in the previous chapters. In general, all guidelines are aimed at maximizing consolidation quality of the final component.

\subsubsection{Prepreg}

The material choice plays an important role in the consolidation process. Matrix material, fiber volume fraction and ply thickness are usually fixed based on the desired mechanical performance of the component, although a low matrix viscosity, 
low fiber volume fraction and high prepreg thickness would be preferred from a processing point of view. The processing behavior can be affected by the tolerances on the prepreg thickness. The prepreg thickness should be consistent along the length of the prepreg and with small batch-to-batch variations. It is recommended that the thickness profile across the width of the prepreg consists of waves with a low amplitude $A$ and wavelength $\lambda$. For example, for the C/PEEK material considered in this thesis, a nominal thickness $h_{0}$ and a cross-ply lay-up, it is recommended that $h_{0}^{-3} A \lambda^{2}<650$ in order to achieve full intimate contact during stamp forming at 100 bar. Having a prepreg with a matrix-rich surface and a non-homogeneous fiber/matrix distribution is beneficial, as this aids in the development of intimate contact due to a lower transverse viscosity. Prepreg with a high intralaminar void content should be avoided, since eliminating intralaminar voids is challenging when the fiber volume fraction and matrix viscosity are high, especially in the short consolidation time available during stamp forming. Prepreg with high internal stresses should be avoided, as this can cause deconsolidation during stamp forming.

\subsubsection{Blank and tooling design}

Much of the blank and tooling design is fixed by the desired final geometry and the lay-up which is required to achieve the desired mechanical performance. However, there are still some design parameters that affect the consolidation process. Having plies in the lay-up with a fiber direction that is parallel to the drop-off is beneficial, as this allows for transverse flow. Extending dropped plies by a few millimeters into the tapering zone also helps in the consolidation of ply-drops by ensuring pressure on the ply-drop and the presence of material to fill the ply-drop pocket. This also makes the process more robust against inaccuracies during blank lay-up or blank-tooling misalignments during stamp forming. A key part of the consolidation process is a matching blank thickness and tooling cavity. The tooling cavity should be designed based on the consolidated ply thickness, such that sufficient consolidation pressure can be applied throughout the entire component. Furthermore, the use of (locally) non-rigid tooling may make the consolidation process more forgiving against small mismatches between blank thickness and tooling cavity. However, this approach was not explored within this thesis.

\subsubsection{Lay-up strategy}

The first step in determining the lay-up strategy is the choice of lay-up process. Both ATP and AFP can be used for lay-up, provided that the lay-up process provides sufficient interlaminar bonding for blank handling. Interlaminar bonding is generally better when using AFP due to the continuous welding. AFP also allows for more design freedom in tailored lay-ups due to the use of narrow tows. However, ATP 
usually offers higher productivity. Full interlaminar bonding during lay-up is not recommended, as this can lead to blank deconsolidation due to moisture expansion. This can be prevented by allowing the interlaminar voids to serve as channels for the release of moisture during blank heating. This takes away the need for an additional heat treatment prior to stamping. Staggering plies with the same orientation aids intimate contact development in ATP blanks by reducing the thickness variation in the blank. A staggering distance of half of the dominant wavelength of the prepreg thickness profile is recommended. If the dominant wavelength is unknown, it is recommended that the staggering distance equals the total tape width divided by the number of plies with that specific orientation. For AFP, it is recommended that the tows are arranged such that the wavelength of the resulting thickness profile of the ply is minimized, for example by alternating thick and thin tows. For example, using this approach, a maximum tow-to-tow thickness variation of $28 \mu \mathrm{m}$ is allowed for the $1 / 4$ inch $C /$ PEEK prepreg considered in this thesis when stamp forming at 100 bar. This requires the tow thickness to be known, which is usually measured during slitting and reported to the customer.

\subsubsection{Stamp forming process}

There are a few things that aid the consolidation process after all the previous considerations have been made. The blank should be heated to the recommended processing temperature. Although an increased temperature will slightly accelerate consolidation processes, overheating is not recommended as this potentially degrades the polymer. Positioning of the blank with respect to the tooling should be accurate, as blank-tooling misalignments can lead to poor consolidation of the tapering regions. The average pressure applied by the tooling is the main parameter that controls the consolidation process. High pressures, 100 bar or more for the C/PEEK material tested in this thesis, are recommended to ensure good consolidation throughout the entire blank, including the tapering zones. The tool temperature is generally isothermal and should be used to control properties such as residual stresses and crystallinity. However, using a high tool temperature together with rapid cooling, for example using an inductive heated tool surface in combination with water cooling, could help in delaying blank cooling for a few seconds while pressure is applied. This would accelerate the consolidation process, while still achieving short cycle times.

\subsection{Forming of tailored blanks}

All work presented in the previous chapters of this thesis have focused on either the deconsolidation or consolidation behavior during the stamp forming process. Forming was eliminated by only considering flat laminates. The manufacturing 
of a realistic tailored component will include forming, as the flat blank is shaped into a complex three dimensional part. During this process, forming defects can occur. These defects include out-of-plane wrinkles, in-plane fiber waviness, broken fibers, split plies, gaps and overlaps, all of which can degrade the mechanical performance. A significant amount of work has been published in the past decades on forming behavior and predictive models for the formation of defects have been developed. This has led to design guidelines and even commercially available forming simulation software. With this software it is possible to identify forming challenges and optimize the forming process in an early stage of the design process, which limits expensive testing or trial and error. However, the blanks considered are generally of uniform thickness and have a constant lay-up throughout the blank. Moreover, the blanks are fully preconsolidated, as opposed to the rapid lay-up blanks with only limited preconsolidation considered in this thesis. Introducing tailoring and limited preconsolidation to the blanks changes forming behavior compared to traditional uniform thickness preconsolidated blanks. Additionally, forming may affect the consolidation behavior. This section addresses issues that can be expected with forming and consolidation of complex tailored components and guides towards future research.

\subsubsection{Forming of complex shapes}

The forming of three dimensional shapes is a complex topic due to the many competing forming mechanisms. However, the consolidation of these shapes also introduces a challenge. A typical component contains folds, flanges or even doubly curved surfaces. Each of the planes in a part should be compacted with sufficient pressure to ensure proper consolidation. Any mismatch between the blank thickness and the tool cavity can lead to poor consolidation due to a local lack of pressure. Additionally, a local high pressure in flanges can induce high tractions, which can lead to undesired fiber reorientation and warpage. The initial blank thickness is likely to be larger than the consolidated thickness for blanks that are manufactured by rapid lay-up due to the presence of voids. Furthermore, deconsoldation may increase the blank thickness even further. As a result of the thickness mismatch, the consolidation pressure is first applied on surfaces that are not perpendicular to the direction of the applied load, for example flanges. This is illustrated in Fig. 6.3 for a C-profile formed from a blank that is thicker than the tool cavity. The compaction of the flanges introduces traction and potential fiber reorientation. Sufficient compaction of the flanges is required in order to ensure that the web section is pressurized and consolidated.

Forming simulations are typically based on a matching blank thickness and tool cavity based on the consolidated ply thickness. Hence, the simulation may miss the high tractions and resulting fiber reorientation that are induced by the larger 


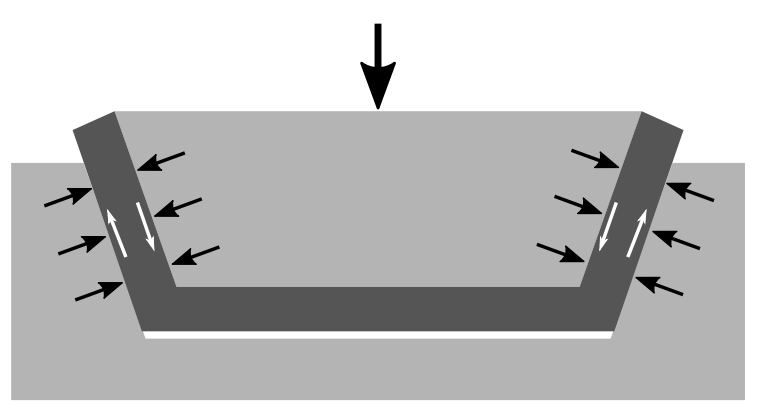

Figure 6.3 Traction in the flanges and lack of consolidation pressure in the web when forming a C-profile with a blank that is thicker than the designed tool cavity.

initial thickness of a blank. The accuracy of forming simulations would therefore be improved by including the true thickness evolution of the blank.

\subsubsection{Forming induced thickness changes}

As discussed in Chapters 3,5, the consolidation quality of a stamp formed blank is very much determined by the blank thickness and tool cavity. Blank thickness variations due to prepreg thickness variations and stacking patterns, as well as a mismatch between designed tool cavity and actual blank thickness, can lead to poor consolidation. A blank-tool cavity mismatch may also arise due to forming. Intraply shearing causes an increase in ply thickness as a blank is formed into its final shape, as shown in Fig. 6.4 (a) [1]. Assuming conservation of volume, the relative ply thickness increase $\Delta h / h_{0}$ as a function of shear angle $\gamma$ is given by

$$
\frac{\Delta h}{h_{0}}=\frac{1}{\cos (\gamma)}
$$

The thickness increase due to shearing can be quite significant, as Fig. 6.4 (b) shows. Even at shear angles below $20^{\circ}$, a thickness increase of up to $10 \%$ can be expected. This is a similar order of magnitude as the prepreg thickness variations found in Chapter 3 and thus is likely to cause problems with consolidation when this thickness change is not taken into account in the design of the tool cavity. Forming simulations can aid in the design process of the tooling by predicting the material thickness based on the local shear angle.

\subsubsection{Influence of blank consolidation quality}

Limited interlaminar bonding exists in the blanks considered in this theses due to the focus on rapid lay-up. Adjacent tapes may also not be bonded well to each other. Additionally, deconsolidation during blank heating causes void growth at the ply interfaces or even complete delamination of plies, as was shown in Chapter 2 . 


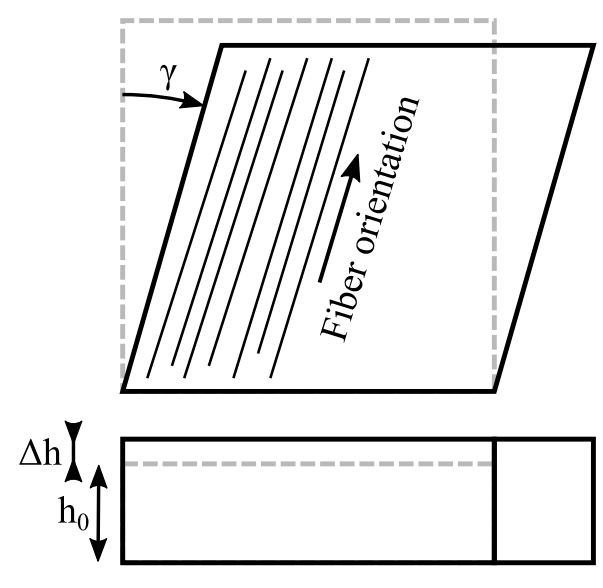

(a)

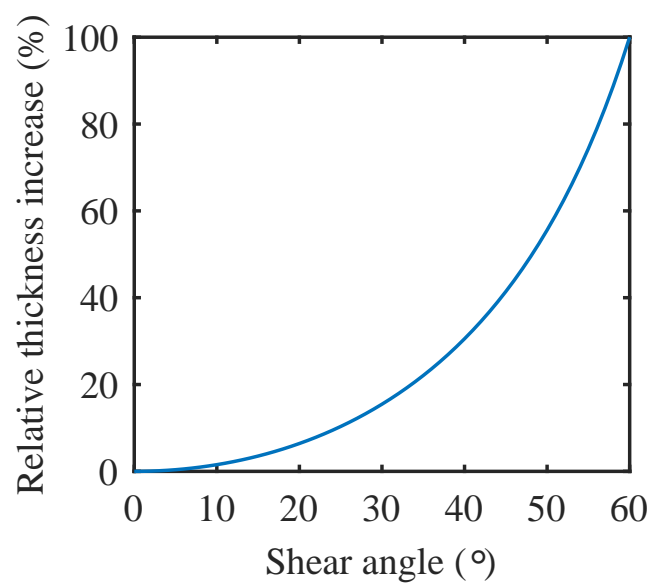

(b)

Figure 6.4 (a) Forming induced thickness increase due to intra-ply shearing. (b) Relative thickness increase as a function of shear angle.

The limited blank integrity makes blank handling challenging. Moreover, the lack of interlaminar bonding will affect the forming behavior and could potentially lead to forming defects such as wrinkles or split plies. Figure 6.5 shows an example of the influence of the blank consolidation quality when stamp forming cross-ply blanks with a hemisphere tool. Blanks that were fully preconsolidated by press consolidation showed intact plies after forming. However, blanks that were manufactured by AFP, having poor interlaminar bonding and showing significant deconsolidation, showed split plies.

The example shows that forming defects indeed can occur due to a limited degree of blank consolidation and subsequent deconsolidation. Deconsolidation should therefore probably be avoided in order to improve blank handling and reduce forming defects. Improved blank integrity can also be achieved by improving the interlaminar bonding in the blank, for example by using prepreg with a matrix-rich surface, as was shown in Chapter 3 .

Current commercially available forming simulation softwares do not take the initial consolidation state of the blank into account. Typically, the material property data used in the simulation software is based on perfectly consolidated plies. This way the forming behavior of unconsolidated or partially consolidated blanks is not represented accurately by the simulation and forming challenges are overlooked. Potentially, the results of current simulations on fully consolidated blanks may be used to find indicators for forming defects in rapid lay-up blanks. However, in a worse case, material property data as a function of consolidation state is required in order to accurately capture the forming behavior of blanks produced by rapid lay-up. 


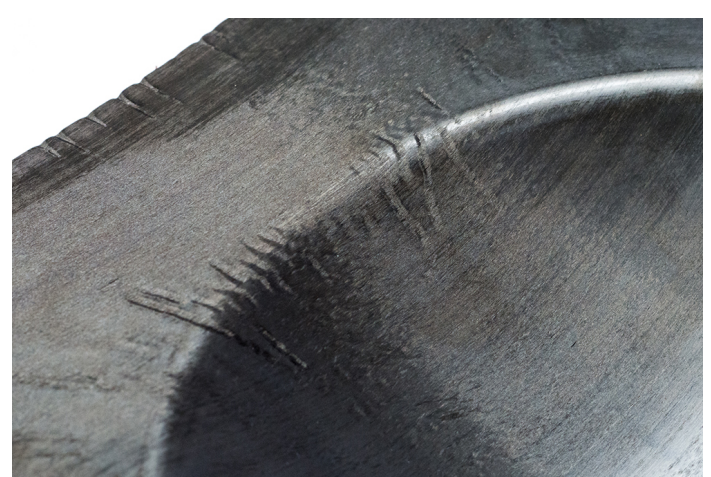

(a)

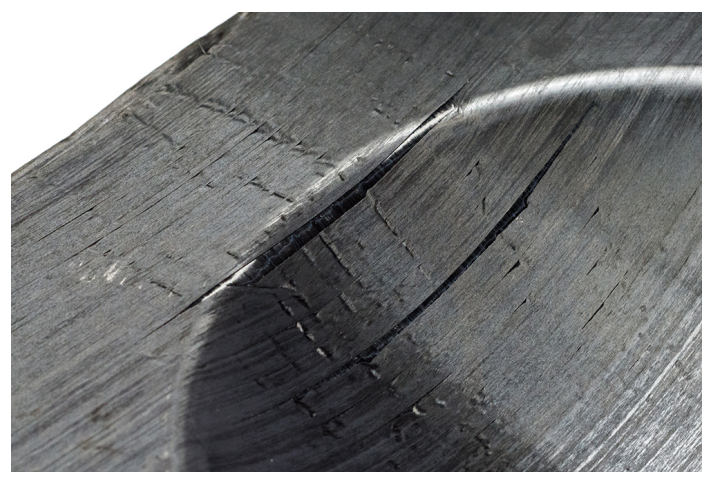

(c)

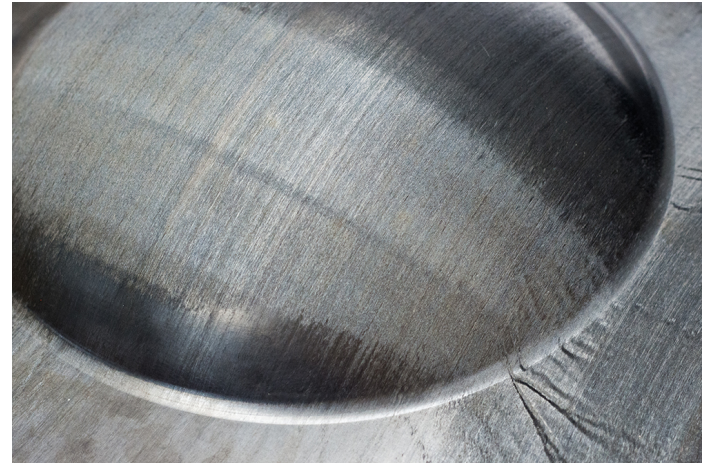

(b)

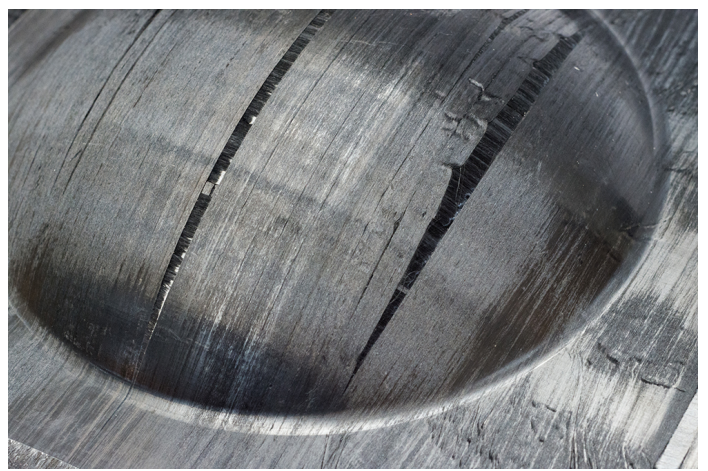

(d)

Figure 6.5 Cross-ply blanks formed with hemisphere tooling. $(a, b)$ Press-consolidated blank: wrinkles, but intact plies. (c,d) AFP blank (with poor interlaminar bonding and deconsolidation): wrinkles and split plies.

\subsubsection{Influence of tailoring}

Tailoring introduces local variations in blank thickness and lay-up. Local reinforcement patches might not extend to the contour of the blank, meaning that their behavior cannot directly be influenced by grippers or blank holders.

Furthermore, the thickness variations affect the local slip distances of the plies. Potential forming issues can be illustrated based on the forming of a simple V-bend with a local reinforcement at the corner, as shown in Fig. 6.6 (a). A quite extreme example is shown, where the number of plies at the radius is doubled by adding plies at the mid-plane. Bending of the blank is required at the radius, which is dominated by inter-ply slip, especially when the consolidation quality of the blank is poor [2, 3]. Due to the difference in path length at the inner and outer radius, there is a larger amount of inter-ply slip required in the legs compared to the uniform thickness blank. This slip is resisted by inter-ply friction in the legs, which causes an in-plane compressive stress on the plies at the inner side of the radius near the tapering zone. This can make these plies buckle out-of-plane, forming wrinkles. This was observed in V-bend forming trials on a blank with a 12-ply quasi-isotropic lay- 
Uniform thickness blank

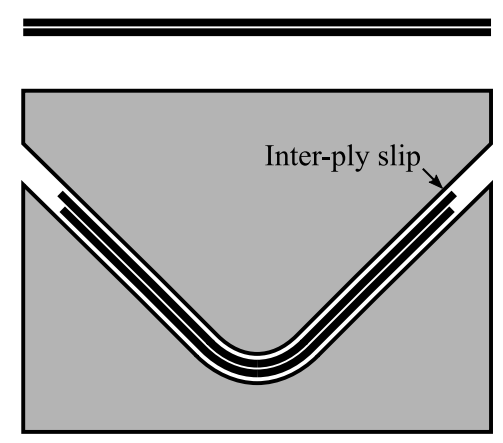

Tailored blank

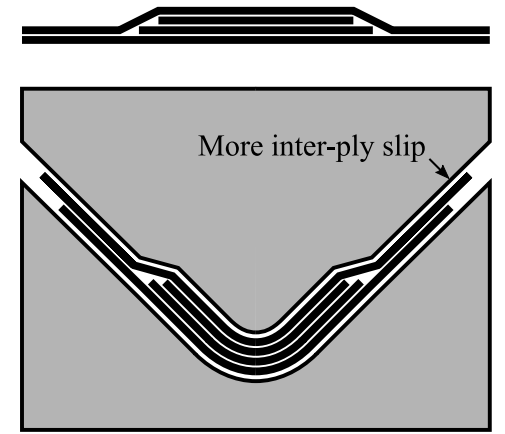

(a)
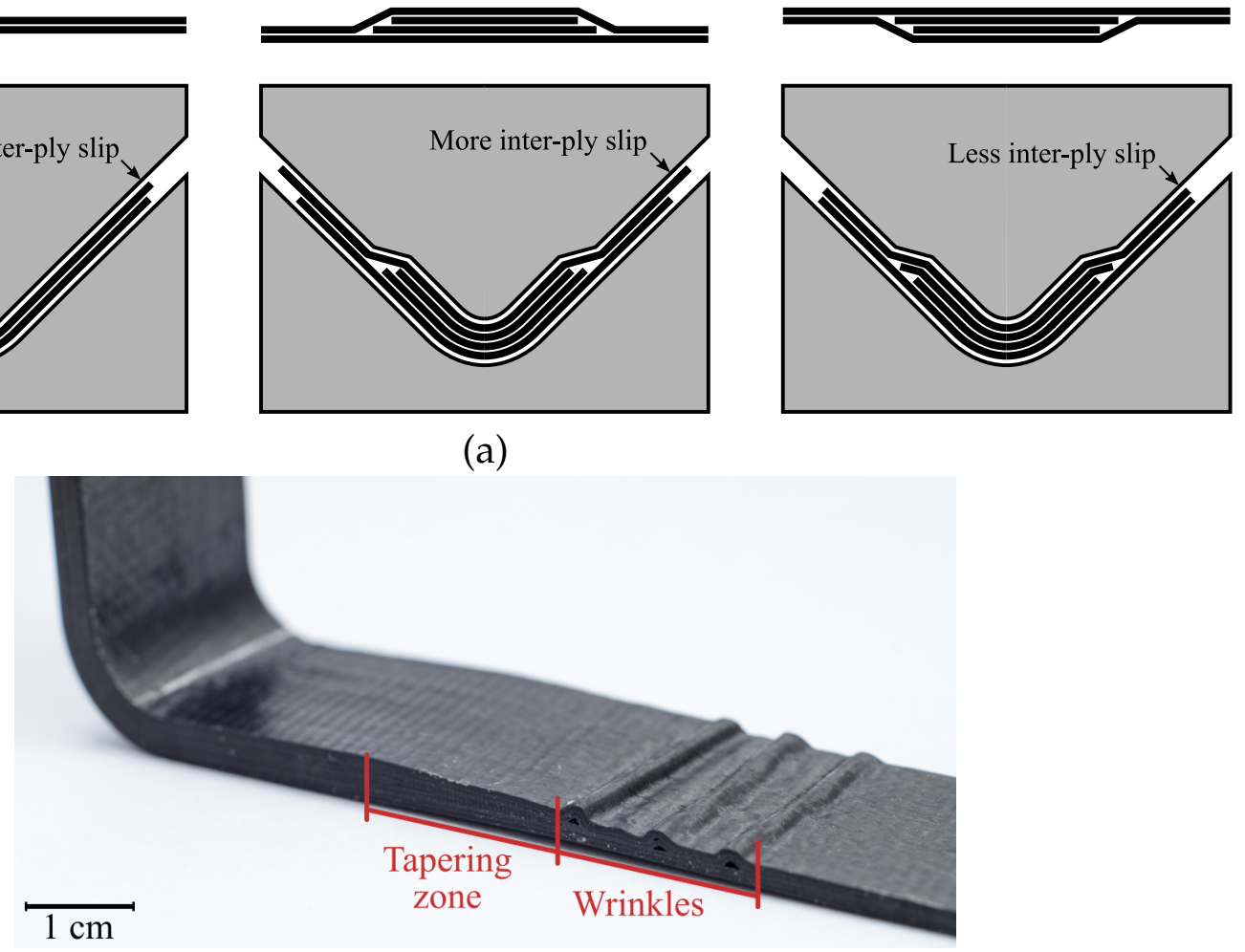

(b)

Figure 6.6 (a) Forming of a V-bend using a uniform thickness blank and a tailored blank where the lay-up is doubled at the radius. Inter-ply slip in the legs is required to bend the blank. (b) Wrinkles appear next to the tapering zone of a tailored blank with a 12-ply quasi-isotropic lay-up which is doubled at the radius.

up which is doubled at the radius, as shown in Fig. 6.6 (b). The wrinkling can most likely be influenced by the exact lay-up, as well as the orientation of the blank. This is illustrated in Fig. 6.6 (a), where turning the blank up side down reduces the slip required in the legs, which may prevent wrinkling.

Furthermore, the thickness variations themselves may affect the forming behavior. Bending of the blank is dominated by inter-ply slip [2, 3]. Basically, the inter-ply slip is needed to accommodate for the difference in path length at the inner and outer radius of a bend, as is illustrated in6.6 (a) for a uniform thickness blank. The slip is resisted by inter-ply friction. These two mechanisms are competing and this is in fact one of the main causes for wrinkling in fiber reinforced thermoplastic composites [2]. Local tailoring can significantly affect the wrinkling formation. Take for example the tailored blank illustrated in 6.6 (a). Here, the bent section has a larger thickness than the legs. The difference in path length at the outer and inner radius, now results in an increased slip length in the legs compared to the uniform thickness case. As a result, the plies in the legs may buckle out-of-plane, forming wrinkles. This was observed during V-bend forming trials with a 12-ply QI lay-up, which was doubled 
at the radius, as shown in Fig. 6.6 (b). The wrinkling can most likely be influenced by the exact lay-up, as well as the orientation of the blank. This is illustrated in Fig. 6.6 (a), where the tailored blank is turned up side down in order to reduce the slip required in the legs, which may prevent wrinkling.

The example demonstrates how local reinforcements can significantly affect the forming behavior. However, there are currently no industrial guidelines to aid the engineer in the design of tailored blanks for defect-free forming of complex components. More research is required on the influence of tailoring on forming behavior such that these guidelines can be developed.

\subsection{Industrial application}

This thesis has presented a novel processing route for the manufacturing of complex tailored components. This section discusses typical features of parts that can be manufactured by this approach. Finally, an example of an industrial application is given by manufacturing a realistic tailored component.

\subsubsection{Typical design and application}

The combination of automated lay-up and stamp forming provides unique opportunities to the components that can be produced, but also some limitations. The following list provides typical features of such components.

- Geometry Using AFP to lay-up flat blanks and using stamp forming to achieve the final shape of the component allows for geometries with small radii and double curvatures. Such parts cannot be manufactured with, for example, insitu AFP due to tight concave corners.

- Contour Complex part contours are possible while minimizing trimming scrap thanks to the near net-shape lay-up. Holes and cut-outs can be included in the blank. Such contours are not possible with, for example, conventional pressconsolidated blanks without generating significant trimming scrap, as these are usually cut from a large rectangular laminate.

- Thickness The stamp forming process limits the applicability to thin-walled shell-like components. The thickness is mainly limited by small radii in the component.

- Loading The use of unidirectional composites and automated lay-up offer the ability to tailor the lay-up to the mechanical loads of the component. This makes the process route very suitable for manufacturing structural components, 
especially those with non-uniform loading throughout the component. Local reinforcements at load introduction points, for example for joining by welding or mechanical fastening, can easily be included in the lay-up.

- Weight Tailoring of the lay-up also offers the opportunity to minimize the weight of the component by eliminating unnecessary material. This makes the process route especially suitable for manufacturing components for applications where weight minimization is key, such as in aerospace industry.

- Size Typical stamp forming components measure up to $1 \mathrm{~m}^{2}$, varying from square to long and slender. Considering a typical stamping pressure of $100 \mathrm{bar}$, this would require a $10 \mathrm{MN}$ forming press. Larger tailored parts can be manufactured by in-situ AFP or AFP followed by autoclave or OoA consolidation.

- Costs Both tailoring and near net-shape lay-up reduce material consumption. The process route can therefore be interesting for applications where material usage is a cost driver. However, an investment in lay-up equipment may be required. An ATP machine will generally offer higher lay-up rates at a lower price than an AFP machine, but with less tailoring capability and more trimming scrap.

- Amount Relatively short cycle times are possible by eliminating the need for an additional preconsolidation step prior to stamp forming. This makes the process route suitable for production of large series.

Based on the described component features, some examples of typical applications can be provided. When looking at the aerospace industry, aircraft components such as ribs or spar sections of a wing, access panels or a thrust reverser blocker door are suitable components. These are thin-walled components with structural loading that can benefit from tailoring. In automotive applications one could think of a tailored car seat back structure, rear wall or tail gate. The process route can be extended to even more complex optimized components by integrating an overmolding step into the stamp forming process. This offers further potential for function integration by overinjecting a fiber reinforced polymer onto the blank directly after forming, for example to add ribs, finish edges or integrate metal inserts for assembly [4, 5].

\subsubsection{Alternative processing routes}

Shell-like components can be manufactured via various process routes, all with their specific advantages and disadvantages. This section compares the process route proposed in this thesis with various alternative available processing routes based on some generic comparison criteria. An overview is provided in Tbl. 6.1. 
Stamp forming of press-consolidated blanks is the conventional approach for manufacturing small to medium sized shell-like components. The blanks are cut from large preconsolidated laminates of uniform thickness, which does not allow for tailored lay-ups and results in a lot of trimming scrap due to blank nesting. However, since many blanks can be preconsolidated in a single press consolidation cycle, the cycle times per blank are attractive for the production of large series.

The components that can be manufactured via the proposed process route are very similar to those that can be manufactured from conventional press-consolidated blanks. However, the use of automated lay-up technologies offers additional layup design freedom that enables tailoring and near net-shape lay-up. Lay-up can either be performed by ATP or AFP, where AFP offers most lay-up flexibility. As a result, more efficient tailoring and near net-shape lay-up are possible with AFP. However, productivity is higher for ATP. Tool costs are low, since the lay-up tooling is a universal flat tool and only component specific stamp forming tooling is required. Investment costs of AFP equipment are generally larger than for ATP equipment.

Other process routes apply AFP directly on a tool that has the final geometry of the component. The cycle times for these approaches are much longer due to either layup with in-situ consolidation, which is currently limited to low rates, or an additional autoclave or OoA consolidation step. This makes these process routes more suitable for larger tailored components, for example wing skins or fuselage panels, which are too large for stamp forming. The costs of autoclave consolidation are high due to the large equipment investment and consumable costs, such as vacuum bagging film and nitrogen. This makes OoA consolidation an attractive alternative.

\subsubsection{Demonstrator: Manufacturing a tailored spar}

The results of this thesis are put together by manufacturing a realistic component in the form of a spar. This demonstrates the capability of the process route, including lay-up tailoring, near net-shape lay-up and consolidation by stamp forming without an additional preconsolidation step.

\section{Design}

Figure 6.7 shows the designed component, which is based on a spar from a wing box of a small wing 1 . Such a spar is a thin-walled component, which makes it suitable for stamp forming. The decreasing load from fuselage to wing tip makes it an excellent example of a component that benefits from a tailored lay-up. Only a small section of the spar is designed due to size restrictions of the forming press at TPRC. The spar

\footnotetext{
${ }^{1}$ Design in cooperation with GKN Fokker Technologies (https://www.gknaerospace.com)
} 


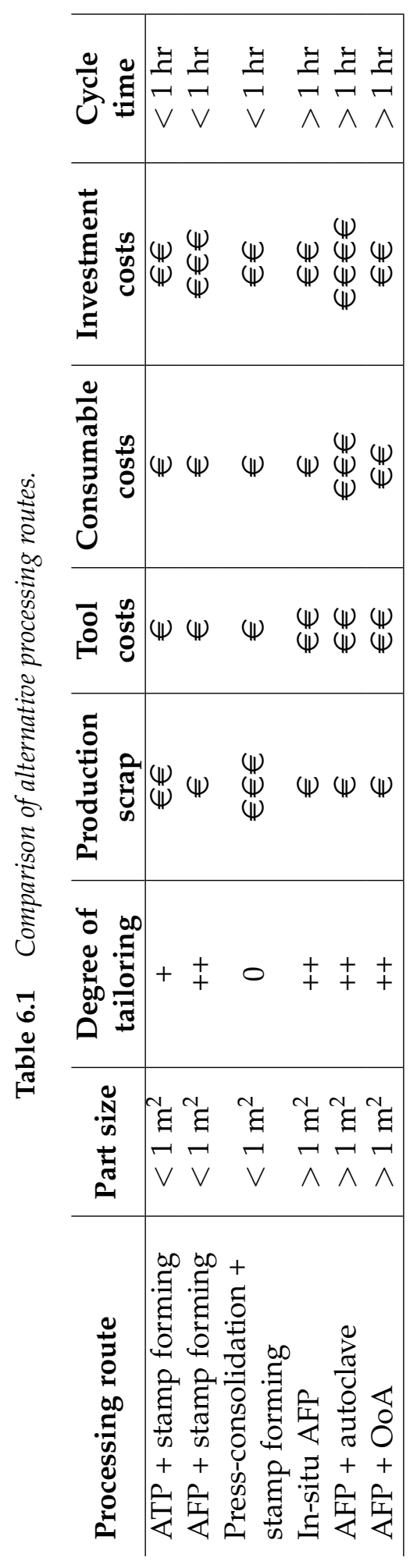


includes a tailored lay-up with local reinforcements. Two joggles are present in order to reduce the height of the spar towards the wing tip.

Four lay-up zones are present and labeled A to D. Zone $C$ is a quasi-isotropic base lay-up. Zones A, B and D include local reinforcements of either the web (B), the endflange (A) or both the web and flanges (D). The number of plies varies between 15 and $23(2-3 \mathrm{~mm})$. Although the main benefit of using tailored lay-ups is the possibility of structural optimization, this thesis focuses on the consolidation of a component with tailored lay-up. Therefore, no structural optimization was performed and the lay-up was chosen in cooperation with GKN Fokker Technologies.

All tapering regions between the lay-up zones are designed based on the findings of Chapter 5 with a tapering ratio of 1:24 (3.2 $\mathrm{mm}$ between each dropped ply) and with the dropped plies interleaved between continuous plies. Dropped plies extend $1.6 \mathrm{~mm}$ into the tapering region to guarantee pressure on the tapering region and to make the blank more robust against blank-tooling misalignments, as these could lead to poor consolidation of the tapering region.

The blank contour was designed such that scrap from trimming operations both before and after forming was minimized. For first trials, a post-forming trimming edge of $1 \mathrm{~cm}$ was assumed in order to guarantee good consolidation close to the edges. Additionally, four gripper tabs were included for blank handling during forming. The minimum tow length that can be placed by an AFP machine has to be taken into account when designing the blank. The minimum tow length was $100 \mathrm{~mm}$ in case of the machine used in this work. This makes near net shape blank lay-up challenging in the corners of the blank. Hence, some pre-forming trimming scrap could not be avoided, in particular for the plies with $\pm 45^{\circ}$ orientations. Figure 6.8 shows the blank contour with the current pre-forming trimming scrap, post-forming trimming scrap and final unfolded spar contour.

Matched metal aluminum tooling was designed to form the part. The tooling cavity was based on an average consolidated ply thickness of $0.135 \mathrm{~mm}$, which was determined based on the final thickness of flat stamped [0/90] $]_{4 \mathrm{~s}}$ AFP blanks (Chapter 3). Note that a $0.2 \mathrm{~mm}$ gap was applied during AFP to accommodate for tape widening during placement and prevent overlaps. Engravings in the tooling allowed for checking the alignment of the blank after stamping.

Forming simulations were performed using AniForm ${ }^{2}$, The simulations enable the prediction of the forming behavior and the occurrence of potential defects. The forming simulations did not reveal any critical issues during forming. The forming simulations also aided the design of the tooling and gripper system, as well as the design of the near-net shape blank contour.

\footnotetext{
${ }^{2}$ Aniform Engineering B.V. (https://www.aniform. com)
} 


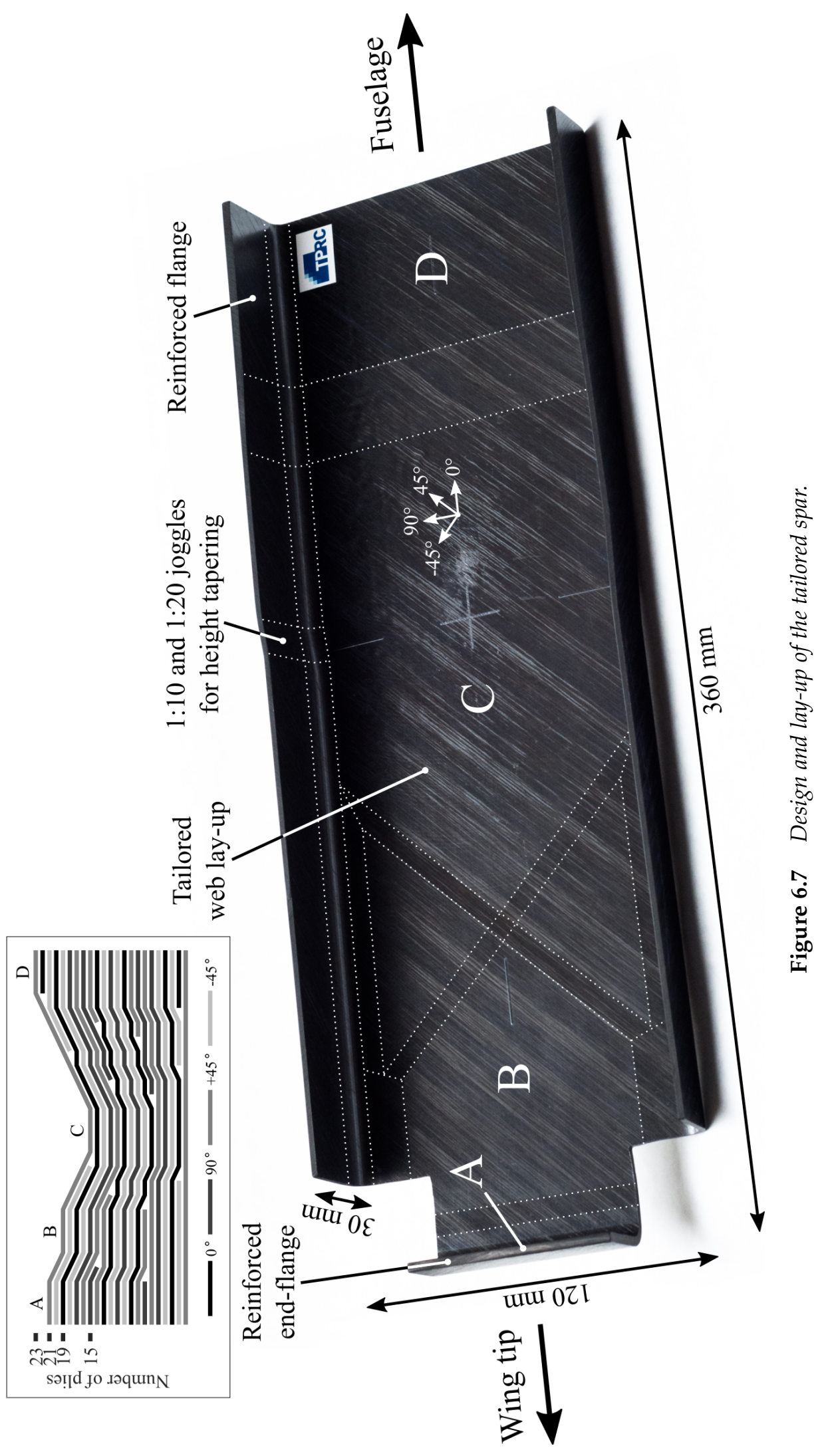




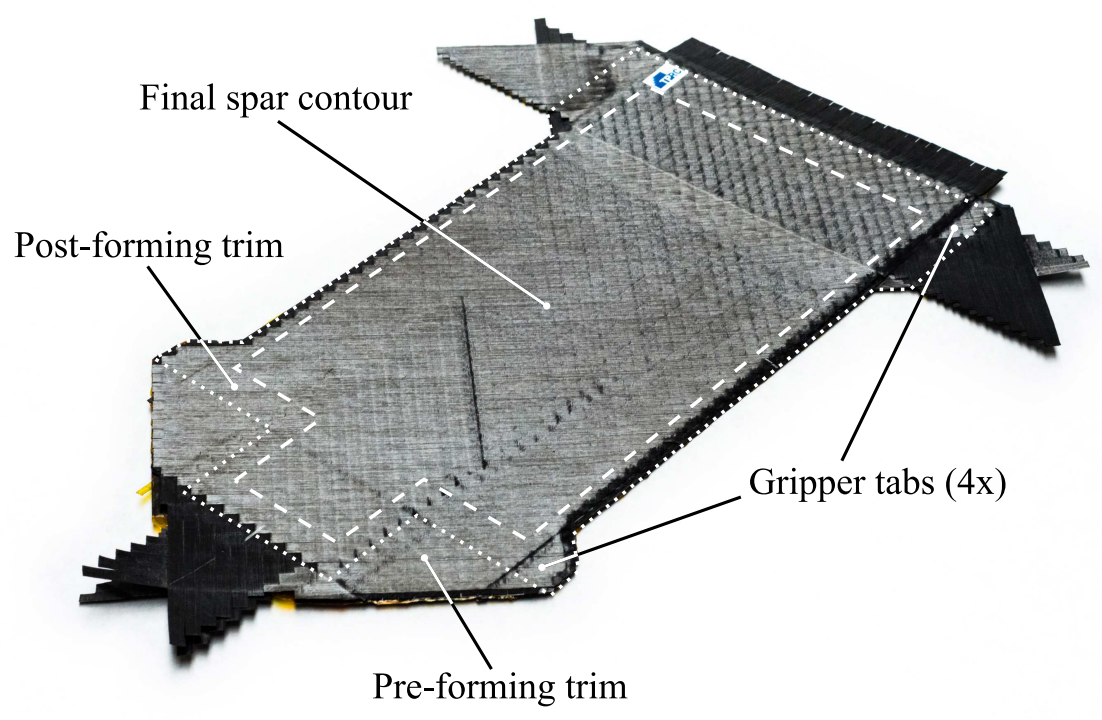

Figure 6.8 Contour of the blank.

\section{Material and processing}

Cytec APC-2 C/PEEK unidirectional prepreg tape was used to lay-up the blanks. This material performed very well in consolidating flat laminates (Chapter 3) and ply-drops (Chapter 5) due to its matrix rich surface and limited deconsolidation. However, the prepreg has an initial intralaminar void content of roughly $5 \%$ and these will most likely not be completely eliminated during stamp forming (Chapter 3).

A single 1/4"-tow Coriolis Composites AFP machine equipped with a $1 \mathrm{~kW}$ diode laser for heating was used to lay-up the blanks. A lay-up rate of $200 \mathrm{~mm} / \mathrm{s}$ was applied, which was limited by the required laser power to reach a nippoint temperature of $450{ }^{\circ} \mathrm{C}$ and the accuracy of starting and stopping tows at high velocity. However, higher lay-up rates of $500 \mathrm{~mm} / \mathrm{s}$ or more and multitow $(8,16$ or 32 tows) placement are possible in the most recent AFP machines available in industry, which greatly increases productivity. After lay-up, a preforming trimming step was performed to eliminate excess material that could not be prevented due to the minimum tape length of the AFP machine. The blanks were then dried in a convection oven for 3 hours at $250{ }^{\circ} \mathrm{C}$ prior to stamping, following the recommendations of Chapter 2 . This prevents void formation and delamination by moisture expansion during stamp forming.

The blanks were stamp formed on a 200 tonnes forming press equipped with an automated transfer frame to transport the blank from the IR oven to the forming station. Laser guiding was used to align the blanks in the transfer frame. Springs with grippers were applied to support the blank at the four gripper tabs (Fig. 6.8), while the end-flange was supported by a thin wire. The blanks were heated in an 


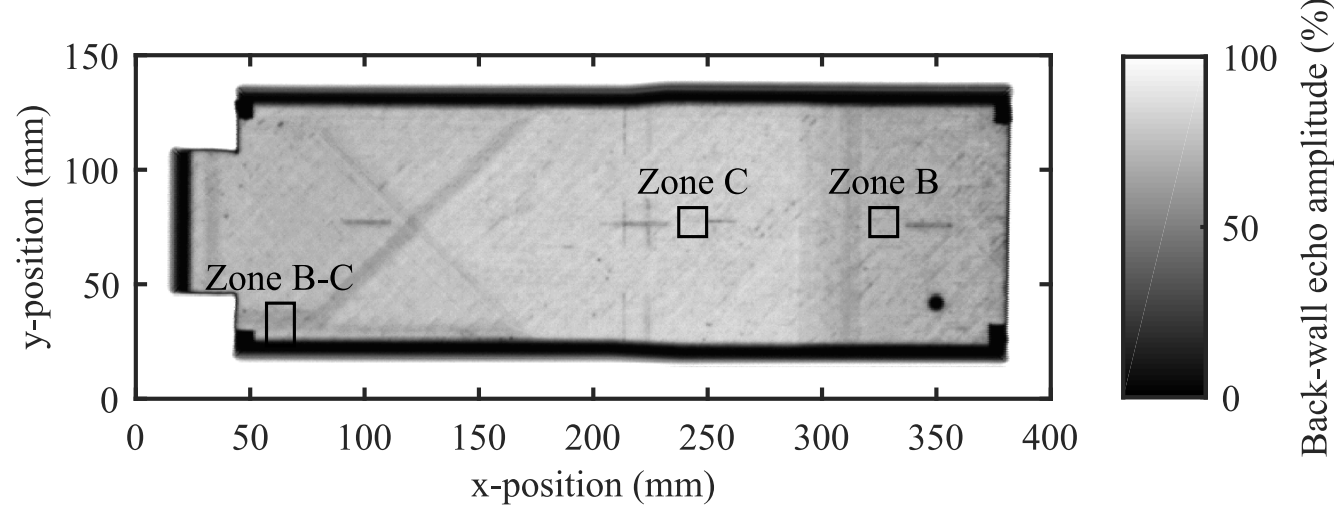

Figure 6.9 C-scan of the web of a spar showing good consolidation in the web. The rectangles mark the location of the cross-sectional micrographs in Fig. 6.10 The black dot is a reference marker.

IR-oven to a core temperature of $390^{\circ} \mathrm{C}$ in 180 seconds. Subsequently, the blank was automatically transferred to the forming station without considerable temperature loss. The tooling was then closed and consolidation occurred by maintaining a pressure of 100 bar $(414 \mathrm{kN})$ for 60 seconds, while the spar was cooled by the isothermal tooling at $250{ }^{\circ} \mathrm{C}$. Finally, a post-forming trimming step was performed to obtain the final shape of the spar as shown in Fig. 6.7 .

\section{Results}

Consolidation quality A series of five spars was produced. The consolidation quality of the spars was checked by visual inspection, C-scan (web), A-scan (flanges) and microscopy. The web of the spars showed consistent C-scans with no defects, as shown in Fig. 6.9. No defects were detected in the flanges during the A-scans. Cross-sections of the spar confirmed good consolidation of all zones, including plydrop regions. Some examples are shown in Fig. 6.10. No interlaminar voids were observed in the cross-sections. A low quantity (less than $1 \%$ ) of intralaminar microvoids has remained from the initial prepreg. A small area with a rough surface was observed in the center of the web, as well as on the outer radii near the joggles. However, cross-sections confirmed that consolidation was good in these regions.

Defects Warpage was observed in al spars, as shown in Fig. 6.11. This warpage is the result of local fiber reorientation in zone $C$ and $D$ of the bottom $45^{\circ}$ ply during forming. The initial blank thickness is slightly larger (less than $10 \%$ ) than the designed tooling cavity, as this is based on the consolidated ply thickness. This mismatch between blank thickness and tooling cavity causes high tool-ply friction in the flanges during tool closure, leading to tensioning and in-plane shearing of the 


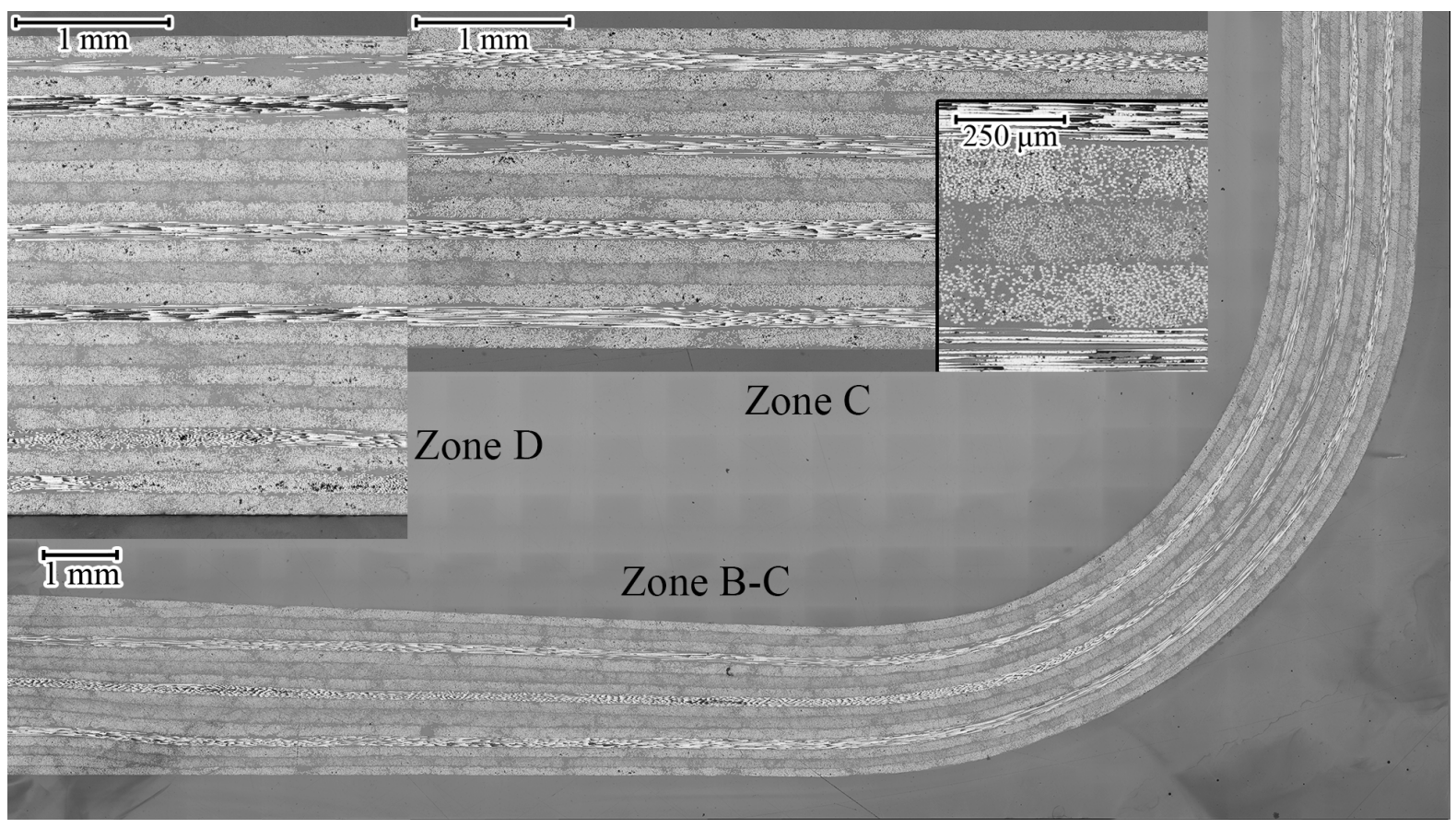

Figure 6.10 Cross-sectional micrographs from zone $C$ and $D$ in the web and the transition from zone $B$ to zone $C$ in the longitudinal flange. The location of the micrographs is marked in Fig. 6.9

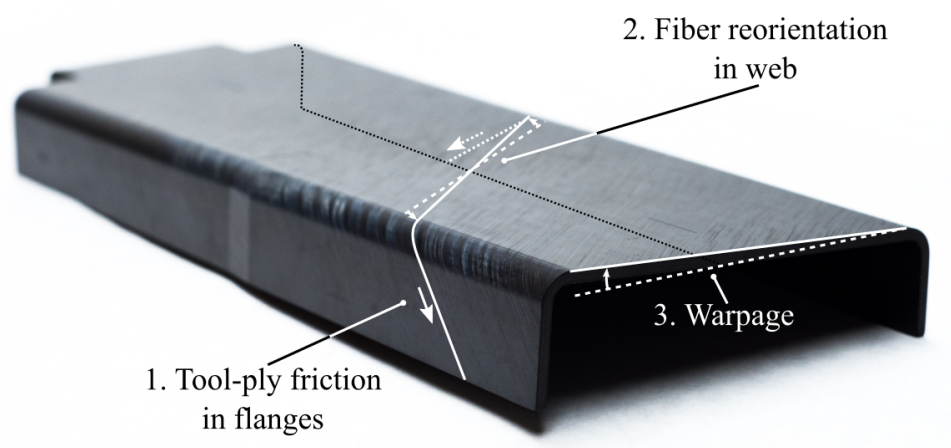

Figure 6.11 Warpage as a result of fiber reorientation due to tool-ply friction in the flanges.

outer ply. Since the compaction load is primarily carried by the flanges, there can be a lack of pressure in the web. This explains the observed rough surface area in the center of the web.

Additional forming trials have shown that the defects become more pronounced when a slightly thicker (only $3 \mu \mathrm{m}$ ) prepreg is used. In combination with a lack of blank integrity and additional deconsolidation, the bottom ply showed splits and there was poor consolidation quality in the web. This confirms once again the sensitivity of the process to the input prepreg material and the importance of a matching blank thickness and tooling cavity. It also highlights the need for further research on the forming and consolidation of complex tailored components, as was 
addressed in Section 6.4 .

Blank manufacturing and material savings The use of a single $1 / 4$ " tow AFP machine and a placement velocity of $200 \mathrm{~mm} / \mathrm{s}$ does not represent rapid lay-up in an industrial application. The duration on a multi-tow machine and at higher layup rates can be estimated using Coriolis Composites CADFiber lay-up simulation software. The current lay-up duration of 108 minutes is reduced to 9 minutes by using an 8-tow AFP machine at $500 \mathrm{~mm} / \mathrm{s}$. This can potentially be reduced even further by laying up multiple blanks simultaneously. Combined with the stamp forming cycle of 4 minutes this provides a good basis for series production of tailored components.

The benefit of near net-shape and tailored lay-up by AFP can be illustrated by comparing the material consumption with a conventional press-consolidated uniform thickness blank (23-ply, lay-up D, $400 \times 230 \mathrm{~mm}^{2}$ ). This is shown in Fig. 6.12. With this rectangular blank, the total trimming scrap accounts for $35 \%$ of the total material consumption of $461 \mathrm{~g}$ per spar. Applying near net shape lay-up reduces the trimming scrap to $26 \%$ and the total material consumption by $12 \%$. Material savings could be even higher for more complex blank contours, as the current blank contour is very close to a rectangle. Applying tailoring reduces the spar weight by $25 \%$ and the trimming scrap by another $9 \mathrm{~g}$. Together, the total material consumption is reduced by $30 \%$. Although the tailored lay-up was not based on structural optimization, and the performance of the conventional uniform thickness spar and tailored AFP spar therefore cannot be compared, these numbers indicate the potential savings in part weight and material consumption by using AFP for blank manufacturing.

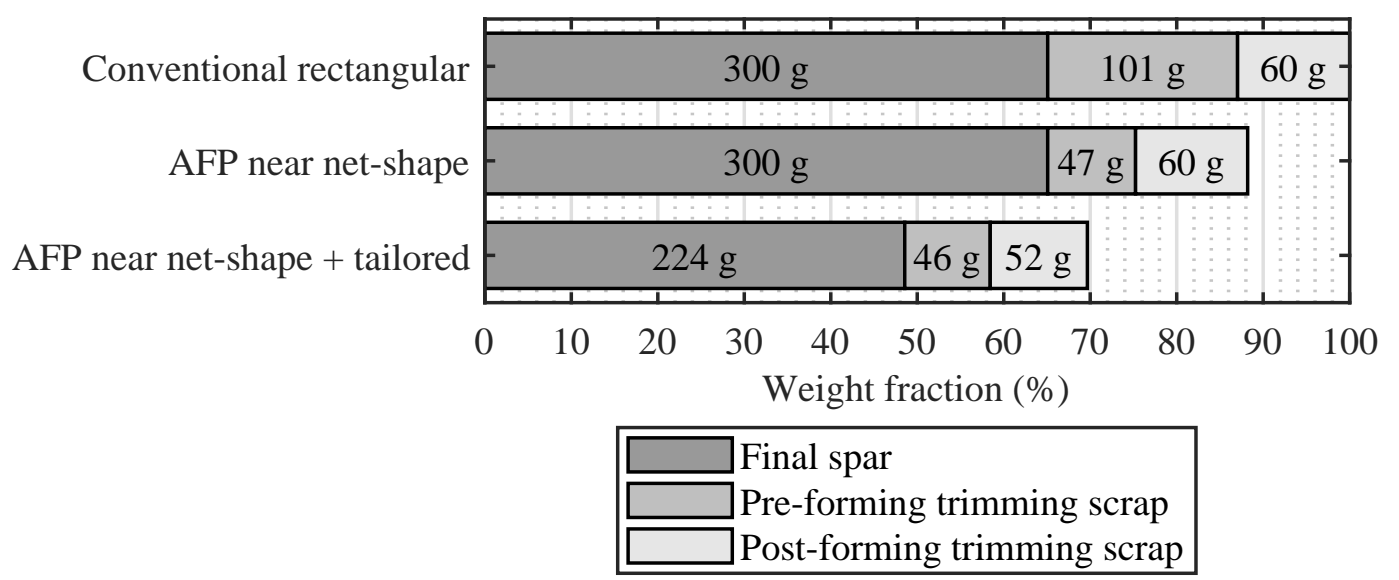

Figure 6.12 Material savings per spar by near-net shape lay-up and tailoring. Note: tailoring not based on structural optimization. $100 \%=461 \mathrm{~g}$. 


\subsection{Concluding remarks}

This chapter has put the results of the previous chapters in a wider perspective by providing an overview of the process route and the involved mechanisms and parameters that govern void formation and elimination. Transverse flow can be considered the most important consolidation mechanism, as it accounts for void elimination both during intimate contact development and the filling of ply-drops. The characteristics of the prepreg, e.g. transverse viscosity and thickness profile, play a key role in the consolidation process. Material, design and processing guidelines for the consolidation of tailored components via automated lay-up and stamp forming were presented. The demonstration of the process route on a tailored spar has confirmed the sensitivity of the process to the input material and highlighted the need for an improved understanding of the forming of more complex tailored parts. Nevertheless, it was also demonstrated that good consolidation can be achieved by combining rapid lay-up with direct press-forming, provided that the tool and blank are designed properly. Altogether this thesis provides a fundamental basis for the further development of the rapid manufacturing route for lightweight tailored composite components.

\section{References}

[1] K. D. White and J. A. Sherwood. Finite Element Simulation of Thickness Changes in Laminate during Thermoforming. In ESAFORM 2017: Proceedings of the 20th International ESAFORM Conference on Material Forming. Dublin, 2017.

[2] S. Haanappel. Forming of UD fibre reinforced thermoplastics: a critical evaluation of intra-ply shear. Ph.D. thesis, University of Twente, Enschede, The Netherlands, 2013.

[3] U. Sachs. Friction and bending in thermoplastic composites forming processes. Ph.D. thesis, University of Twente, 2014.

[4] G. Gardiner. Overmolding as enabler for composites, aerospace to automotive, 2018.

Retrieved from: https://www.compositesworld.com/blog/post/ overmolding-as-enabler-for-composites-aerospace-to-automotive.

[5] P. Mapleston. Thermoplastic composites go from strength to strength. Injection World, (January/February):15-22, 2018. 


\section{Chapter 7}

\section{Conclusions and Recommendations}

\subsection{Conclusions}

This thesis focused on the consolidation of tailored components using rapid automated lay-up followed by stamp forming. The objective was to develop a processing strategy for tailored components that results in high consolidation quality, i.e. low void content, but without the use of conventional press or autoclave consolidation. The main conclusions of this thesis can be summarized as follows:

- Rapid automated lay-up followed by stamp forming can result in tailored laminates with a high consolidation quality without the need of an additional press or autoclave consolidation cycle. A void content of less than $1 \%$ and flexural performance similar to that of press-consolidated blanks were obtained after stamp forming for the tested materials and ATP and AFP lay-up processes. Good consolidation quality was also obtained when forming an actual tailored part.

- The final consolidation quality is the result of the entire processing chain, where each step has a critical function in the consolidation process. However, an optimum state of the blank is required, as the time available for consolidation is very short during stamp forming. This makes the obtainable consolidation quality highly dependent on the early links the process chain, i.e. the prepreg and lay-up process. The consolidation process during stamp forming is dominated by the elimination of thickness variations in the blank by transverse flow. Hence, the optimum state of the blank is determined by the blank 
thickness variations and the transverse viscosity, but not so much by the interlaminar void content. In other words, a fully preconsolidated blank is not required, as long as the blank thickness variations are within acceptable limits for the used material.

- Deconsolidation of the blank occurs during the heating phase of the stamp forming process. Deconsolidation is undesired, as it forms additional voids and delaminations that have to be eliminated. However, deconsolidation was not found to be a limiting factor for the consolidation of automated lay-up blanks during stamp forming. The main mechanisms for deconsolidation were found to be the expansion of dissolved moisture and the release of internal stresses. Deconsolidation by moisture expansion can be reduced by a heat treatment on the blank prior to stamp forming. The internal stresses are present after prepreg manufacturing and are only relieved in long consolidation cycles. Hence, the stresses remain in the blank during rapid lay-up and have to be accepted as such.

- The thickness variations that dominate the consolidation process originate from the prepreg and the stacking pattern used during lay-up of the blank. Transverse flow is required to eliminate thickness variations and develop intimate contact between the plies. An intimate contact model was developed and used to evaluate the influence of prepreg thickness profile, stacking pattern and stamp forming process parameters on the consolidation behavior. The amplitude and wavelength of the thickness profile were identified as key parameters. The model was also used to demonstrate that staggering and smart tow arrangement during lay-up can significantly aid intimate contact development.

- The consolidation of ply-drops is dominated by transverse flow of the dropped ply or surrounding plies. Having ply orientations that allow for transverse flow therefore aids rapid consolidation. Misalignments between blank and tooling or inaccuracies during blank lay-up result in a lack of pressure and increased ply-drop pocket volume, which can lead to poor consolidation. Intentionally extending dropped plies into the ply-drop region makes consolidation of the ply-drops more robust against blank misalignments and placement inaccuracies.

- Good consolidation quality can be achieved when combining the right input material, blank and tooling and processing parameters, as was demonstrated on a realistic component. However, forming related defects were observed which appear to be specific to tailored blanks. The observations suggest that forming and consolidation interact with each other. 


\subsection{Recommendations}

The present work focused on consolidation of tailored components by combining rapid automated lay-up and stamp forming. Fundamental knowledge on the underlying consolidation mechanisms was provided and key material and processing parameters were identified. A processing strategy for optimal consolidation was provided. Although these are important steps towards the rapid manufacturing of tailored components, additional research is required. This section addresses important topics for future research.

- Flow transverse to the fibers was identified as the dominant mechanism responsible for consolidation. A first step was made towards a predictive consolidation model by modeling non-isothermal intimate contact development in flat plates. This should be extended further to more complex geometries. Furthermore, one of the key parameters governing transverse flow is the temperature dependent transverse viscosity of the composite material. Accurate predictive modeling requires proper material characterization. Additionally, more knowledge is required on the influence of fiber/matrix distribution and a matrix rich surface on transverse flow. This knowledge can lead to a prepreg design which is optimized for rapid processing.

- The prepreg plays a key role in the consolidation process. One of the most important characteristics of the prepreg is the thickness profile. Reliable processing of the prepreg requires consistent quality in terms of thickness variation. Prepreg manufacturing processes with accurate dimensional control are therefore essential. Additionally, internal stresses in the prepreg were found to be a major cause of deconsolidation. Further research is proposed to identify the origin of these stresses in order to serve the development of stress-free prepreg. This will aid consolidation during rapid manufacturing by reducing deconsolidation.

- The main consolidation challenge using the proposed process route stems from the fact that there is a combination of high cooling rates and rigid tooling when stamp forming. The rigid tooling implies that material flow is required in order to eliminate any mismatch between blank thickness and tooling cavity and provide pressure for consolidation throughout the entire component. The high cooling rates imply that the transverse viscosity increases rapidly when the pressure is applied, which slows down the flow process. Further improvement of the process route for rapid consolidation could include exploring the use of non-rigid tooling, as well as methods for advanced tool temperature control, such as inductive tool heating in combination with water cooling. 
- Forming behavior has been and still is an important topic related to the stamp forming process. Accurate predictive tools are required to aid the designer in manufacturing defect-free components. While commercial predictive models are already available for traditional preconsolidated blanks with uniform thickness, these do not capture the influence of blank consolidation quality (and deconsolidation) and tailored lay-ups on forming behavior. Hence the coupling between consolidation quality and forming behavior should be explored further. Of particular interest are the influence of consolidation state on forming behavior, as well as the effect of forming induced thickness changes on the consolation behavior. The influence of tailoring on the forming behavior also deserves attention. 


\section{Dankwoord}

\section{Zondag, 3 februari 2019}

Tijdens mijn afstudeeronderzoek bij het ThermoPlastic composites Research Center (TPRC) werd er al voorzichtig gepolst of ik interesse zou hebben in een promotieonderzoek. Alhoewel ik mijzelf altijd meer een toekomst als ontwerper dan onderzoeker voorgesteld had, had ik tijdens mijn stage en afstuderen aardig de smaak te pakken gekregen. Ik besloot dan ook, weliswaar na enig wikken en wegen, om de uitdaging aan te gaan om mij verder als onderzoeker te ontwikkelen en op 1 januari 2015 begon het avontuur. Ik claimde mijn plekje in de PhD-room terug, waar ik mij als masterstudent al thuis had gevoeld tussen de 'grote jongens'. Dit had uiteraard ook een belangrijke rol gespeeld bij mijn keuze voor het promotieonderzoek. Er wordt onder de TPRC-collega's wel eens gegrapt met de Trumpiaanse uitspraak 'Make TPRC great again!'. Alsof TPRC nooit 'great' geweest is?! Met de combinatie van geweldige leuke en kundige collega's, een fantastisch lab en de korte link met de universiteit en de industriële partners had ik mij geen betere plek kunnen wensen om mijn promotieonderzoek uit te voeren.

$\mathrm{Nu}$, iets meer dan vier jaar later, kijk ik dan ook met plezier terug op een geslaagd avontuur. Met trots presenteer ik dit boekwerk waarmee ik mij bewijs als zelfstandig onderzoeker en waarmee ik mijn bijdrage heb geleverd aan de toekomst van thermoplastische composieten. Desondanks was dit proefschrift niet tot stand gekomen zonder de hulp van talloze mensen. Ik wil dan ook graag iedereen bedanken die op enige manier, bewust of onbewust, bijgedragen heeft aan mijn promotieonderzoek.

Om te beginnen wil ik mijn promotor Remko Akkerman bedanken. Allereerst voor het aanbieden van dit promotieonderzoek. Daarnaast voor het vertrouwen in mijn kunnen en de ondersteuning en toewijding in het tot stand brengen van dit proefschrift, tot en met de laatste puntjes op de i. Het is geweldig hoe jij, na zelf een moeilijke periode achter de rug gehad te hebben, met veel enthousiasme je weer mengde in mijn onderzoek om mijn werk tot een hoger niveau te tillen. Ook de laatste maanden intensief worstelen met het consolidatiemodel worden zeer gewaardeerd. Wie ook een onmisbare rol in het verloop van mijn onderzoek hebben gespeeld zijn mijn dagelijkse begeleiders Wouter Grouve, Laurent Warnet en later ook Sebastiaan Wijskamp. Bedankt voor jullie vertrouwen, steun en, waar nodig, duwtjes in de rug. 
Onze bijna-wekelijkse discussies zijn allesbepalend geweest voor het goede verloop van mijn onderzoek. Altijd stimulerend, inspirerend en vol ruimte voor eigen ideeën. En met natuurlijk de nodige lol en wat wijze woorden op het moment dat ik het even niet meer wist. En de A4'tjes natuurlijk, simpel, maar effectief! Met de hulp van jullie vieren en het nodige lees en feedback werk, van globale structuur tot de kleinste details, is het gelukt om mijn onderzoek op papier te zetten en te vertalen tot dit proefschrift. Merci gents!

Een onderzoek komt niet tot stand zonder geld. Daarom wil ik TPRC en alle partners bedanken voor hun financiële steun die mijn onderzoek mogelijk gemaakt heeft. Daarnaast heeft mijn onderzoek de laatste twee jaar financiële steun mogen ontvangen van de Nederlandse Organisatie voor Wetenschappelijk Onderzoek (NWO), waarvoor dank. Ook wil ik TPRC en algemeen directeur Harald Heerink bedanken voor de mogelijkheid mijn onderzoek uit te kunnen voeren in zo'n inspirerende omgeving met leuke collega's en uitstekende faciliteiten. De ontelbare uren in het lab van TPRC, waar ik gebruik kon maken van onder andere de AFP-robot en vormpers, zijn onmisbaar geweest voor mijn onderzoek. Ik wil ook graag de leden van de Technical Advisory Board van TPRC bedanken voor hun enthousiasme, steun en bijdrage om de industriële revelatie van het onderzoek te waarborgen. Een aantal mensen wil ik graag nog specifiek bedanken voor hun directe betrokkenheid bij het project: Denis Cartie (Coriolis Composites), Sebastiaan Haanappel en Dennis Brands (AniForm Engineering B.V.), Michael Wielandt en Johan Meuzelaar (GKN Fokker Technologies), Hans Luinge (TenCate Advanced Composites) en Agnes BlomSchieber (Boeing).

Als PhD-student heb ik de luxe gehad maar tot maar liefst twee groepen collega's te behoren. Of zijn we eigenlijk gewoon één grote groep? Laat ik beginnen bij mijn collega's van de Universiteit Twente. Als eerste wil ik graag Martina Tjapkes, Debbie Zimmerman en Belinda Bruinink bedanken voor hun organisatorische hulp bij het regelen van reizen, meetings en administratieve zaken. Daarnaast wil ik Bert Vos, Ivo Vrooijink en Nick Helthuis bedanken voor hun ondersteuning in het lab. Ook wil ik de overige staf en PhD studenten van de vakgroep Production Technology bedanken voor de goede discussies en lekkere baksels die we gedeeld hebben tijdens de tweewekelijkse Monday Morning Meetings.

Dan mijn collega's bij TPRC. Zij zijn misschien wel dé reden waarom ik de afgelopen jaar met zoveel plezier naar mijn werk ben gegaan. Een enthousiast jong team met slimme mensen die hun neus dezelfde kant op hebben staan. Maar bovenal een ontzettend gezellige en leuke groep mensen van allerlei nationaliteiten. Om te beginnen bij de PhD-room en de Compete Scientists, misschien wel de 'harde kern' van TPRC. Naast alle inhoudelijke discussies wil ik jullie vooral bedanken voor alle lol die we samen tijdens en buiten werktijden gehad hebben en een perfecte balans vormde met het serieuze. Met als hoogtepunt misschien wel onze flansprojecten en presentaties vol ongecensureerde humor over promoverende of vertrekkende 
collega's. Ik kan niet wachten op wat jullie over mij hebben weten te verzamelen... Dus Thijs Kok, Francisco Sacchetti, Iqbal Rasheed, Devi Wolthuizen, Ulrich Sachs, Guillaume Vincent, Mark Bouwman, Marten van der Werff, Ramona Sitohang, Erik Krämer, Jagadeesh Swamy, Rick Schrijver, Vanessa Marinosci, Thijs Donderwinkel, Jeroen Houwers, Coen Hartjes en natuurlijk onze twee 'outsiders', Ali Waqas en Arka Bhakta, bedankt! Daarbij mag ik mijn overige collega's niet vergeten: Harald Heerink, Sebastiaan Wijskamp, Wouter Grouve, Selma Kalee, Gert-Jan Nevenzel, Edwar Boer, Iris de Klerk, Bert Rietman, Renata Heerink, Nick van der Vall, Simone Schapink, Reinier Jansen, Sotiris Koussios, Esther van der Veen, Freya Nordmann, Sanne Bruggink en Mathijs van der Velden. En onze buren van AniForm, Sebastiaan Haanappel, Dennis Brands, Rene ten Thije en Peter Sloetjes. Bedankt allemaal voor de leuke tijd samen aan de Palatijn 15/17. Gert Jan en Edwar wil ik daarnaast ontzettend bedanken voor het soepel laten verlopen van mijn werk in het lab of, als het even niet zo soepel liep, hun extra inzet om het weer op de rails te krijgen. Tot slot is er een ontzettend grote groep studenten de revue gepasseerd bij TPRC, waarvan ik er twee in het bijzonder wil bedanken voor hun bijdrage aan het onderzoek, namelijk Fransisco Saraiva en Yannick Buser. Met veel plezier heb ik met jullie samengewerkt.

Als laatste wil ik graag mijn lieve vriendin Arenda, mijn ouders Jan en Carla, mijn zus Rimke en mijn overige familie en vrienden bedanken. Ook al is het waarschijnlijk voor velen van jullie een raadsel gebleven waar ik nou eigenlijk mee bezig was, jullie liefde en vriendschap hebben mij door de afgelopen vier jaar heen geholpen op momenten dat het wat minder soepel liep. Zeker het laatste half jaar, toen het schrijfwerk, de deadline en mijn eigen perfectionisme aan mij begonnen te knagen en mij wellicht af en toe veranderden in een futloze zombie of chagrijnig vriendje die zelfs met een Snickers niet meer vrolijk te krijgen was. Bedankt voor jullie steun en de leuke dingen die we samen beleefd hebben en mij het hoofd boven water hebben gehouden tot het... EINDE!

Bedankt,

Tjitse 


\section{Publications}

\section{Journal articles}

1. T.K. Slange, W.J.B. Grouve, L.L. Warnet, R. Akkerman. Deconsolidation of $\mathrm{C} /$ PEEK blanks: on the role of prepreg, blank manufacturing method and conditioning. Published in: Composites Part A: Applied Science and Manufacturing, 113, 89-99, 2018 (Chapter 2 of this thesis)

2. T.K. Slange, W.J.B. Grouve, L.L. Warnet, S. Wijskamp, R. Akkerman. Towards the combination of automated lay-up and stamp forming for consolidation of tailored composite components. Published in: Composites Part A: Applied Science and Manufacturing, 2019 (Chapter 3 of this thesis)

3. T.K. Slange, U. Sachs, W.J.B. Grouve, L.L. Warnet, S. Wijskamp, R. Akkerman. Consolidating blanks with thickness variations during stamp forming. To be submitted to: Composites Part A: Applied Science and Manufacturing (Chapter 4 of this thesis)

\section{Conference proceedings}

1. T.K. Slange, W.J.B. Grouve, L.L. Warnet, R. Akkerman. Influence of preconsolidation on consolidation quality after stamp forming of $\mathrm{C} / \mathrm{PEEK}$ composites. ESAFORM 2016: Proceedings of the 19th International ESAFORM Conference on Material Forming, 2016, Nantes, France.

2. T.K. Slange, W.J.B. Grouve, L.L. Warnet, R. Akkerman. Influence of prepreg characteristics on stamp consolidation. ESAFORM 2017: Proceedings of the 20th International ESAFORM Conference on Material Forming, 2017, Dublin, Ireland.

3. T.K. Slange, W.J.B. Grouve, L.L. Warnet, R. Akkerman. Challenges in Stamp forming Tailored Blanks. SAMPE Europe Conference 2017 Proceedings, 2017, Stuttgart, Germany.

4. T.K. Slange, W.J.B. Grouve, L.L. Warnet, R. Akkerman. Consolidation quality and mechanical performance of stamp formed tailored blanks produced by 
rapid AFP. ESAFORM 2018: Proceedings of the 21st International ESAFORM Conference on Material Forming, 2018, Palermo, Italy.

5. T.K. Slange, Y.M. Buser, W.J.B. Grouve, L.L. Warnet, S. Wijskamp, R. Akkerman. Rapid Manufacturing of a Tailored Spar by AFP and Stamp Forming. ITHEC 2018 Conference Proceedings, 2018, Bremen, Germany.

\section{Awards}

1. ITHEC 2018/JEC Best Paper Award for the conference article on "Rapid Manufacturing of a Tailored Spar by AFP and Stamp Forming," Bremen, Germany, 2018.

\section{Other}

1. T.K. Slange, Y.M. Buser, W.J.B. Grouve, L.L. Warnet, S. Wijskamp, R. Akkerman. Rapid Manufacturing of a Tailored Spar by AFP and Stamp Forming. JEC Composites Magazine, 126, 56-59, 2019. 


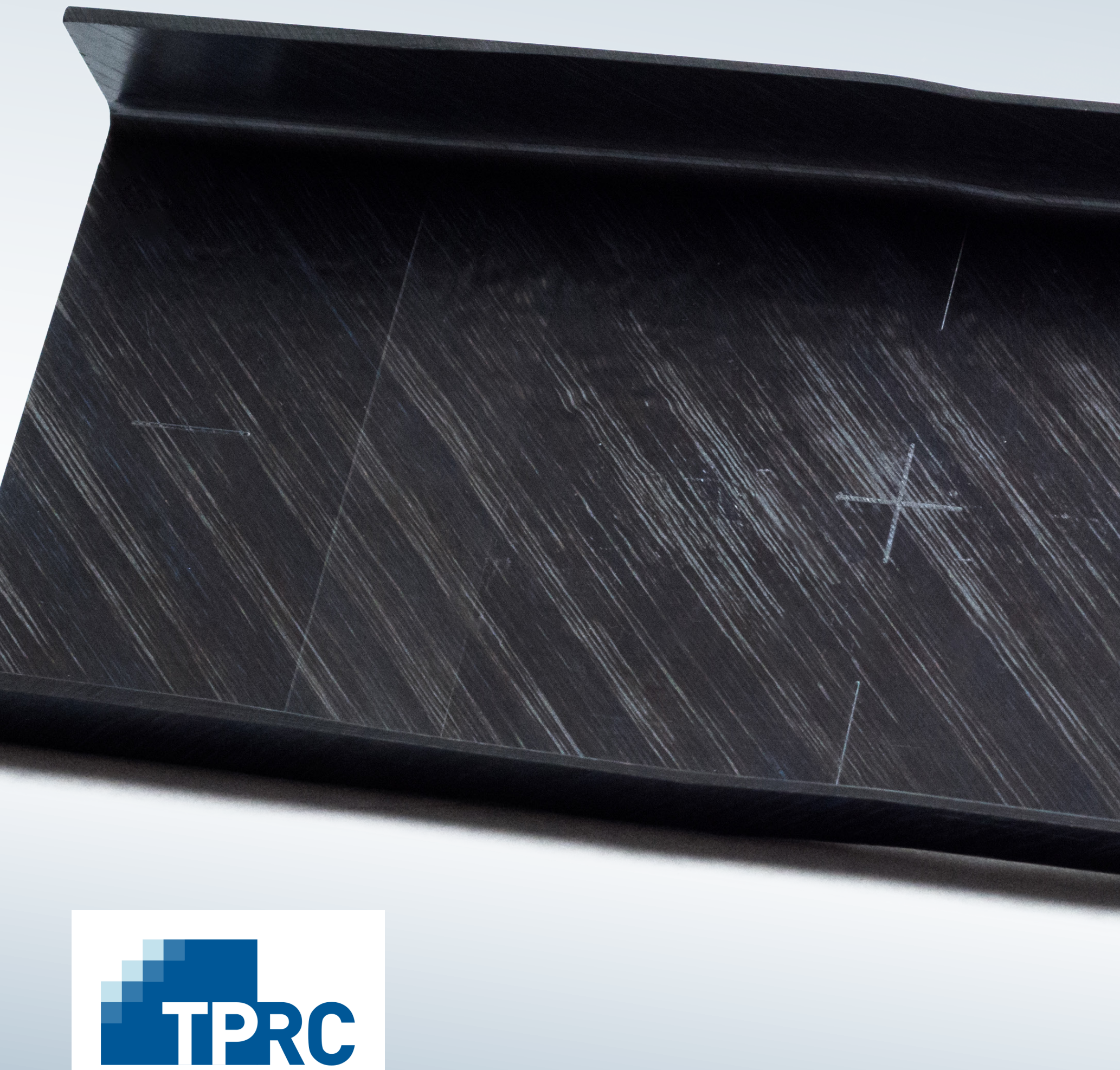

THERMOPLASTIC COMPOSITES RESEARCH CENTER

\section{UNIVERSITY OF TWENTE.}

